\title{
PPARs as modulators of cardiac remodelling
}

Citation for published version (APA):

Smeets, P. J. H. (2008). PPARs as modulators of cardiac remodelling. [Doctoral Thesis, Maastricht University]. Maastricht University. https://doi.org/10.26481/dis.20081204ps

Document status and date:

Published: 01/01/2008

DOI:

$10.26481 /$ dis.20081204ps

Document Version:

Publisher's PDF, also known as Version of record

\section{Please check the document version of this publication:}

- A submitted manuscript is the version of the article upon submission and before peer-review. There can be important differences between the submitted version and the official published version of record.

People interested in the research are advised to contact the author for the final version of the publication, or visit the DOI to the publisher's website.

- The final author version and the galley proof are versions of the publication after peer review.

- The final published version features the final layout of the paper including the volume, issue and page numbers.

Link to publication

\footnotetext{
General rights rights.

- You may freely distribute the URL identifying the publication in the public portal. please follow below link for the End User Agreement:

www.umlib.nl/taverne-license

Take down policy

If you believe that this document breaches copyright please contact us at:

repository@maastrichtuniversity.nl

providing details and we will investigate your claim.
}

Copyright and moral rights for the publications made accessible in the public portal are retained by the authors and/or other copyright owners and it is a condition of accessing publications that users recognise and abide by the legal requirements associated with these

- Users may download and print one copy of any publication from the public portal for the purpose of private study or research.

- You may not further distribute the material or use it for any profit-making activity or commercial gain

If the publication is distributed under the terms of Article $25 \mathrm{fa}$ of the Dutch Copyright Act, indicated by the "Taverne" license above, 
PPARS AS MODULATORS OF CARDIAC REMODELLING 
(c) Pascal Jozef Henri Smeets

Cover photograpy: @ Veerle Stulens

Printed by Ponsen \& Looijen

ISBN: 978-90-6464-310-1 


\title{
PPARs as modulators of cardiac remodelling
}

\author{
PROEFSCHRIFT \\ ter verkrijging van de graad van doctor \\ aan de Universiteit Maastricht, \\ op gezag van de Rector Magnificus, \\ Prof. Mr. G.P.M.F Mols \\ volgens het besluit van College van Decanen, \\ in het openbaar te verdedigen \\ op donderdag 4 december 2008 om 16:00 uur
}

door

\section{Pascal Jozef Henri Smeets}

Geboren op 5 augustus 1979

te Genk, België 


\section{Promotor}

Prof. dr. G.J. van der Vusse

\section{Copromotor}

Dr. M. van Bilsen

\section{Beoordelingscommissie}

Prof. dr. H.A.J. Struijker-Boudier, voorzitter

Prof. dr. L.H.E.H. Snoeckx

Prof. dr. M.H. Hofker (Rijksuniversiteit Groningen)

Prof. dr. E.E. Blaak

Dr. L.J. de Windt (Universiteit Utrecht)

Financial support by the Netherlands Heart Foundation for the publication of this thesis is gratefully acknowledged.

Medtronic Bakken Research Center, AstraZeneca and the J.E. Jurriaanse foundation are gratefully acknowledged for their financial support. 


\section{CONTENT}

\section{CHAPTER 1}

General introduction

CHAPTER 2

Peroxisome proliferator-activated receptors and inflammation: take it to heart

ChAPTER 3

Inflammatory pathways are activated during cardiomyocyte hypertrophy and attenuated by PPAR $\alpha$ and PPAR $\delta$

CHAPTER 4

Cardiac hypertrophy is enhanced in PPAR $\alpha-/-$ mice in response to chronic pressure overload

\section{Chapter 5}

Transcriptomic analysis of PPAR $\alpha$-dependent alterations during cardiac hypertrophy

Chapter 6

Loss of PPAR $\alpha$ reduces infarct size and promotes hypertrophy of the surviving murine myocardium

Chapter 7

General discussion

REFERENCES

SUMMARY

SAMENVATTING

LIST OF PUBLICATIONS

Curriculum VITAE

129

DANKWOORD 


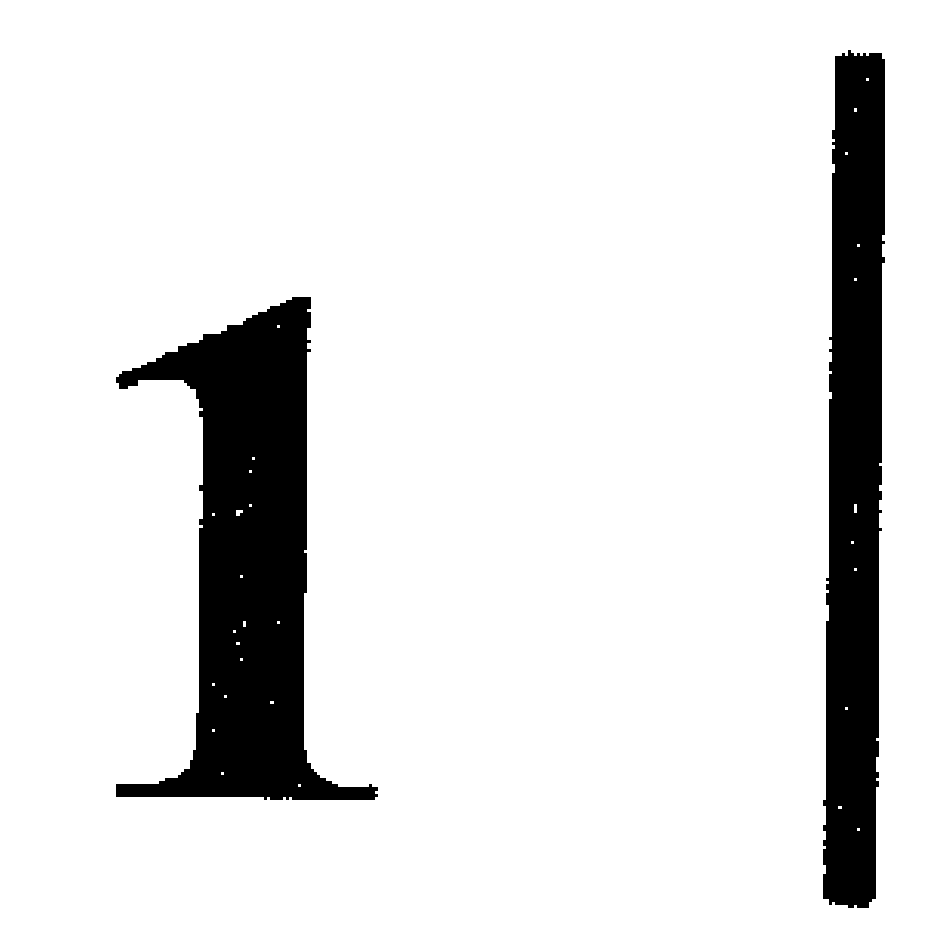

GENERAL INTRODUCTION 


\section{INTRODUCTION}

In the Netherlands, cardiovascular disease (CVD) is the primary cause of death, representing over 45,000 deaths ( $33 \%$ of total mortality) each year. ${ }^{1}$ Although the number of CVD deaths is decreasing in recent years, its financial burden on present healthcare is still increasing. Next to ischemic heart disease and cerebrovascular disease, heart failure (HF) contributes significantly to mortality from CVD. Heart failure has a prevalence in the Netherlands of 200,000 and the estimated healthcare cost in 2003 amounted to $€ 375$ million. ${ }^{2}$ It is expected that the prevalence of heart failure will increase due to aging of the Dutch population and increased survival after myocardial infarction. Therefore, heart failure represents a serious socio-economic burden requiring further research for new therapies.

\section{MYOCARDIAL REMODELLING AND HEART FAILURE}

The healthy heart efficiently pumps blood through the lungs and the peripheral organs to provide oxygen. ${ }^{3}$ The cardiac muscle cells swiftly respond to an increased oxygen demand of the body like during a chronically increased level of physical exercise. Despite this highly adaptive physiological response, the cardiac response can become maladaptive as occurs during several pathophysiological conditions. A sustained increase in blood pressure or loss of cardiac tissue due to regional myocardial infarction are examples of such conditions. The subsequent changes in heart structure, termed cardiac remodelling, are shown in figure 1 and discussed below.

\section{CARDIAC HYPERTROPHY}

Pathological cardiac hypertrophy is characterized as the process in which the heart increases in size in response to e.g., hypertension or genetic defects in contractile proteins (familial hypertrophic cardiomyopathy ${ }^{4}$ ). Increased wall thickness without change or a reduction in size of the ventricular cavity is referred to as concentric hypertrophy (Fig. 1). At the cellular level increased cardiomyocyte size, especially in the cross-sectional area of the muscle cells, and re-induction of the foetal gene programme are typical for this pathological form of hypertrophy.

\section{MYOCARDIAL INFARCTION}

One of the most frequent causes of HF is regional myocardial infarction, when part of the cardiac muscle is deprived of blood supply. This lack of blood supply results in irreversible loss of viable tissue due to apoptosis and/or necrosis of cardiac myocytes. ${ }^{5-7} \mathrm{Next}$, macrophage infiltration, (myo)fibroblast activation and collagen deposition occur in the subsequent infarct during the healing process. Furthermore, rapidly activated inflammatory processes are an important feature of myocardial infarction during the first phase of infarct 
healing. At the same time remodelling of the non-infarcted surviving myocardium takes place, resulting in cardiomyocyte hypertrophy and interstitial fibrosis. The loss of viable myocardium and remodelling of the surviving myocardium eventually decrease cardiac function (Fig. 1). ${ }^{8}$

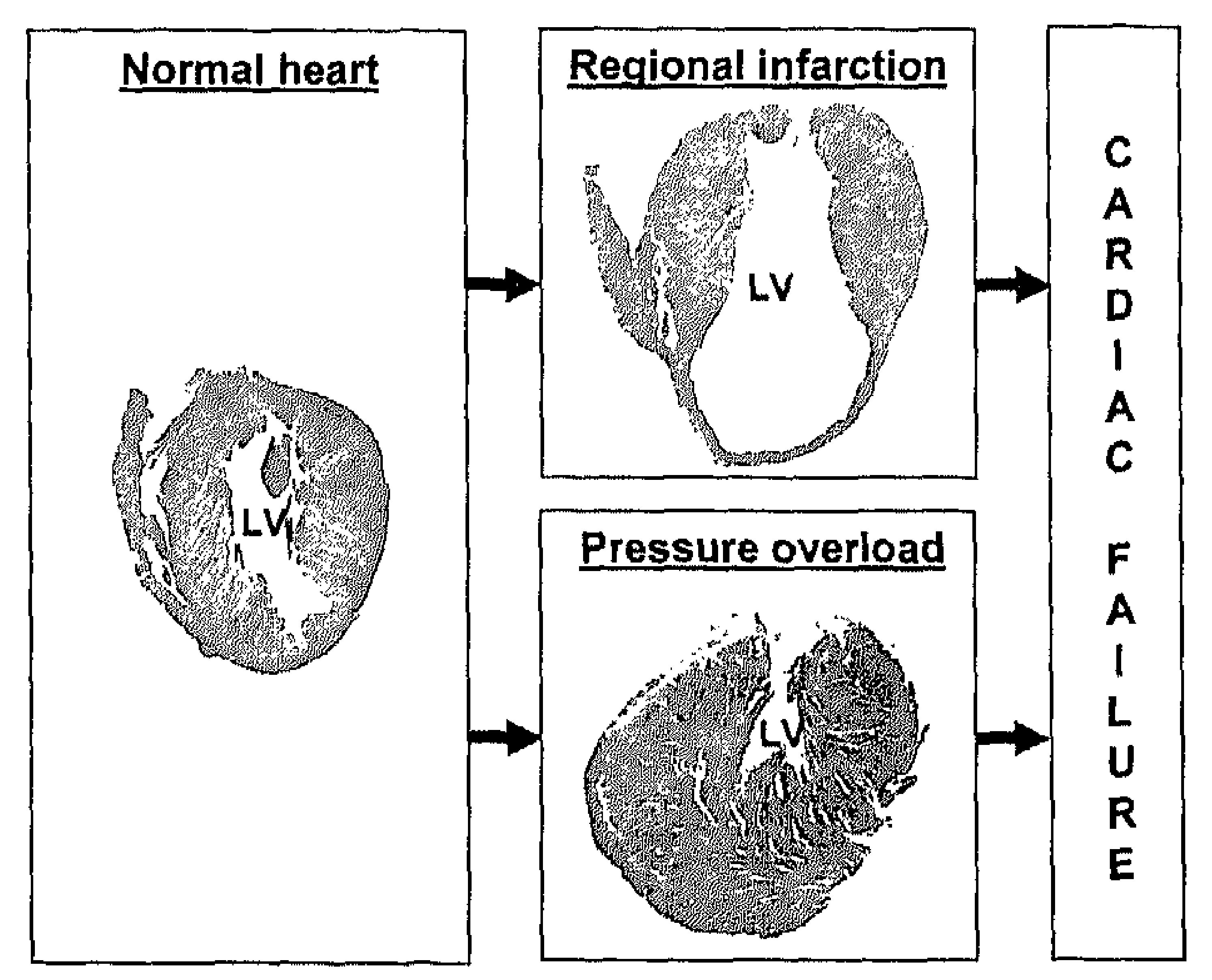

Figure 1. Myocardial infarction and pressure overload-induced hypertrophy both can cause cardiac failure. LV: left ventricle.

Thus, pressure overload and myocardial infarction lead to structural alterations, commonly referred to as myocardial remodelling. ${ }^{9}$ Myocardial remodelling is also accompanied with metabolic changes, namely a shift in substrate utilization from fatty acids to glucose. ${ }^{10}$ Eventually, the cardiac function deteriorates and heart failure ensues, which is defined as failure of the heart to pump enough blood to satisfy the needs of the body. ${ }^{3}$ It is commonly accepted that interventions aimed at reducing hypertrophy delay the progression towards heart failure.

\section{MOLECULAR BIOLOGY OF MYOCARDIAL REMODELLING}

Myocardial remodelling is in general accompanied by (1) changes in the phenotype of the cardiac myocytes, (2) extracellular matrix (ECM) remodelling and (3) activation of apoptotic processes. " A common denominator in these processes is the change in gene expression as an underlying cause during chronic cardiac remodelling. Furthermore, metabolism is affected and fibrosis develops. In recent years, inflammatory processes are acknowledged to be an established part of the remodelling process. ${ }^{12-15}$ In this respect, advances in molecular biology have increased the knowledge of, and the possibilities to study, heart disease. For 
instance, knock-out mice have become indispensable tools in cardiovascular research. Moreover, tools to study gene expression are extremely helpful in elucidating molecular pathways in the failing and non-failing heart. For instance, the mouse lacking the gene for peroxisome proliferator-activated receptor- $\alpha$ (PPAR $\alpha$ ) is an eligible example of a mouse model that has helped to understand the function of this nuclear receptor. This genetically modified mouse model was used to clarify the role of PPAR $\alpha$ in lipid metabolism ${ }^{16}$ and pointed to the association of PPAR with inflammation ${ }^{17}$ and hypertrophy ${ }^{18}$. Ever since their discovery in the early nineties PPARs have gradually came to the notice of researchers in various disciplines. ${ }^{19}$

\section{PEROXISOME PROLIFERATOR-ACTIVATED RECEPTORS}

PPARs are ligand-activated transcription factors and well-known key regulators of lipid metabolism. ${ }^{20}$ To date, three PPAR isoforms have been identified, i.e., PPAR $\alpha$ (NR1C1), PPAR (NR1C2) and PPAR $\gamma$ (NR1C3). ${ }^{21}$ Two of the three PPAR isoforms, PPAR $\alpha$ and PPAR $\delta$, are abundantly expressed in the heart, more specifically in cardiac muscle cells and fibroblasts. ${ }^{22,23}$

As already mentioned, PPARs are especially known for their activation of genes involved in fatty acid metabolism, a process called transactivation (Fig. 2A). Later on, PPARs were

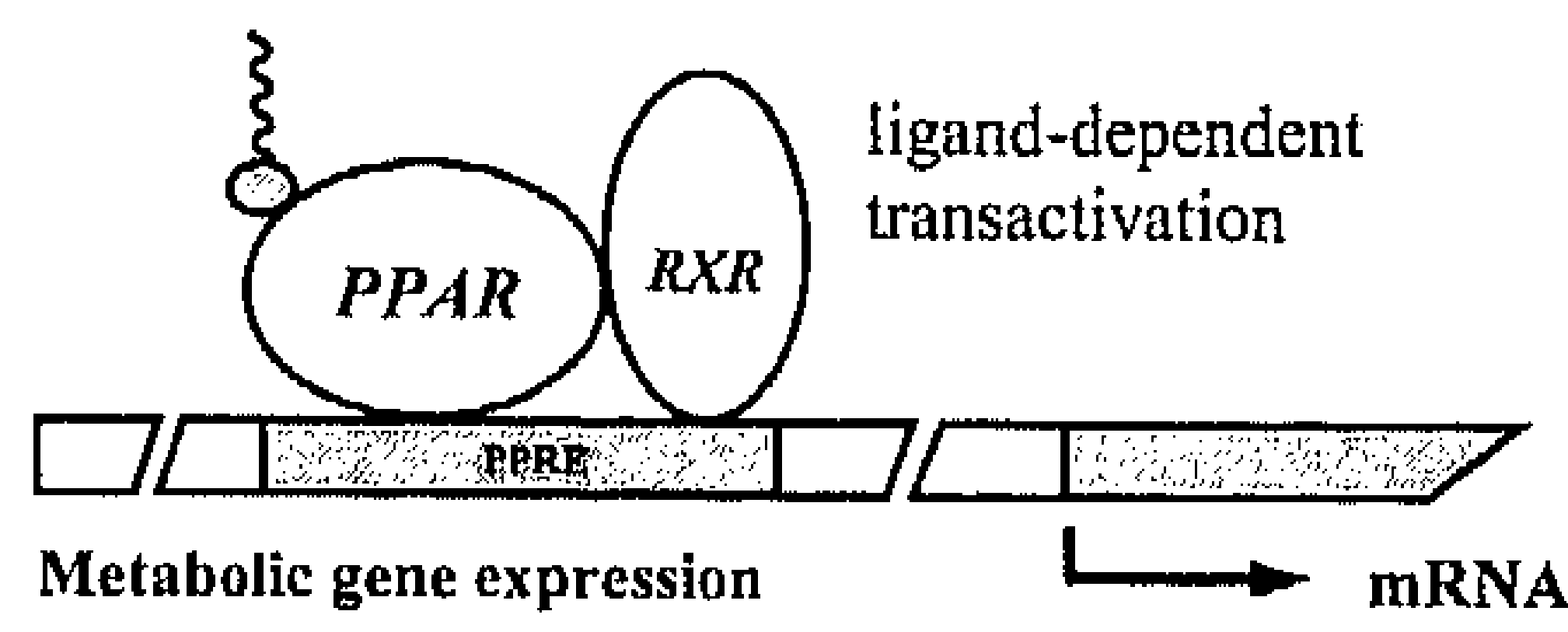

B.

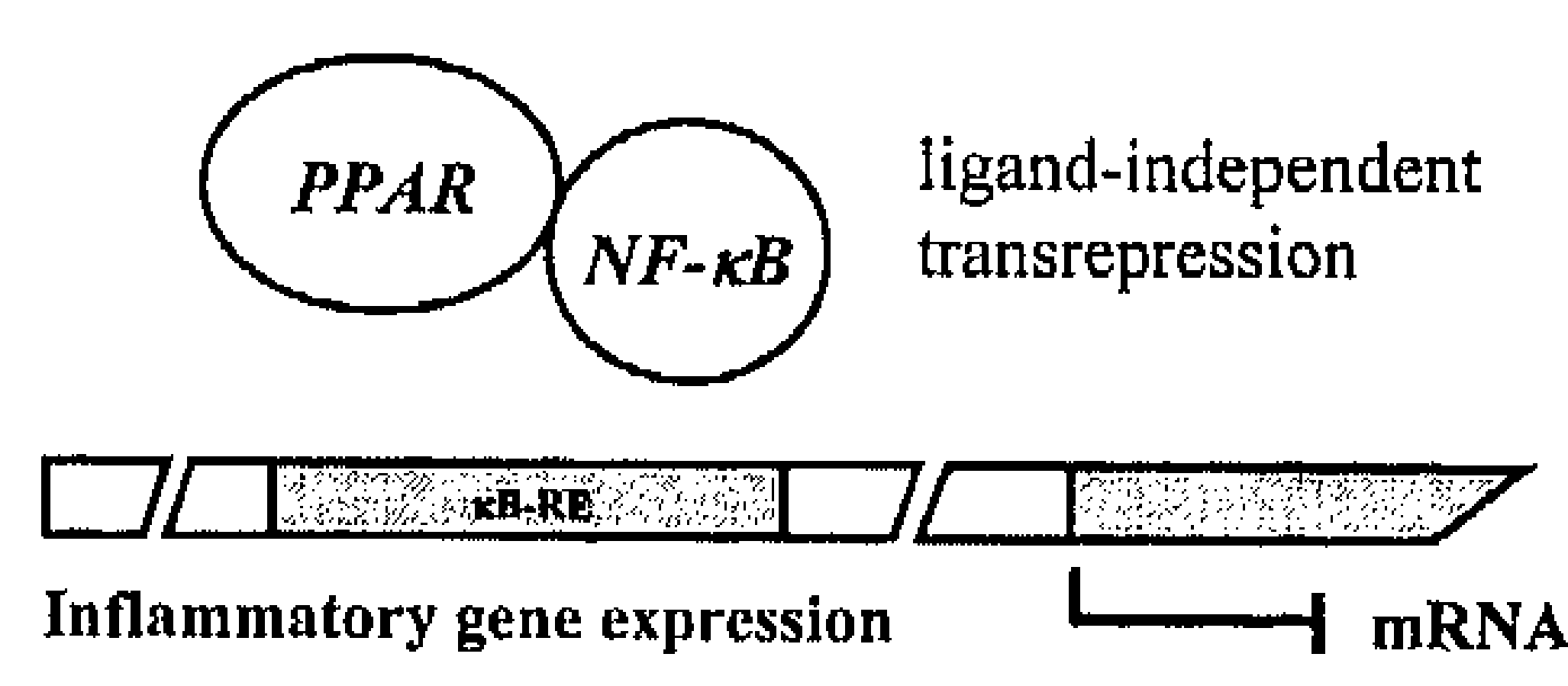

Figure 2. Transactivation and transrepression properties of PPAR. (A) Transactivation of PPAR. Upon binding to its ligands, PPAR heterodimerizes with the 9-cis retinoid-X-receptor ( $R X R)$ and binds to peroxisome proliferator response elements (PPREs) in the promoter region of their target genes, thereby increasing gene transcription in a ligand-dependent manner. (B) Transrepression property of PPAR. Current evidence supports the notion that physical interactions between PPARs and other transcription factors, such as NF- $k B$, play an important role in attenuating pro-inflammatory signalling pathways, This interaction prevents the binding of NF-kB to its response element in the promoter of proinflammatory genes. This process can be either ligand-independent (as depicted here) or liganddependent.

associated with cardiac disease. ${ }^{24,25}$ Administration of PPAR ligands to various animal and cell models suggested inhibition of the hypertrophic response as initiated by adrenergic stimulation in vitro ${ }^{26,27}$ or increased load in vivo. ${ }^{27,28}$ However, the role of PPARs in cardiac 
disease is still controversial as demonstrated by (1) mice overexpressing PPAR $\alpha$ which develop diabetic cardiomyopathy ${ }^{29}$ and (2) the better cardiac recovery after ischemiareperfusion in isolated hearts from PPAR $\alpha-/$ - mice compared to wild-type mice. ${ }^{30}$ The antiinflammatory effects of PPARs have gained interest as a putative mediator of the cardioprotective effects of PPAR ligands. Binding of PPAR to pro-inflammatory transcription factors, either in a ligand-independent or ligand-dependent manner, attenuates the transcription of pro-inflammatory genes, a process referred to as transrepression (figure 2B). Finally, PPARs are also associated with fibrosis, cell proliferation and apoptosis, processes involved in the remodelling of the heart.

\section{AIMS OF THIS THESIS}

Given the pleiotropic effects of PPARs and their role in the control of myocardial fatty acid metabolism and inflammation, the aim of this thesis is to study the effect of PPAR in cardiac hypertrophy and myocardial infarction. The research questions are formulated as follows:

(I) Do PPAR $\alpha$ and PPAR $\delta$ interfere with inflammatory signalling, more specifically nuclear factor- $\mathrm{kB}$ (NF-kB), and does this affect the hypertrophic response?

(II) Does the lack of PPAR $\alpha$ result in altered cardiac responses after myocardial infarction or chronic pressure overload?

(III) Which genes under PPAR $\alpha$ regulation are affected during chronic pressure overload?

\section{OUTLINE OF THIS THESIS}

In Chapter two, the biological significance of PPARs and their activation in ischemiareperfusion, myocardial infarction and hypertrophy are reviewed in detail. This chapter also focuses on the putative mechanisms by which PPARs exert their salutary effects, namely via repression of inflammatory processes.

As described in Chapter three, the relationship between PPAR and NF- $\mathrm{KB}$ is studied since NF- $\mathrm{KB}$ is one of the most important inflammatory pathways and activation of NF- $\mathrm{KB}$ is considered as an essential step in cardiac hypertrophy. Thereto, an in vitro hypertrophy model consisting of neonatal rat cardiac myocytes stimulated with an $\alpha_{1}$-adrenergic agonist was used to assess PPAR signalling in relation to inflammatory pathways during hypertrophy.

To study the effects of PPAR $\alpha$ during cardiac hypertrophy, pressure overload was induced in PPAR $\alpha-/$ - mice. The findings of this experimental model are described in Chapter four and based on measures of hypertrophic growth and cardiac dysfunction. Furthermore, it was investigated if there is an association between hypertrophic growth and altered expression of markers of inflammation and ECM remodelling. 
In Chapter five, the PPAR $\alpha$-dependent responses during cardiac hypertrophy are studied in more detail. Using microarray technology, genes regulated by PPAR $\alpha$ in the unstressed and pressure overloaded heart are hunted in wild-type mice and mice lacking PPAR $\alpha$.

Chapter six describes the effects of myocardial infarction in PPAR $\alpha-/-$ mice. Upon ligation of the left coronary descending artery, the affected region of the left ventricle is deprived of blood supply. The effect of PPAR $\alpha$ is evaluated by determining infarct size, the incidence of cardiac rupture, and cardiac function in PPAR $\alpha-/$ and wild-type mice after myocardial infarction.

Finally, in Chapter seven a general discussion is presented on the main findings, their clinical implications, and future lines of research. 


\title{
2
}

\section{PEROXISOME PROLIFERATOR-ACTIVATED RECEPTORS AND INFLAMMATION: TAKE IT TO HEART}

\author{
Pascal J.H. Smeets, Anna Planavila, Ger J. van der Vusse and Marc van Bilsen
}

Acta Physiologica 2007;191(3):171-188.

\begin{abstract}
Peroxisome proliferator-activated receptors (PPARs) are ligand-activated transcription factors acting as key regulators of lipid metabolism as well as modulators of inflammation. The role of PPAR $\alpha$ and PPAR $\gamma$ in cardiac ischemia-reperfusion injury, infarct healing and hypertrophy is subject of intense research. Due to the later development of PPAR $\delta$ specific ligands, the role of this PPAR isoform in cardiac disease remains to be established. Although many studies point to salutatory effects of PPAR ligands in cardiac disease, the exact molecular mechanism is still largely unsolved. Both the metabolic (via transactivation) and the more recently discovered anti-inflammatory (via transrepression) effects of PPARs are likely to play a role. In this review the reported, and sometimes contradictory, effects of PPAR ligands on ischemia-reperfusion, infarct healing and cardiac hypertrophy are critically evaluated. In particular the role of inflammation in these disease processes, the ability of PPARs to interfere with pro-inflammatory processes, and the mechanisms of transrepression are discussed. Currently, the significance of PPARs as therapeutic targets in cardiovascular disease is receiving widespread attention. Accordingly, detailed understanding of the mechanisms controlling the activity of these nuclear hormone receptors is essential.
\end{abstract}




\section{INTRODUCTION}

Low-grade chronic inflammation is considered to be an important mediator of cardiac disease progression. ${ }^{31}$ This notion is based, among others, on the observation that in patients suffering from heart failure plasma levels of pro-inflammatory cytokines, like tumour necrosis factor- $\alpha$ (TNF- $\alpha$ ), are elevated. ${ }^{32}$ This has led to the so-called 'cytokine hypothesis', which states that cytokines play a pivotal role in the progression of heart failure. ${ }^{33}$ Accumulating evidence indicates that inflammation is not only of critical importance during the final stages of heart failure but also plays a role in early stages like the development of cardiac hypertrophy. ${ }^{12,14}$ Furthermore, inflammatory processes appear to be involved in transient (ischemia-reperfusion; $\mathrm{I} / \mathrm{R}$ ) and chronic (infarction) ischemia of the myocardium. ${ }^{6}$ The inflammatory process involves the activation of endogenous inflammatory signalling pathways (e.g. nuclear factor- $\mathrm{KB}$; NF- $\mathrm{KB}$ ) within the myocardial tissue (cardiomyocytes, fibroblasts, endothelial cells), leading to the local production and release of chemokines and cytokines. ${ }^{34}$ Secondly, infiltrating leucocytes will aggravate the inflammatory response in the jeopardized myocardium. ${ }^{6}$ Finally, it has been postulated that as a result of cardiac failure the underperfusion of other organs, like the intestines, leads to an additional rise in the plasma levels of pro-inflammatory cytokines. ${ }^{35}$

Therefore, it is to be anticipated that inhibition of inflammation should be therapeutically effective in the treatment of cardiac disease. The outcomes of several clinical studies in heart failure patients, however, do not support this contention. Trials using anti-TNF- $\alpha$ therapy (etanercept and infliximab) and selective COX-2 inhibitors (COXIBs) were discontinued because of lack of efficacy or even signs of increased mortality. ${ }^{36-39}$ In contrast to these specific anti-inflammatory therapies, unexpected beneficial effects were observed using drugs, like the statins, which are believed to possess anti-inflammatory side effects. Statins are widely prescribed cholesterol-lowering agents that act by inhibiting 3-hydroxy-3methylglutaryl-CoA (HMG-CoA) reductase, a critical step in cholesterol biosynthesis. They also exert pleiotropic effects independent of their capacity to suppress plasma cholesterol levels, presumably via attenuation of pro-inflammatory processes. ${ }^{40}$

In recent years, the significance of peroxisome proliferator-activated receptors (PPARs) as therapeutic targets in cardiovascular disease has gained momentum. PPARs are ligand activated transcription factors and well-known key regulators of lipid metabolism. ${ }^{20}$ Recent studies underscore their capacity to attenuate inflammation as well. ${ }^{41,42}$ As ligands for PPARs are already commonly used in clinical practice for the treatment of diabetes (glitazones, also referred to as thiazolidinediones or TZDs) and hyperlipidemia (fibrates), it should be realized that the application of these PPAR ligands may have profound implications for cardiac phenotype and function. Indeed, several clinical trials demonstrated reductions in cardiovascular events in type 2 diabetic patients treated with PPAR $\alpha$ and 
PPAR $\gamma$ ligands, ${ }^{43}, 44$ but negative outcomes were reported as well. In this respect, metaanalysis revealed that the dual PPAR $\alpha / \gamma$ agonist muraglitazar and the TZD rosiglitazone increased the risk of death, cardiovascular events and myocardial infarction. ${ }^{45}$, 46 These clinical observations indicate that the effects of PPAR ligands are still incompletely understood, and that a detailed understanding of the pleiotropic actions of these drugs is still eagerly awaited for.

In this review, we focus on the potential role of PPARs in several cardiac disorders, i.e. I/R, infarction and hypertrophy. Special attention is paid to the molecular mechanisms by which PPARs could interfere with inflammatory signalling pathways.

\section{PEROXISOME PROLIFERATOR-ACTIVATED RECEPTORS}

PPARs belong to the nuclear hormone receptor superfamily. To date, three PPAR isoforms have been identified, i.e., PPAR $\alpha$ (NR1C1), PPAR $(\mathrm{NR} 1 \mathrm{C} 2)$ and PPAR $\gamma$ (NR1C3). ${ }^{21}$ PPAR $\alpha$ is primarily expressed in tissues with a high level of fatty acid (FA) metabolism (liver, heart, kidney, skeletal muscle and brown adipose tissue), while the PPAR $\delta$ isoform is ubiquitously expressed. PPAR $\gamma$ has two splice variants: PPAR $\gamma 1$ is expressed in various cell types, among which vascular cells and blood cells, like macrophages, while PPAR $\gamma 2$ is exclusively expressed in adipocytes. ${ }^{47}$ Two of the three PPAR isoforms, PPAR $\alpha$ and PPAR $\delta$, are abundantly expressed in the heart, more specifically in cardiac muscle cells and fibroblasts. ${ }^{22,23}$

PPARs consist of four structural domains: the ligand-independent activation domain (A/B or $\mathrm{AF}-1$ ), the DNA binding domain $(\mathrm{C})$, the $\mathrm{D}$ domain and the ligand-dependent activation domain (E/F or AF-2) (Fig. 1). PPAR heterodimerizes with the 9-cis retinoid-X-receptor (RXR) and binds to peroxisome proliferator response elements (PPREs) in the promoter region of their target genes, thereby increasing gene transcription in a ligand-dependent manner (transactivation). PPARs are activated by natural ligands, e.g. long-chain fatty acids and eicosanoids, which show relatively little specificity towards the different isoforms. Synthetic ligands were developed being selective for the distinct isoforms, such as TZDs (e.g. rosiglitazone and pioglitazone) for PPAR $\gamma$, and fibrates (e.g. fenofibrate and clofibrate) for PPAR $\alpha$. The transactivation of PPARs is also dependent on the presence of co-activators and co-repressors. Transcriptional co-activators, such as PPAR $\gamma$ coactivator- $1 \alpha$ (PGC- $1 \alpha$ ) or steroid receptor co-activator (SRC) possess intrinsic histone acetylase (HAT) activity or attract proteins with HAT activity to initiate transcription. ${ }^{48}$ Co-repressors, on the other hand, are bound to PPARs in their unliganded state and prevent the binding of co-activators. ${ }^{49}$ Ligand binding leads to conformational changes in the AF-2 region, thereby reducing the affinity for co-repressors and allowing recruitment of co-activators. For more detailed 
information of the molecular aspects of PPAR regulation or function, the reader is referred to a number of excellent reviews. ${ }^{50,51}$

A

\begin{tabular}{|c|c|c|c|c|}
\multicolumn{2}{c}{ DBD } & \multicolumn{3}{c}{ LBD } \\
\hline $\mathrm{A} / \mathrm{B}$ & $\mathrm{C}$ & $\mathrm{D}$ & $\mathrm{E}$ & $\mathrm{F}$ \\
\hline $\mathrm{AF}-1$ & $\mathrm{C}$
\end{tabular}

B

\begin{tabular}{|c|c|c|}
\hline PPAR $\alpha$ & PPAR $\delta$ & PPAR $y$ \\
\hline Tissue distribution & Tissue distribution & Tissue distribution \\
\hline $\begin{array}{c}\text { Liver, skeletal muscle, } \\
\text { heart, kidney }\end{array}$ & Ubiquitously & $\begin{array}{c}\text { Macrophages (PPAR } \gamma 1 \text { ); } \\
\text { Adipocytes (PPAR } \gamma 2 \text { ) }\end{array}$ \\
\hline Properties & Properties & Properties \\
\hline FA metabolism & FA metabolism & Adipogenesis \\
\hline Cell cycle & Wound healing & Inflammation \\
\hline Inflammation & Inflammation & \\
\hline
\end{tabular}

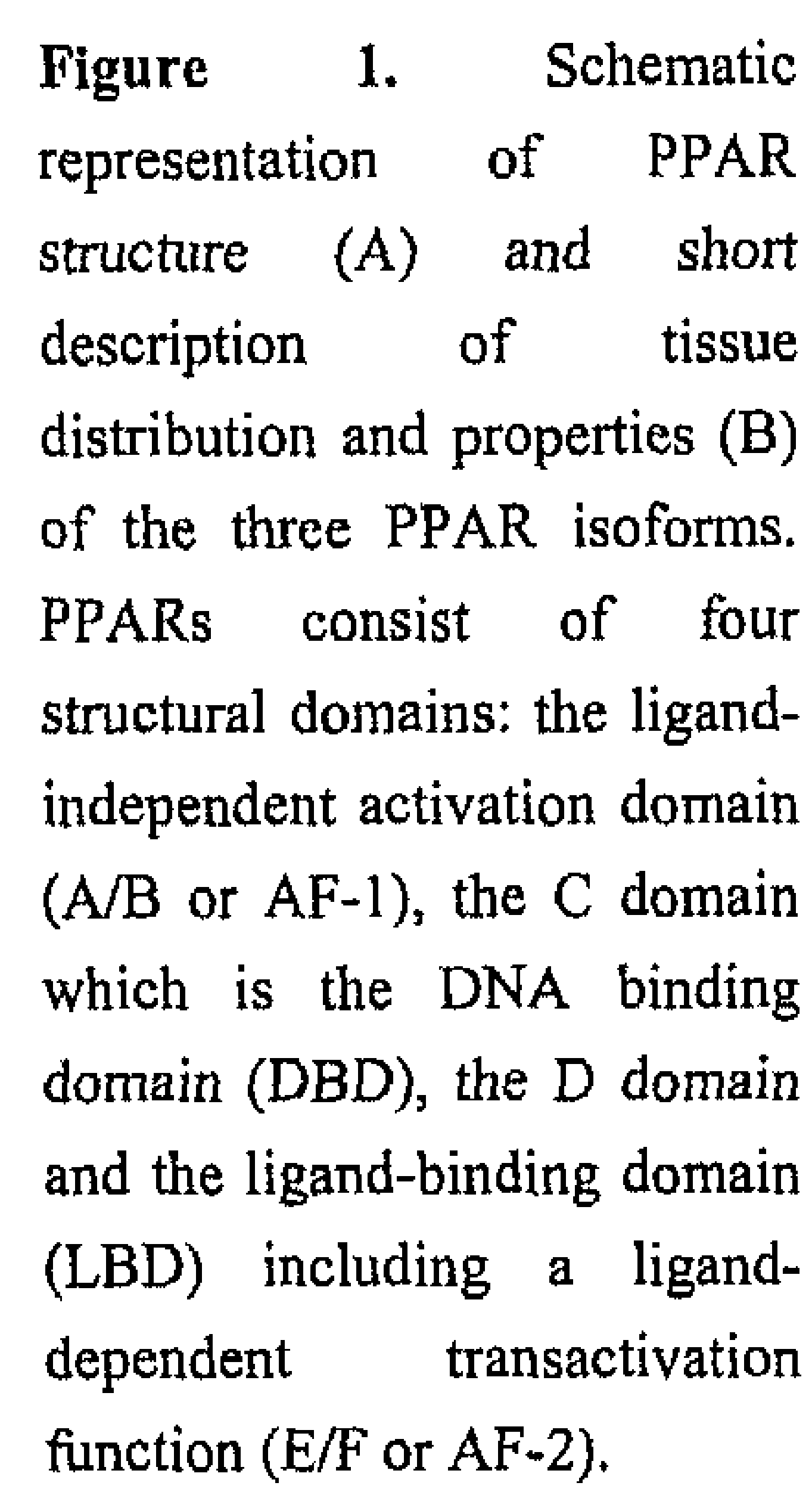

Next to acting as PPAR ligands, long-chain fatty acids are vital to cardiac function as approx. $65 \%$ of the energy conversion, needed to sustain the mechanical activity of the heart, is derived from fatty acid oxidation (FAO). ${ }^{52}$ The majority of genes regulated by PPAR via transactivation are involved in lipid metabolism. Besides these transactivation properties, PPARs are able to inhibit gene expression via transrepression. The precise mechanisms of transrepression are still incompletely understood. It is of interest to note that most of the genes inhibited by PPAR are involved in inflammatory signalling. The anti-inflammatory properties of PPARs were first observed in PPAR $\alpha$ knock-out mice showing a prolonged inflammatory response following an ear-swelling test. ${ }^{17}$ Although the majority of studies focussed on the role of PPAR $\alpha$ and PPAR $\gamma$ in attenuating inflammation, recent findings indicate that PPAR $\delta$ has also a strong potential to inhibit inflammation. ${ }^{53,54}$

\section{INVOLVEMENT OF PPARS IN CARDIAC DISORDERS}

PPARs play a prominent role in the heart and their metabolic and anti-inflammatory profile has fuelled research into the role of PPARs as therapeutic targets in a variety of cardiac diseases. In the following sections, we discuss the effects of the different PPAR isoforms (and their selective agonists) on I/R-induced tissue damage, myocardial infarction, and 
cardiac hypertrophy. Emphasis will be on the ability of PPARs to modulate inflammation (transrepression properties) as the effects of PPARs on metabolism (transactivation properties) in general, and cardiac metabolism in particular, has already been subject of several recent, and excellent reviews. ${ }^{50,}{ }^{55-57}$ In addition, the association of PPAR polymorphisms and cardiac disease is considered.

\section{ISCHEMIA-REPERFUSION}

Cardiac I/R is characterized by transient occlusion of a coronary artery resulting in reduced oxygen delivery to the flow-deprived cardiac region. Timely restoration of flow (reperfusion) to the ischemic area is pivotal to preserve viability of the jeopardized myocardium. It has been shown that tissue damage is not only caused by the ischemic insult, but also by reperfusion per se. ${ }^{58}$ Exposure of ex vivo perfused hearts to ischemia leads to activation of $\mathrm{NF}-\mathrm{kB}$, and this pro-inflammatory response is further exacerbated during reinstallation of flow. ${ }^{59}$ Reperfusion of the heart in situ is associated with infiltration of macrophages and neutrophils, further enhancing the inflammatory response. ${ }^{6}$ Accordingly, limitation of the inflammatory response is an important target to limit I/R-induced injury. Indeed, inhibition of $\mathrm{NF}-\mathrm{KB}$ was effective in attenuating reperfusion injury after transient coronary artery occlusion in the rat. ${ }^{60}$ This has led to the concept that, due to the anti-inflammatory properties of PPARs, the application of PPAR ligands also exerts salutatory effects. In this context it is noteworthy that at least for the PPAR $\alpha$ isoform it has been shown that hypoxia and ischemia/reperfusion are associated with a decline in cardiac PPAR $\alpha$ content ${ }^{61,62}$, which may limit the ability to salvage the myocardium subsequent to treatment with PPAR ligands.

Although conflicting findings have been reported with respect to outcome (see Table 1 for overview $)^{24,30,62-69}$, the majority of studies indicated that treatment with PPAR $\alpha$-specific ligands results in protection of the heart, when the heart was subjected to I/R in vivo. Pretreatment of rats with PPAR $\alpha$ ligands caused a marked decrease in infarct area ${ }^{24,63,67}$ and increased rate-pressure product and contractility upon reperfusion, indicating preservation of myocardial function. ${ }^{64,67}$ The reduction in infarct size by the PPAR $\alpha$ ligand GW7647 was abolished in PPAR $\alpha-/$ - mice subjected to in vivo I/R, suggesting that the beneficial effect is truly PPAR $\alpha$-dependent. ${ }^{64}$ The cardioprotective effect of PPAR $\alpha$ in I/R has been attributed to attenuation of the pro-inflammatory NF-KB signalling pathway. ${ }^{64,70}$ This contention is based on the observation that PPAR $\alpha$ activation was associated with increased cytoplasmic protein levels of the inhibitor- $\mathrm{KB} \alpha$-subtype $(\mathrm{I} \kappa \mathrm{B} \alpha)^{64}$ and decreased translocation of NF- $\mathrm{\kappa B}$ to the nucleus. ${ }^{70}$ The PPAR $\alpha$ ligand-mediated decline in NF- $\mathrm{KB}$ activation was associated with a marked reduction in apoptosis in the ischemic-reperfused myocardium. ${ }^{70}$ The latter finding 
Table 1. Studies exploring the effect of PPAR $\alpha$ and PPAR $y$ on ischemia-reperfusion (I/R) induced injury

\begin{tabular}{|c|c|c|c|c|}
\hline Reference & Model (species) & Duration of $\mathrm{I} / \mathrm{R}$ & Effect & Treatment \\
\hline \multicolumn{5}{|l|}{$P P A R \alpha$} \\
\hline Wayman et al. 2002; & In Vivo (Rat) & $30 \mathrm{~min} / 2 \mathrm{~h}$ & + & Wy-14,643 \\
\hline Wayman et al. 2002 & & & & Clofibrate \\
\hline \multirow[t]{2}{*}{ Tabernero et al. 2002} & Ex vivo (Mice) & $30 \mathrm{~min} / 60 \mathrm{~min}$ & + & PPAR $\alpha-/-$ \\
\hline & & & & Fenofibrate \\
\hline \multirow[t]{2}{*}{ Yue et al. 2003} & In vivo (Mice) & $30 \mathrm{~min} / 24 \mathrm{~h}$ & + & GW7647 \\
\hline & & & & $\operatorname{PPAR} \alpha-/$ \\
\hline A.asum et al. 2003 & Ex vivo (Mice) & $13 \mathrm{~min} / 70 \mathrm{~min}$ & $=$ & BM 17.0774 \\
\hline Panagia et al. 2005 & Ex vivo (Mice) & $40 \mathrm{~min} / 30 \mathrm{~min}$ & - & PPAR $\alpha,-1-$ \\
\hline Dewald et al. 2005 & In vivo (Mice) & Repetitive I/R & - & Wy-14,643 \\
\hline Tian et al. 2006 & Ex vivo (Rat) & $30 \mathrm{~min} / 2 \mathrm{~h}$ & + & Clofibrate \\
\hline Bulhak et al. 2006 & In vivo (Rat) & $30 \mathrm{~min} / 2 \mathrm{~h}$ & + & Wy-14,643 \\
\hline Yeh et al. 2006 & In vivo (Rabbit) & $60 \mathrm{~min} / 4 \mathrm{~h}$ & + & Wy-14,643 \\
\hline \multirow[t]{2}{*}{ Sambandam et al. 2006} & Ex vivo (Mice) & $18 \mathrm{~min} / 40 \mathrm{~min}$ & - & MHC-PPAR $\alpha$ \\
\hline & & & & PPAR $\alpha-/-$ \\
\hline Xu et al. 2006 & In vivo (Pig) & $90 \mathrm{~min} / 2 \mathrm{~h}$ & $=$ & Fenofibrate \\
\hline \multicolumn{5}{|l|}{$P P A R y$} \\
\hline Shimabukuro et al. 1996 & Ex vivo (Rat) & $10 \mathrm{~min} / 30 \mathrm{~min}$ & + & Troglitazone \\
\hline Zhu et al. 2000 & In Vivo (Pig) & $90 \mathrm{~min} / 90 \mathrm{~min}$ & + & Troglitazone \\
\hline Yue et al. 2001 & In vivo (Rat) & $30 \mathrm{~min} / 24 \mathrm{~h}$ & + & Rosiglitazone \\
\hline \multirow[t]{5}{*}{ Wayman et al, 2002} & In Vivo (Rat) & $30 \mathrm{~min} / 2 \mathrm{~h}$ & + & Rosiglitazone \\
\hline & & & & Ciglitazone \\
\hline & & & & Pioglitazone \\
\hline & & & & $15 \mathrm{~d}-\mathrm{PGJ}_{2}$ \\
\hline & & & & PGA \\
\hline Khandoudi et al. 2002 & Ex vivo (Rat) & $30 \mathrm{~min} / 30 \mathrm{~min}$ & + & Rosiglitazone \\
\hline Sidell et al. 2002 & Ex vivo (Rat) & $32 \mathrm{~min} / 32 \mathrm{~min}$ & + & Rosiglitazone \\
\hline Xu et al, 2003 & In vivo (Pig) & $90 \mathrm{~min} / 90 \mathrm{~min}$ & - & Troglitazone \\
\hline Ito et al. 2003 & In vivo (Rat) & $30 \mathrm{~min} / 24 \mathrm{~h}$ & + & Pioglitazone \\
\hline Lee and Chou 2003 & In vivo (Dog) & $60 \mathrm{~min} / 2 \mathrm{~h}$ & + & Troglitazone \\
\hline Liu et al. 2004 & In vivo (Rabbit) & $60 \mathrm{~min} / 4 \mathrm{~h}$ & + & Rosiglitazone \\
\hline Sivarajah et al. 2005 & In vivo (Rat) & $15-25 \mathrm{~min} / 2 \mathrm{~h}$ & + & Ciglitazone \\
\hline \multirow[t]{2}{*}{$\mathrm{Xu}$ et al. 2005} & In vivo $(\mathrm{Pig})$ & $90 \mathrm{~min} / 90 \mathrm{~min}$ & $=$ & Troglitazone \\
\hline & & & & Rosiglitazone \\
\hline Wynne et al. 2005 & Ex vivo (Rat) & $35 \mathrm{~min} / 2 \mathrm{~h}$ & + & Pioglitazone \\
\hline Molavi et al. 2006 & In vivo (Rat) & $60 \mathrm{~min} / 60 \mathrm{~min}$ & + & Rosiglitazone \\
\hline Yeh et al. 2006 & In vivo (Rabbit) & $60 \mathrm{~min} / 4 \mathrm{~h}$ & $=$ & $15 \mathrm{~d}-\mathrm{PGJ} \mathrm{J}_{2}$ \\
\hline Gonon et al. 2007 & Ex vivo (Mice) & $25-30 \mathrm{~min} / 30 \mathrm{~min}$ & + & Rosiglitazone \\
\hline \multirow[t]{2}{*}{ Zingarelli et al. 2007} & In vivo (Rats) & $30 \mathrm{~min} / 2 \mathrm{~h}$ & + & Ciglitazone \\
\hline & & & & $15 \mathrm{~d}-P G J_{2}$ \\
\hline
\end{tabular}


could indicate that prevention of myocardial apoptosis contributes to the cardioprotective effects of PPAR $\alpha$ ligands during $I / R$.

In contrast, investigations on isolated, ex vivo perfused hearts from PPAR $\alpha-/$ - mice showed that the absence of PPAR $\alpha$ is associated with improved functional recovery after an ischemic episode. ${ }^{30,69}$ Moreover, post-ischemic functional recovery was compromised in isolated hearts that overexpress PPAR $\alpha$ in a cardiac-specific manner. ${ }^{69}$ The authors argued that the detrimental effect of PPAR $\alpha$ overexpression is the consequence of metabolic changes, in particular the decline in GLUT4 expression, resulting in impaired glucose metabolism and, hence, decreased metabolic efficiency. As PPAR $\alpha$ promotes cardiac FAO at the expense of glucose oxidation, which is metabolically more efficient (higher ATP/O ratio), PPAR $\alpha$ can negatively influence cardiac performance during the early reperfusion. ${ }^{71}$ This notion is supported by the observation that pharmacological measures to increase post-ischemic cardiac glucose oxidation improved hemodynamic function of the reperfused heart. ${ }^{72}$ It is important to note that in the isolated heart model the artificial nature of the perfusion buffer could obscure beneficial effects of PPAR ligands related to the inhibition of infiltration of pro-inflammatory leucocytes in the injured myocardium. Thus, the collective findings suggest that PPAR $\alpha$ activation is beneficial because of its anti-inflammatory effects. Conversely, the concurrent stimulation of FAO during early reperfusion is potentially hazardous and may obscure the otherwise salutatory anti-inflammatory effects of PPAR $\alpha$ ligands during I/R.

With respect to the cardioprotective effect of PPAR $\gamma$ and its ligands on I/R injury the findings are more consistent (Table 1). With the exception of one in vivo study, which showed that the PPAR $\gamma$ agonist troglitazone increased the incidence of fatal arrhythmias in pigs, ${ }^{73}$ activation of PPAR $\gamma$ has been shown to reduce infarct area or to improve cardiac function following I/R. For instance, in situ administration of rosiglitazone enhanced left ventricle (LV) contractility during reperfusion after $30 \mathrm{~min}$ of coronary occlusion in vivo as compared to vehicle-treated rats. ${ }^{74}$ The recovery of LV developed pressure during reperfusion of the $e x$ vivo perfused heart was significantly higher in rosiglitazone-pretreated than non-treated mice. ${ }^{75}$ In vivo studies attributed these beneficial effects to the anti-inflammatory properties of PPAR $\gamma$ ligands. TZD treatment reduced neutrophil and macrophage accumulation. ${ }^{74,76}$ Moreover, experimental findings indicate that PPAR $\gamma$ interferes with NF- $\mathrm{KB}$ signalling, as demonstrated by the diminished IKB $\alpha$ degradation and the decrease of MCP-1 and iNOS nRNA levels upon $15 \mathrm{~d}-\mathrm{PGJ}_{2}$ treatment. ${ }^{24}$ To investigate whether the protective effects are truly PPAR $\gamma$ dependent, Sivarajah et al. ${ }^{77}$ applied the specific PPAR $\gamma$ antagonist GW9662. Indeed, infarct size was increased after antagonist treatment. The beneficial effects of PPAR $\gamma$ agonists were not only observed when animals were pre-treated for extended periods of

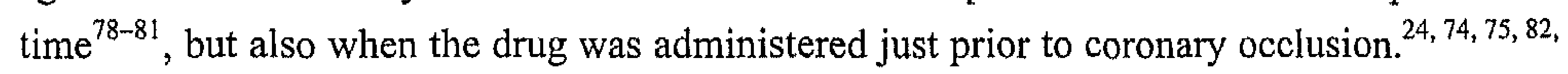
${ }^{83}$ In the latter case, the relatively short duration of ligand treatment points to a relatively fast 
response and suggests that non-genomic alterations could also contribute to the protective effect of PPAR $\gamma$ on I/R injury.

As already stipulated above in relation to PPAR $\alpha$, most investigations pointing to antiinflammatory and, hence, beneficial effects of PPAR $\gamma$ were performed in vivo. So far, studies addressing the role of PPAR $\gamma$ in ex vivo models of $\mathrm{I} / \mathrm{R}$ focussed on metabolic, rather than anti-inflammatory effects of PPAR $\gamma$ ligands. The fact that these ex vivo studies were mainly performed on diabetic heart models ${ }^{79,84-86}$ further complicates the extrapolation of these findings to the non-diabetic heart.

The collective findings suggest that PPAR $\gamma$ ligands ameliorate I/R-induced tissue injury via a decrease of the cardiac inflammatory response. However, it should be kept in mind that PPAR $\gamma$ is hardly expressed in the heart. ${ }^{22}$ Hence, it is well conceivable that indirect, systemic effects of PPAR $y$ ligands, such as for instance the insulin-sensitizing effect in adipose tissue and skeletal muscle, do play a role and modulate the response of the heart to a transient ischemic insult in in vivo studies.

To the best of our knowledge, no studies using PPAR $\delta$ ligands or transgenic PPAR $\delta$ models have been performed so far. As PPAR $\delta$ also possesses anti-inflammatory properties ${ }^{87}$, investigations on the in vivo effect of PPAR $\delta$ activation in the $\mathrm{I} / \mathrm{R}$-injured heart are warranted.

\section{MYoCARDIAL INFARCTION}

Permanent cessation of blood supply to cardiac muscle provokes apoptosis and/or necrosis of cardiac myocytes, inevitably resulting in irreversible loss of viable tissue. ${ }^{5-7}$ The subsequent infarct healing process is characterized by macrophage infiltration, (myo)fibroblast activation and collagen deposition. As already stipulated for $\mathrm{I} / \mathrm{R}$, during the first phase of infarct healing inflammatory processes become activated rapidly. At the same time remodelling of the noninfarcted surviving myocardium takes place, resulting in cardiomyocyte hypertrophy and interstitial fibrosis. The loss of viable myocardium and remodelling of the surviving myocardium eventually decrease cardiac function, predisposing to heart failure. ${ }^{8}$

Relatively few studies addressed the role of PPARs during permanent coronary artery occlusion (Table 2). Administration of the PPAR $\alpha$ ligand fenofibrate to rats, starting 8 weeks after induction of infarction and continued for 12 weeks, did not ameliorate cardiac function following myocardial infarction, but was associated with an increased LV mass, indicative of altered hypertrophic remodelling. ${ }^{88}$ It should be realized, however, that in this experimental set-up fenofibrate treatment was initiated when infarct healing was close to completion, excluding any effects of this ligand on early inflammatory or fibrotic processes during infarction. 
Table 2. In vivo studies investigating the role of PPAR $\alpha$ or PPAR $\gamma$ in animal models of myocardial infarction (MI)

\begin{tabular}{|c|c|c|c|}
\hline Reference & Species & Effect & Start of treatment \\
\hline \multicolumn{4}{|l|}{$\overline{P P A R \alpha}$} \\
\hline Morgan et al. 2006 & Rat & $\begin{array}{l}\text { Increased LV hypertrophy but no effect on cardiac } \\
\text { function }\end{array}$ & $\begin{array}{l}\text { Fenofibrate } \\
\text { (8 wk post } \mathrm{MI})\end{array}$ \\
\hline \multicolumn{4}{|l|}{$P P A R \gamma$} \\
\hline Shiomi et al. 2002 & Mouse & Improved LV systolic function & $\begin{array}{l}\text { Pioglitazone } \\
(6 \mathrm{~h} \text { post } \mathrm{MI})\end{array}$ \\
\hline Lygate et al. 2003 & Rat & $\begin{array}{l}\text { Increased mortality, no effect on } \mathrm{LV} \text { remodelling, } \\
\text { small positive effect on heart function }\end{array}$ & $\begin{array}{l}\text { Rosiglitazone } \\
(6 \mathrm{~h} \text { post MI) }\end{array}$ \\
\hline Geng et al. 2006 & Mouse & No effect & $\begin{array}{l}\text { Pioglitazone } \\
(7 \mathrm{~d} \text { post } \mathrm{MI})\end{array}$ \\
\hline Frantz et al. 2004 & Rat & $\begin{array}{l}\text { Improved post infarct } L V \text { remodelling and heart } \\
\text { function }\end{array}$ & $\begin{array}{l}\text { Rosiglitazone } \\
\text { ( } 24 \mathrm{~h} \text { post } \mathrm{MI})\end{array}$ \\
\hline
\end{tabular}

The notion that the time interval between onset of infarction and start of treatment is critical, is also supported by the findings of studies on the effect of PPAR $\gamma$ ligands. When treatment was started 7 days after permanent coronary artery occlusion, the PPAR $\gamma$ agonist pioglitazone did not influence infarct size, LV remodelling or mortality in rats. ${ }^{89}$ However, early treatment, starting $24 \mathrm{~h}$ after the onset of infarction, significantly improved hemodynamic function, and attenuated LV remodelling. The latter was concluded from less pronounced collagen deposition and reduced cardiac angiotensin II and aldosteron concentrations in the treated animals. ${ }^{90}$ Studies in mice also indicated preservation of LV function and mitigation of the hypertrophic response, when pioglitazone administration started relatively early, e.g. 6 h after coronary artery occlusion. ${ }^{91}$ It should be emphasized that the increased mortality observed by Lygate et $a l .{ }^{92}$ in rats subjected to permanent coronary artery occlusion and treated with rosiglitazone $6 \mathrm{~h}$ after surgery could not be corroborated by others. ${ }^{89-91}$ At present, no explanation can be offered for these deviant findings. The role of PPAR $\delta$ in relation to myocardial infarct healing has not been investigated so far.

The limited number of studies performed so far and the differences in study design (e.g. time interval between onset of infarction and start of treatment) do not allow us to draw final conclusions as to the cardioprotective effect of PPARs in myocardial infarction. Furthermore, in determining the effectiveness of PPAR ligands both the effects of these drugs on infarct healing in the flow-deprived region and on hypertrophic remodelling of the viable myocardium need to be taken into account.

\section{HYPERTROPHY}

Cardiac hypertrophy is characterized by increased cardiomyocyte size and re-induction of the fetal gene programme, and is generally considered an adaptive mechanism to compensate for 
a chronic increase in workload. In the long term, however, it becomes maladaptive, fibrosis sets in, and compensated hypertrophy can evolve to decompensated cardiac failure. ${ }^{93,94}$ Accumulating evidence indicates that activation of the inflammatory signalling pathways promotes both cardiomyocyte hypertrophy and fibrosis. ${ }^{12,13,95,96}$ In this context, NF-kB activation was shown to be essential for the hypertrophic response of neonatal cardiomyocytes during $\alpha_{1}$-adrenergic stimulation. ${ }^{14}$ In addition, cytokines can induce a hypertrophic growth response in cardiac myocytes. ${ }^{97}$ In the in vivo setting, aortic banding in rats was associated with increased activity of NF-kB. ${ }^{15}$ Moreover, cardiac specific ablation of $N F-\kappa B$ was found to attenuate myocardial hypertrophy in TNF- $\alpha$ overexpressing mice ${ }^{98}$ and pharmacological inhibition of NF- $\mathrm{KB}$ diminished cardiac hypertrophy in spontaneously hypertensive rats. ${ }^{99}$ These findings strongly support the notion that activation of proinflammatory signalling pathways is essential for the hypertrophic growth process, rendering the NF- $\mathrm{KB}$ pathway an attractive target for therapy.

Regarding PPAR $\alpha$, the current paradigm reads that PPAR $\alpha$ target genes are downregulated during hypertrophy either due to reduced expression of PPAR $\alpha$ per $s e^{25,100}$, or to diminished expression of the PPAR binding partner RXR or the co-activator PGC1- $\alpha{ }^{101,102}$ This results in a decrease in FAO capacity, which is supposed to lead to energy starvation in the long term. ${ }^{10}$ From this point of view, ligand-mediated activation of PPAR $\alpha$ could help to restore the energy homeostasis in the hypertrophied heart and, hence, cardiac pump function. Available data, however, do not support this contention (Table 3). In rats subjected to pressure overload, treatment with the PPAR $\alpha$ ligand Wy-14,643 led to a marked decrease in performance of the hypertrophic heart. ${ }^{103}$ The authors demonstrated that the PPAR $\alpha$ ligand caused a substantial decline in glucose oxidation rather than an increase in FAO, which, in turn, was considered responsible for the poor hemodynamic function of the hypertrophied heart. Cardiac-specific overexpression of PPAR $\alpha$ in mice resulted not only in reduced myocardial glucose oxidation but also in increased FAO. ${ }^{29}$ Again, this shift in substrate utilization was associated with impaired cardiac function and the development of a cardiomyopathic phenotype. ${ }^{29}$

Table 3. Studies exploring the role of PPARs in cardiac hypertrophy

\begin{tabular}{llll}
\hline Reference & Model (species) & Effect & Treatment \\
\hline PPAR $\alpha$ & & & \\
Young et al. 2001 & In vivo (Rat) & Severe depression of cardiac power & Wy-14,643 \\
Hamano et al. 2001 & In vivo (H9c2) & Increased expression of the hypertrophy & Wy-14,643 \\
& In vitro (Rat) & marker MLC-2 & Clofibrate \\
Ogata et al. 2002 & In vivo (Rat) & Decreased cardiac fibrosis & Fenofibrate \\
Finck et al. 2002 & In vivo (Mice) & Induction of LVH & MHC-PPAR \\
Liang et al. 2003 & In vitro (NCM) & Decreased expression of the hypertrophy & Fenofibrate
\end{tabular}




\begin{tabular}{|c|c|c|c|}
\hline & & marker BNP & $\mathrm{Wy}-14,643$ \\
\hline Iglarz et al. 2003 & In vivo (Rat) & $\begin{array}{l}\text { Decreased cardiac fibrosis and } \\
\text { inflammation }\end{array}$ & Fenofibrate \\
\hline Wu et al. 2004 & In vivo (Rat) & No effect & $W y-14,643$ \\
\hline Diep et al. 2004 & In vivo (Rat) & Improved myocardial inflammation & Fenofibrate \\
\hline $\begin{array}{l}\text { Irukayama-Tomobe et al. } \\
2004\end{array}$ & $\begin{array}{l}\text { In vitro }(\mathrm{NCM}) \\
\text { In vivo (Rat) }\end{array}$ & Decreased cardiac hypertrophy & Fenofibrate \\
\hline Ichihara et al. 2006 & In vivo (Rat) & Decreased LVH and heart failure & Fenofibrate \\
\hline Duhaney et al. 2007 & In vivo (Mice) & Increased LVH & $\begin{array}{l}\text { PPAR } \alpha-/- \\
\text { Fenofibrate }\end{array}$ \\
\hline Rose et al. 2007 & In vivo (Rats) & Decreased cardiac hypertrophy & Fenofibrate \\
\hline Li et al. 2007 & In vitro $(\mathrm{NCM})$ & Decreased cardiac hypertrophy & Fenofibrate \\
\hline \multicolumn{4}{|l|}{$P P A R y$} \\
\hline Yamamoto et al. 2001 & In vitro $(\mathrm{NCM})$ & Decreased cardiac hypertrophy & $\begin{array}{l}\text { Troglitazone } \\
15 \mathrm{~d}_{-} \mathrm{PGJ}_{2}\end{array}$ \\
\hline Asakawa et al. 2002 & $\begin{array}{l}\text { In vitro (NCM) } \\
\text { In vivo (Mice) }\end{array}$ & $\begin{array}{l}\text { Ligands reduce cardiac hypertrophy } \\
\text { PPAR } \gamma+/ \text { mice more prone to } \\
\text { hypertrophy }\end{array}$ & $\begin{array}{l}\text { Troglitazone } \\
\text { Pioglitazone } \\
\text { Rosiglitazone } \\
\text { PPAR } \gamma+/-\end{array}$ \\
\hline Sakai et al. 2002 & In vivo (Rat) & Reduced cardiac hypertrophy & $\begin{array}{l}\text { Troglitazone } \\
\text { Pioglitazone }\end{array}$ \\
\hline Liang et al. 2003 & In vitro $(\mathrm{NCM})$ & Decreased BNP expression & $\begin{array}{l}\text { Rosiglitazone } \\
\text { GW9662 }\end{array}$ \\
\hline Iglarz et al. 2003 & In vivo (Rat) & $\begin{array}{l}\text { Decreased concentric LVH and cardiac } \\
\text { fibrosis }\end{array}$ & Rosiglitazone \\
\hline Arakawa et al. 2004 & In vivo (Rat) & Induction of eccentric hypertrophy & $\mathrm{T}-174$ \\
\hline Wu et al. 2004 & In vivo (Rat) & Induction of LVH & Rosiglitazone \\
\hline Duan et al. 2005 & In vivo (Mice) & $\begin{array}{l}\text { Cardiac hypertrophy in cardiac PPAR } \gamma-/- \\
\text { and rosiglitazone-treated mice }\end{array}$ & $\begin{array}{l}\text { Cardiac PPAR } \gamma / / \\
\text { Rosiglitazone }\end{array}$ \\
\hline Bell \& McDermott 2005 & In vitro $(\mathrm{NCM})$ & $\begin{array}{l}\text { Mild hypertrophic effect after chronic } \\
\text { exposure }\end{array}$ & Rosiglitazone \\
\hline Edgley et al. 2006 & In vivo (Rat) & Induction of cardiac hypertrophy & $\mathrm{X} 334$ \\
\hline Rose et al. 2007 & In vivo (Rats) & Decreased cardiac hypertrophy & Rosiglitazone \\
\hline \multicolumn{4}{|l|}{$P P A R \delta$} \\
\hline Cheng et al. 2004 & In vivo (Mice) & Induction of cardiomyopathy & Cardiac PPAR $\delta-/-$ \\
\hline Planavila et al. $2005 \mathrm{~b}$ & In vitro $(\mathrm{NCM})$ & Decreased hypertrophy & $\mathrm{L}-165041$ \\
\hline
\end{tabular}

In addition to the reported negative effects of PPAR $\alpha$ activation described above, a substantial amount of data indicates that PPAR $\alpha$ activation can have beneficial effects as well. In fact, all three PPAR isoforms have been reported to play a role in the cardiac remodelling process by modulating cardiomyocyte hypertrophy as well as cardiac fibrosis. 
This notion is supported by in vitro studies using isolated cardiomyocytes in which fenofibrate was able to inhibit endothelin-1 (ET-1)-induced cardiomyocyte enlargement and protein synthesis. ${ }^{26,}{ }^{27}$ In the in vivo setting, 10 week treatment with fenofibrate normalised LV weight and fractional shortening in Dahl salt-sensitive rats. ${ }^{104}$ Furthermore, in vivo activation of PPAR $\alpha$ with synthetic ligands (e.g. fenofibrate and Wy-14,643) attenuated LV hypertrophy ${ }^{27,104}$ and cardiac fibrosis. ${ }^{104-106}$ The positive effects of PPAR $\alpha$ activation on LV remodelling have been linked to the interaction of PPAR $\alpha$ with pro-inflammatory pathways converging on activator protein-1 (AP-1) and NF-KB. PPAR $\alpha$ activation was indeed associated with a decrease in both c-Jun N terminal kinase (JNK) phosphorylation and NF- $\mathrm{KB}$ DNA-binding activity. ${ }^{27,}{ }^{106}$ In addition, following pressure overload the expression of fibrotic markers, such as collagen I and III was reduced following PPAR $\alpha$ activation. ${ }^{105,106}$

In summary, ligand-dependent activation of endogenous PPAR $\alpha$ in the setting of cardiac hypertrophy may have detrimental consequences by either increasing $\mathrm{FA}$ oxidation or decreasing glucose oxidation. Concurrently, PPAR $\alpha$ activation mitigates inflammatory signalling, thereby inhibiting cardiac hypertrophy and fibrosis. These findings once more underscore the delicate balance between the potentially adverse metabolic and beneficial antiinflammatory effect of PPAR $\alpha$ activation in preserving cardiac function.

Initially, in vitro and in vivo studies claimed potent anti-hypertrophic effects of PPAR $\gamma$ ligands. Activation of PPAR $\gamma$ by its ligands (TZDs or the putative natural ligand $15 \mathrm{~d}-\mathrm{PGJ}_{2}$ ) attenuated hypertrophy, most likely via the NF-kB pathway. ${ }^{107}$ The pivotal role of PPAR $\gamma$ in hypertrophic remodelling was further demonstrated using heterozygous PPAR $\gamma+/-$ mice, which display a more pronounced increase in cardiac mass following pressure overload than wild-type mice. ${ }^{108}$ The PPAR $\gamma$ antagonist GW9662 enhanced BNP promoter activity in isolated neonatal rat cardiomyocytes, again supporting the contention that PPAR $\gamma$ has antihypertrophic properties. ${ }^{26}$ Furthermore, an elegant model for studying the role of PPAR $\gamma$ in cardiac hypertrophy was developed by Duan et al. ${ }^{109}$ Using cardiac-specific PPAR $\gamma$-/- mice they showed that these mice spontaneously developed pronounced concentric hypertrophy after 6 months. Unexpectedly, in this study treatment of wild-type mice with the PPAR $\gamma$ agonist rosiglitazone also led to cardiac hypertrophy. To explain these discrepant findings, the authors speculated about the role of different signalling pathways that were activated. While hearts from PPAR $\gamma-/$ - mice showed increased activation of NF-KB, treatment of wildtype mice with rosiglitazone was associated with activation of p38-MAPK.

Recent studies have challenged the concept that TZDs exert anti-hypertrophic effects. ${ }^{110-112}$ The TZD T-174 dose-dependently induced eccentric hypertrophy in rats after two weeks of treatment. ${ }^{113}$ Treatment with T-174 was also associated with an increase in blood volume preceding the increase in heart weight, suggesting that the pro-hypertrophic effect may be secondary to volume overload. The fluid retention is believed to be due to effects of TZDs on 
PPAR $\gamma$-mediated renal sodium reabsorption as deletion of PPAR $\gamma$ in the collecting ducts of the kidney prevented TZD-induced fluid retention. ${ }^{114}$ In this way PPAR $\gamma$ ligands may increase the risk of oedema in cardiac patients. Hence, the role of PPAR $\gamma$ in hypertrophic remodelling is still controversial to say the least. Moreover, the observation that PPAR $\gamma$ is hardly expressed in the cardiac muscle cells ${ }^{22}$ seems at odds with the notion that cardiac PPAR $\gamma$ plays an important role and, hence, could serve as a direct cardiac therapeutic target. Until now only two studies addressed the role of PPAR $\delta$ in cardiac hypertrophy. ${ }^{54,87}$ In cardiac-specific PPAR $\delta$ - /- mice the expression of FA handling genes and myocardial FAO capacity were decreased. ${ }^{87}$ These mice had increased myocardial lipid accumulation, cardiac hypertrophy and congestive heart failure. The authors suggested that these detrimental effects were due to cardiac lipotoxicity. Activation of PPAR $\delta$ with the synthetic ligand L-165041 inhibited in vitro hypertrophy of neonatal rat cardiomyocytes following $\alpha_{1}$-adrenergic stimulation. ${ }^{54}$ This effect was attributed to the anti-inflammatory properties of PPAR $\delta$ since L-165041 was able to diminish NF-kB DNA-binding activity. The limited data warrants further studies on the potential beneficial effect of PPAR $\delta$ activation in modulating hypertrophic growth of the heart.

\section{PPAR POLYMORPHISMS}

Another line of evidence underscoring the biological significance of PPARs in cardiac disease stems from polymorphisms in the genes encoding for PPAR $\alpha$, PPAR $\delta$ and PPAR $\gamma$ (referred to as PPARA, PPARD and PPARG). PPAR polymorphisms leading to loss- or gainof-function have been studied in relation to distinct cardiac disorders in human populations. In a large cohort study, the association of PPARA and PPARG variants with cardiovascular risk was investigated in type 2 diabetic patients. ${ }^{115,116}$ Polymorphisms, resulting in low expression of PPAR $\alpha$ (L162V variant) or decreased activity of PPAR $\gamma$ (C143T variant), were found to be associated with an increased risk of cardiovascular events in general, and myocardial infarction, in particular. ${ }^{115,116}$ Another PPARG variant (Pro12Ala) was associated with reduced risk of myocardial infarction ${ }^{116}$, although this was not confirmed in other studies. ${ }^{117,118}$ The $+294 \mathrm{~T} / \mathrm{C}$ polymorphism in the human PPARD gene was associated with low plasma HDL levels and increased risk of coronary heart disease in both men and women. $^{119,120}$ This polymorphism is associated with an increased tissue content of PPAR $\delta$. The association of the $+294 \mathrm{~T} / \mathrm{C}$ polymorphism in the human PPARD gene with increased PPAR $\delta$ is remarkable since PPAR $\delta$ is reported to positively influence lipid metabolism. It is important to note that PPAR polymorphisms are often associated with altered plasma lipoprotein concentrations, insulin sensitivity and obesity. These metabolic alterations predominantly influence the incidence of athero-thrombotic events leading to myocardial infarction (Table 4). Interestingly, the $\mathrm{G} / \mathrm{C}$ variant in intron 7 of the PPARA gene was 
associated with cardiac hypertrophy, since LV mass was found to be increased in homozygotes for the $\mathrm{C}$ allele in British army recruits after 10 weeks of strenuous exercise and in a cohort of hypertensive subjects. ${ }^{121}$

Table 4. Overview of studies investigating the association of PPAR polymorphisms with cardiovascular disease

\begin{tabular}{|c|c|c|}
\hline Reference & Variant & Effect \\
\hline \multicolumn{3}{|l|}{ PPARA } \\
\hline Jamshidi et al. 2002 & Intron $7 \mathrm{G} / \mathrm{C}$ & Increased LVH \\
\hline \multirow[t]{2}{*}{ Flavell et al. 2002} & L162V & Increased risk for $\mathrm{CHD}$ \\
\hline & Intron $7 \mathrm{G} / \mathrm{C}$ & \\
\hline \multirow[t]{2}{*}{ Doney et al. 2005} & V162 & Protective to non-fatal MI \\
\hline & $\mathrm{C} 2528$ & Higher risk of non-fatal MI \\
\hline \multicolumn{3}{|l|}{$P P A R G$} \\
\hline Wang et al. 1999 & $\mathrm{C} 161 \mathrm{~T}$ & Reduced CHD risk \\
\hline \multirow[t]{2}{*}{ Doney et al. 2004} & Alal2 & Reduced risk for MI \\
\hline & $\mathrm{T} 1431$ & Increased risk for MI \\
\hline Chao et al. 2004 & $161 \mathrm{~T}$ & Higher risk of MI in smokers \\
\hline Pischon et al. 2005 & Ala12 & No effect on CHD \\
\hline Li et al. 2006 & Ala12 & Increased risk for $\mathrm{Ml}$ \\
\hline \multicolumn{3}{|l|}{$P P A R D$} \\
\hline Skogsberg et al. 2003 & $+294 \mathrm{C}$ & Higher risk for $\mathrm{CHD}$ in men \\
\hline Aberle et al. 2006 & $+294 \mathrm{C}$ & Higher risk for $\mathrm{CHD}$ in women \\
\hline
\end{tabular}

\section{MECHANISM OF TRANSREPRESSIVE EFFECT OF PPAR}

Insight into the molecular mechanisms underlying the impact on heart function is fundamental to the understanding of PPAR function, on the one hand, and their involvement in disease mechanisms, on the other. PPARs act in two ways: transactivation (mainly resulting in metabolic effects) and transrepression (mainly resulting in anti-inflammatory effects). An important issue therefore is whether the reported beneficial effects of PPAR agonists are due to inhibition of inflammation and/or modulation of cardiac metabolism. It is even conceivable that these two properties are mutually related as suggested by studies showing that stimulation of inflammation (via NF- $\mathrm{KB}$ activation) resulted in decreased lipid metabolism ${ }^{122,123}$ and, vice versa, that attenuation of cardiac inflammation was associated with preservation of PPAR $\alpha$-regulated gene expression. ${ }^{124}$ Given that the mechanism of transactivation is rather well established and has been subject of various reviews ${ }^{50,56}$, here we will focus primarily on the transrepression properties of PPARs.

Before discussing the relation between PPARs and inflammation, the distinct pathways leading to an inflammatory response will be introduced. The most important inflammatory transcription factors are NF- $\mathrm{KB}, \mathrm{AP}-1$, signal transducers and activators of transcription 
(STAT) and SMAD (derived from SMA-small body size- and MAD-mothers against decapentaplegic) (Fig. 2).

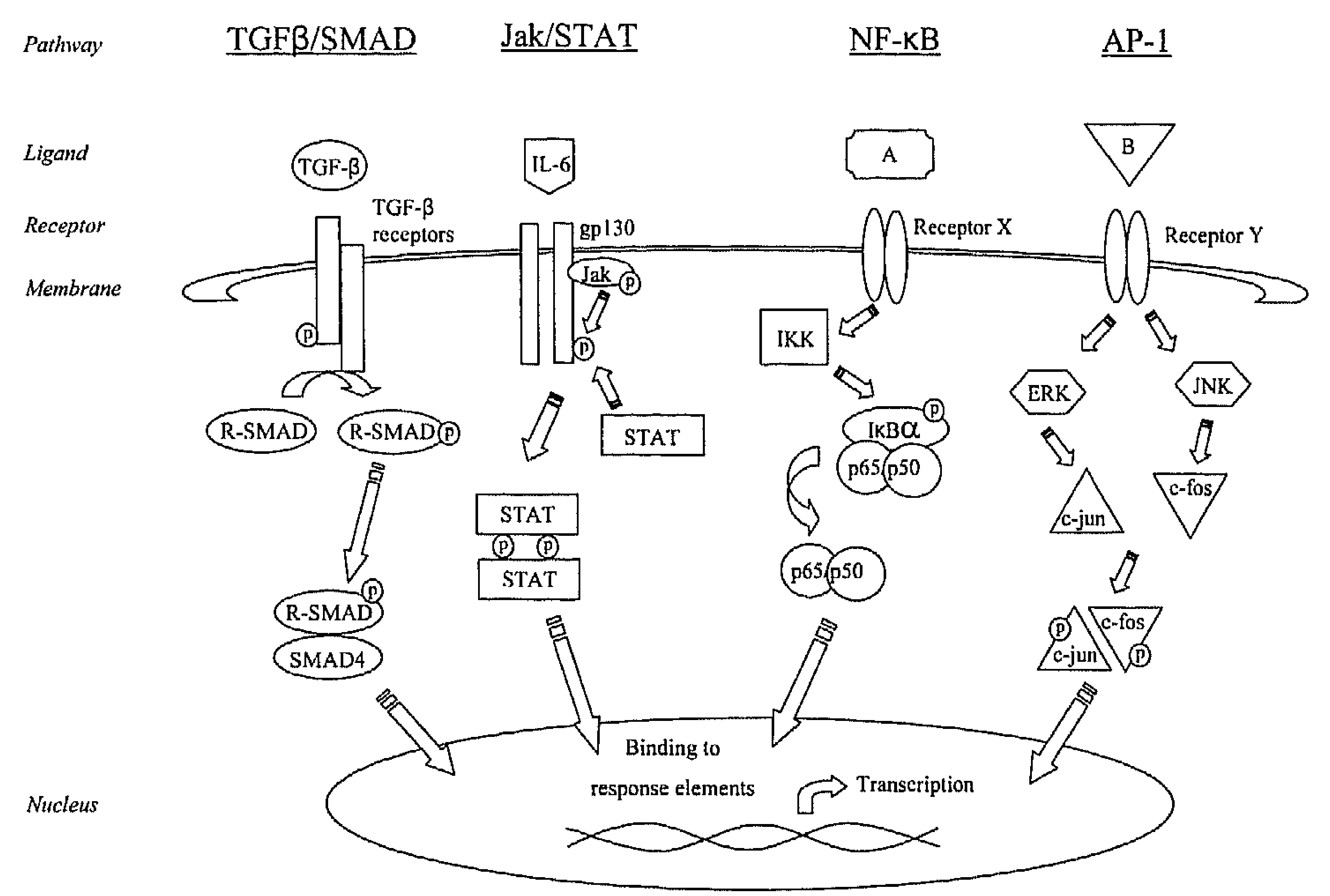

Figure 2. Scheme representing the most important pro-inflammatory signalling pathways. The distinct pathways lead to the activation of NF-KB, AP-1, STAT and SMAD, respectively. These transcription factors have in common that they are prone to phosphorylation and translocate into the nucleus to induce gene expression. Stimulus $\mathrm{A}$ or $\mathrm{B}$ and receptor $\mathrm{X}$ or $\mathrm{Y}$ indicate that the connecting pathways can be activated by more than one stimulus acting on more than one receptor. Therefore, these receptors and possible stimuli are not specified. Moreover, crosstalk between all these signalling pathways exists. See text for detailed explanation.

NF- $\mathrm{KB}$ is composed of different homo- and heterodimers of which the $\mathrm{p} 50 / \mathrm{p} 65$ dimer is the most common. In its inactive state NF- $\kappa B$ resides within the cytoplasm captured by $I \kappa B \alpha$. Upon phosphorylation of $I \kappa B \alpha$ by IKK $\beta$ (Inhibitor- $\kappa B$ Kinase- $\beta$ ), NF- $\kappa B$ dissociates from I $\kappa \mathrm{B} \alpha$ allowing its translocation to the nucleus where it binds to $\kappa \mathrm{B}$-response elements of its target genes (e.g. TNF- $\alpha$, iNOS). ${ }^{125}$ The second transcription factor, AP-1, is also composed of different subunits (e.g. c-fos, c-jun, JunD). The transcriptionally most active form is a heterodimer composed of c-jun and c-fos. Phosphorylation of c-jun and c-fos by ERK and $\mathrm{JNK}$, respectively, is required for activation of AP-1 and, subsequently, transcriptional expression of AP-1 related target genes. STATs are part of the Janus kinase-STAT (Jak/STAT) pathway which is co-regulated by Suppressor Of Cytokine Signalling (SOCS). 
Cytokines, like IL-6, bind to the glycoprotein 130 (gp 130) receptor, promoting phosphorylation of receptor-bound Jak. This, in turn, induces Jak-mediated phosphorylation of the receptor itself, thereby providing docking sites for STATs. The STATs are phosphorylated and released from the receptor, dimerize and translocate to the nucleus to induce gene expression. ${ }^{126}$ Finally, SMADs are transcription factors mediating TGF- $\beta$ signalling. The receptor-regulated SMADs (R-SMADs) are phosphorylated by the TGF- $\beta$ receptors upon binding of TGF- $\beta .{ }^{127}$ R-SMADs associate with SMAD4 which move to the nucleus to form complexes with co-activators and co-repressors to regulate gene expression. The ability of PPARs to cross-talk with each of the pro-inflammatory signalling pathways will be discussed below.

TGF-B/SMAD

PPAR $\gamma$ ligands have been reported to inhibit TGF- $\beta$-induced $\alpha$-smooth muscle actin and collagen I expression in skin fibroblasts. ${ }^{128}$ Furthermore, rosiglitazone inhibited vascular fibrosis in angiotensin II-treated rats, possibly via interference of PPAR $\gamma$ with SMADmediated expression of pro-fibrotic connective tissue growth factor. ${ }^{129}$ The inhibitory effect of PPAR $\gamma$ on fibrosis and inflammation involves interference with SMAD signalling ${ }^{128-130}$ through direct interaction between PPAR $\gamma$ and SMAD proteins. ${ }^{130}$ Indeed, physical interaction of PPAR $\gamma$ and SMAD3 in vitro was demonstrated in glutathione-S-transferase pull-down experiments. ${ }^{131}$ In contrast, no protein-protein interaction could be detected between PPAR $\alpha$ and SMAD in pull-down assays. ${ }^{132}$

\section{JAK/STAT}

The PPAR $\gamma$ ligand $15 \mathrm{~d}-\mathrm{PGJ}_{2}$ was found to inhibit IL-6 and IL-10 induced STAT3 activation. ${ }^{133,}{ }^{134}$ Furthermore, PPARs are reported to bind to STAT5b in COS-1 cells. ${ }^{135-137}$ The binding of PPAR $\alpha$ with STATs affected both STAT5b- and PPAR $\alpha$-mediated transcription. ${ }^{135,137}$ In primary astrocytes and microglia various PPAR $\alpha$ ligands suppressed STAT1 activation by decreasing STAT1 phosphorylation and the binding of STAT1 to its DNA-response element. The PPAR $\gamma$ ligands $15 \mathrm{~d}-\mathrm{PGJ}_{2}$ and rosiglitazone were also demonstrated to inhibit STAT signalling by increasing the expression of SOCS, although this effect could be partly explained by PPAR $\gamma$-independent effects of the ligands. ${ }^{138}$

$\mathrm{NF}-\mathrm{KB}$

Co-immunoprecipitation assays convincingly showed that PPAR $\delta$ physically interacts with the $\mathrm{p} 65$ subunit of NF- $\mathrm{KB}$ in $\mathrm{H} 9 \mathrm{c} 2$ myotubes. ${ }^{54}$ This interaction prevents binding of NF- $\mathrm{KB}$ to its response element in the promoter region of its target genes, thereby diminishing expression of pro-inflammatory genes. The association of PPAR $\gamma$ and $\mathrm{p} 65$ has also been 
shown to promote the nuclear export of NF-KB in Caco-2 cells, thereby preventing NF-KBmediated gene activation. ${ }^{139}$ In addition to the physical interaction between PPARs and NF$\kappa B$, PPARs are also able to inhibit NF- $\mathrm{KB}$ signalling via transcriptional mechanisms. For instance, IKB $\alpha$ expression was increased by PPAR $\alpha .{ }^{140}$ However, this effect is not achieved by direct transactivation of the I $\mathrm{KB} \alpha$ promoter, but probably involves indirect effects, the nature of which still remains to be elucidated.

AP-1

PPAR $\alpha$ and PPAR $y$ ligands have been reported to suppress the transcriptional activity of AP1 in various cell types. ${ }^{141-143}$ In neonatal cardiomyocytes the PPAR $\alpha$ ligand fenofibrate inhibited the ET-1-induced upregulation of c-jun mRNA and the phosphorylation of JNK, leading to reduced binding of the AP-1 dimer to its cognate DNA-binding site. ${ }^{27}$ Again, physical interaction of PPAR $\alpha$ with pro-inflammatory transcription factors, in this case c-jun, was claimed to be the principal mechanism. ${ }^{42}$

Post-translational modification of the PPARs also provides pivotal control points in regulating transrepression. Pascual et al. ${ }^{144}$ proposed a mechanism by which transcription of the pro-inflammatory gene iNOS is suppressed in a PPAR $\gamma$ ligand-dependent manner involving post-translational SUMOylation of the PPAR $\gamma$ ligand-binding domain. When SUMOylated, PPAR $\gamma$ forms a stable repressor complex with the nuclear hormone receptor co-repressor (NCoR) and histone deacetylase-3 (HDAC3). In macrophages this complex prevented NF-kB-mediated transcriptional activation of the iNOS promoter. ${ }^{144}$ Next to SUMOylation, phosphorylation of PPARs has been shown to modulate the transrepression properties of PPARs. Protein Kinase C (PKC) was found to regulate the transactivation and transrepression properties of PPAR $\alpha$ via phosphorylation of serine residues (S179 and S230) in the $\mathrm{D}$ domain. ${ }^{145}$ Pharmacological inhibition of PKC with R031-8220 increased transrepression of PPAR $\alpha$ on the fibrinogen- $\beta$ promoter, while at the same time decreasing PPAR $\alpha$ transactivation in liver cells. ${ }^{145}$

An important issue is whether the transrepression effects are ligand-dependent or ligandindependent. The common observation in animal models of cardiac disease, in which the treatment with PPAR agonists is associated with a diminished inflammatory response, strongly favours the notion that transrepression is ligand-mediated. On the other hand, based on the putative molecular mechanisms described, there is no strict requirement for ligands in mediating the transrepressive effects of PPARs. Indeed, in smooth muscle cells the PPAR $\alpha-$ mediated inhibition of c-jun and p 65 appeared to be ligand-independent. ${ }^{42}$ In line with this, a PPAR $\delta$ mutant with an ablated ligand-binding domain was still able to transrepress LPSinduced TNF $\alpha$ expression in cardiomyocytes. ${ }^{146}$ Alternatively, ligand-dependent mechanisms 
of PPAR $\delta$-mediated transrepression have also been postulated. ${ }^{53,147}$ Hereby, the B-cell lymphoma- 6 (Bcl-6) repressor is bound to the inactive PPAR $\delta$. Upon ligand binding, Bcl- 6 is released and exerts anti-inflammatory actions. It remains to be established whether Bcl-6 is also relevant for the anti-inflammatory effects in cardiac myocytes or fibroblasts.

In conclusion, a variety of molecular mechanisms, working at different levels in the signalling cascades (Fig. 3), have been proposed to explain the anti-inflammatory actions of PPARs. Current evidence supports the notion that, in particular, physical interactions between PPARs and other transcription factors play an important role in attenuating pro-inflammatory signalling pathways. Additional mechanisms, however, should not be excluded.

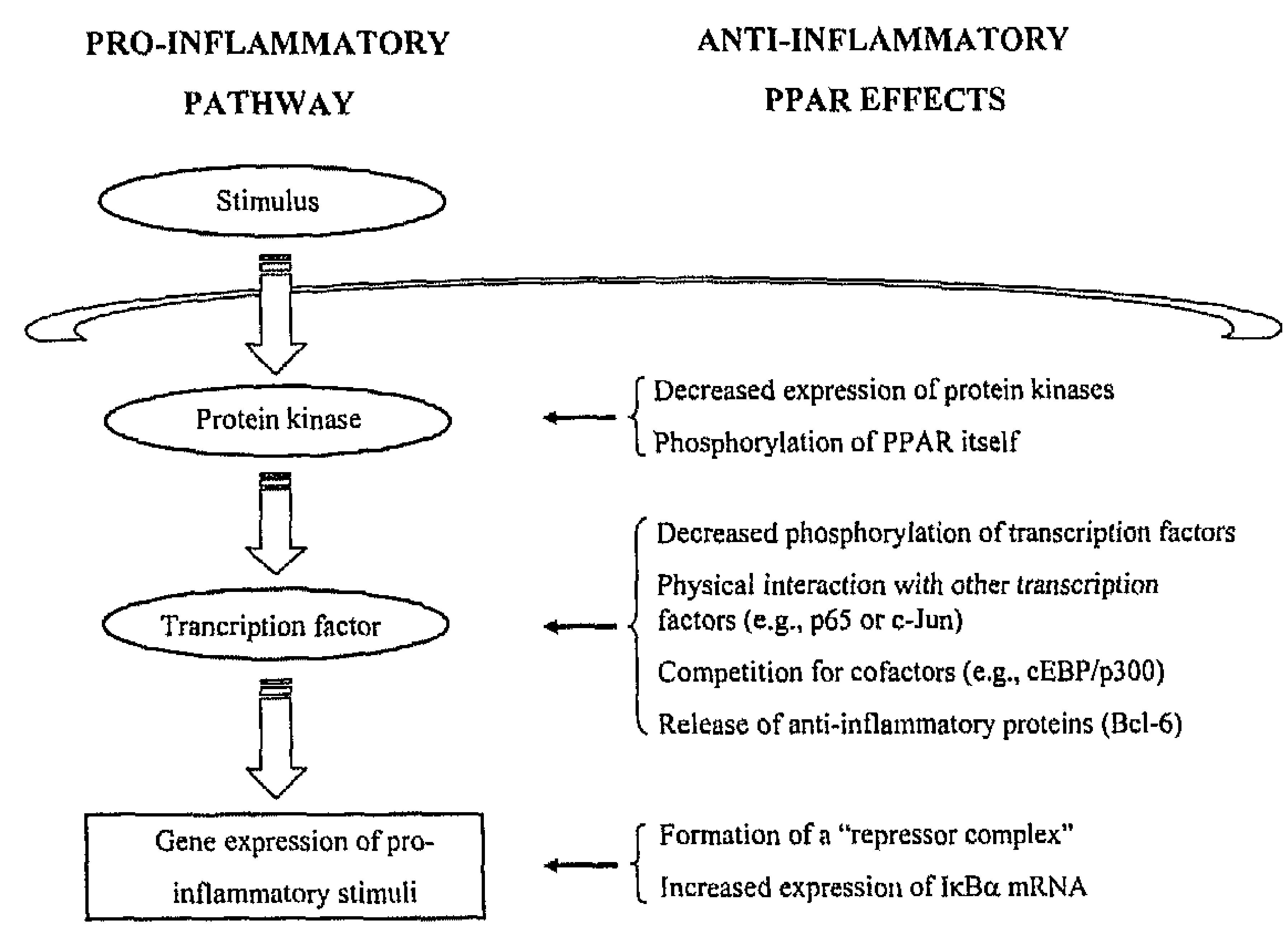

Figure 3. Schematic representation of the levels at which PPARs can interfere with inflammatory signalling pathways.

\section{PPAR ACTIVATION: DETRIMENTAL OR BENEFICIAL?}

As reviewed above and summarized in Table 1-3, there is incomplete consensus on the effects of PPAR activation in cardiac I/R, infarction as well as hypertrophy. The outcome of studies from different laboratories employing pharmacological (PPAR agonists or antagonists) or molecular biological interventions (gain- or loss-of-function approaches) are in a number of cases contradictory. To some extent, this is inherent to the pleiotropic effects of PPARs and the focus of the study. It is remarkable that most studies addressing the metabolic (transactivation) component of PPARs tend to be biased to explain the functional 
outcome in terms of metabolic effects of PPARs, often ignoring the anti-inflammatory (transrepression) component, and vice versa.

Experimental model and study design are other important determinants. As discussed earlier the inflammatory response during $\mathrm{I} / \mathrm{R}$ and infarction encompasses both an intrinsic component (NF- $\mathrm{kB}$ activation within the various cell types constituting the heart) and the infiltration of neutrophils and macrophages into the injured myocardium. By design the latter component is excluded when studying $I / R$ in a buffer-perfused isolated heart model. By inference the putative advantageous effect of PPAR ligands on leucocyte infiltration does not contribute to the outcome in this ex vivo model. The choice of animal species will possibly affect the outcome as well. At least for the liver, it has already been established that PPAR $\alpha$ levels and, hence, effects of PPAR $\alpha$ ligands, are much more pronounced in mice than in humans. ${ }^{148}$ Whether such species differences are also relevant to the heart remains to be established. In this respect, it is of note that in rodents the effects of PPAR $\alpha$ ligands on the expression of metabolic genes is far less pronounced in cardiac than hepatic tissue. ${ }^{149}$

Likewise the dose, timing and duration of ligand administration are also relevant. When studying $\mathrm{I} / \mathrm{R}$, for instance, pre-treatment of animals with ligands for several days to weeks can lead to a different outcome than when the ligand is added just prior to the intervention. In the latter case the time to exert genomic effects (via transactivation) is simply too short. However, transrepression effects (based on protein-protein interaction) might still play a role under these conditions. Furthermore, the doses applied are sometimes in a concentration range in which PPAR isoform specificity becomes questionable. ${ }^{150,151}$ In addition, PPARindependent effects of several ligands have been reported as well. ${ }^{152,153} \mathrm{~A}$ case in point is a recent study reporting increased mortality and adverse cardiac effects after administration of fenofibrate to PPAR $\alpha-/$ - mice. ${ }^{153}$

Given the widespread tissue distribution of PPARs, ligand administration to animals will have numerous extra-cardiac effects including alterations in circulating substrate and, possibly, cytokine levels, adipose mass, body-fluid volume and blood pressure. Each of these factors can act as a potential confounder when studying direct effects of PPAR ligands on cardiac disorders such as $I / R$, infarct healing, or cardiac hypertrophy.

Next to study design a number of fundamental questions need to be answered even before we are able to judge whether PPAR activation should be considered good or bad. Regarding I/R the prevailing hypothesis states that promoting glucose oxidation during early reperfusion is advantageous. Hence, from a metabolic point of view the use of FAO promoting therapies, such as PPAR $\alpha$ and PPAR $\delta$ ligands is to be discouraged. With respect to cardiac hypertrophy and failure the present paradigm reads that a metabolic shift from FA to glucose metabolism occurs (unless complicated by co-morbidity such as diabetes). However, whether this is a direct consequence of a reduction in cardiac PPAR $\alpha$ activity is controversial. Even more so, 
the question whether this metabolic shift should be considered as an adaptive or maladaptive response, and hence needs to be corrected, is incompletely understood. Finally, there is little doubt that the inhibition of inflammatory processes is beneficial. However, infarct healing requires cleaning-up of irreversibly damaged cells by infiltrating leukocytes and extracellular matrix production by fibroblasts. The question remains whether it is good or bad to inhibit these processes by means of PPAR activation.

Future studies should delineate the role and mode of action of each PPAR isoform in cardiac disease. In this context the generation of cardiac-specific transgenic and knock-out mouse models has already provided valuable information regarding the role of PPAR isoforms in the heart per se. For example, cardiac-specific ablation of PPAR $\delta$ and PPAR $\gamma$ is associated with concentric and eccentric hypertrophy, respectively ${ }^{87,109}$, suggesting that partly different hypertrophic signalling pathways are being activated. Very recently, Kelly et al. showed that cardiac specific overexpression of PPAR $\alpha$ and PPAR $\delta$ leads to different cardiac phenotypes. ${ }^{154}$ The availability of such mouse models is instrumental to sort out the contribution of metabolic and inflammatory processes during cardiac malfunctioning and to explore the beneficial or detrimental effects of PPAR activation on the diseased heart.

\section{GENERAL CONCLUSIONS}

The different cardiac disorders described in this review, i.e., I/R, myocardial infarction and cardiac hypertrophy, are all accompanied by activation of pro-inflammatory processes, either via the activation of signalling pathways with the different types of cells constituting the heart (myocytes, fibroblasts, endothelial cells), or secondary to infiltrating leukocytes. An exaggerated inflammatory response could drive the heart towards malfunctioning and, eventually, failure. Attenuation of the inflammatory response can therefore have significant salutatory effects on the cardiac muscle.

Each of the three PPAR isoforms is endowed with the dual capacity to modulate both metabolism and inflammation. In this way these nuclear receptors are likely to interfere with cardiac remodelling, ultimately affecting cardiac energy homeostasis, apoptosis, fibrosis, and possibly angiogenesis. The fact that the activity of PPARs is regulated in a ligand-dependent manner makes them attractive candidates for therapy. On the other hand, the wide range of cellular processes in which PPARs are involved, could also become a serious drawback. One interesting approach to circumvent this problem will be to design drugs or interventions that specifically put a PPAR isoform in either the transactivation or the transrepression mode. This challenge requires detailed molecular understanding about the regulation of the transactivating and transrepressing properties of the PPAR isoforms. Such knowledge will allow optimal use of the therapeutic potential of PPARs in the diseased heart. 


\section{ACKNOWLEDGEMENTS}

This study was funded by a grant from the Netherlands Organisation for Scientific Research (NWO 912-04-017 to M.v.B.) and EU FP6 grant LSHM-CT-2005-018833/EUGeneHeart. A. Planavila was supported by a post-doctoral fellowship from the Spanish Ministry of Education (EX2005-1376). 


\section{INFLAMMATORY PATHWAYS ARE ACTIVATED DURING CARDIOMYOCYTE HYPERTROPHY AND ATTENUATED BY PPAR $\alpha$ AND PPAR $\delta$}

Pascal J.H. Smeets, Birgit E.J. Teunissen, Anna Planavila, Heleen M. Vogel-van den Bosch, Peter H.M. Willemsen, Ger J. van der Vusse and Marc van Bilsen

Journal of Biological Chemistry 2008;283(43):29109-28118.

\footnotetext{
ABSTRACT $\mid$ Accumulating evidence indicates an important role of inflammation in cardiac hypertrophy and failure. Peroxisome proliferator-activated receptors (PPARs) have been reported to attenuate inflammatory signalling pathways and, as such, may interfere with cardiac remodelling. Accordingly, the objectives of the present study were to explore the relationship between cardiomyocyte hypertrophy and inflammation and to investigate whether PPAR $\alpha$ and PPAR $\delta$ are able to inhibit NF- $\mathrm{KB}$ activation and, consequently, the hypertrophic growth response of neonatal rat cardiomyocytes (NCM). mRNA levels of markers of both hypertrophy and inflammation were increased following treatment with the pro-hypertrophic factor phenylephrine (PE) or the chemokine TNF- $\alpha$. Induction of inflammatory genes was found to be fast (within $2 \mathrm{~h}$ after stimulation) and transient, while induction of hypertrophic marker genes was more gradual (peaking at 24-48 h). Inflammatory and hypertrophic pathways appeared to converge on NF- $\mathrm{KB}$ as both PE and TNF- $\alpha$ increased NF- $\mathrm{KB}$ binding activity as measured by electrophoretic mobility shift assay. Following transient transfection the p65-induced transcriptional activation of a NF- $\mathrm{kB}$ reporter construct was significantly blunted after co-transfection of PPAR $\alpha$ or PPAR $\delta$ in the presence of their respective ligands. Finally, adenoviral overexpression of PPAR $\alpha$ and PPAR $\delta$ markedly attenuated cell enlargement and the expression of hypertrophic marker genes in PE-stimulated NCM. The collective findings reveal a close relationship between hypertrophic and inflammatory signalling pathways in the cardiomyocyte. It was shown that both PPAR $\alpha$ and PPAR $\delta$ are able to mitigate cardiomyocyte hypertrophy in vitro by inhibiting NF- $\mathrm{KB}$ activation.
} 


\section{INTRODUCTION}

Evidence is accumulating that chronic inflammation plays an important role in cardiac disease. This notion is based, among others, on the observation that heart failure patients show elevated plasma levels of pro-inflammatory cytokines, such as tumour necrosis factor- $\alpha$ $(\mathrm{TNF}-\alpha){ }^{32}$ In addition, cytokines have been implicated in the development of cardiac hypertrophy ${ }^{12,97}$, most likely via downstream activation of pro-inflammatory transcription factors such as nuclear factor- $\mathrm{kB}$ (NF-kB). ${ }^{14} \mathrm{NF}-\mathrm{kB}$ is composed of different homo- and heterodimers of which $\mathrm{p} 50 / \mathrm{p} 65$ is transcriptionally the most active dimer in the heart. ${ }^{34}$ In its inactive state $\mathrm{NF}-\kappa \mathrm{B}$ resides within the cytoplasm through its interaction with inhibitor- $\mathrm{\kappa B} \alpha$

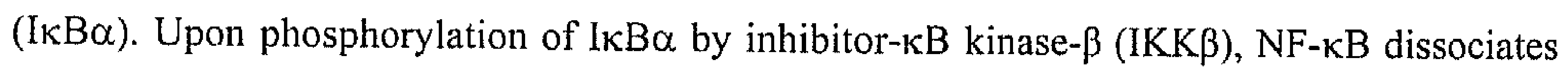
from I $\kappa \mathrm{B} \alpha$ allowing its translocation to the nucleus where it binds to NF- $\kappa B$ response ciselements in target genes. It is proposed that inhibition of pro-inflammatory pathways, in general, and NF- $\mathrm{KB}$, in particular, could be beneficial for the diseased heart. ${ }^{155,156}$

Peroxisome proliferator-activated receptors (PPARs) are ligand-activated transcription factors acting as modulators of lipid metabolism as well as inflammation. ${ }^{20,41}$ The anti-inflammatory effect of PPARs appears to be related to interference with NF-KB signalling. ${ }^{146,155}$ Indeed, treatment of animals with PPAR ligands has been reported to mitigate inflammation following cardiac ischemia and reperfusion. ${ }^{24,} 63,70,81$ Two of the three PPAR isoforms, i.e., PPAR $\alpha$ (NR1C1) and PPARס (NRIC2), are abundantly expressed in the cardiac muscle cell. ${ }^{22}$ Although the majority of studies focused on the anti-inflammatory properties of PPAR $\alpha$ and PPAR $\gamma^{42,157-159}$, several studies indicate that PPAR $\delta$ is likely to possess similar features. ${ }^{53,54,}$ 146 Whether the putative anti-inflammatory properties of PPAR $\alpha$ and PPAR $\delta$ affect cardiomyocyte hypertrophy still remains to be established.

We hypothesized that growth-promoting stimuli elicit an inflammatory response in cardiomyocytes and that pro-hypertrophic and inflammatory signalling pathways converge on

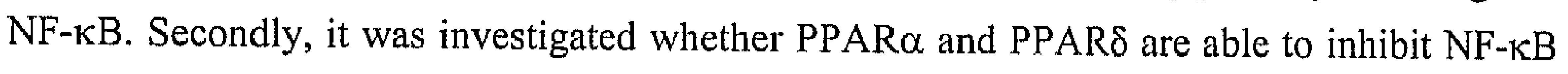
activation in the cardiomyocyte and whether this provides a molecular mechanism to mitigate cardiac hypertrophy. Thereto, rat neonatal cardiomyocytes (NCM) were stimulated with several growth-promoting neuroendocrine factors or with pro-inflammatory agents for up to 48 hours and time-dependent changes in the expression of established markers of hypertrophy and inflammation were assessed by quantitative PCR (qPCR). Activation of NF- $\mathrm{KB}$ was monitored by electrophoretic mobility shift assay (EMSA). Transient transfection studies with expression vectors and promoter/reporter constructs were performed to investigate the functional interaction of the NF-KB subunit p65 with PPARs. In addition, the ability of PPARs to attenuate cardiomyocyte hypertrophy was explored using pharmacological (isoform-specific PPAR ligands) and molecular tools (adenoviral overexpression of PPAR $\alpha$ and PPAR $\delta$ ). 
The collective findings reveal a close relationship between hypertrophic and inflammatory signalling pathways in the cardiomyocyte. We demonstrate for the first time that both PPAR $\alpha$ and PPAR $\delta$ are able to inhibit NF-KB activation in vitro and, in this way, may mitigate hypertrophic remodelling of the cardiac muscle cell.

\section{Methods}

\section{CHEMICALS}

TNF- $\alpha$ and transforming growth factor- $\beta$ (TGF- $\beta$ ) were purchased from PeproTech (Rocky Hill, NJ, USA) and angiotensin II (AngII) from Bachem (Bubendorf, Switzerland). Isoform specific ligands for PPAR $($ Wy-14,643) and PPAR (GW501516) were obtained from Biomol (Plymouth Meeting, PA, USA) and Calbiochem (EMD Biosciences, Darmstadt, Germany), respectively. All other chemicals were purchased from Sigma (St. Louis MO, USA). The PPAR ligands were dissolved in DMSO; TGF- $\beta$ and AngII in phosphate-buffered saline (PBS); phenylephrine (PE) in Dulbecco's Modified Eagle Medium (DMEM) and all other chemicals in distilled water.

\section{Cell culture}

Neonatal cardiomyocytes (NCM) were isolated and cultured as described by de Vries et al. ${ }^{160}$ using differential plating to separate myocytes from non-myocytes. All experiments were approved by the Institutional Animal Care and User Committee of the Maastricht University. Briefly, 1 to 2 days old Lewis rats were decapitated and the hearts removed. The hearts were digested with a collagenase solution (Collagenase Type I, Gibco) followed by differential plating. Cells were plated in a density of $2.5 \times 10^{4}$ per well in 6-well plates or $2 \times 10^{6}$ in 10 $\mathrm{cm}$ dishes coated with $1 \%$ gelatine and cultured overnight in plating medium (4:1 DMEM and Media 199) supplemented with $10 \%$ horse serum, $5 \%$ newborn calf serum, $50 \mathrm{mg} / \mathrm{L}$ gentamicine, $10 \mathrm{mM}$ glucose and $10 \mu \mathrm{M}$ cytosine $\beta$-D-arabino furanoside (Ara C). Ara $C$ was added to suppress growth of remaining fibroblasts. $16 \mathrm{~h}$ after cell isolation, NCM were incubated in serum-free medium consisting of a 4:1 mixture of DMEM/M199, gentamicin $(50 \mathrm{mg} / \mathrm{L})$ and glucose $(10 \mathrm{mM})$ as the sole substrate for $24 \mathrm{~h}$. Subsequently, experimental medium was applied to the cells. The experimental medium consisted of serum-free medium enriched with $0.25 \mathrm{mM}$ L-carnitine, $0.25 \mathrm{mU} / \mathrm{ml}$ insulin and $1 \%$ bovine serum albumin. Ara C was present during the entire cell culture.

NCM were stimulated with either hypertrophic growth factors, i.e., the $\alpha_{1}$-adrenergic agonist PE $(10 \mu \mathrm{M})$, endothelin-1 $(\mathrm{ET}-1,1 \mathrm{nM})$, AngII $(10 \mu \mathrm{M})$, TGF- $\beta(10 \mathrm{ng} / \mathrm{ml})$ or with the inflammatory agents lipopolysaccharide (LPS, $100 \mathrm{ng} / \mathrm{ml})$ and TNF- $\alpha(50 \mathrm{ng} / \mathrm{ml})$, and cells were harvested for RNA or protein isolation 2, 12, 24 and $48 \mathrm{~h}$ after exposure. Appropriate 
vehicles served as controls. At the concentrations used none of the agents induced significant cell loss.

\section{RNA ISOLATION AND QPCR}

RNA isolation, cDNA synthesis and qPCR were performed as previously described. ${ }^{23} 100 \mathrm{ng}$ of RNA was used for cDNA synthesis. Primers used are given in supplementary table I. Results were normalised to the house-keeping gene cyclophilin A. Relative changes in expression were calculated using GeneX software (Bio-Rad).

\section{PLASMIDS}

For transient transfection studies the following promoter/reporter constructs were used; mCPT-I-luc ${ }^{22}$, mutated mCPT-I-luc construct ${ }^{23},(-638 \mathrm{bp})$ ANF promoter-luc and p19TK-luc containing three NF-kB consensus sites (kind gift from Dr. Van der Saag, Hubrecht Lab, Utrecht, the Netherlands). Expression vectors used were: pSG5 containing cDNA of mouse PPAR $\alpha$ or PPAR $\delta$ (kindly provided by Dr. Staels, Institut Pasteur, Lille, France); pCMV4 containing cDNA of human p65 (kind gift from Dr. Van der Saag) and pON249 containing CMV- $\beta$-galactosidase. As positive control for the transfection assay we used pSVOAL-luc in which luciferase is driven by the RSV promoter.

\section{TRANSIENT TRANSFECTION}

NCM were transfected $24 \mathrm{~h}$ after cell isolation using the transfection reagent FuGENE 6 (Roche, Indianapolis IN, USA) with $0.5 \mu \mathrm{g}$ of promoter/reporter vector. ${ }^{22}$ The CMV- $\beta$ galactosidase containing vector pON249 $(0.25 \mu \mathrm{g})$ was co-transfected to check for transfection efficiency. In a sub-series of experiments $0.25 \mu \mathrm{g}$ of expression vectors containing the cDNA of PPAR $\alpha$, PPAR $\delta$ or p65 were co-transfected. The total amount of plasmid DNA per well $(1.25 \mu \mathrm{g})$ was kept constant by adding empty pSG5 vector (Promega, Madison, WI, USA). After $16 \mathrm{~h}$ of transfection, experimental medium was added to the cells followed by exposure to PE $(10 \mu \mathrm{M})$ in the absence or presence of Wy-14,643 $\left(10 \mu \mathrm{M}, \mathrm{EC}_{50}=\right.$ $0.63 \mu \mathrm{M})$ or GW501516 $\left(1 \mu \mathrm{M}, \mathrm{EC}_{50}=0.024 \mu \mathrm{M}\right)$. The affinity and selectivity of these ligands for their PPAR isoforms have been described previously. ${ }^{22}$ Cells were harvested $24 \mathrm{~h}$ (m-CPT-I and NF-KB reporter/promoter) or $48 \mathrm{~h}$ (ANF reporter/promoter) after start of treatment and immediately processed for the determination of reporter activity. Luciferase activity was determined using a commercial firefly luciferase assay according to the supplier's instructions (Steady Glo, Promega) in white 96-well plates (Nalge Nunc International, Maperville, IL, USA) on a FluorS imager (Bio-Rad) for measuring luminescence. $\beta$-Galactosidase activity was assessed spectrophotometrically (Titertek Multiskan Plus MKII, Thermo LabSystems, Helsinki, Finland) as described previously. ${ }^{161}$ 


\section{PREPARATION OF NUCLEAR EXTRACTS}

NCM were exposed to TNF- $\alpha$ or PE for the times indicated. Cells were harvested by scraping in ice-cold PBS supplemented with phosphatase inhibitors (125 mM NaF, $250 \mathrm{mM} \beta$ glycerophosphate and $25 \mathrm{mM} \mathrm{NaVO}_{3}$ ), followed by centrifugation $(300 \mathrm{~g}, 5 \mathrm{~min})$. The cell pellet was resuspended in $400 \mu$ l of icecold low-salt buffer ( $10 \mathrm{mM}$ HEPES-KOH, pH 7.9, 1.5 $\mathrm{mM} \mathrm{MgCl} 2,10 \mathrm{mM} \mathrm{KCl}, 0.5 \mathrm{mM}$ dithiothreitol (DTT), $0.2 \mathrm{mM}$ phenylmethylsulfonyl fluoride (PMSF), $5 \mu \mathrm{g} / \mathrm{ml}$ aprotinin). Cells were allowed to swell at $4^{\circ} \mathrm{C}$ for 10 min and then vortexed for $10 \mathrm{~s}$. Subsequently the supernatant fraction was discarded after a short spin. Pellets were resuspended in $30 \mu \mathrm{l}$ of icecold high-salt buffer $(20 \mathrm{mM}$ HEPES-KOH, $\mathrm{pH} 7.9$, $25 \%$ glycerol, $420 \mathrm{mM} \mathrm{NaCl}, 1.5 \mathrm{mM} \mathrm{MgCl}_{2}, 0.2 \mathrm{mM}$ EDTA, $0.5 \mathrm{mM}$ DTT, $0.2 \mathrm{mM}$ PMSF, $5 \mu \mathrm{g} / \mathrm{ml}$ aprotinin) and incubated at $4^{\circ} \mathrm{C}$ for $30 \mathrm{~min}$. Nuclear debris was removed by centrifugation at $1000 \mathrm{~g}$ at $4^{\circ} \mathrm{C}$ for $10 \mathrm{~min}$, and the supernatant (containing DNA-binding proteins) was stored at $-80^{\circ} \mathrm{C}$. Protein concentration of nuclear extracts was determined with the Bradford method. ${ }^{162}$

\section{ELECTROPHORETIC MOBILITY SHIFT ASSAY (EMSA)}

A double-stranded oligonucleotide containing the NF- $\mathrm{KB}$ consensus binding site (5'AGTTGAGGGGACTTTCCCAGGC-3') was end-labeled at $37^{\circ} \mathrm{C}$ in the following reaction mix: $2 \mu 1$ of ds oligonucleotide $(1.75 \mathrm{pmol} / \mu 1), 2 \mu 1$ of $5 \mathrm{x}$ kinase buffer, $1 \mu 1$ of $\mathrm{T}_{4}$ polynucleotide kinase $(10 \mathrm{U} / \mu \mathrm{l})$, and $2.5 \mu 1$ of $\left[\gamma-{ }^{32} \mathrm{P}\right] \mathrm{dATP}(3000 \mathrm{Ci} / \mathrm{mmol}$ at $10 \mathrm{mCi} / \mathrm{ml})$. After $2 \mathrm{~h}$ the reaction was stopped by adding $90 \mu 1$ of TE buffer. To separate the labeled probe from unbound ATP, the reaction mixture was eluted on ProbeQuant G-50 Micro columns (Amersham). Nuclear extracts $\left(4 \mu \mathrm{g}\right.$ protein) were incubated for $10 \mathrm{~min}$ at $4^{\circ} \mathrm{C}$ in binding buffer containing $10 \mathrm{mM}$ Tris- $\mathrm{HCl}(\mathrm{pH} 8.0), 25 \mathrm{mM} \mathrm{KCl}, 0.5 \mathrm{mM}$ DTT, $0.1 \mathrm{mM}$ EDTA (pH 8.0), 5\% glycerol, $5 \mathrm{mg} / \mathrm{ml} \mathrm{BSA}$ and $50 \mu \mathrm{g} / \mathrm{ml}$ poly(dI-dC) Next, ${ }^{32} \mathrm{P}$-labeled oligonucleotide probe (approximately $60,000 \mathrm{cpm}$ ) was added and the reaction was incubated for $15 \mathrm{~min}$ at $4^{\circ} \mathrm{C}$. Where indicated, p65 antibody (Santa-Cruz) or specific competitor oligonucleotide were added 10 min prior to incubation with labeled probe at $4^{\circ} \mathrm{C}$. ProteinDNA complexes were separated by electrophoresis at $4^{\circ} \mathrm{C}$ on a $5 \%$ acrylamide gel. After drying of the gels autoradiography was performed using Hyperfilm (Amersham) and by scanning on a Phospho-imager (Bio-Rad).

\section{ADENOVIRAL INFECTION}

Recombinant adenoviruses expressing human PPAR $\alpha$ (AdPPAR $\alpha$ ), human PPAR $\delta$ (AdPPAR $\delta$ ) and control virus (AdCMV) were kindly provided by Dr. Staels (Institut Pasteur, Lille, France). Adenoviruses were multiplied and purified as previously described. ${ }^{23}$ Prior to treatment with Wy-14,643 or GW501516, NCM were infected with 50 IFU/cell for $24 \mathrm{~h}$ in serum-free medium. To check functionality of adenoviral infection of NCM at 50 IFU, the 
expression of the PPAR-target gene PDK4 was assessed. There was no significant cell death induced by adenoviral infection at 50 IFU.

\section{ASSESSMENT OF CELL SIZE}

NCM were grown on laminin $(10 \mu \mathrm{g} / \mathrm{ml})$ coated glass coverslips and fixated with methanol for $3 \mathrm{~min}$ at $-20^{\circ} \mathrm{C}$. After permeabilization with $0.1 \%$ Triton-X100 for $5 \mathrm{~min}$ and blocking with $2 \%$ BSA for $30 \mathrm{~min}$, cells were incubated overnight with an antibody against $\alpha$-actinin (Sigma) dissolved in PBS containing 10\% normal goat serum (Dako, Glostrup, Denmark). Next, cells were washed with PBS and incubated with Texas Red conjugated secondary antimouse IgG (Jackson ImmunoResearch, West Grove, PA, USA) dissolved in PBS containing $10 \%$ normal goat serum. Cells were washed again, mounted in Vectashield (Vector Laboratories, Burlingame, CA, USA) and analysed using a fluorescence microscope. Cardiomyocyte surface area $\left(\mu \mathrm{m}^{2}\right)$ was determined from randomly selected fields from three independent cell cultures using Quantimet 570 software (Leica, the Netherlands).

\section{STATISTICS}

Each experiment was conducted in triplicate in at least three independent cardiomyocyte isolations. Results are presented as mean \pm SEM. Data were analysed by one-way ANOVA, followed by Bonferonni Post-Hoc test or Dunnet's Post-Hoc when appropriate using SPSS 12 software (SPSS Inc.). A p-value of less than 0.05 was considered to be statistically significant.

\section{RESULTS}

\section{CARDIOMYOCYTE HYPERTROPHY AND INFLAMMATION}

To investigate the relationship between cardiac hypertrophy and inflammation NCM were incubated with either neuroendocrine growth factors (AngII, ET-1, PE or TGF- $\beta$ ) or proinflammatory agents (LPS or TNF- $\alpha$ ). The early $(2 \mathrm{~h})$ and late $(24 \mathrm{~h})$ effects of these distinct stimuli on the expression of COX-2 and ANF, markers of inflammation and hypertrophy, respectively, were determined. Already $2 \mathrm{~h}$ after administration of pro-hypertrophic as well as inflammatory agents COX-2 mRNA levels were increased several fold (Fig. 1A), whereas the mRNA level of ANF was not affected to a significant extent yet (Fig. 1B). After $24 \mathrm{~h}$, however, COX-2 expression had returned to near basal levels, whereas expression of ANF was markedly upregulated at this later time point. 


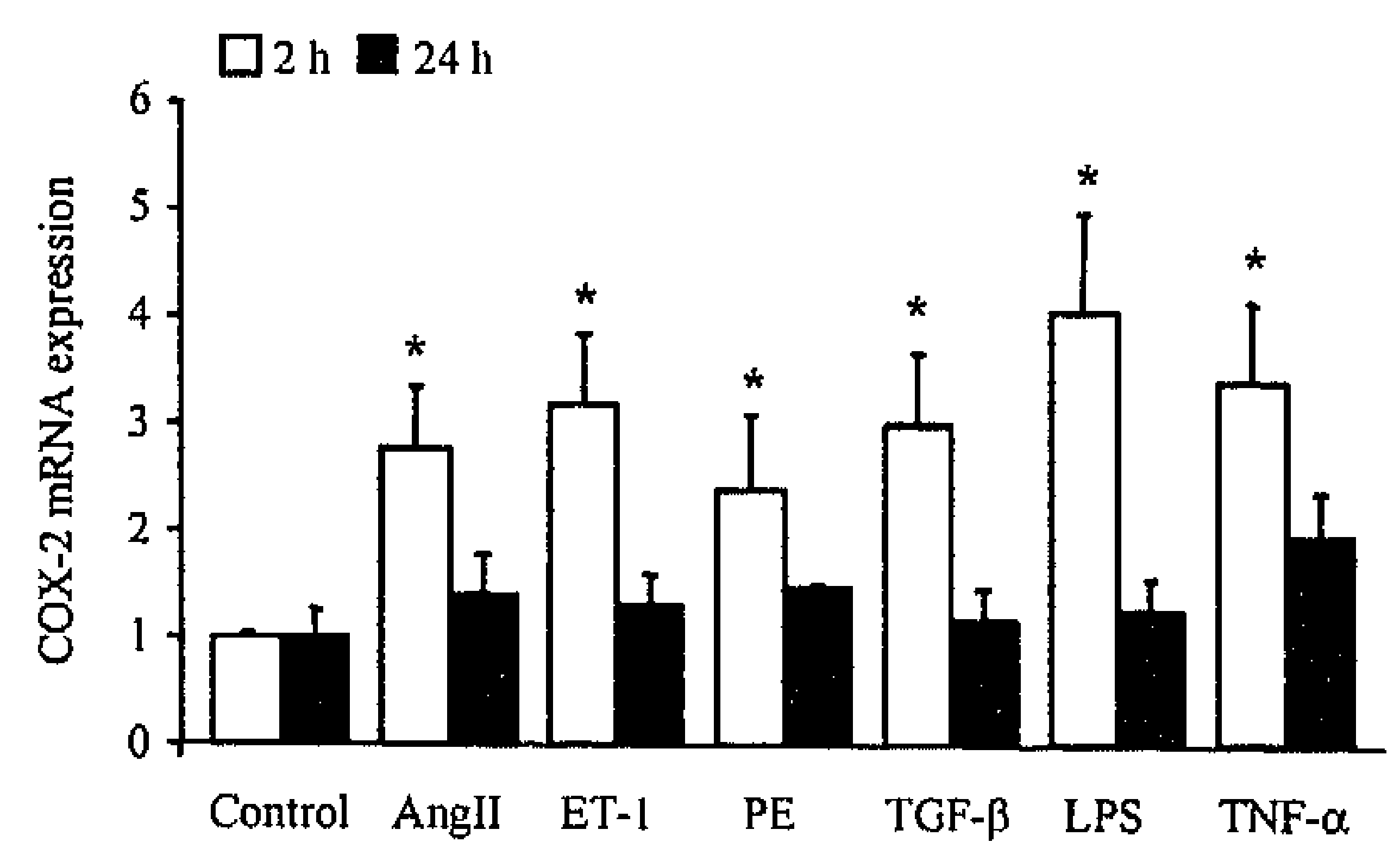

B

Figure 1. Effect of hypertrophic and inflammatory stimuli on mRNA levels of the inflammatory marker COX-2 (A) and the hypertrophy marker ANF (B). NCM were

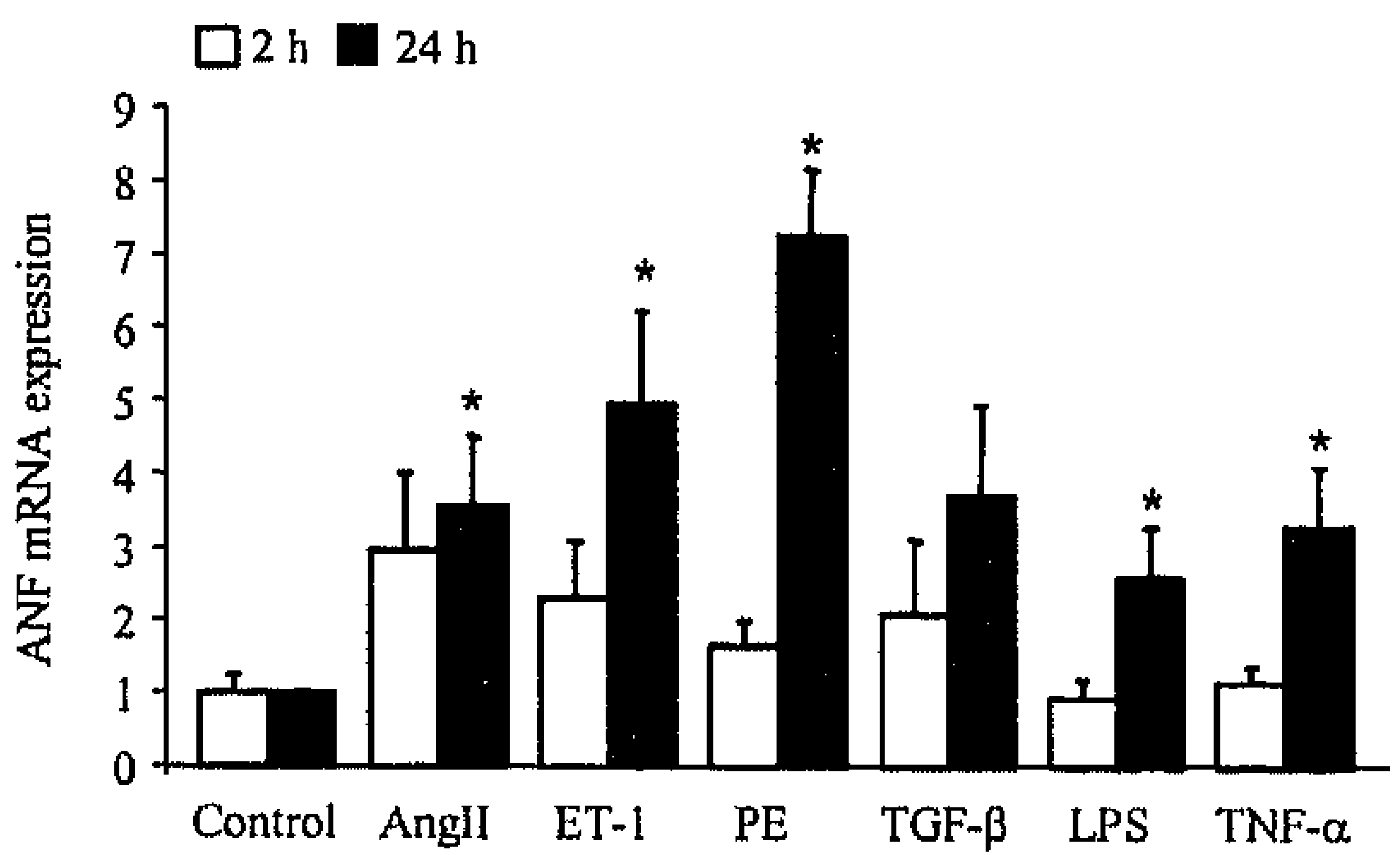
exposed to either $10 \mu \mathrm{M}$ AngII, $1 \mathrm{nM}$ ET-1, 10 $\mu \mathrm{M}$ PE, $10 \mathrm{ng} / \mathrm{ml} \mathrm{TGF}-\beta, 100 \mathrm{ng} / \mathrm{ml}$ LPS or 50 $\mathrm{ng} / \mathrm{ml}$ TNF- $\alpha$. RNA was isolated at $2 \mathrm{~h}$ or $24 \mathrm{~h}$ after exposure. Changes in mRNA levels are expressed as fold change relative to timematched vehicle-treated, control cells, of which the level of expression was arbitrarily set at 1.0. Data presented as mean \pm SEM. * indicates statistically significant $(\mathrm{p}<0.05)$ compared to corresponding control.

Given the temporal differences in response of COX-2 or ANF to the pro-hypertrophic and pro-inflammatory stimuli, the time course of changes in the expression of an extended set of markers of hypertrophy (the natriuretic proteins ANF and BNP, the sarcomeric protein $\alpha$ skeletal actin, $\alpha$-SKA) and inflammation (COX-2, TNF- $\alpha$ ) was examined in more detail using $\mathrm{PE}$ and TNF- $\alpha$ as hypertrophic and inflammatory stimulus, respectively. Following PE or TNF- $\alpha$ stimulation the expression of ANF showed a gradual increase as a function of time, reaching statistical significance at $12 \mathrm{~h}$ (Fig. 2A). After $2 \mathrm{~h}$ of stimulation with either PE or TNF- $\alpha$ BNP mRNA was already upregulated (Fig. 2B). Only in PE-treated cells BNP expression increased further thereafter. The expression of $\alpha$-SKA was found to increase slowly during PE and TNF- $\alpha$ stimulation (Fig. 2C). In contrast, the expression of the two inflammatory genes COX-2 and TNF- $\alpha$ (Fig. 2D and 2E) rapidly increased within the first 2$12 \mathrm{~h}$ and declined thereafter in both PE and TNF- $\alpha$ treated cardiomyocytes. Collectively, these findings point to a functional relationship between hypertrophy and inflammation in that established hypertrophic stimuli give rise to the expression of inflammatory genes and, vice versa, that inflammatory stimuli induce expression of established hypertrophic genes. 
$\mathbf{A}$

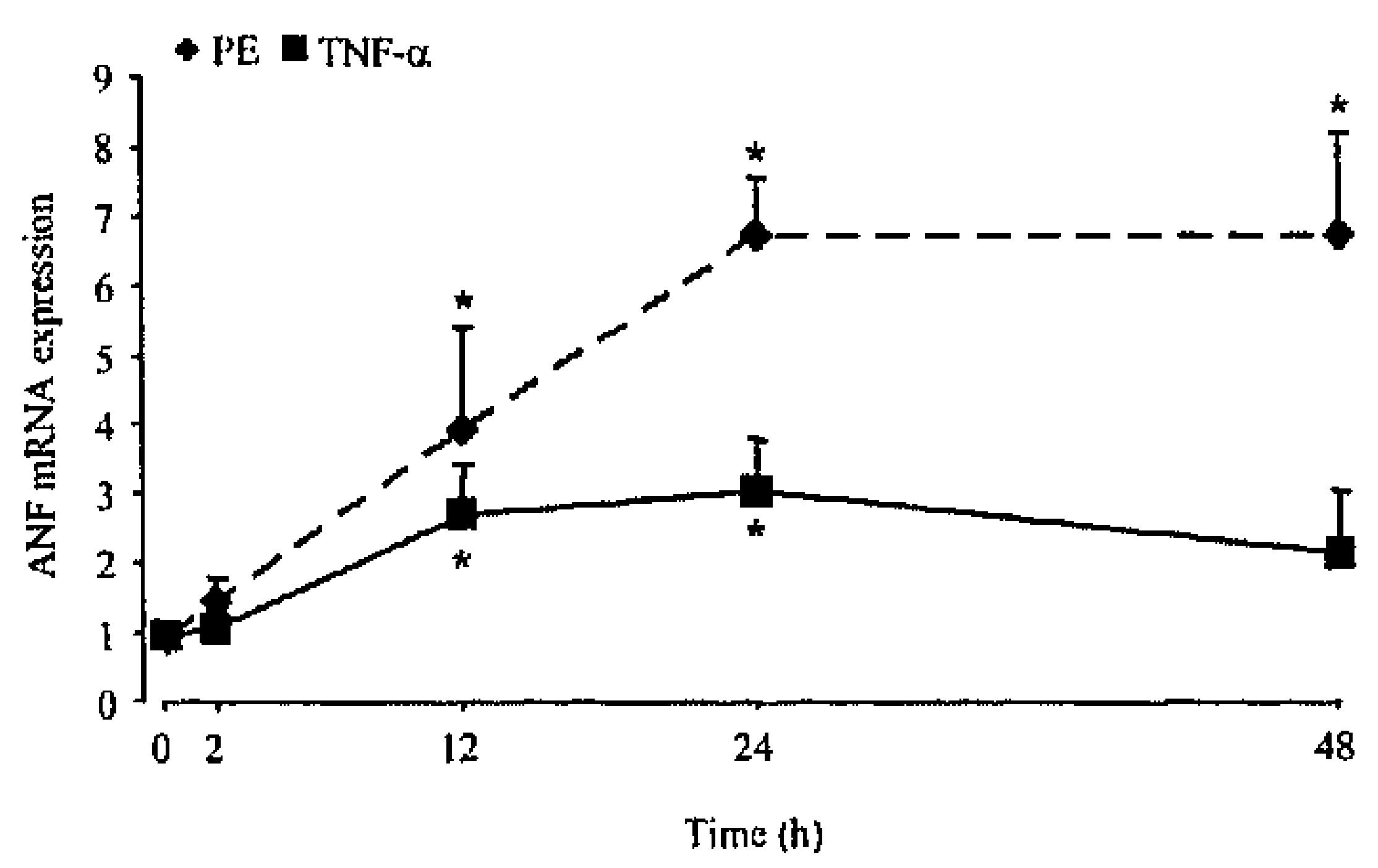

C

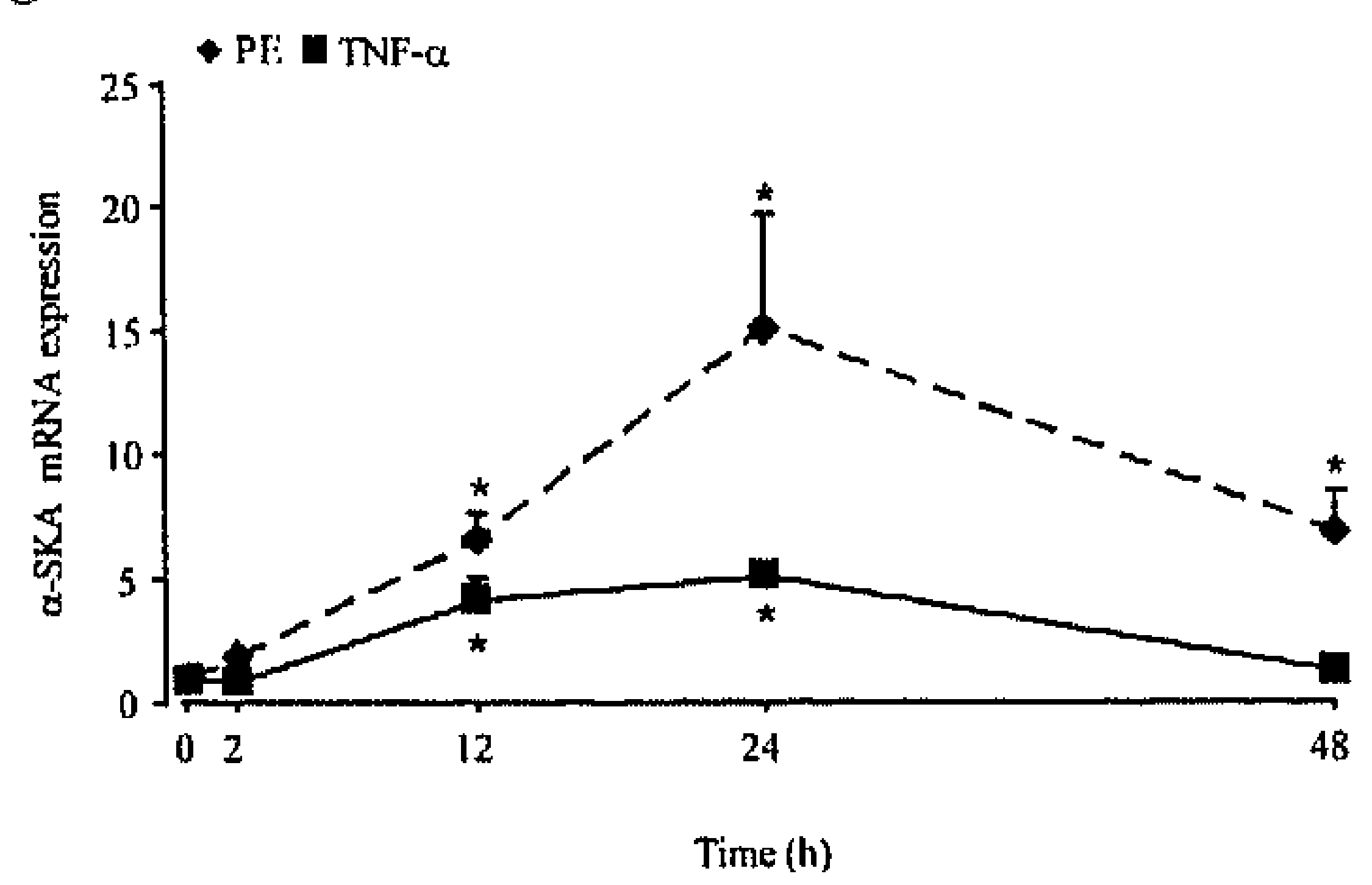

$\mathbf{E}$

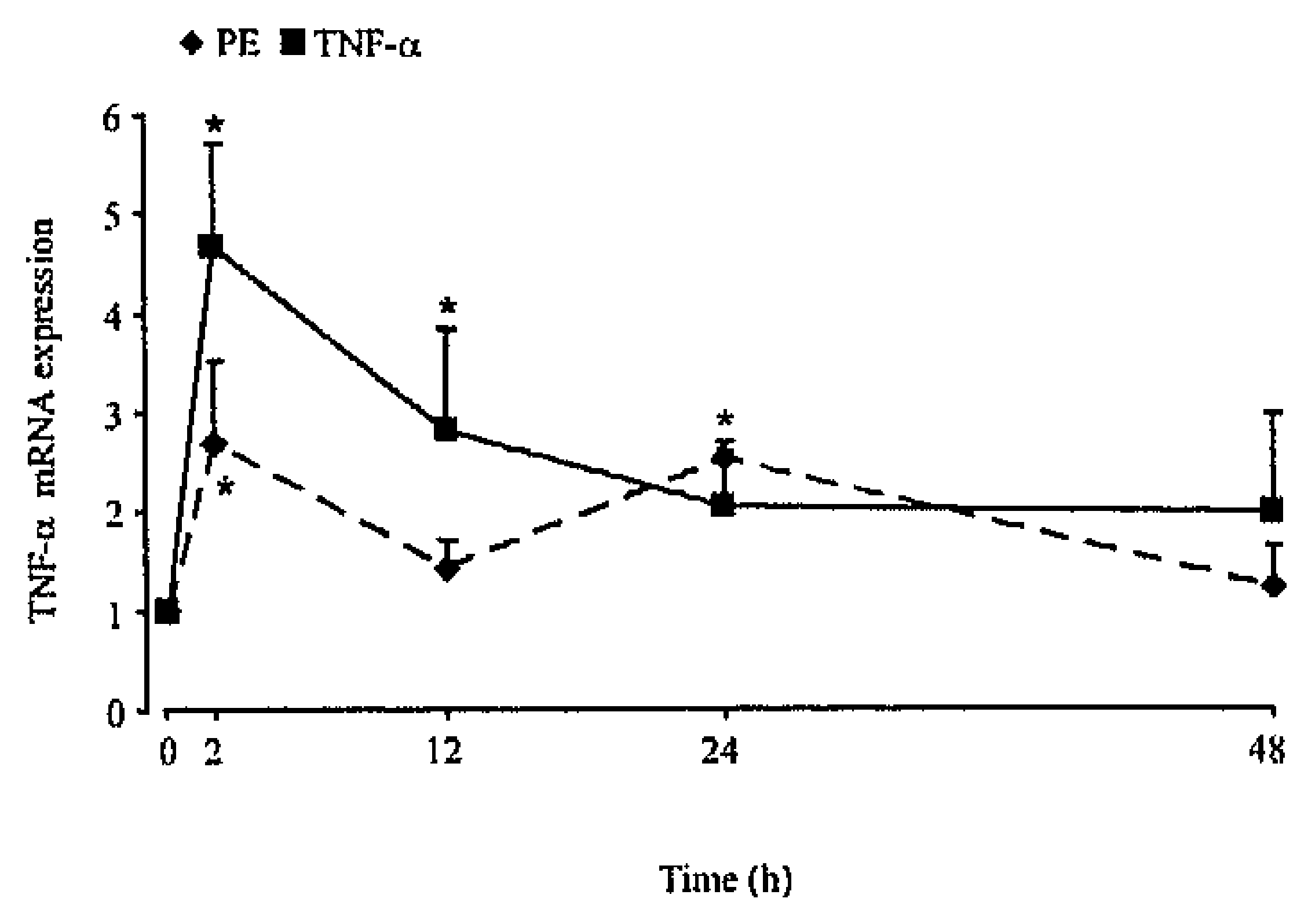

B
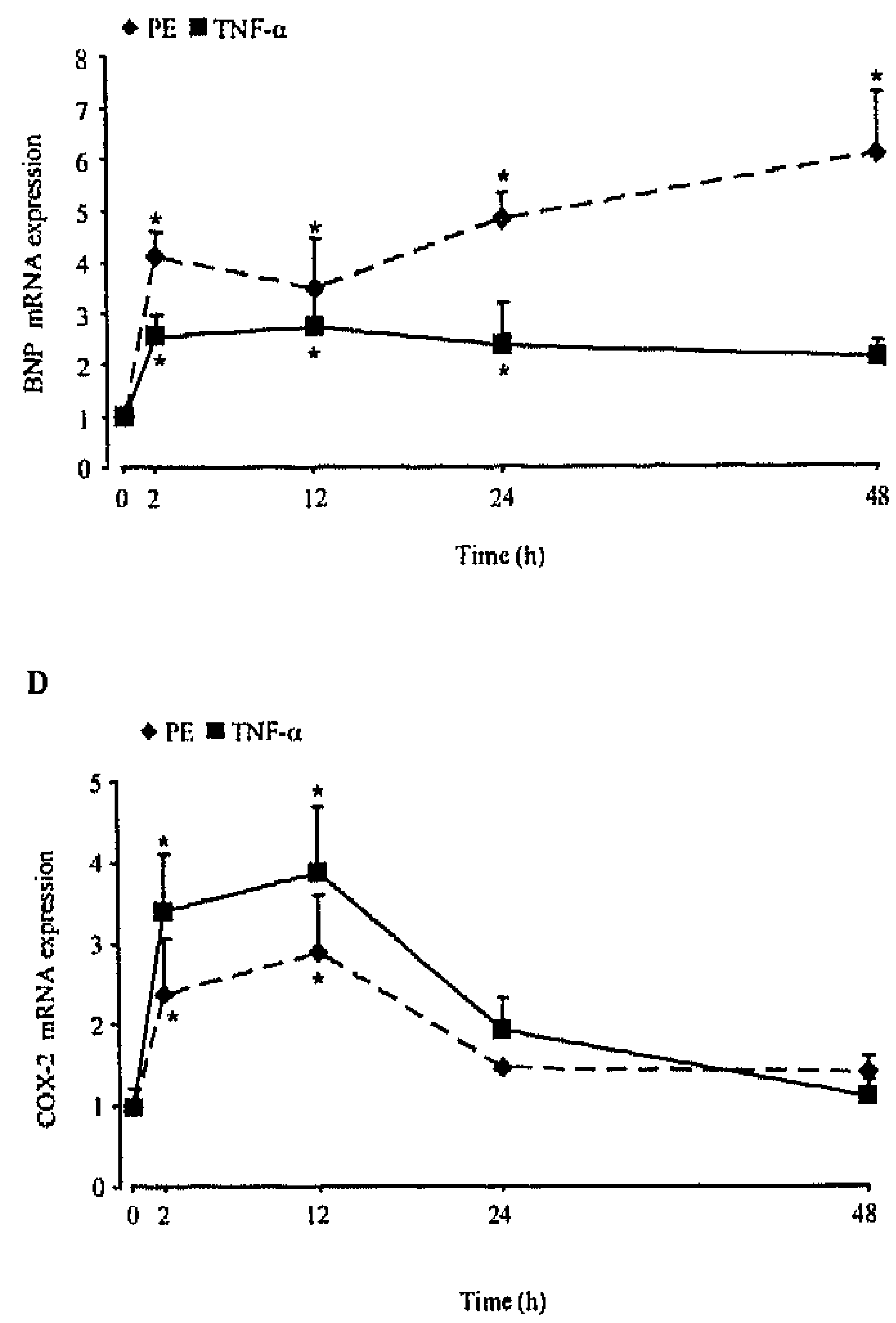

Figure 2. Time-dependent changes in cardiomyocyte mRNA levels of ANF (A), BNP (B), $\alpha$-SKA (C), COX2 (D) and TNF- $\alpha$ (E) after PE (10 $\mu \mathrm{M})$ and TNF- $\alpha$ (50 $\mathrm{ng} / \mathrm{ml}$ ) treatment. Changes in mRNA levels are expressed as fold change relative to time-matched vehicle-treated, control cells, of which the level of expression was arbitrarily set at 1.0. Since the expression levels of the mRNA's investigated remained constant in time in the vehicle-treated NCM, these control data are not shown in the figures. Data are presented as mean \pm SEM. * indicates statistically significant $(\mathrm{p}<0.05)$ compared to time-matched vehicletreated, control cells.

\section{NF-KB ACTIVATION DURING HYPERTROPHY AND INFLAMMATION}

To explore whether the early expression of pro-inflammatory genes following application of the $\alpha_{1}$-adrenergic agonist PE and the cytokine TNF- $\alpha$ was associated with activation of the $N F-\kappa B$ pathway, NF- $\kappa B$ DNA-binding activity was monitored by EMSA (Fig. 3). The NF- $\mathrm{BB}$ oligonucleotide incubated with nuclear extracts of NCM gave rise to 3 distinct bands. The p65-antibody resulted in a supershift of only one band, indicating that this band contains the p65-subunit of NF- $\mathrm{kB}$ (Fig. 3A). Exposure of NCM to TNF- $\alpha$ evoked a robust increase in 
NF- $\mathrm{KB}$ DNA binding, reaching maximal intensity after $30 \mathrm{~min}$ (Fig. 3B). PE stimulation of $\mathrm{NCM}$ also resulted in an early increase in NF- $\mathrm{KB}$ DNA binding, albeit that peak levels were lower. At later time points $(2-48 \mathrm{~h}), \mathrm{NF}-\mathrm{kB}$ DNA binding activity in PE-stimulated cells returned to control levels, whereas binding activity remained elevated in TNF- $\alpha$ stimulated NCM (Fig. 3C).

A

$$
\text { B }
$$
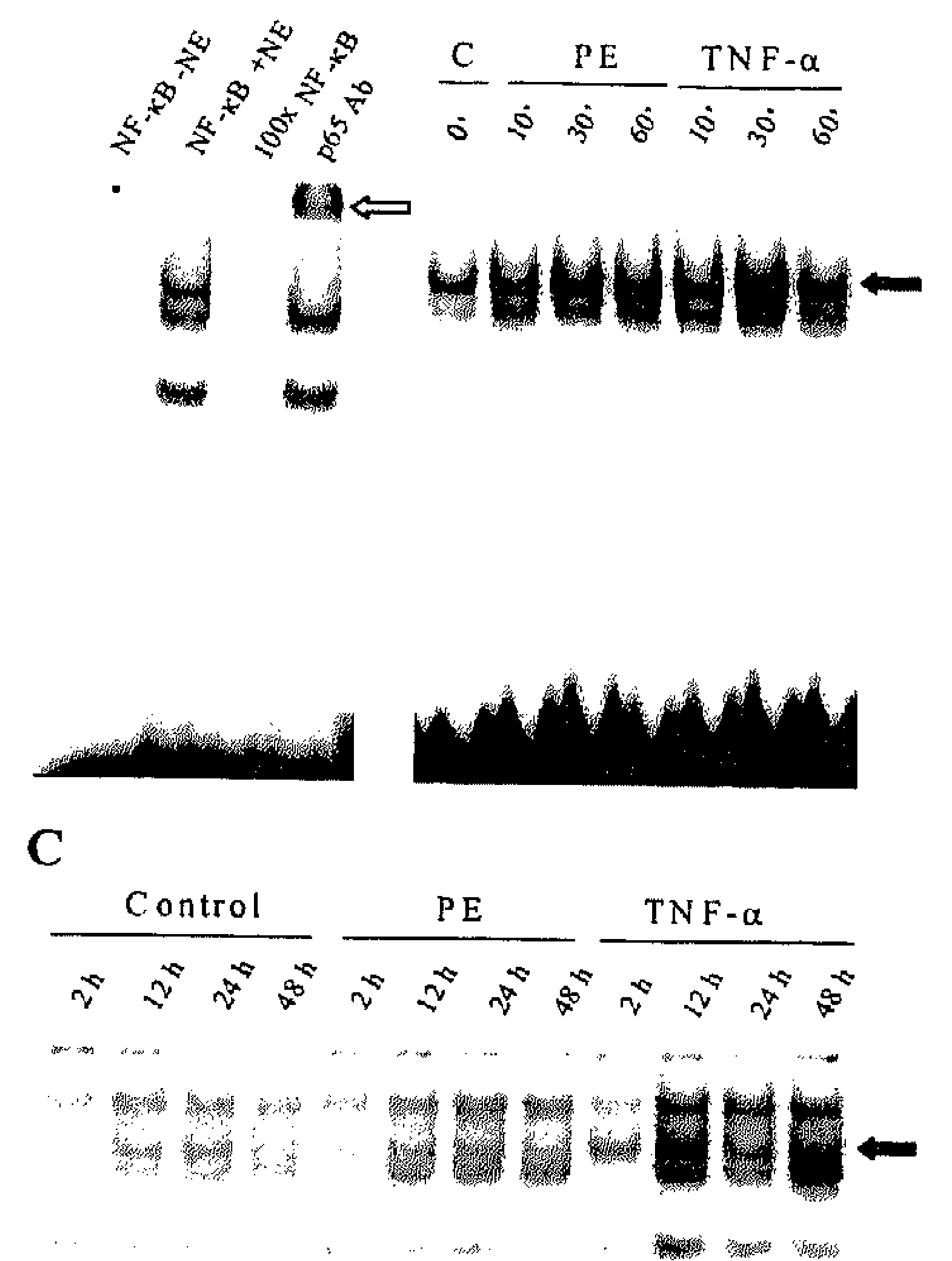

Figure 3. Effect of PE and TNF- $\alpha$ on NF-KB activation as measured by EMSA. Incubation of ${ }^{32} \mathrm{P}$ labeled $\mathrm{NF}_{-} \mathrm{KB}$ oligonucleotide with nuclear extract $(+\mathrm{NE})$ of NCM showed several complexes. The specificity of the signal was checked by adding a $100 x$ excess of unlabeled NF- $\mathrm{KB}$ probe (100x NF$\kappa B)$. Incubation with an antibody against $\mathrm{p} 65$ (p65 $\mathrm{Ab}$ ) resulted in a supershift of the upper band (open arrow) (panel A). Nuclear extracts were prepared from untreated and PE- and TNF- $\alpha$ treated NCM at the indicated time points to monitor acute effects (panel B) and more long-term effects (panel C). The specific p65 signal is indicated by the black arrow.

\section{INTERACTION OF PPAR AND NF-KB}

The results above demonstrate that hypertrophic stimuli cause NF-kB activation and increased expression of pro-inflammatory genes. Previous studies provided evidence that crossinteraction exists between PPARs and pro-inflammatory signalling pathways. ${ }^{42},{ }^{54}$ Therefore, it was examined whether in the cardiomyocyte context PPAR $\alpha$ and PPAR $\delta$ inhibit the activity of NF-kB. Thereto, NCM were co-transfected with a p65 expression vector and the NF- $\mathrm{kB}$ reporter construct. Subsequently, the ability of PPAR $\alpha$ and PPAR $\delta$-in the absence or 
presence of their cognate ligands- to inhibit the p65-induced NF- $\mathrm{kB}$ transcriptional activity was determined. Overexpression of p65 led to a more than 8-fold increase in NF- $\mathrm{KB}$ transcriptional activity (Fig. 4). Treatment of NCM with the PPAR $\alpha$ ligand Wy-14,643 or the PPARס ligand GW501516, or co-transfection with either PPAR $\alpha$ or PPAR $\delta$, did not alter the p65-mediated transcriptional activity of NF- $\mathrm{KB}$. However, in combination with their cognate ligands co-transfection with PPAR $\alpha$ and PPAR $\delta$ significantly blunted NF-KB activity by $40-$ $50 \%$ (Fig. 4A and 4B).

A

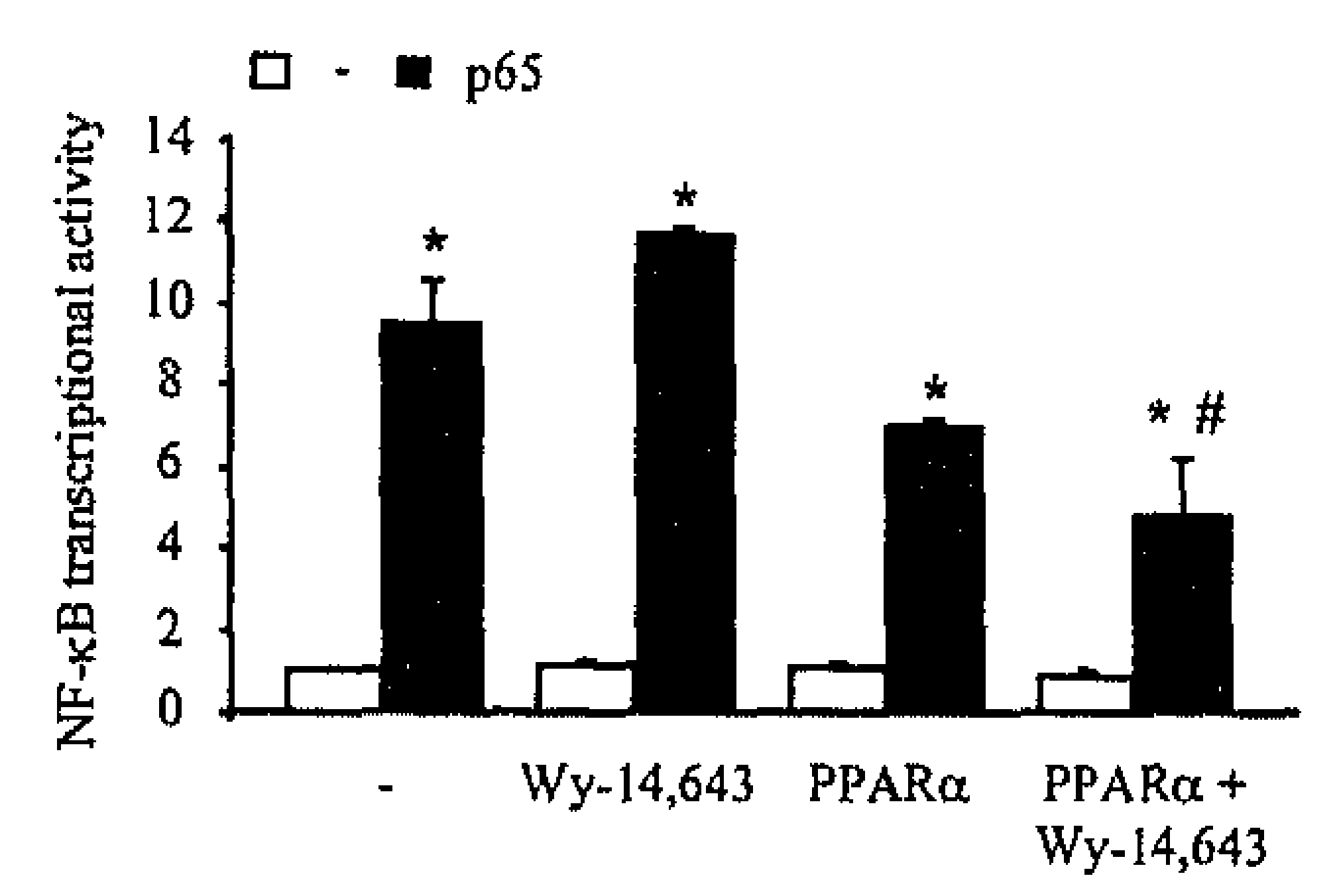

B

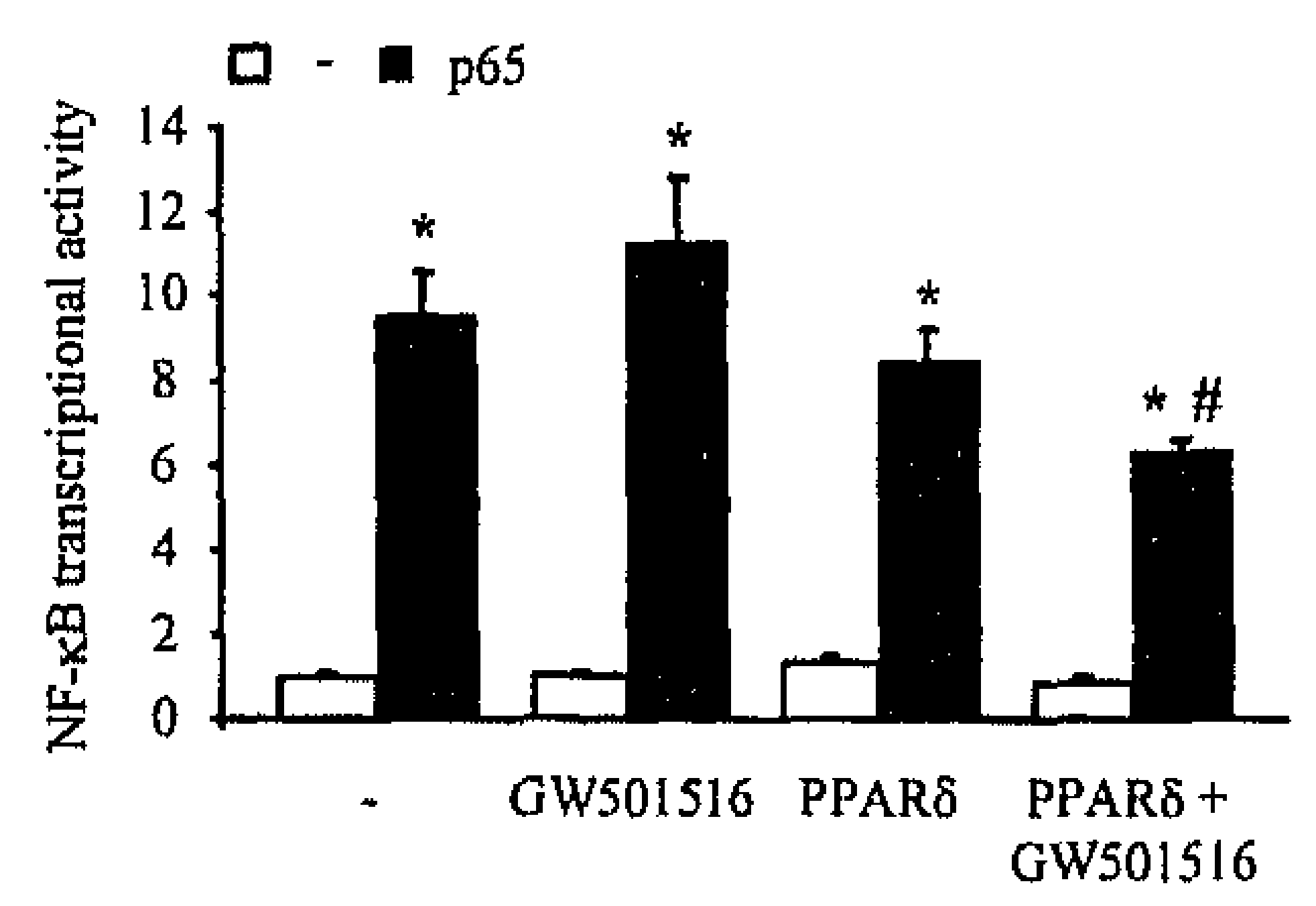

Figure 4. Effect of PPAR $\alpha$ and PPAR $\delta$ on p65-induced transcriptional activity of NF-kB. NCM were transfected with a $3 \times \mathrm{NF}-\mathrm{kB}$ reporter/luciferase construct and co-transfected with a control vector (open bars) or a p65 expression vector (black bars) along with PPAR $\alpha$ (panel A) and PPAR (panel B) expression vectors. Where indicated, cells were treated with $10 \mu \mathrm{M}$ Wy-14,643 or $1 \mu \mathrm{M}$ GW501516 for $24 \mathrm{~h}$. Changes in NF-kB reporter activity are expressed relative to vehicle-treated, control cells. Data presented as mean $\pm \mathrm{SEM}$. * indicates statistically significant $(\mathrm{p}<0.05)$ compared to corresponding control cells. \# indicates statistically significant $(\mathrm{p}<0.05)$ compared to NF- $\mathrm{kB}$ transcriptional activity by $\mathrm{p} 65$ alone.

Next, it was tested whether p65 interferes with PPAR-mediated transactivation of the PPARresponsive mCPT-1 promoter/reporter construct. Addition of Wy-14,643 and GW501516 resulted in a 3- and 4-fold increase of the transcriptional activity of the mCPT-1 promoter, respectively (Fig. 5A and 5B). Interestingly, following co-transfection with p65, Wy-14,643 and GW501516-mediated mCPT-1 promoter activation was almost completely abrogated. The experiments were repeated with a mCPT-I promoter in which the PPAR-response element (PPRE) binding-site was mutated. None of the above conditions affected the transcriptional activity of the mutated promoter, thereby verifying that the effects were dependent on a functional PPRE (Fig. 5A and 5B). 
A

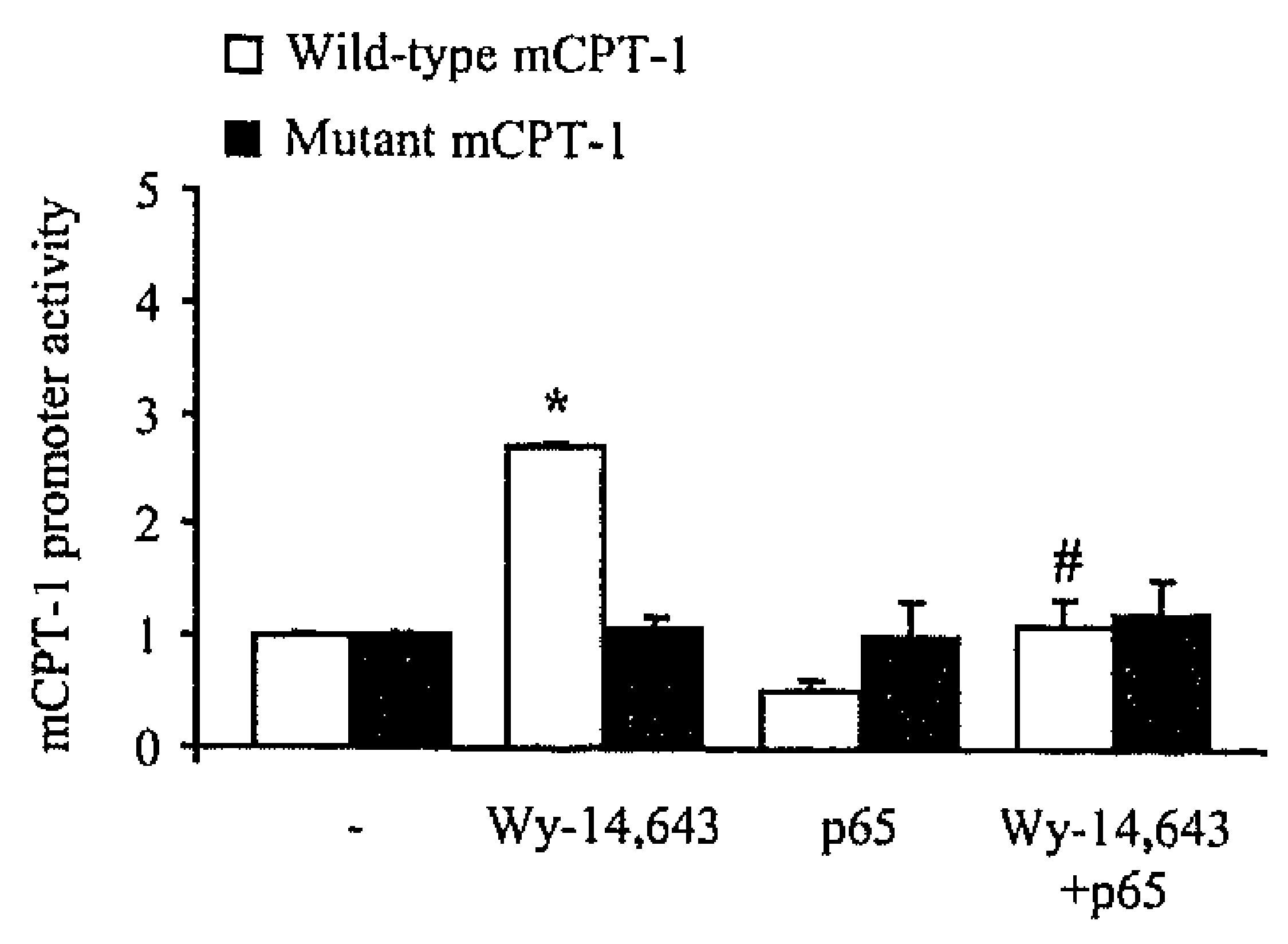

B

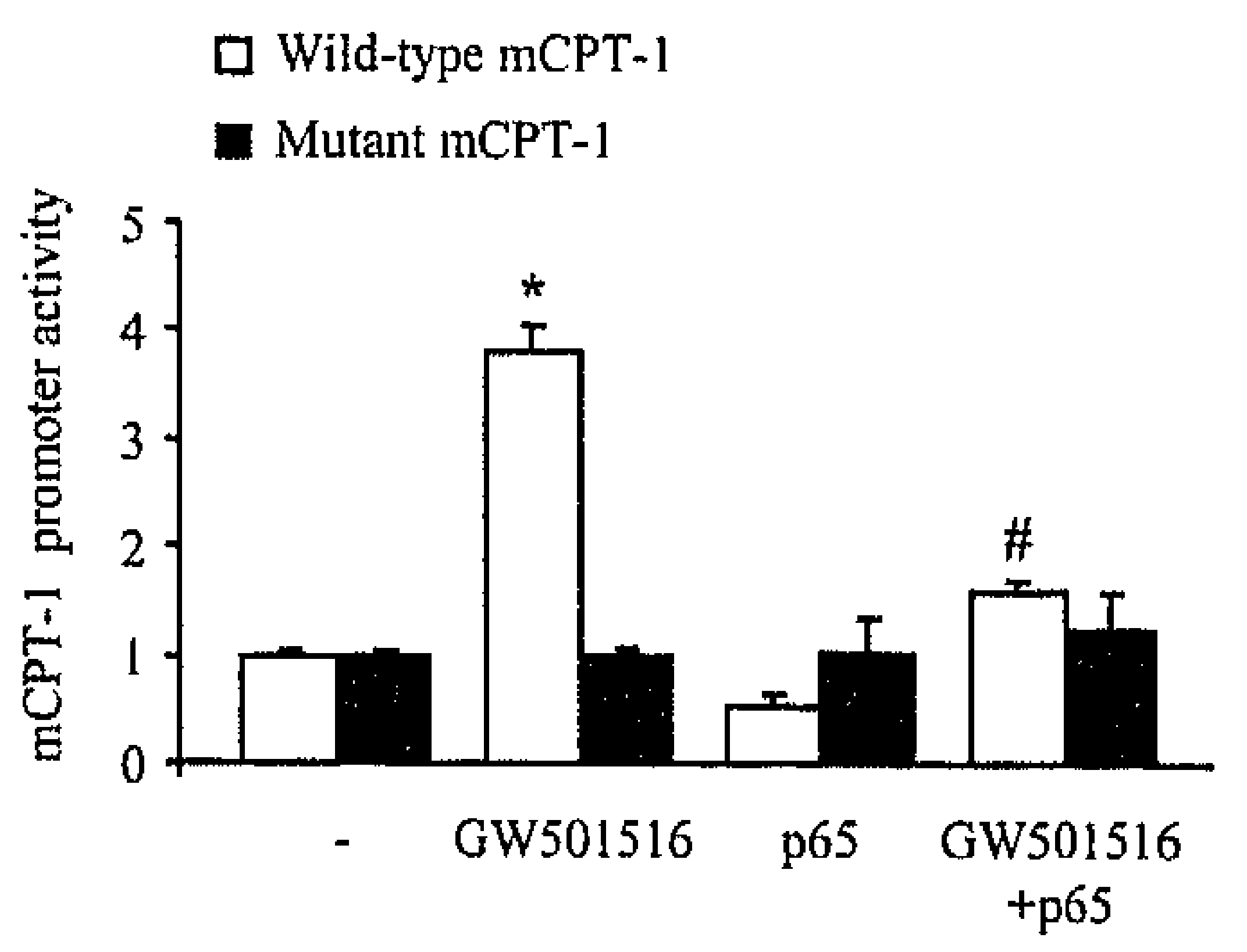

Figure 5. Effect of $\mathrm{p} 65$ on the transcriptional activity of the PPAR-responsive mCPT-1 promoter. NCM were transfected with the wild-type (open bars) or PPRE-mutated (black bars) mCPT-1 promoter/luciferase vector, in the presence or absence of $\mathrm{p} 65$ expression vector, and exposed to vehicle or the PPAR $\alpha$ ligand Wy-14,643 (10 $\mu \mathrm{M})$ (panel A) or the PPAR $\delta$ ligand GW501516 $(1 \mu \mathrm{M})$ (panel B). Changes in mCPT-1 promoter activity are expressed relative to corresponding vehicle-treated control cells, the value of which was set at 1.0. Data are presented as mean \pm SEM. $*$ indicates statistically significant $(\mathrm{p}<0.05)$ compared to vehicle-treated control cells. \# indicates statistically significant $(\mathrm{p}<0.05)$ compared to mCPT-1 transcriptional activity induced by PPARligand alone.

\section{PPAR OVEREXPRESSION AND HYPERTROPHY}

Subsequently, it was investigated whether PPAR $\alpha$ or PPAR $\delta$ are able to attenuate hypertrophy. NCM were infected with either AdPPAR $\alpha$ or AdPPAR $\delta$, or with AdCMV (control) prior to stimulation with PE. The functionality of the PPAR viruses was confirmed by showing that the expression of the PPAR-responsive gene PDK4 increased substantially following infection (data not shown). Treatment of AdCMV infected, control NCM with PE for $24 \mathrm{~h}$ significantly increased sarcomere organization (Fig. 6A) and cardiomyocyte size (Fig. 6B), indicative of cellular hypertrophy. AdPPAR $\alpha$ or AdPPAR $\delta$ infection significantly attenuated the PE-induced sarcomere formation and cell enlargement, irrespective of the addition of Wy-14,643 or GW501516. Treatment with Wy-14,643 or GW501516 alone did not affect the PE-induced cell morphology (data not shown).

Stimulation of NCM with TNF- $\alpha$ did not give rise to a significant increase in NCM size. In line with previous studies ${ }^{146,163}$, infection with AdPPAR $\alpha$ or AdPPAR $\delta$ blunted the TNF- $\alpha$ induced expression of inflammatory markers like COX-2 (data not shown).

Secondly, in AdPPAR $\alpha$ or AdPPAR $\delta$ infected NCM the PE-induced ANF mRNA expression was lowered by almost 50\% (Fig. 7A and 7B) and induction of BNP was almost completely blunted (Fig. 7C and 7D). Treatment of AdPPAR $\alpha$ or AdPPAR $\delta$ infected NCM with Wy14,643 or GW501516 did not result in an additional effect. 
A

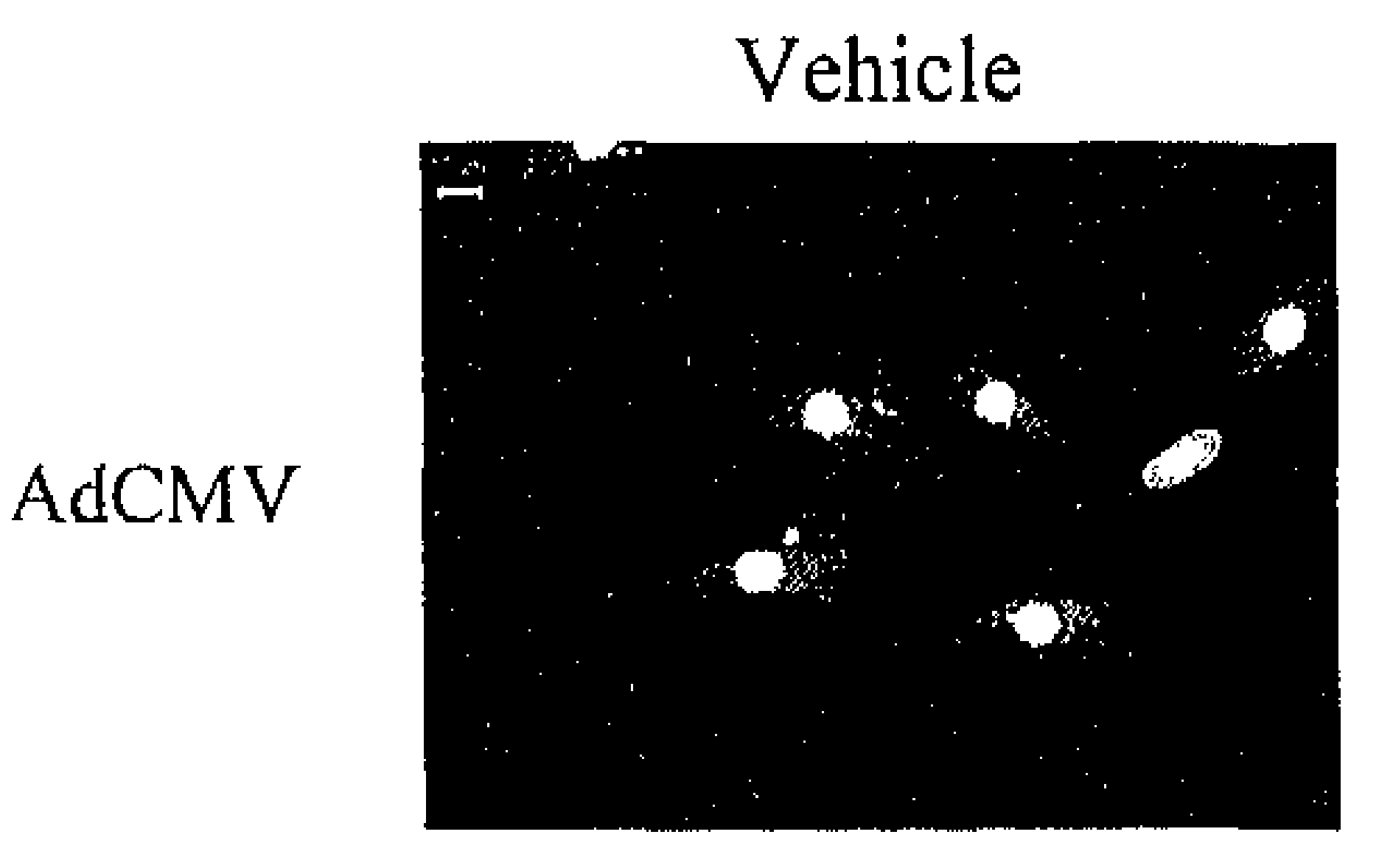

PE

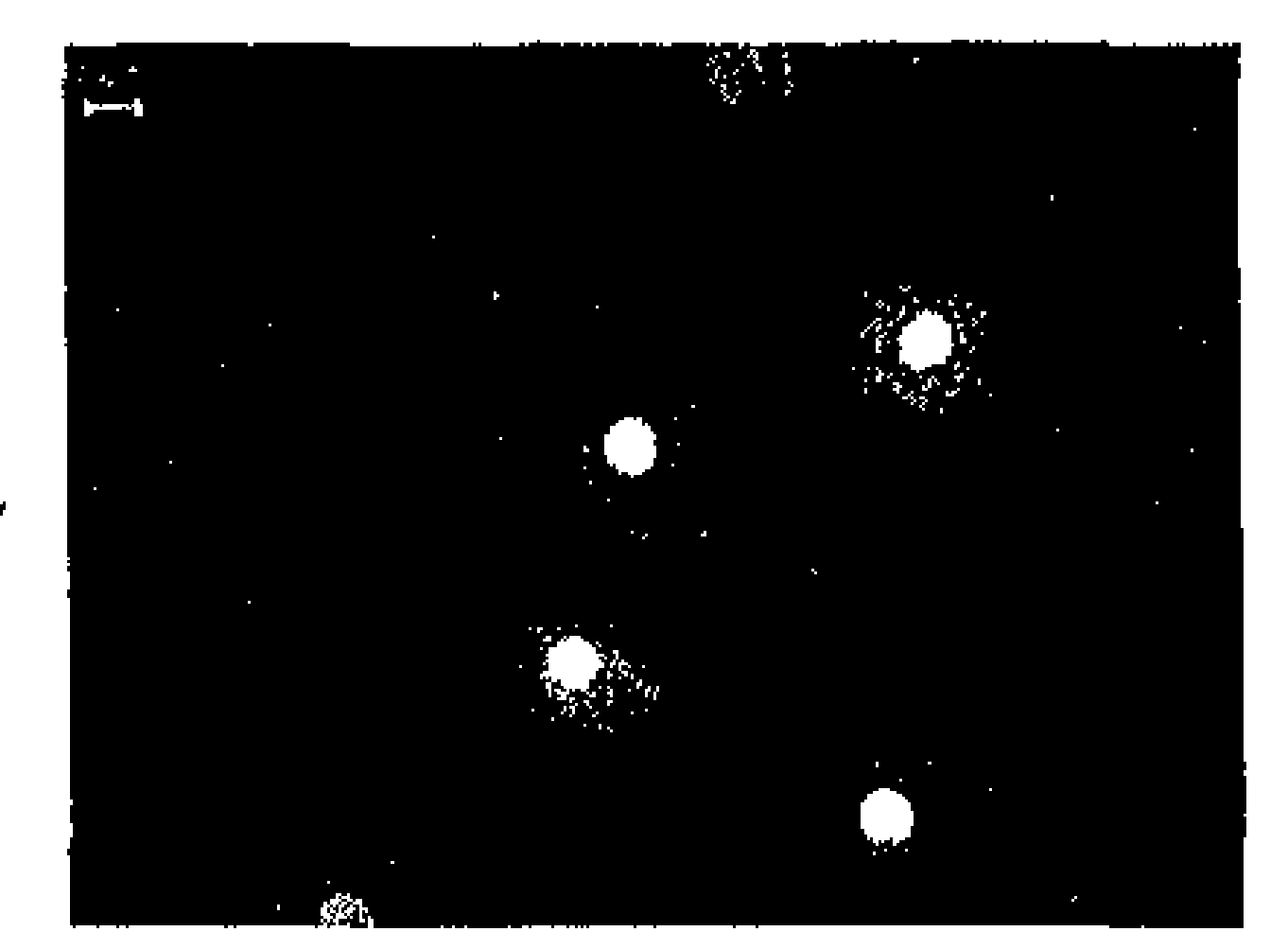

PE

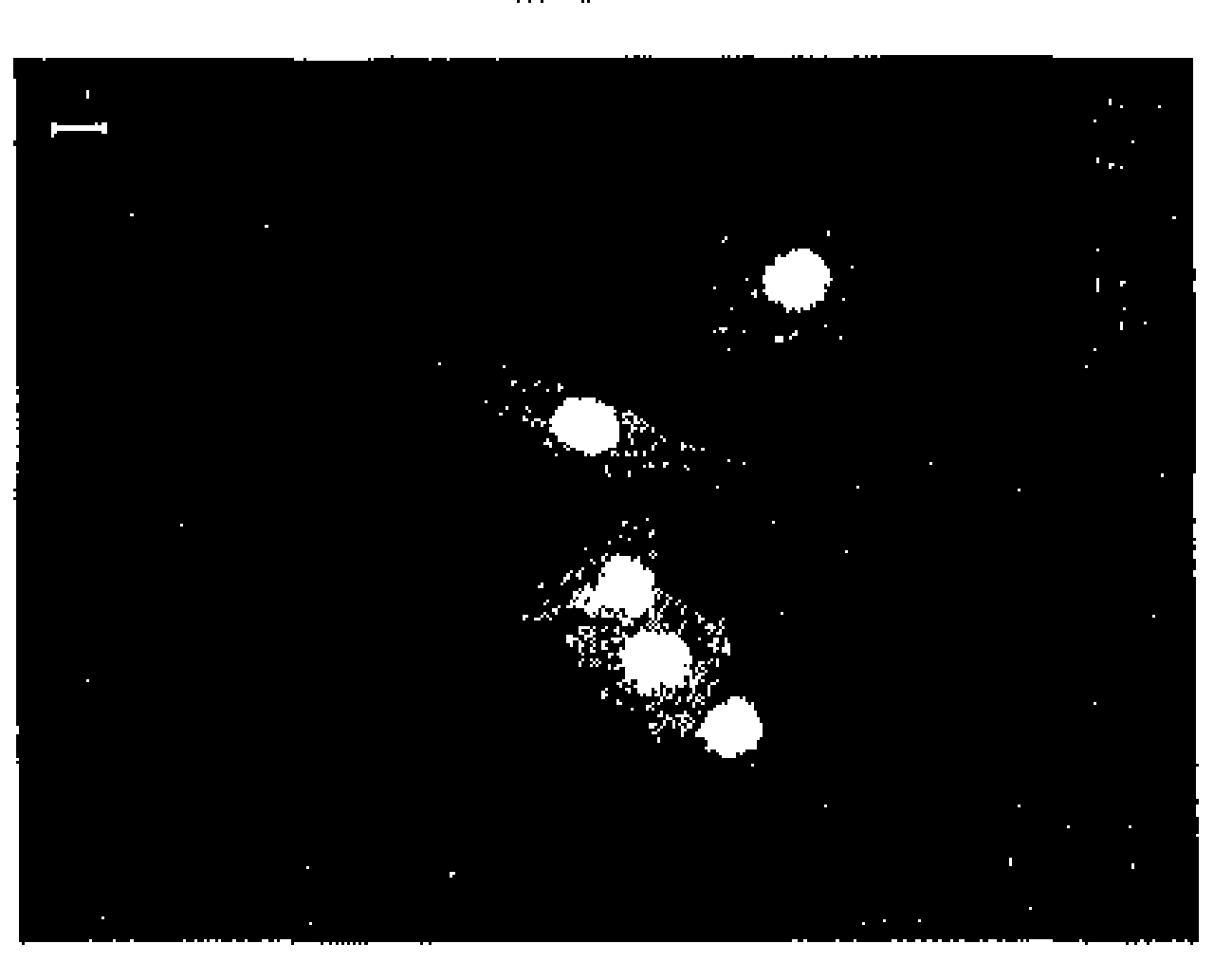

PE+GW501516

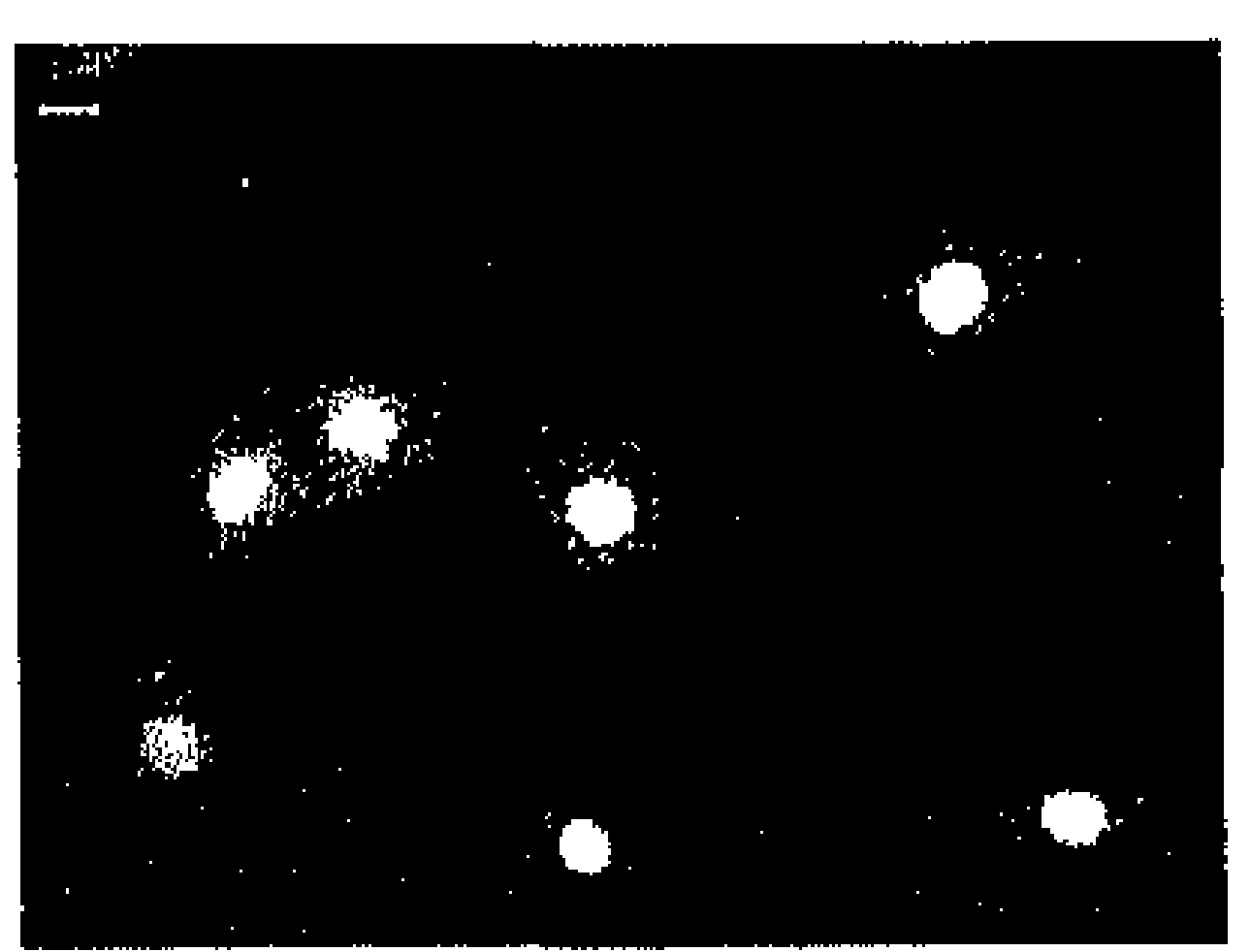

B

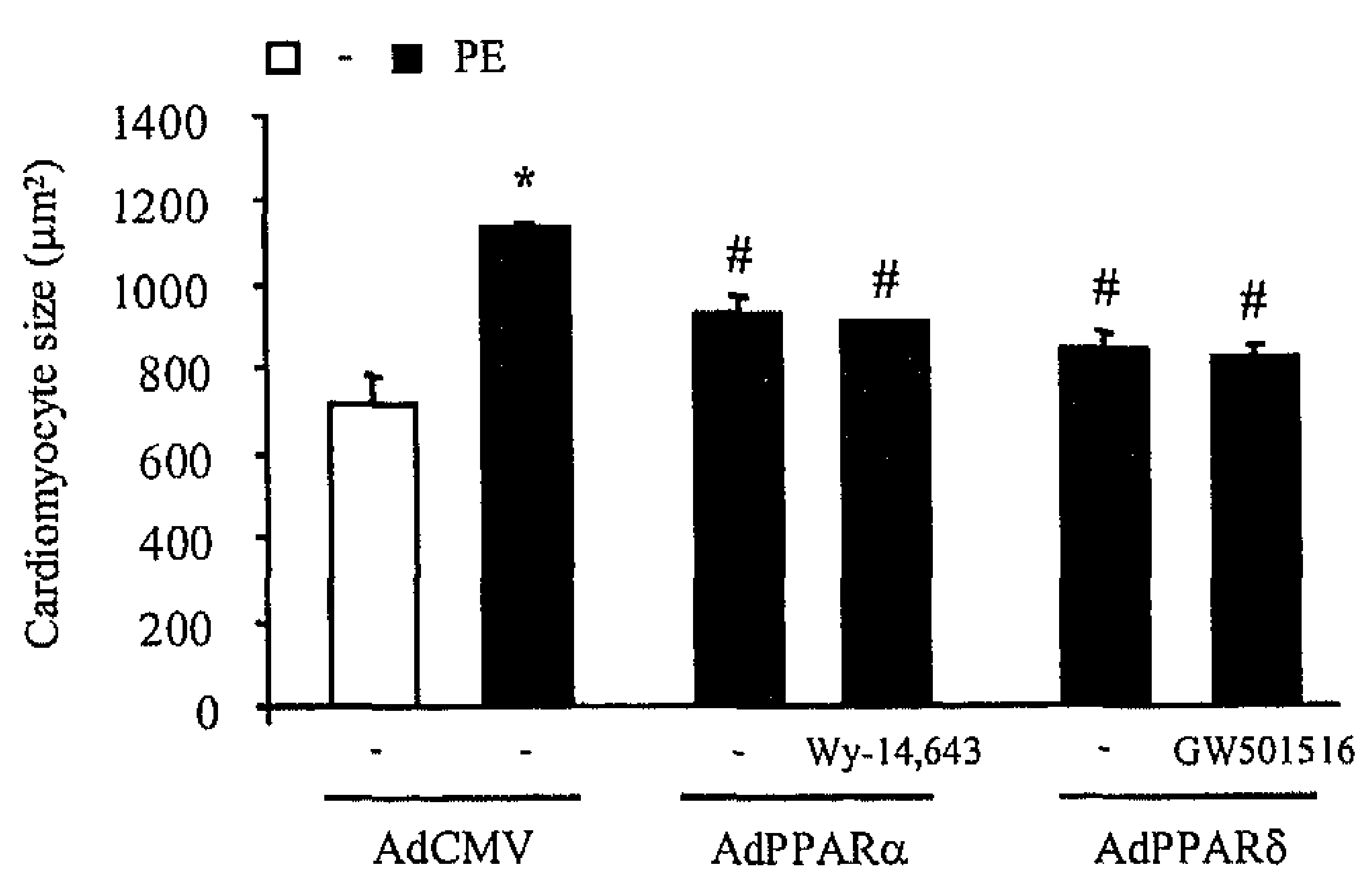

Figure 6. Effect of adenoviral overexpression of PPARs on PE-induced changes in myocyte morphology.

(A) Representative examples of $\alpha$-actinin-stained NCM infected with AdPPAR $\alpha$ or AdPPAR $\delta$ or its appropriate control vector AdCMV, respectively (50 IFU/cell) are shown. Subsequently cells were either stimulated with $\mathrm{PE}(10 \mu \mathrm{M})$ or vehicle and/or treated with the PPAR $\alpha$ ligand Wy-14,643 $(10 \mu \mathrm{M})$ or PPAR8-ligand GW501516 $(1 \mu \mathrm{M})$ for $24 \mathrm{~h}$. Findings of vehicle-treated AdPPAR $\alpha$ and AdPPAR $\delta$ infected cells are not shown since their appearance did not change. (B) Cardiomyocyte crosssectional area. Cell size was quantified using Quantimet 570 software. Data presented as mean \pm SEM. ${ }^{*}$ indicates statistically significant $(\mathrm{p}<0.05) \quad$ compared to AdCMV-infected, vehicletreated, control cells (open bars). \# indicates statistically significant $\quad(\mathrm{p}<0.05)$ compared to AdCMVinfected, PE-stimulated cells. 
A

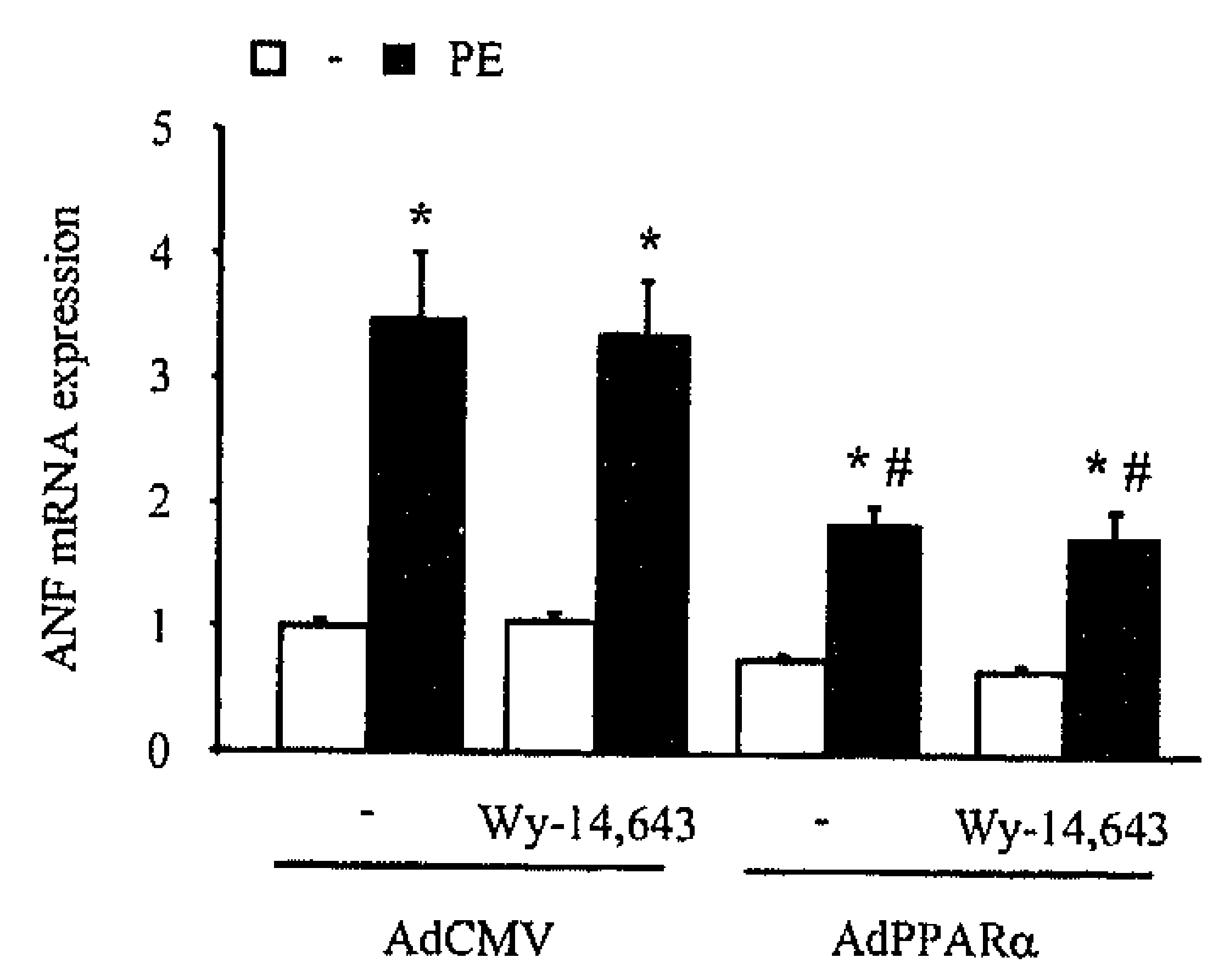

B

ㅁ - $\mathrm{PE}$

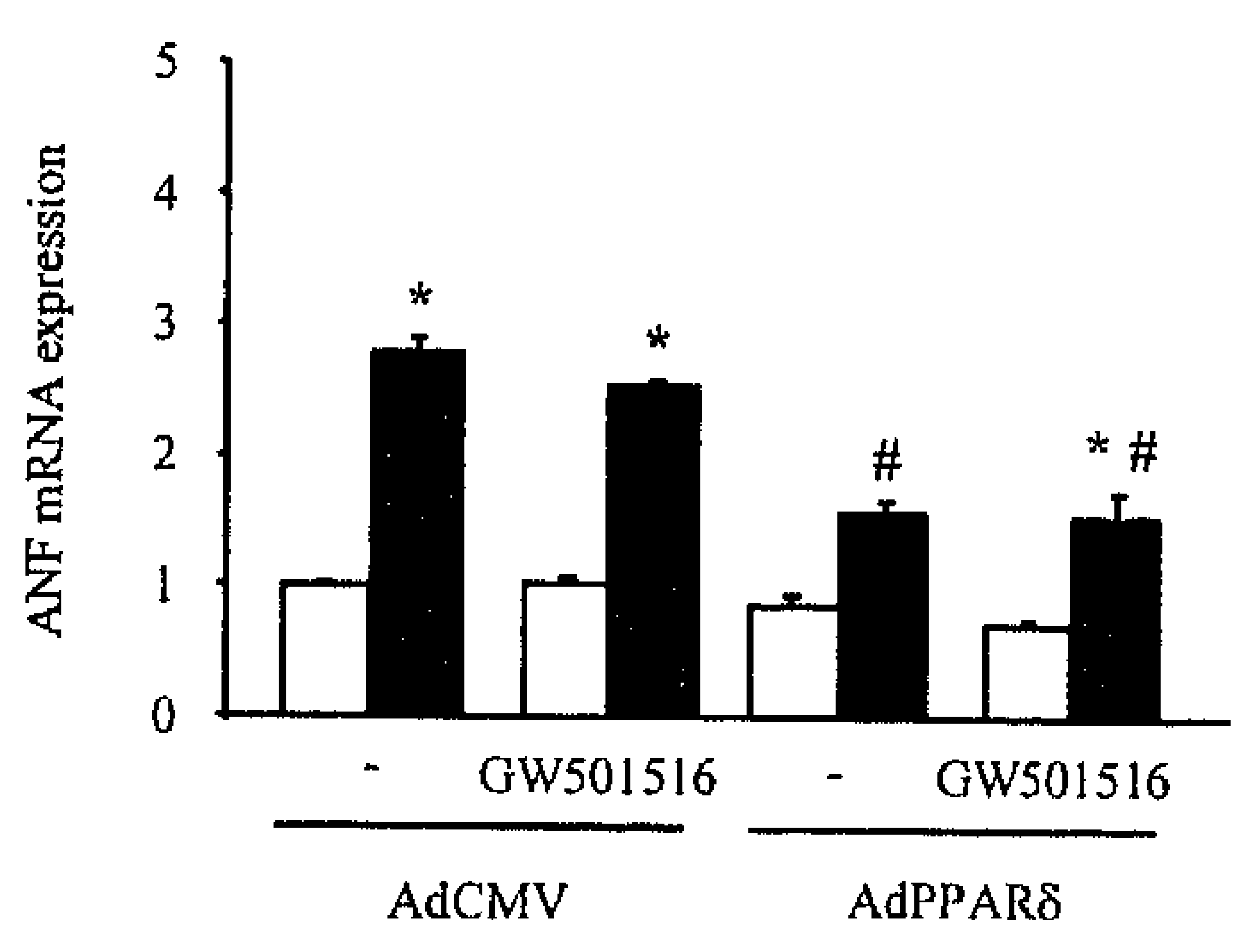

C

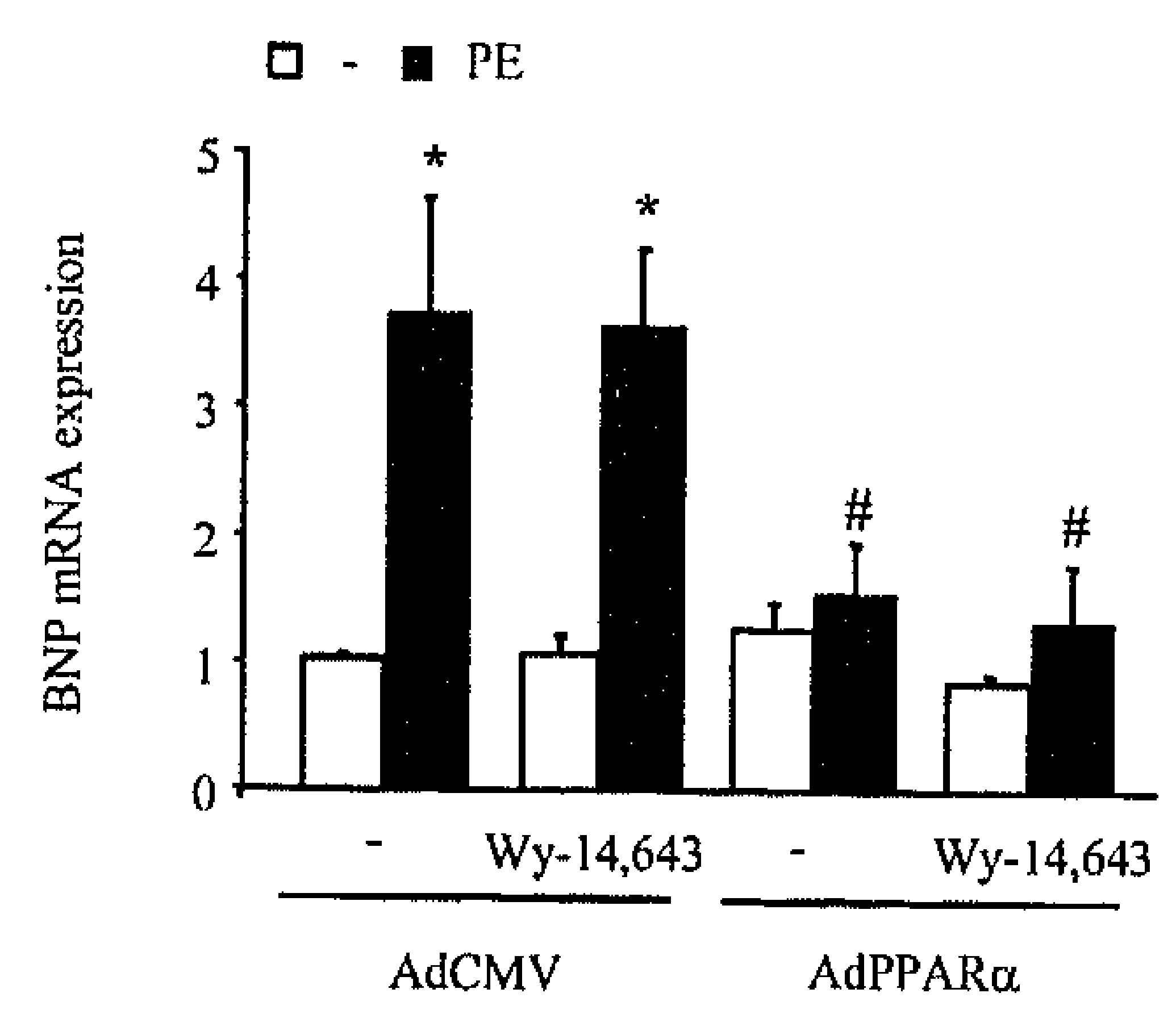

D

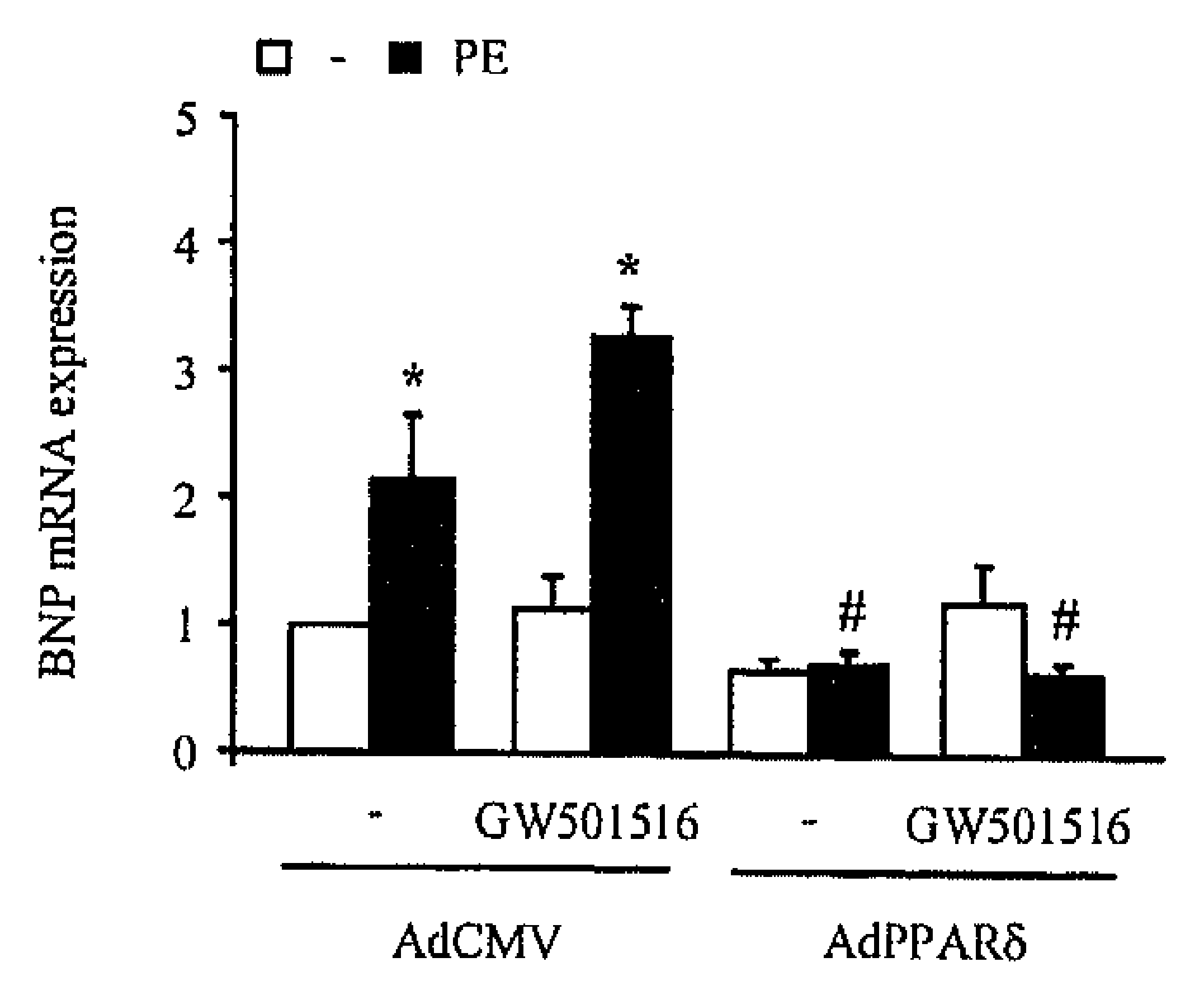

Figure 7. Effect of adenoviral overexpression of PPARs on PE-induced ANF and BNP expression. NCM were infected with AdPPAR $\alpha$ (panel $A, C$ ) or AdPPAR $\delta$ (panel B, D) or its appropriate control vector AdCMV, respectively (50 IFU/cell). Subsequently cells were either stimulated with PE (10 $\mu \mathrm{M})$ (black bars) or vehicle (non-stimulated cells; white bars) and/or treated with the PPAR $\alpha$-ligand Wy-14,643 $(10 \mu \mathrm{M})$ or PPARס-ligand GW501516 $(1 \mu \mathrm{M})$ for $24 \mathrm{~h}$. Changes in ANF mRNA levels are expressed relative to AdCMV-infected, vehicle-treated, control cells. Data presented as mean \pm SEM. * indicates statistically significant $(p<0.05)$ compared to vehicle-treated, control cells. \# indicates statistically significant $(p<0.05)$ compared to AdCMV-infected, PE-stimulated cells.

Finally, transient transfection assays were performed using an ANF promoter/reporter construct as read-out for the hypertrophic gene programme. PE-stimulation led to an almost 15-fold increase in ANF promoter activity (Fig. 8). The PE-induced ANF promoter activity was not affected when cardiomyocytes were exposed to either Wy-14,643 or GW501516. When the cells were co-transfected with PPAR $\alpha$ or PPAR $\delta$ expression vectors, ANF promoter activity was further enhanced. However, in combination with their corresponding ligands overexpression of each PPAR isoform profoundly inhibited PE-induced ANF 
promoter activity. The collective findings indicate that PPAR overexpression mitigated cardiomyocyte hypertrophy.

A

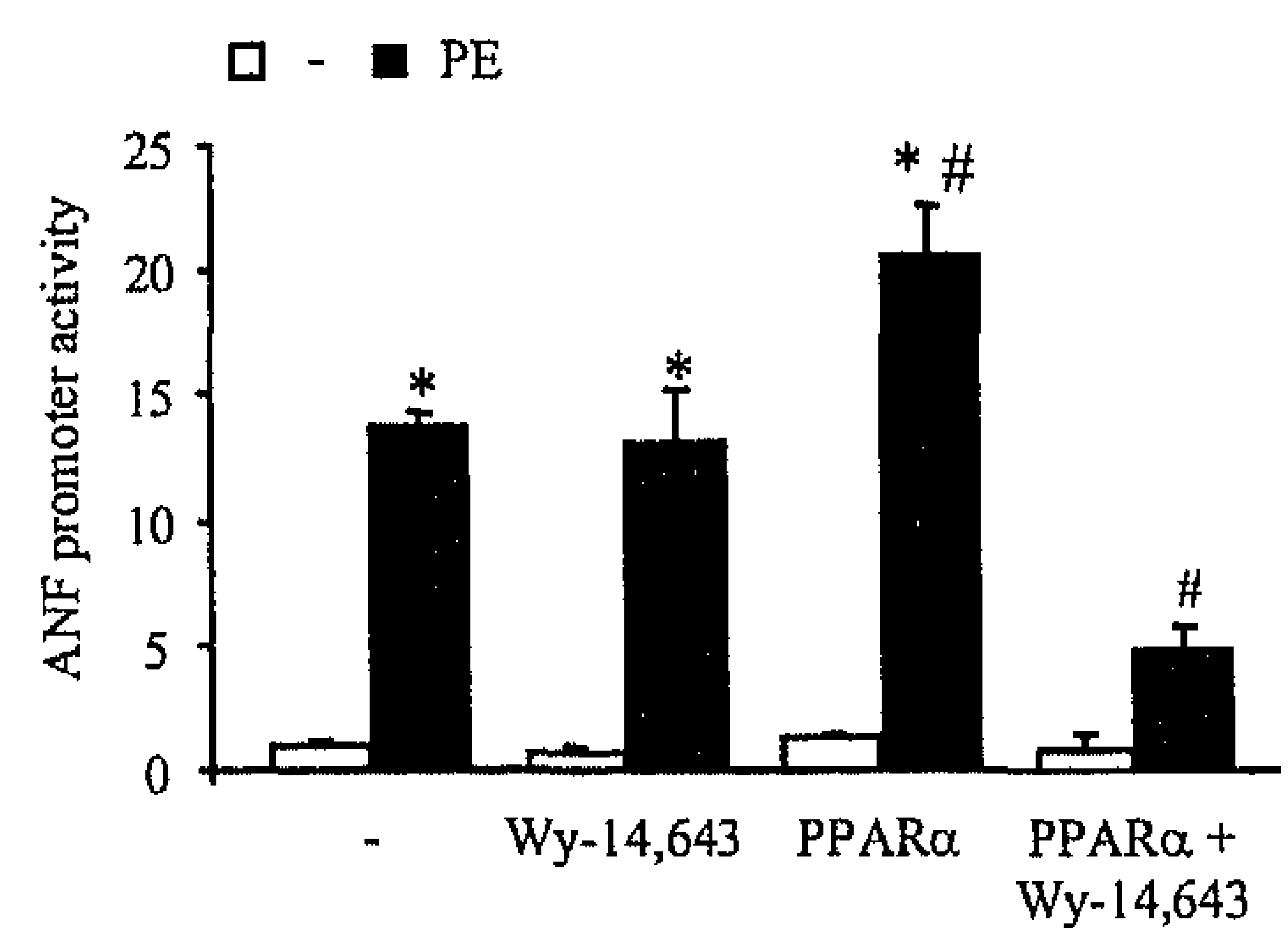

B

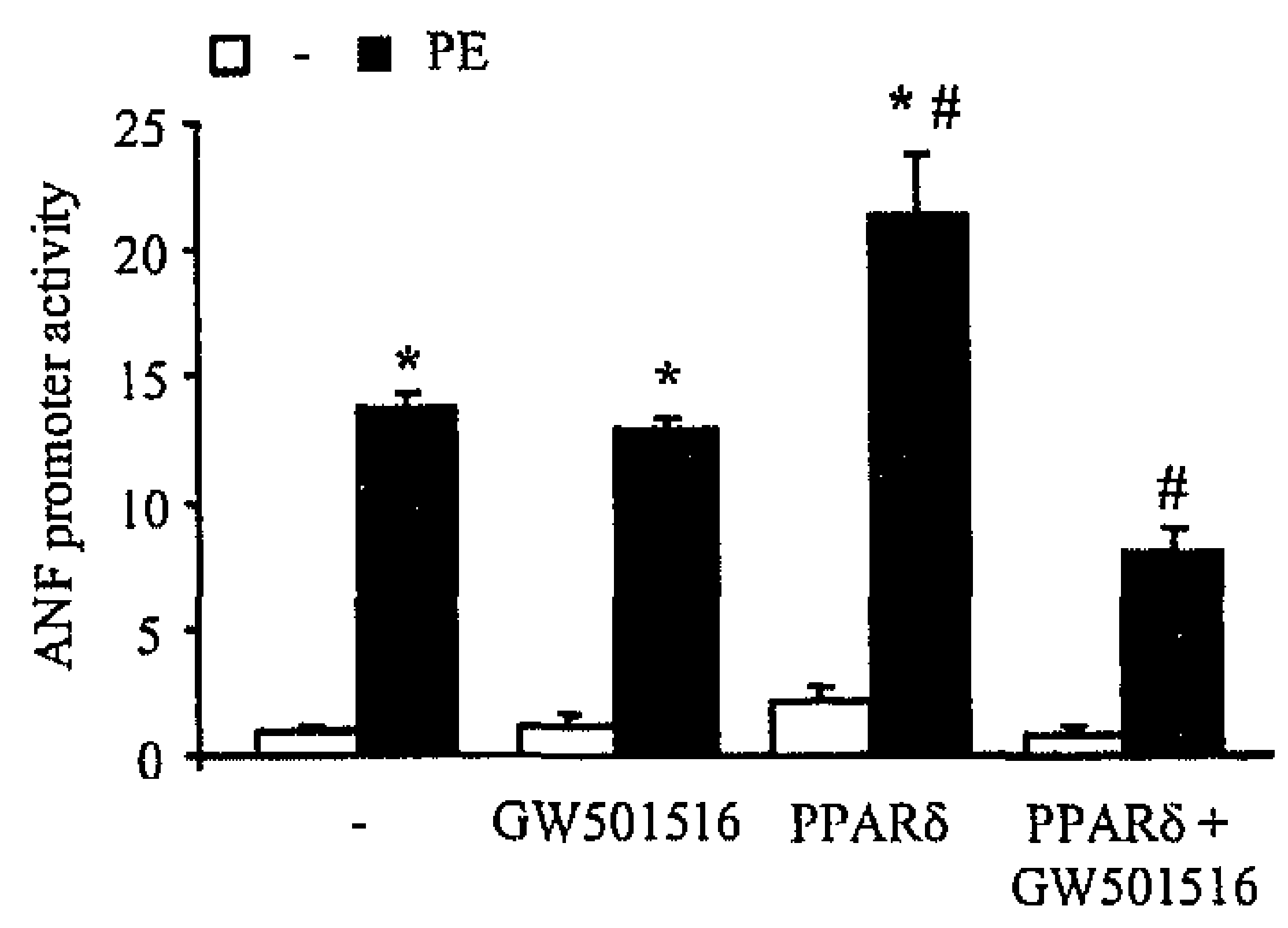

Figure 8. Effect of PPARs on PE-induced ANF promoter activation. NCM were transfected with ANF promoter/reporter construct in the absence or presence of a PPAR $\alpha$ (panel A) or PPAR $\delta$ (panel B) expression vector. Subsequently cells were either stimulated with PE $(10 \mu \mathrm{M})$ (black bars) or vehicle (control cells; white bars) and/or treated with the PPAR $\alpha$-ligand Wy-14,643 $(10 \mu \mathrm{M})$ or PPAR $\delta$-ligand GW501516 $(1 \mu \mathrm{M})$ for $24 \mathrm{~h}$. Changes in ANF transcriptional activity are expressed relative to vehicle-treated, control cells. Data presented as mean \pm SEM. $*$ indicates statistically significant $(p<0.05)$ compared to corresponding vehicle-treated control cells. \# indicates statistically significant $(\mathrm{p}<0.05)$ compared to ANF promoter activity induced by $\mathrm{PE}$ alone.

\section{DisCUSSION}

In the present study it is demonstrated that, similar to bona fide pro-inflammatory stimuli, a variety of growth-promoting factors elicit a marked inflammatory response, characterized by induction of TNF- $\alpha$ and COX-2 expression by NCM. The pro-hypertrophic and inflammatory signalling pathways in the cardiomyocyte appear to converge on NF- $\mathrm{KB}$. These observations point to a close relationship between the hypertrophic and inflammatory signalling pathways in the cardiac muscle cell and suggest that anti-inflammatory interventions could be therapeutically effective. Accordingly, the ability of PPAR $\alpha$ and PPAR $\delta$ to attenuate inflammation, and thereby hypertrophy, was investigated. Both PPAR isoforms inhibited NF$\mathrm{KB}$ activity and their overexpression exerted anti-hypertrophic effects, as evidenced from the mitigation of ANF and BNP mRNA expression and the blunted increase in cardiomyocyte size. 


\section{CARDIAC HYPERTROPHIC AND INFLAMMATORY PATHWAYS ARE MUTUALLY RELATED}

The present study demonstrates that hypertrophic as well as inflammatory stimuli exert a direct effect on both cardiac hypertrophy and inflammatory pathways. It is of interest to note that the inflammatory response seems to precede the hypertrophy response. The induction of inflammatory genes was found to be relatively fast (within $2 \mathrm{~h}$ after stimulation) and transient. More detailed analysis revealed that maximal induction was reached within 30-60 minutes (data not shown). In contrast, the increase in expression of hypertrophic marker genes was more gradual in nature (peaking at $24-48 \mathrm{~h}$ ). These time-related changes in gene expression are suggestive of a causal relationship between activation of inflammatory pathways and the subsequent hypertrophic response and, to the best of our knowledge, have not been reported before. Furthermore, as expected the pro-inflammatory factors TNF- $\alpha$ and LPS not only elicited a prominent inflammatory response ${ }^{164}$, but also gave rise to a hypertrophic response. The latter finding is in line with earlier observations that cytokines, e.g. IL-1 $\beta$ or TNF- $\alpha$, are able to induce hypertrophic growth of NCM and can activate signalling pathways involved in cardiac hypertrophy. ${ }^{12,97,165}$ Additional support is provided by in vivo studies, indicating that mice with cardiomyocyte-specific overexpression of IL-1 $\alpha$ and TNF- $\alpha$ develop left ventricular hypertrophy and dilated cardiomyopathy, respectively. ${ }^{166,167}$ It should be noted, however, that in the present study the degree of cellular hypertrophy induced by TNF- $\alpha$ is less prominent than that by $\mathrm{PE}$, as reflected by the absence of a statistically significant increase in cell size and a less prominent induction of the hypertrophic marker genes ANF, BNP and $\alpha-$ SKA. The latter findings indicate that, in addition to inflammatory signalling, other pathways most likely contribute to the hypertrophic growth response elicited by $\alpha$-adrenergic stimulation.

\section{NF- $K$ B IN CARDIAC INFLAMMATION AND HYPERTROPHY}

The intricate relationship between hypertrophic and inflammatory pathways suggests the presence of a common factor in the two seemingly unrelated processes. Previous studies have shown that $\alpha_{1}$-adrenergic stimulation activates $\mathrm{NF}-\mathrm{\kappa B}$ in vitro ${ }^{14}$ and that $\mathrm{NF}-\mathrm{\kappa B}$ activation is required for the induction of cardiac hypertrophy in vivo ${ }^{15}$. Furthermore, treatment of aorticbanded and spontaneously hypertensive rats with a specific NF- $\mathrm{kB}$ inhibitor mitigated the cardiac hypertrophic response ${ }^{99,168}$, and cardiac specific ablation of NF- $\mathrm{KB}$ was found to attenuate cardiac hypertrophy in TNF- $\alpha$ overexpressing mice. ${ }^{98}$ Accordingly, NF-kB might serve as the common factor, functionally linking the hypertrophy and inflammatory pathways in the cardiac muscle cell. In support of this contention we observed that DNA-binding activity of NF- $\mathrm{KB}$ is significantly increased after stimulation of the cardiomyocytes by both an inflammatory (TNF- $\alpha$ ) and hypertrophic stimulus (PE). Our study also shows that PE increased the expression of NF- $\mathrm{BB}$-regulated genes, implying that $\mathrm{NF}-\kappa \mathrm{B}$ is an important factor in integrating the inflammatory and hypertrophic signalling pathways. 


\section{MUTUAL INTERACTION OF NF-KB AND PPAR}

To date PPARs are under extensive investigation as targets to inhibit inflammation. ${ }^{41,}{ }^{169}$ The present study shows that also in the cardiac context PPAR $\alpha$ and PPAR $\delta$ are able to attenuate the inflammatory response, since in transient transfection studies on cardiac muscle cells the combination of overexpression of PPAR $\alpha$ or PPAR $\delta$ and treatment with their respective synthetic ligands inhibited p65-induced activation of a NF-kB-responsive promoter reporter. In vascular smooth muscle cells a comparable inhibitory effect of PPAR $\alpha$ was demonstrated, following p65-induced transcription of the IL-6 promoter. ${ }^{42}$ Recently, Ding and coworkers have shown anti-inflammatory properties of PPAR $\delta$ in LPS-treated NCM. ${ }^{146}$ Several mechanisms have been proposed to explain the inhibitory effect of PPARs on NF-kB [reviewed in ${ }^{170}$ ]. At present, protein-protein interaction, as revealed by coimmunoprecipitation assays ${ }^{54}$, is considered the predominant mechanism for the transrepression property of PPARs. By inference, this implies that NF- $\mathrm{kB}$ also modulates PPAR-mediated events. Consistent with this notion, p65 overexpression in cardiomyocytes inhibited mCPT-1 promoter activity, an effect shown to be dependent on an intact PPARresponse element. Moreover, Planavila and colleagues ${ }^{123}$ recently showed that exposure of H9c2 myotubes to the pro-inflammatory agent LPS caused a reduction in the expression of PDK4, a PPAR-regulated gene, as well.

The collective observations points to a pivotal role of PPARs in limiting the inflammatory response. This property could be of paramount importance in pathophysiological conditions, such as cardiac hypertrophy or ischemia-reperfusion, when NF-kB gets activated.

\section{PPARS AND HYPERTROPHY}

The current observations indicate that PPARs, through their anti-inflammatory actions, exert anti-hypertrophic effects on the cardiac muscle in vitro. Adenoviral overexpression of PPAR $\alpha$ or PPAR blunted the increase in ANF and BNP mRNA levels and inhibited cell size enlargement of PE-stimulated NCM both in the absence and presence of ligands. Likewise, PE-mediated induction of the -638 bp ANF promoter/reporter construct was substantially attenuated when PPAR $\alpha$ and PPAR $\delta$ were co-transfected. However, the response of the ANF promoter appeared to be ligand-dependent, showing an increase or decrease in the absence or presence of PPAR ligands, respectively. In this respect, the $-638 \mathrm{bp}$ ANF promoter and the endogenous ANF gene appeared to react differently. It is feasible that regulatory sequences outside the $-638 /+62$ ANF promoter region are responsible for the differences observed.

The finding that PPAR $\alpha$ and PPAR $\delta$ inhibited the induction of the fetal gene programme is in line with previous studies showing that the PPAR $\alpha$ agonist fenofibrate attenuated ET-1 induced protein synthesis and enlargement of $\mathrm{NCM}^{26,}{ }^{27}$ Moreover, recently we showed that the hearts of mice deficient in PPAR $\alpha$ developed a more pronounced hypertrophy after pressure overload, a response that was associated with enhanced expression of inflammatory 
genes. ${ }^{171}$ Collectively, these earlier and present observations indicate that the $\alpha$ - and $\delta$ isoform of PPAR suppress inflammation, a process closely linked to the induction of cardiac hypertrophy. In this respect it is of note that Jucker and colleagues ${ }^{172}$ reported that PPAR $\delta$ activation in hearts with regional infarction significantly reduced right ventricular hypertrophy in vivo.

In summary, the present findings demonstrate that in the cardiac muscle cell inflammatory and hypertrophic stimuli converge on NF- $\mathrm{kB}$. In addition, the transcription factors PPAR and $\mathrm{NF}-\mathrm{kB}$ are functionally intertwined in their ability to regulate hypertrophic and inflammatory processes in the cardiac muscle cell. The close relationship between hypertrophy and inflammation is also from a clinical point of view of great importance since chronic low-grade inflammation is thought to play a significant role in cardiac hypertrophy and failure. ${ }^{31}$ PPARs are able to inhibit myocardial inflammation and hypertrophy via inhibition of NF- $\mathrm{KB}$. It is therefore tempting to speculate that PPARs serve as therapeutic targets to inhibit inflammatory signalling and, consequently, prevent hypertrophic growth of the heart.

\section{ACKNOWLEDGEMENTS}

This study was funded by a grant from the Netherlands Organisation for Scientific Research (NWO 912-04-017 to M.v.B.) and EU FP6 grant LSHM-CT-2005-018833/EUGeneHeart. A. Planavila was supported by a post-doctoral fellowship from the Spanish Ministry of Education (EX2005-1376).

\section{NoTE}

Supplementary figure 1 and colour figure 6 can be found on www.jbc.org. 


\title{
$4 \mid$
}

\section{CARDIAC HYPERTROPHY IS ENHANCED IN PPAR $\alpha-/-$ MICE IN RESPONSE TO CHRONIC PRESSURE OVERLOAD}

\author{
Pascal J.H. Smeets, Birgit E.J. Teunissen, Peter H.M. Willemsen, Frans A. van \\ Nieuwenhoven, Agnieszka E. Brouns, Ben J.A. Janssen, Jack P.M. Cleutjens, \\ Bart Staels, Ger J. van der Vusse and Marc van Bilsen
}

Cardiovascular Research 2008;78(1):79-89.

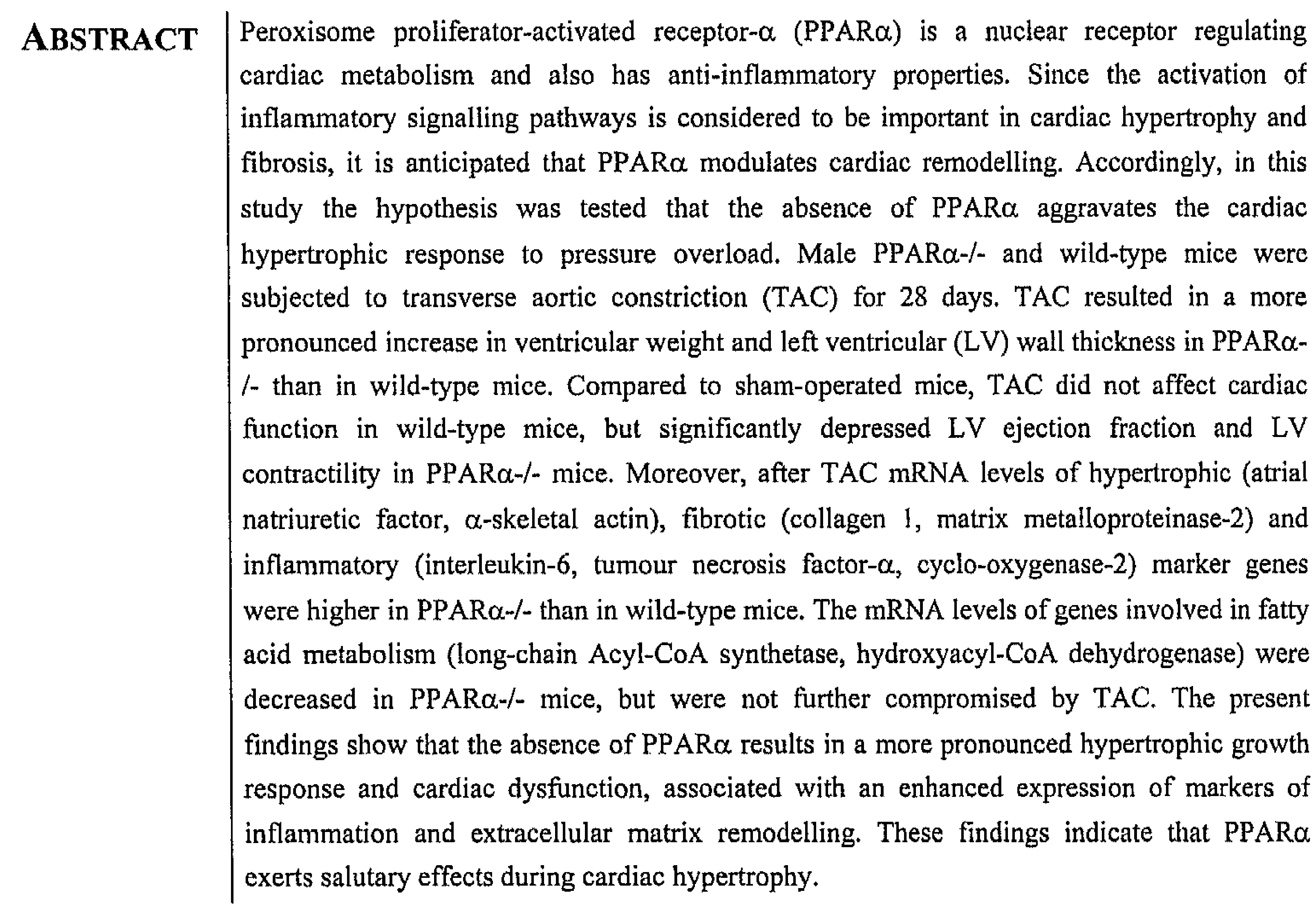




\section{INTRODUCTION}

Cardiac hypertrophy is considered to be an adaptive mechanism compensating for a chronic increase in workload. ${ }^{93}$ In the long term, however, it can become maladaptive, fibrosis develops, and compensated hypertrophy evolves into cardiac failure, which is characterized by an inadequate cardiac pumping activity. ${ }^{9,93}$ Cardiac hypertrophic growth is associated with neuro-hormonal as well as metabolic changes. In addition, activation of inflammatory signalling pathways has been considered to promote both cardiac hypertrophy and fibrosis. ${ }^{12}$, 13, 95, 96 Conversely, inhibition of inflammation can attenuate the development of cardiac hypertrophy. 98,99

Several ligand-activated nuclear hormone receptors, including peroxisome proliferatoractivated receptor- $\alpha$ (PPAR $\alpha$ ), have been reported to attenuate the activation of inflammatory signalling pathways ${ }^{42,173}$ and as such may inhibit cardiac hypertrophy and fibrosis. Consistent with this notion the specific PPAR $\alpha$ ligand fenofibrate was able to reduce cardiac hypertrophy both in vitro and in vivo. ${ }^{170}$ Given the diverse effects of PPAR $\alpha$ the exact mechanism for this anti-hypertrophic effect remains largely elusive, and may involve both stimulatory effects on cardiac fatty acid metabolism ${ }^{20}$ as well as anti-inflammatory effects. ${ }^{104,}$ 106,163

Accordingly, the aims of this study were to assess if deletion of the PPAR $\alpha$ gene deteriorates pressure overload induced hypertrophy of the heart and to explore which processes may underlie possible PPAR $\alpha$-related differences in the hypertrophic growth response. Thereto male PPAR $\alpha-/$ - and wild-type mice were subjected to transverse aortic constriction (TAC) and cardiac growth and function were evaluated non-invasively (echocardiography) and invasively (left ventricular pressure monitoring during a dobutamine stress test) after 4 weeks. To assess whether PPAR $\alpha$ deletion affected cardiac hypertrophy, inflammation and fibrosis, gene expression was assessed by quantitative PCR (qPCR). Here we report that i) absence of $\operatorname{PPAR} \alpha$ results in a more pronounced hypertrophic growth response, suggesting that PPAR $\alpha$ attenuates cardiac remodelling following pressure overload; ii) mechanical function is depressed in the PPAR $\alpha$-lacking hypertrophied heart and iii) deficiency of PPAR $\alpha$ is associated with enhanced inflammatory and fibrotic activity in the hypertrophying heart.

\section{METHODS}

\section{EXPERIMENTAL ANIMALS}

Male PPAR $\alpha-/-$ mice $^{174}$, backcrossed for more than 10 generations into a pure C57B16/J background, and age-matched wild-type C57B16/J mice were included in this study. The genotype was confirmed by qPCR (data not shown). Mice were kept on a $12 \mathrm{~h} / 12 \mathrm{~h}$ light/dark cycle in temperature-controlled rooms and had ad libitum access to water and standard labchow (Ssniff R/M-H, Ssniff, Soest, Germany). The investigation conforms to the Guide for 
the Care and Use of Laboratory Animals published by the US National Institutes of Health (NIH Publication No. 85-23, revised 1996).

\section{TRANSVERSE AORTIC CONSTRICTION}

The surgical procedure of TAC has been previously described. ${ }^{175}$ Briefly, 12 to 14 weeks old mice were anesthetized with xylazine $(5 \mathrm{mg} / \mathrm{kg}$ s.c.) and ketamine $(100 \mathrm{mg} / \mathrm{kg}$ i.m.). Anesthesia was maintained by isoflurane inhalation (1.5-2.5\%). After opening the chest, the transverse aorta of PPAR $\alpha-/-(n=23)$ and wild-type mice $(n=13)$ was ligated between the truncus brachiocephalicus and the left common carotid artery by tying a $6-0$ silk suture against a 25 gauge needle. Sham-operated PPAR $\alpha-/(n=11)$ and wild-type mice $(n=9)$ underwent the same procedure without ligation of the aorta. Animals recovered at $30^{\circ} \mathrm{C}$ for 24 $\mathrm{h}$ and were injected with the analgesic buprenorphine (Temgesic; $0.1 \mathrm{mg} / \mathrm{kg} \mathrm{s.c.).} \mathrm{Mice} \mathrm{were}$ sacrificed 28 days after TAC or sham operation.

\section{ECHOCARDIOGRAPHIC AND HEMODYNAMIC MEASUREMENTS}

Transthoracic echocardiography was performed 4 weeks after TAC or sham operation using a Hewlett-Packard $15 \mathrm{MHz}$ linear array transducer interfaced with a Sonos 5500 ultrasound machine (Philips, Eindhoven, the Netherlands) as previously described in De Celle et al. ${ }^{176}$ Mice were anesthetized with isoflurane and body temperature was maintained by placing the mice on a heating pad $\left(37^{\circ} \mathrm{C}\right)$. Left ventricular (LV) end-diastolic and end-systolic diameter (LVIDd and LVIDs), anterior and posterior wall thickness end-diastolic (AWTd and PWTd) and end-systolic (AWTs and PWTs), fractional shortening (FS), ejection fraction (EF) and end-diastolic and end-systolic volume (EDV and ESV) of the LV were measured using data from short-axis (AWT, PWT, LVID and FS) and parasternal long-axis (EF, EDV and ESV) views.

Heart rate (HR), LV systolic pressure and LV contractility $\left(+\mathrm{dP} / \mathrm{dt}_{\max }\right)$ were also measured 4 weeks after TAC or sham operation under baseline conditions and during a dobutamine stress test as previously described. ${ }^{176}$ Briefly, mice were anaesthetized with urethane $(2.5 \mathrm{mg} / \mathrm{kg}$ i.p.) and a Millar catheter (Mikro-tip 1.4F; SPR-671, Millar Instruments, Houston, TX, USA) was inserted in the right carotid artery. Additionally, a fluid-filled catheter was inserted in the femoral artery to determine the pressure-gradient across the aortic constriction. Next, the Millar catheter was advanced into the LV to measure LV pressure and its first derivative $+\mathrm{dP} / \mathrm{dt}(\mathrm{mm} \mathrm{Hg} / \mathrm{s})$ as a measure of LV contractility. Dobutamine (Sigma, St. Louis MO, USA) was infused via a catheter in the vena jugularis with increasing doses up to $0.1 \mathrm{mg} / \mathrm{kg} / \mathrm{min}$.

\section{EXCISION OF THE HEART AND CARDIAC TISSUE PREPARATION}

After completion of the hemodynamic measurements the heart was excised, the atria were removed and total ventricular tissue was weighed. Thereafter ventricles were separated in LV, 
right ventricle (RV) and septum and snap frozen for RNA analysis. In a subset of animals, the ventricles were dissected longitudinally. One half was fixed for $24 \mathrm{~h}$ in $4 \%$ paraformaldehyde dissolved in PBS and subsequently embedded in paraffin for further histological analysis. The other half was divided in LV, RV and septum and snap frozen in liquid nitrogen. Snap frozen LV tissue samples were used for RNA analysis.

\section{HISTOLOGICAL ANALYSIS}

Paraffin sections were deparaffinized and subsequently stained with hematoxylin and eosin (H\&E) to determine cardiomyocyte short-axis cross-sectional area (CSA) in the LV. ${ }^{177}$ Interstitial fibrosis was measured using Sirius red staining. ${ }^{178}$ Stained H\&E and Sirius red sections were quantified using Quantimet 570 software (Leica, the Netherlands).

\section{GENE EXPRESSION}

LV tissue was homogenised using an UltraTurrax (Janke \& Kunkel, Staufen, Germany) and total RNA was isolated with TRI reagent (Sigma) according to the manufacturer's protocol and complemented with an additional wash step of $70 \%$ ethanol to increase the purity of the RNA. Integrity of the RNA was checked by means of the 260/280 ratio. cDNA synthesis and qPCR assays were performed as previously described ${ }^{23}$ Primers used for analysis are given in table 1. Results were normalised to the geometric mean of three reference genes, i.e., cyclophilin A (CycloA), acidic ribosomal phosphoprotein P0 (ARBP) and hypoxanthine guanine phosphoribosyl transferase (HPRT) according to Vandesompele et al.$^{179}$ using qBase software. ${ }^{180}$ The expression of these reference genes was not affected by genotype and intervention.

Table 1. Primers used for qPCR

\begin{tabular}{lll}
\hline Gene & Forward & Reverse \\
\hline ARBP & GGACCCGAGAAGACCTCCTT & GCACATCACTCAGAATTTCAATGG \\
Cyclo A & CAAATGCTGGACCAAACACAA & TTCACCTTCCCAAAGACCACAT \\
HPRT & CCTAAGATGAGCGCAAGTTGAA & CCACAGGACTAGAACACCTGCTAA \\
PPAR $\alpha$ & TATTCGGCTGAAGCTGGTGTAC & CTGGCATTTGTCCGGTTCT \\
ANF & ATTGACAGGATTGGAGCCCAGAGT & TGACACACCACAAGGGCTTAGGAT \\
$\alpha-$ SKA & TGAGACCACCTACAACAGCA & CCAGAGCTGTGATCTCCTTC \\
Acs 11 & GAGGGTGAGGTGTGTGTGAA & CAGCTGTTCTTGCTGGGTCT \\
Hadha & GGTGTCCCTGAAGTGTTGCT & TCTGTCTGCACGAATGTTCC \\
TNF- $\alpha$ & CATCTTCTCAAAATTCGAGTGACAA & TGGGAGTAGACAAGGTACAACCC \\
COX-2 & GGGTGTCCCTTCACTTCTTTCA & TGGGAGGCACTTGCATTGA \\
IL-6 & CTGCAAGAGACTTCCATCCAGTT & GAAGTAGGGAAGGCCGTGG \\
MCP-1 & TTAAAAACCTGGATCGGAACCAA & GCATTAGCTTCAGATTTACGGGT \\
C011 & CGAAGGCAACAGTCGCTTCA & GGTCTTGGTGGTTTTGTATTCGAT \\
MMP-2 & TTTGCTCGGGCCTTAAAAGTAT & CCATCAAACGGGTATCCATCTC \\
HO-1 & TCTATCGTGCTCGCATGAAC & AAGGCGGTCTTAGCCTCTTC \\
\hline
\end{tabular}




\section{STATISTICS}

Results are presented as mean \pm SEM. Data were analysed by one-way ANOVA and contrast analysis for multiple comparisons using SPSS 12 software (SPSS Inc.). The dose-dependent curves for dobutamine were compared using two-way ANOVA and a post-hoc Bonferonni test. A p-value of less than 0.05 was considered to be statistically significant.

\section{RESULTS}

\section{TAC-INDUCED HYPERTROPHY}

None of the PPAR $\alpha-/$ - and wild-type sham-operated animals and of the wild-type animals subjected to TAC died during the course of the study. However, 11 out of $23(48 \%)$ of the PPAR $\alpha-/$ mice died within $1 \mathrm{~h}$ after TAC surgery, indicating that the TAC surgical procedure was poorly tolerated by PPAR $\alpha-/$ - mice. In sham-operated control animals total ventricular weight (VW) was slightly higher in PPAR $\alpha-/$ - mice than in wild-type mice (Table 2). After 28 days of TAC, VW was significantly increased in both wild-type and PPAR $\alpha-/$ mice. The increase in VW was more pronounced in PPAR $\alpha-/$ - TAC than in wild-type TAC, both when expressed as absolute weight, or when normalized to tibia length or body weight (VW/body weight $+37 \%$ vs. $+24 \%$, respectively). In wild-type mice, TAC resulted in an increase in the right carotid artery pressure and a pressure gradient of $\sim 40 \mathrm{mmHg}$ across the constriction as measured after 28 days. In PPAR $\alpha-/-$ mice the pressure-gradient was comparable, but the pressures in both the right carotid artery and femoral artery were lower than in wild-type mice.

Table 2. Characteristics of wild-type and PPAR $\alpha-/-$ mice 28 days after TAC or sham-operation

\begin{tabular}{lcccc}
\hline & \multicolumn{2}{c}{ Wild-type } & \multicolumn{2}{c}{ PPAR $\alpha-/-$} \\
\hline $\mathrm{N}$ & Sham & TAC & Sham & TAC \\
\cline { 2 - 5 } Age, wks & 9 & 13 & 11 & 12 \\
Body weight (BW), g & $16.2 \pm 0.1$ & $17.6 \pm 0.4$ & $17.5 \pm 0.2 \#$ & $16.6 \pm 0.5 \#$ \\
R. carotid artery pressure, mm Hg & $26.3 \pm 0.6$ & $26.3 \pm 0.3$ & $28.9 \pm 0.4 \#$ & $27.6 \pm 0.5^{*} \#$ \\
Femoral artery pressure, mm Hg & $60.7 \pm 2.4$ & $91.4 \pm 6.6^{*}$ & $63.1 \pm 1.6$ & $74.3 \pm .3 .2^{*} \#$ \\
Pressure-gradient, mm Hg & $53.5 \pm 2.7$ & $51.7 \pm 2.0$ & $51.3 \pm 4.7$ & $39.3 \pm 2.7^{*} \#$ \\
Ventricular weight (VW), mg & $7.2 \pm 3.9$ & $39.7 \pm 7.1^{*}$ & $11.8 \pm 4.3$ & $35.0 \pm 2.6^{*}$ \\
Tibia length (TL), mm & $110 \pm 3$ & $135 \pm 3^{*}$ & $125 \pm 3 \#$ & $161 \pm 7^{*} \#$ \\
VW/BW, mg/g & $17.3 \pm 0.2$ & $16.8 \pm 0.4$ & $17.2 \pm 0.3$ & $16.5 \pm 0.2$ \\
VW/TL, mg/mm & $4.2 \pm 0.1$ & $5.2 \pm 0.1^{*}$ & $4.3 \pm 0.1$ & $5.9 \pm 0.2^{*} \#$ \\
Lung weight (wet), mg & $6.7 \pm 0.2$ & $8.3 \pm 0.2^{*}$ & $7.3 \pm 0.2 \#$ & $10.1 \pm 0.4^{*} \#$ \\
* indicates statistically significant difference compared to corresponding sham-operated animals (p<0.05). & $130 \pm 5$ & $135 \pm 3$ & $147 \pm 1 \#$ & $149 \pm 5 \#$ \\
\# indicates statistically significant difference compared to corresponding wild-type animals (p<0.05)
\end{tabular}


Wet lung weight was approximately $10 \%$ higher in PPAR $\alpha-/$ - than in wild-type mice. However, when normalized to body weight no significant differences were apparent. Moreover, the ratio between wet and dry lung weight was similar for all groups, indicating that the differences in wet lung weight were not related to pulmonary oedema.

\section{CARDIAC DIMENSIONS AND HEMODYNAMIC FUNCTION}

Diastolic and systolic anterior and posterior wall thickness (AWT and PWT) were similar in sham-operated wild-type and PPAR $\alpha$-/- mice as determined echocardiographically (Table 3). TAC significantly increased AWT and PWT in both wild-type and PPAR $\alpha-/$ - mice during diastole. The increase in diastolic AWT and PWT was more pronounced in PPAR $\alpha-/-$ TAC animals. Histological examination of H\&E-stained LV tissue sections revealed that the cardiomyocyte cross-sectional area (CSA) tended to be larger in sham-operated PPAR $\alpha-/$ mice compared to wild-type mice ( $\mathrm{p}=0.078$ ) (Fig. 1). CSA significantly increased in both PPAR $\alpha-/$ mice and in wild-type mice after TAC. The increase in CSA after TAC tended to be higher in PPAR $\alpha-/$ - mice compared to wild-type $(\mathrm{p}=0.081)$.

Table 3. Left ventricular dimensions of wild-type and PPAR $\alpha-/-$ mice 28 days after TAC or sham-operation.

\begin{tabular}{lcccc}
\hline & \multicolumn{2}{c}{ Wild-type } & \multicolumn{2}{c}{ PPAR $\alpha-/-$} \\
\hline LVIDd, mm & Sham & TAC & TAC \\
\cline { 2 - 5 } LVIDs, mm & $4.00 \pm 0.03$ & $4.05 \pm 0.05$ & $4.30 \pm 0.05 \#$ & $4.39 \pm 0.09^{*}$ \\
AWTd, mm & $2.84 \pm 0.06$ & $2.97 \pm 0.11$ & $3.12 \pm 0.03 \#$ & $3.40 \pm 0.10^{*} \#$ \\
AWTs, mm & $0.67 \pm 0.01$ & $0.76 \pm 0.03^{*}$ & $0.65 \pm 0.02$ & $0.92 \pm 0.05^{*} \#$ \\
PWTd, mm & $1.19 \pm 0.02$ & $1.23 \pm 0.04$ & $1.13 \pm 0.02$ & $1.31 \pm 0.05^{*}$ \\
PWTs, mm & $0.78 \pm 0.02$ & $0.91 \pm 0.05^{*}$ & $0.75 \pm 0.01$ & $1.13 \pm 0.07^{* \#}$ \\
EDV, mm & $1.21 \pm 0.04$ & $1.31 \pm 0.05$ & $1.20 \pm 0.02$ & $1.43 \pm 0.05^{*}$ \\
ESV, $\mathrm{mm}^{3}$ & $42.4 \pm 3.0$ & $43.9 \pm 1.4$ & $54.1 \pm 1.4 \#$ & $52.2 \pm 2.2 \#$ \\
\hline
\end{tabular}

LVIDd, LV internal diameter during diastole; LVIDs, LV internal diameter during systole; AWTd, anterior wall thickness during diastole; AWTs, anterior wall thickness during systole; PWTd, posterior wall thickness during diastole; PWTs, posterior wall thickness during systole; EDV, end-diastolic volume; ESV, end-systolic volume.

* indicates statistically significant difference compared to corresponding sham-operated animals $(p<0.05)$.

\# indicates statisticaliy significant difference compared to corresponding wild-type animals $(\mathrm{p}<0.05)$. 
A.

Wild-type

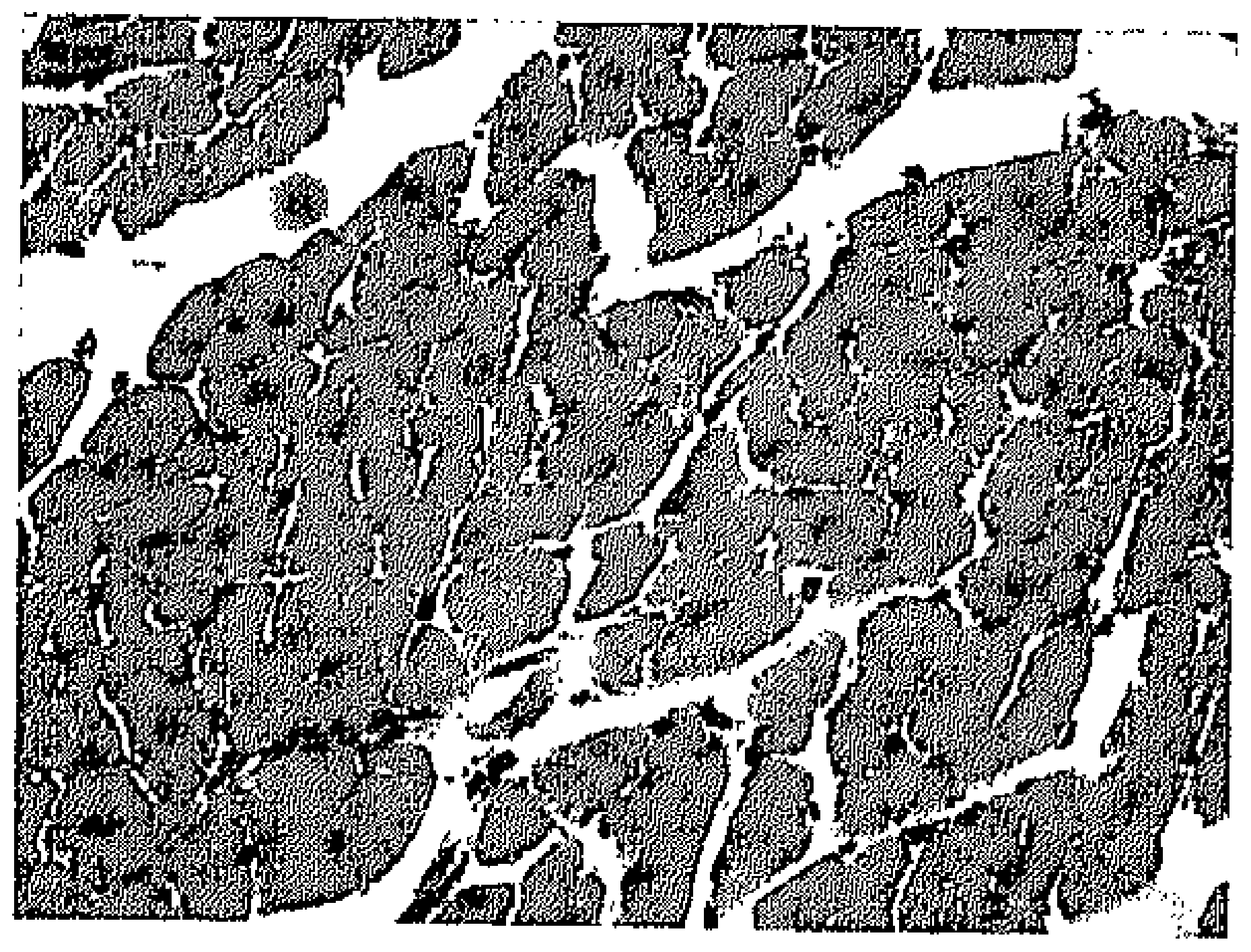

TAC

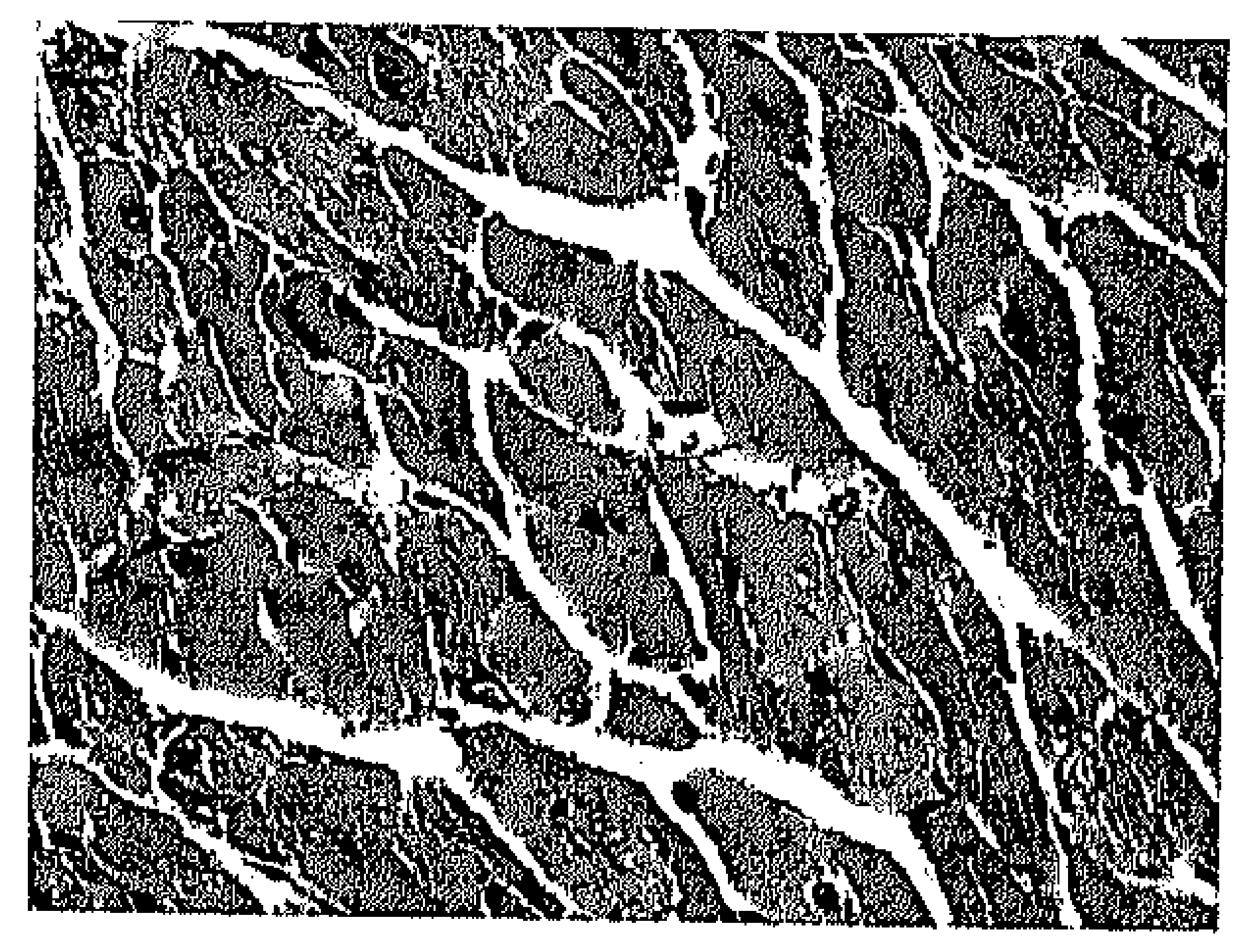

PPAR $\alpha$ -
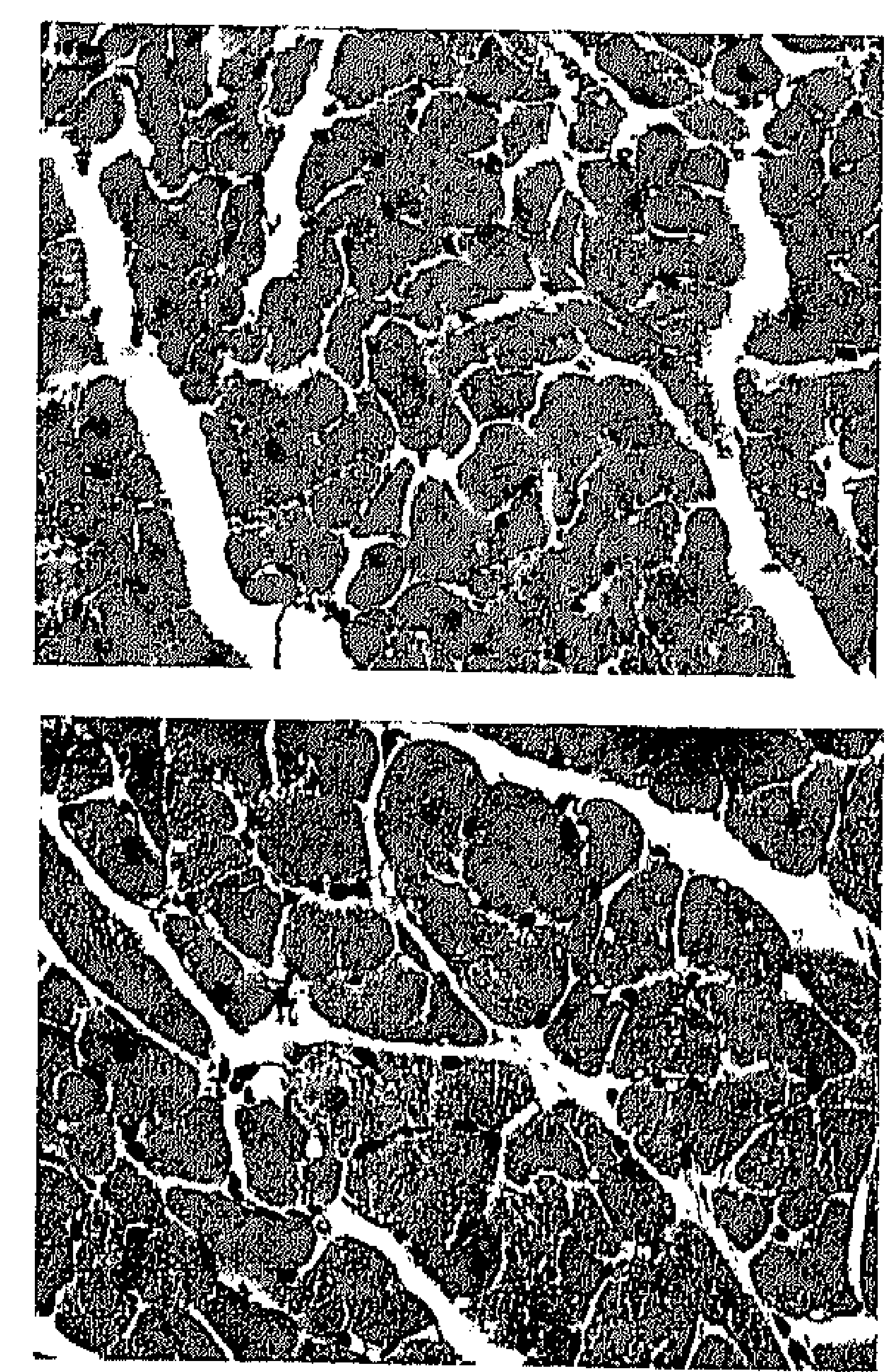

B.

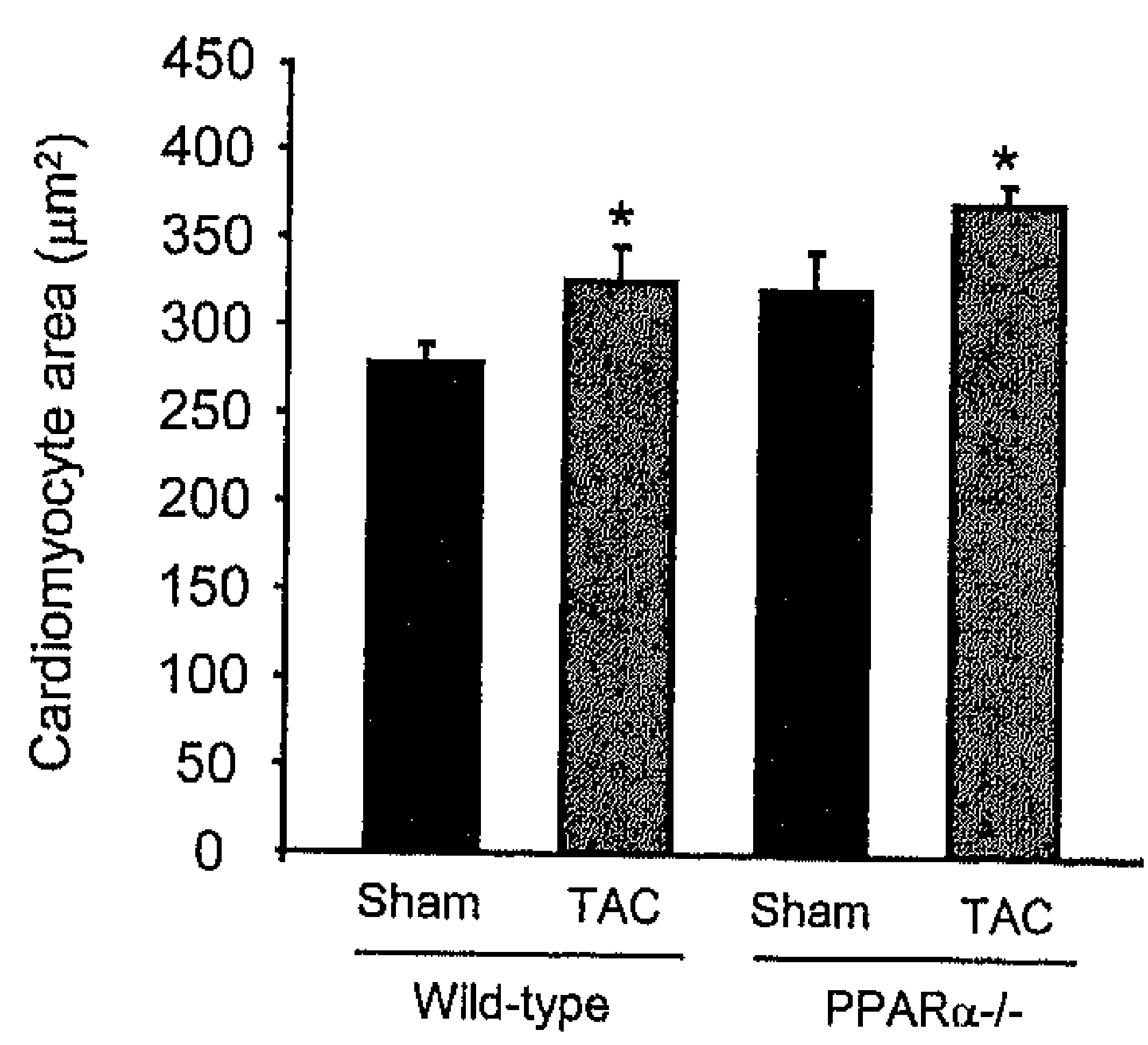

Figure 1. Cardiomyocyte cross-sectional area of sham-operated and TAC-subjected wild-type and PPAR $\alpha-/$ mice. (A) Representative examples of $H \& E$ stained left ventricular tissue from sham- or TAC-operated wild-type and PPAR $\alpha-/$ mice. (B) Cardiomyocyte cross-sectional area in LV tissue sections was quantified using Quantimet 570 software. Results are expressed as mean \pm SEM. * indicates statistically significant difference compared to corresponding sham-operated animals $(\mathrm{p}<0.05)$.

In sham-operated animals the diastolic and systolic LV internal diameter (LVIDd and LVIDs) of PPAR $\alpha-/$ - mice were slightly, but significantly, larger compared to wild-type mice. LVIDd and LVIDs did not increase in wild-type animals after TAC. However, LVIDs of PPAR $\alpha-/-$ TAC mice was $9 \%$ larger than that of PPAR $\alpha-/-$ sham mice. In wild-type mice ejection fraction (EF) and fractional shortening (FS) were not affected by TAC (Fig. 2A and $\mathrm{B}$ ). In PPAR $\alpha-/$ - mice, however, TAC resulted in a significant decline of both $\mathrm{EF}$ and FS. 


\section{A. Ejection fraction}

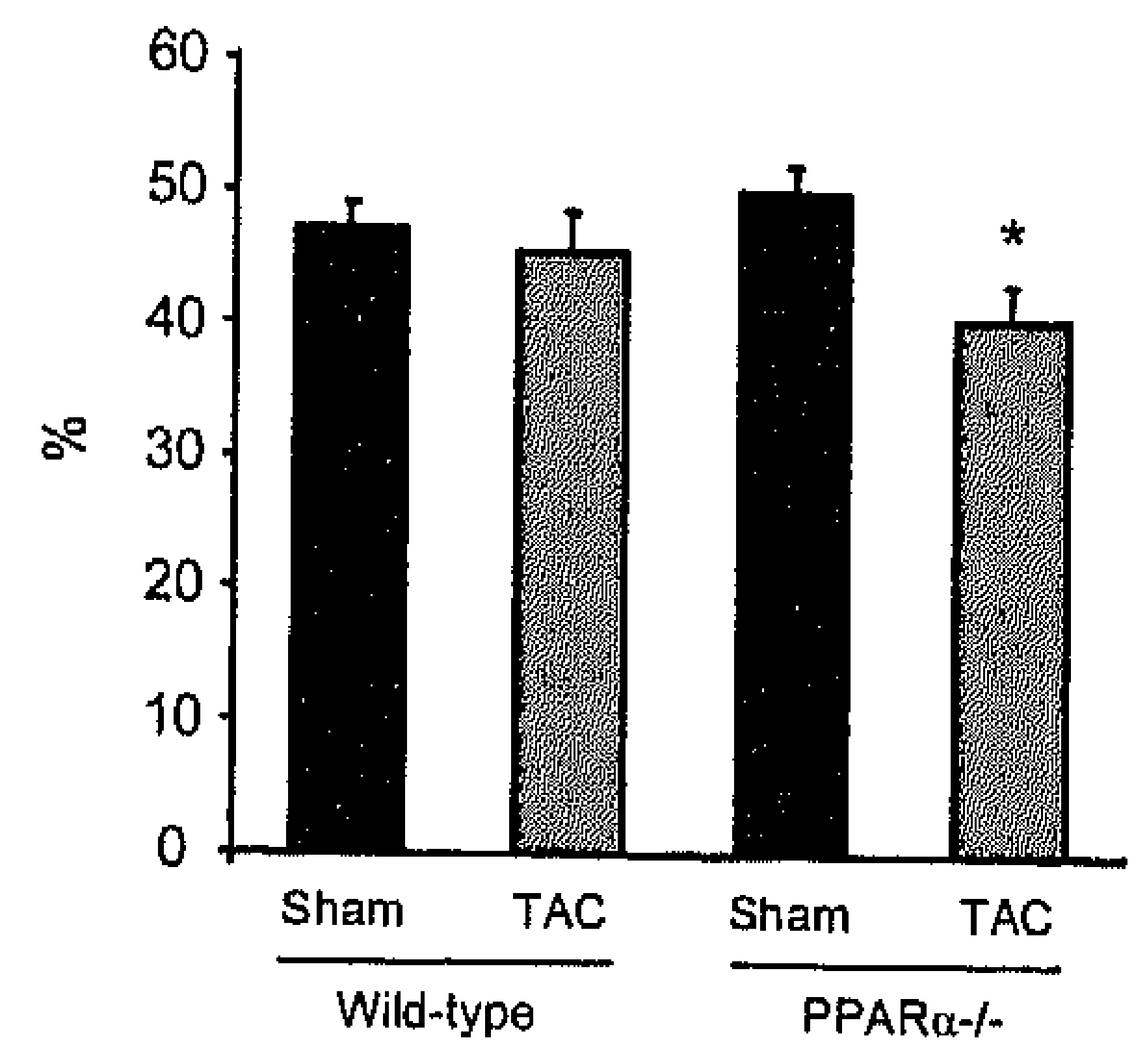

B. Fractional shortening

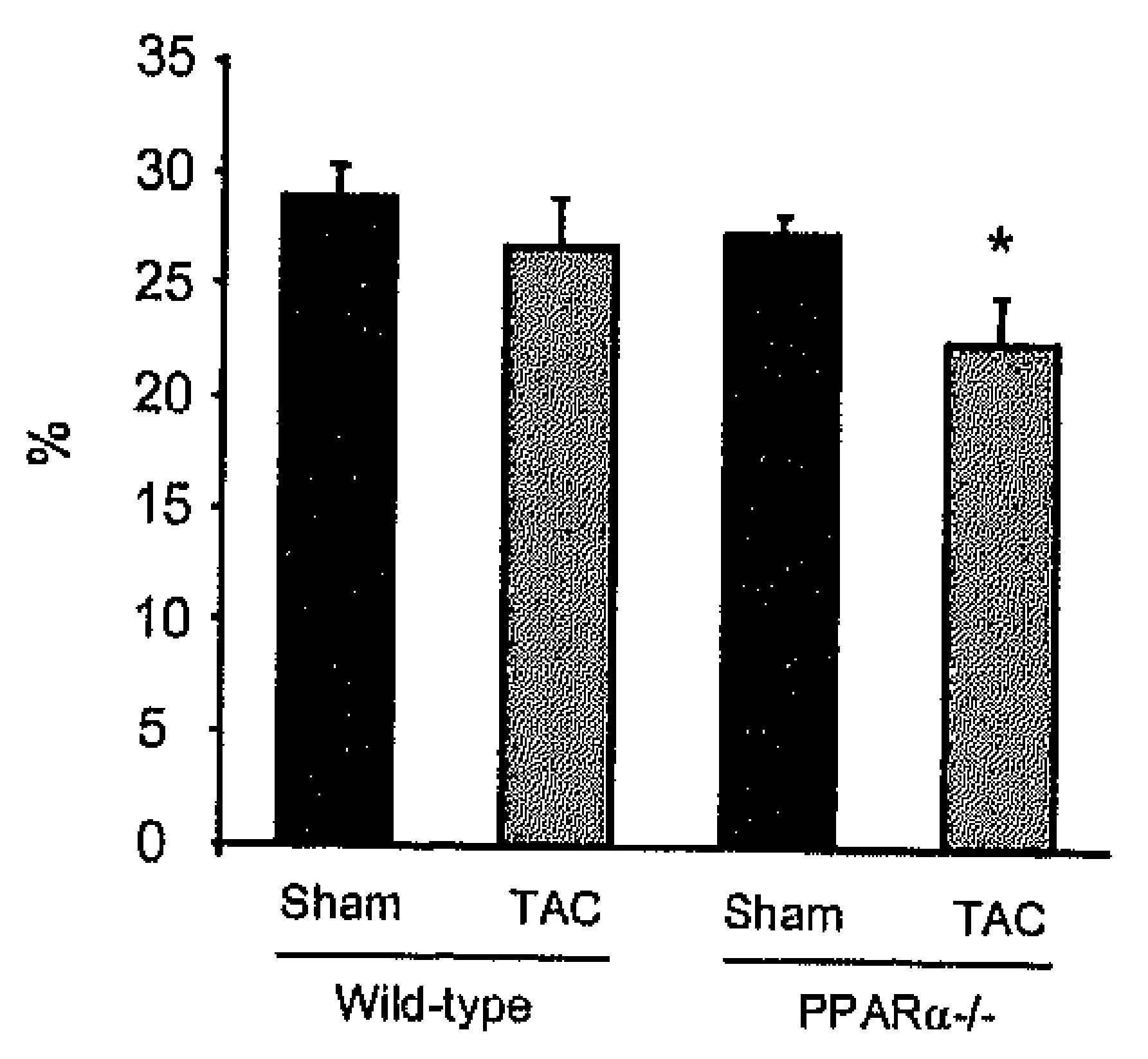

C. LV systolic pressure

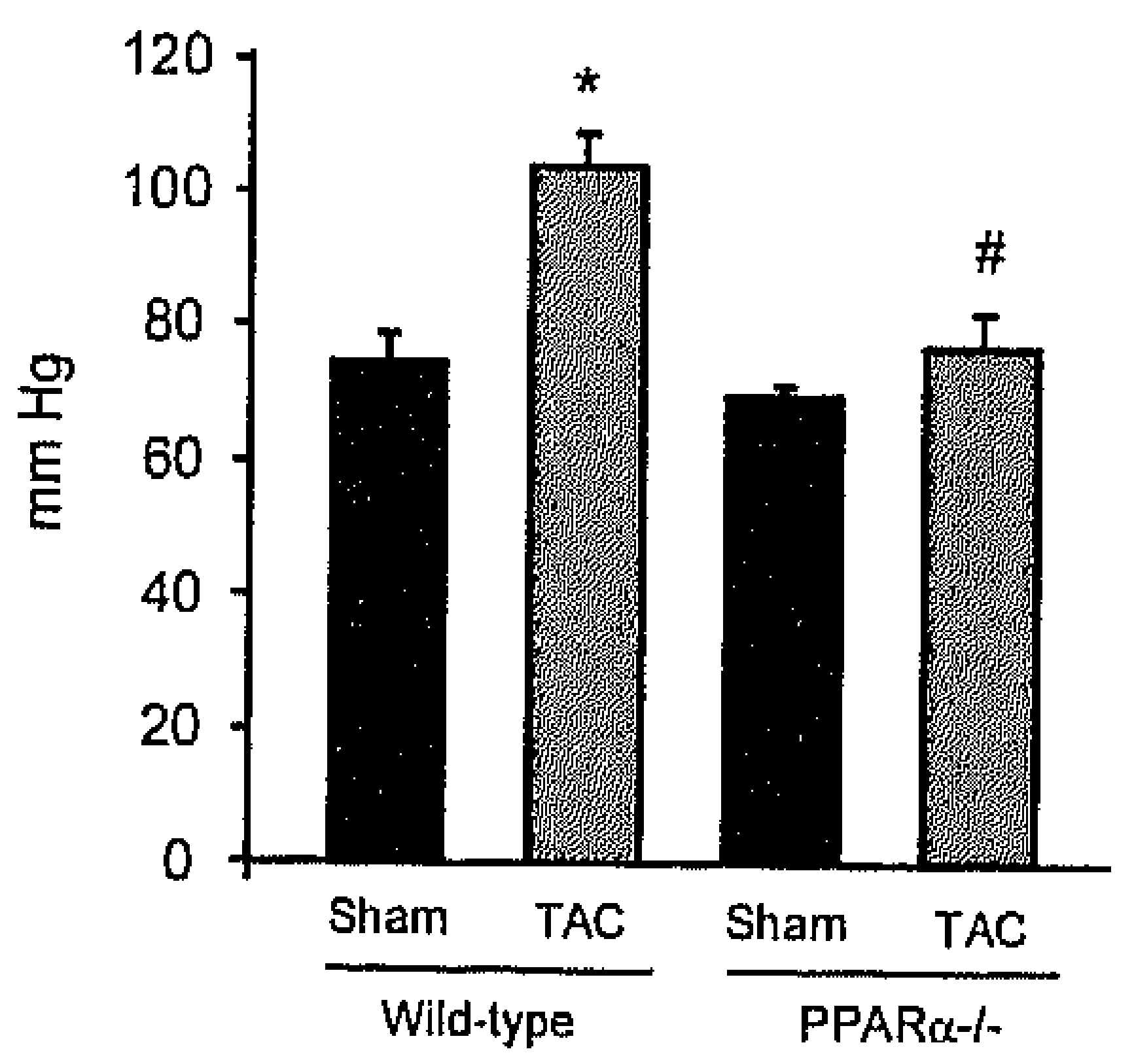

D. LV contractility

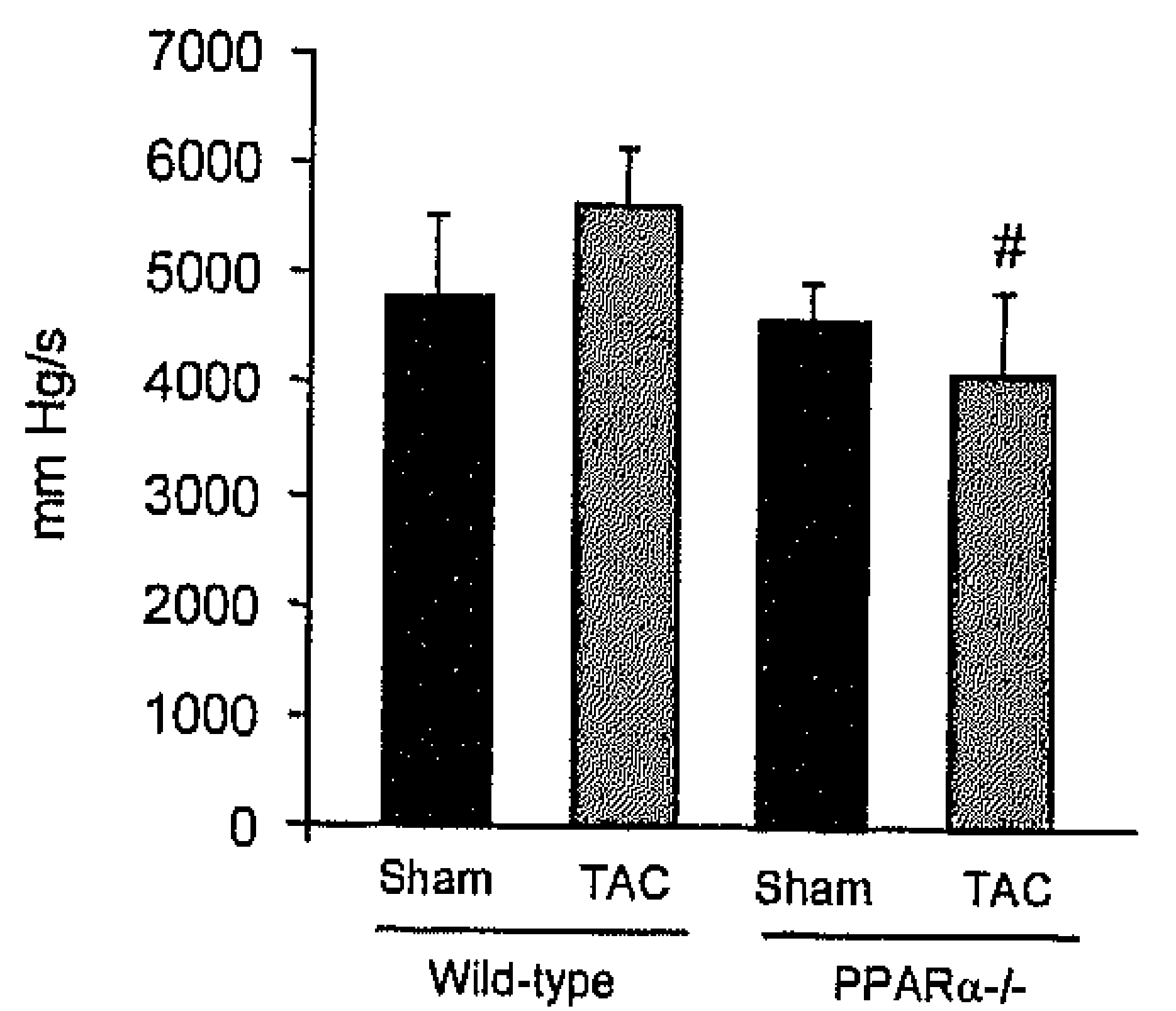

Figure 2. Parameters of cardiac hemodynamic function in wild-type and PPAR $\alpha-/$ - mice after TAC. (A) Ejection fraction, (B) Fractional shortening, (C) LV systolic pressure and (D) $+\mathrm{dP}^{\mathrm{d}} / \mathrm{dt}_{\max }$ were measured by echocardiographic (A, B) and hemodynamic measurements (C, D) 28 days after TAC. Results are expressed as mean \pm SEM of $n=8-11$ mice per experimental group. ${ }^{*}$ indicates statistically significant difference compared to corresponding sham-operated animals $(p<0.05$ ). \# indicates statistically significant difference compared to corresponding wild-type animals $(\mathrm{p}<0.05)$.

Invasive hemodynamic analysis showed that $L V$ systolic pressure and $+\mathrm{dP} / \mathrm{dt}_{\max }$ did not differ between sham-operated wild-type and PPAR $\alpha-/$ - mice (Fig. 2C and D). TAC was associated with a significantly higher LV systolic pressure in wild-type mice, but not in PPAR $\alpha-/$ - mice suggesting that the hearts of PPAR $\alpha-/$ mice were unable to cope with the increase in afterload to which they were exposed for 28 days. The $+\mathrm{dP}^{\mathrm{d}} \mathrm{dt}$ max also was lower in PPAR $\alpha-/-$ mice compared to wild-type mice after TAC. When hearts were stressed with dobutamine, the increase in $+d P / d t_{\max }$ was less in PPAR $\alpha$-/- sham mice than in wild-type sham mice (Fig. 3A). In wild-type mice TAC did not influence the dobutamine dose-dependent increase in $+\mathrm{dP}^{\mathrm{d}} \mathrm{dt}_{\max }$. In contrast, in PPAR $\alpha-$ mice subjected to $\mathrm{TAC}+\mathrm{dP} / \mathrm{dt}_{\max }$ was further 
compromised. At the highest dobutamine dose tested $+\mathrm{dP} / \mathrm{dt}_{\max }$ was almost $20 \%$ lower in PPAR $\alpha-/-$ TAC than in wild-type TAC mice. Heart rate (HR) was similar for all groups under basal conditions as wells as after maximal stimulation with dobutamine (Fig. 3B).

\section{A. LV contractility}

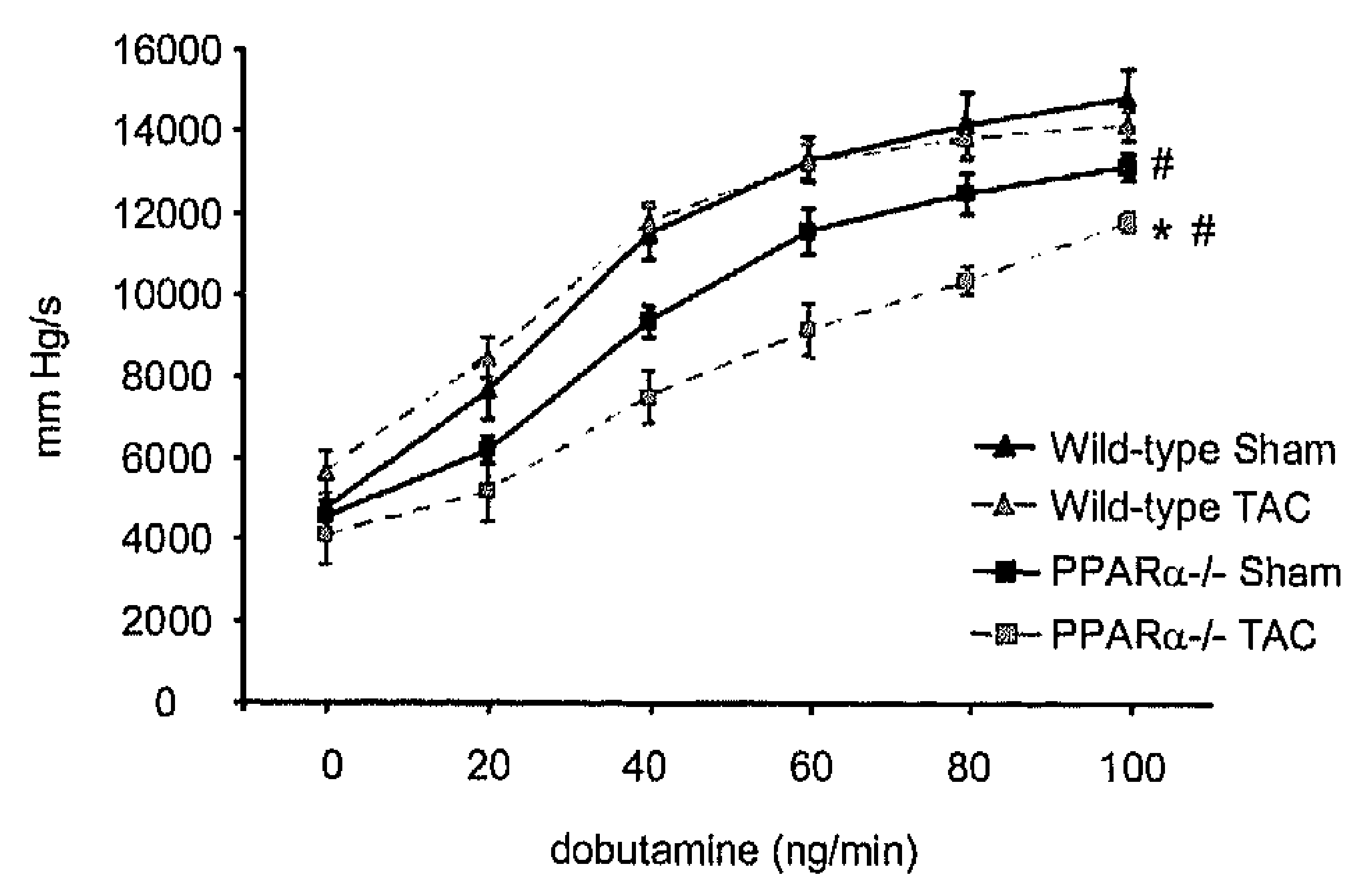

\section{B. Heart rate}

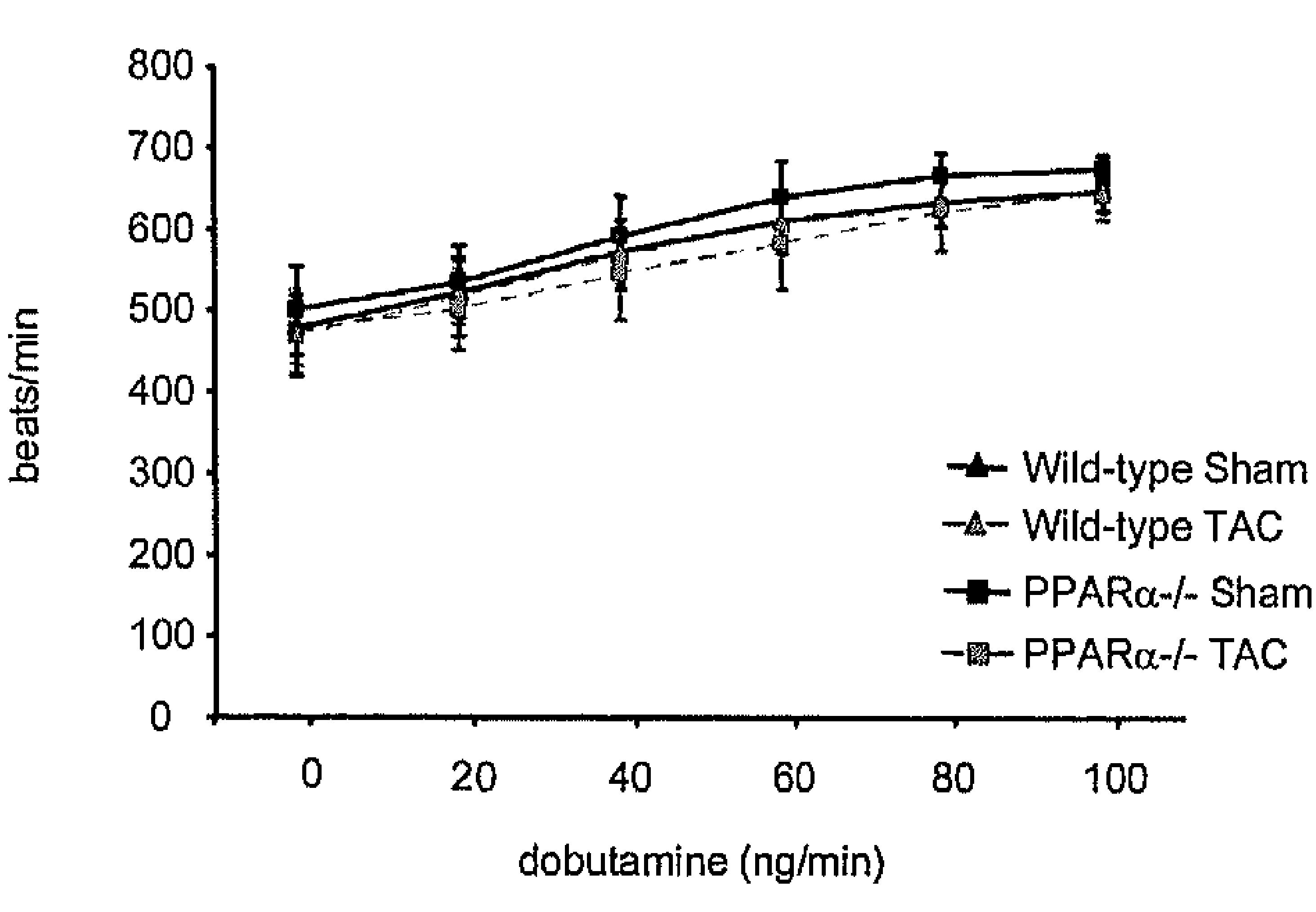

Figure 3. Left ventricular contractility and heart rate in wild-type and PPAR $\alpha$ - mice after TAC. (A) LV contractility and $(B)$ heart rate were measured during increasing doses of dobutamine infusion in PPAR $\alpha-\%$ and wild-type mice 28 days after TAC. Results are expressed as mean \pm SEM of $n=8-11$ mice per experimental group. ${ }^{*}$ indicates curve is statistical significant different compared to corresponding sham-operated animals $(p<0.05)$. \# indicates curve is statistical significant different compared to wild-type TAC animals $(\mathrm{p}<0.05)$.

\section{GENE EXPRESSION}

The mRNA level of hypertrophic marker genes ANF and $\alpha$-skeletal actin ( $\alpha$-SKA) was similar in both sham-operated groups (Fig. 4A and B). TAC increased ANF and $\alpha$-SKA mRNA after 28 days both in wild-type and PPAR $\alpha-/-$ mice. The increase in ANF and $\alpha-S K A$ mRNA was more pronounced in PPAR $\alpha-/$ - mice than in wild-type mice, although in the case of $\alpha$-SKA the difference did not reach the level of statistical significance.

To investigate whether TAC is accompanied by increased cardiac expression of inflammatory marker genes, mRNA levels of the pro-inflammatory cytokines interleukin-6 (IL-6), tumour 
necrosis factor- $\alpha$ (TNF- $\alpha$ ), cyclo-oxygenase-2 (COX-2) and monocyte chemo-attractant protein-1 (MCP-1) were determined (Fig. 4C-F). Inflammatory gene expression was comparable in sham-operated PPAR $\alpha-/$ and wild-type mice. After TAC, IL- 6 and COX-2 mRNA were unaltered in wild-type mice, but were markedly increased in PPAR $\alpha-/$ - animals. TNF- $\alpha$ mRNA levels also tended to increase in PPAR $\alpha-/-$ TAC animals $(\mathrm{p}=0.093)$. The mRNA level of MCP-1 was affected neither in wild-type mice nor in PPAR $\alpha-/$ - mice subjected to TAC.

As markers for fibrosis, we evaluated the expression of collagen 1 (Col1) and matrix metalloproteinase 2 (MMP-2). The expression of these fibrotic markers was similar in the two sham groups. TAC led to a substantial increase of Coll and MMP2 expression in PPARa-/mice, but not in wild-type mice (Fig. $4 \mathrm{G}$ and H). Histological staining for fibrosis, however, did not reveal significant differences in fibrotic area (averaging $2 \%$ of total tissue area) related to genotype or in response to TAC (data not shown).

As anticipated the mRNA level of PPAR-responsive genes involved in fatty acid metabolism, e.g. Acyl-CoA synthetase long-chain family member 1 (Acs11) and the $\beta$-oxidation enzyme hydroxyacyl-Coenzyme A dehydrogenase (Hadha) was decreased in PPAR $\alpha-/$ - mice. The expression of both genes was not affected by TAC (Fig. 4I and J).

\section{DISCUSSION}

In this study we demonstrate that the absence of PPAR $\alpha$ is associated with a more pronounced hypertrophic response of the murine heart following pressure overload. The increased hypertrophy is accompanied by decreased hemodynamic cardiac function as deduced from echocardiographic analysis and dobutamine stress tests. Moreover, gene expression analysis reveals that fibrotic and inflammatory responses are enhanced in the hearts of PPAR $\alpha-/$ - mice subjected to TAC. The collective findings indicate that loss of PPAR $\alpha$ activity is detrimental for the heart when subjected to a chronic increase in workload and suggest that the enhanced cardiac inflammatory response contributes to this negative effect.

\section{FUNCTIONAL CHARACTERIZATION OF PPAR $\alpha-/$ - MICE}

The PPAR $\alpha-/$ - mouse is a well-established murine model to study the role of PPAR $\alpha$ in lipid metabolism and the relation between changes in lipid handling and disease progression. ${ }^{181-183}$ At first sight these mice develop normally and do not show phenotypical abnormalities. However, after imposition of stress, e.g. in response to a metabolic challenge or exercise, or during ageing, phenotypical differences become readily apparent in particular in tissues with high oxidative capacity such as the heart. ${ }^{16,182,184}$ 
In the present study no differences were observed in baseline cardiac performance of shamoperated wild-type and PPAR $\alpha-/$ - mice. A number of studies reported that cardiac function is

\section{A. ANF}

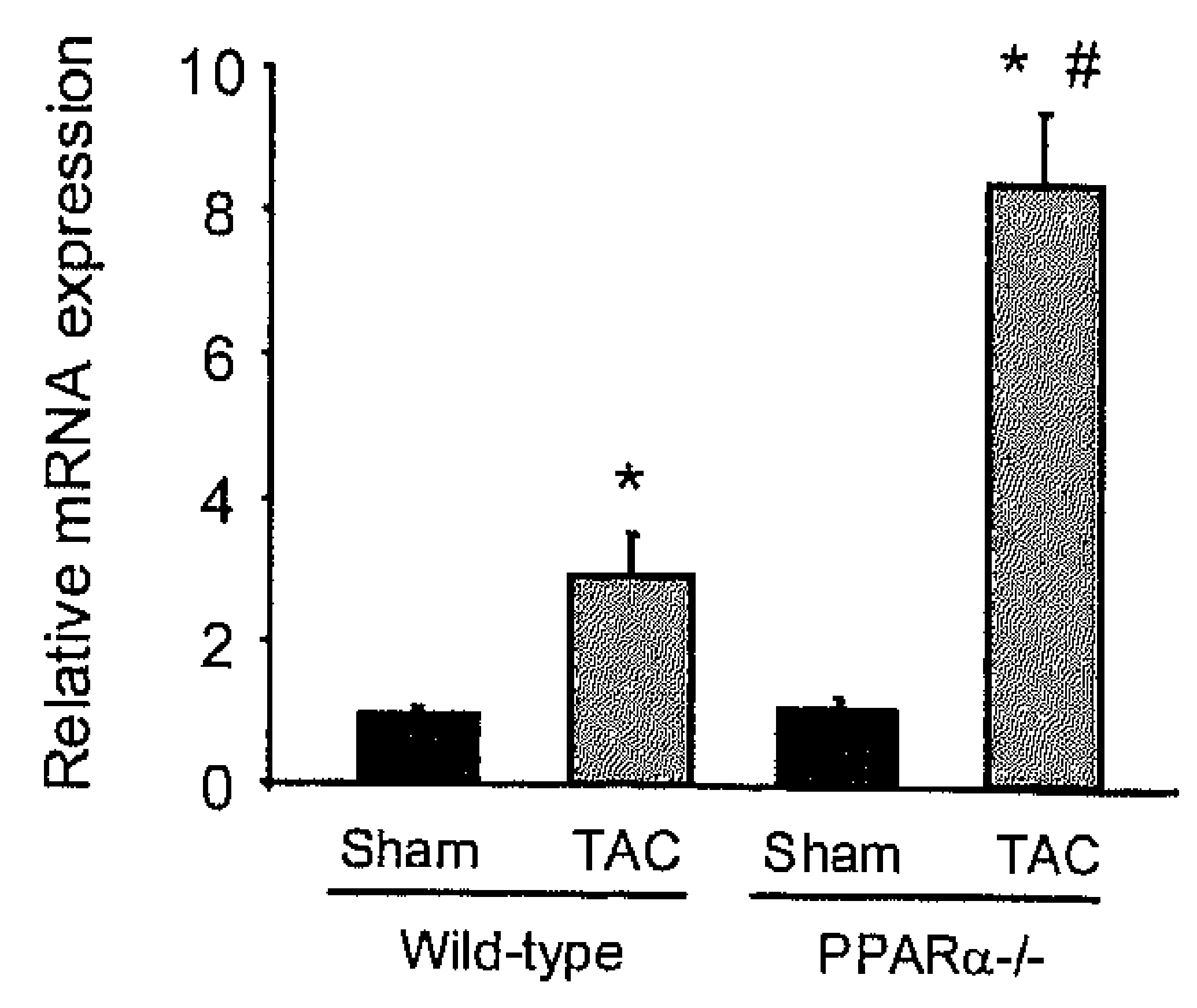

C. IL- 6

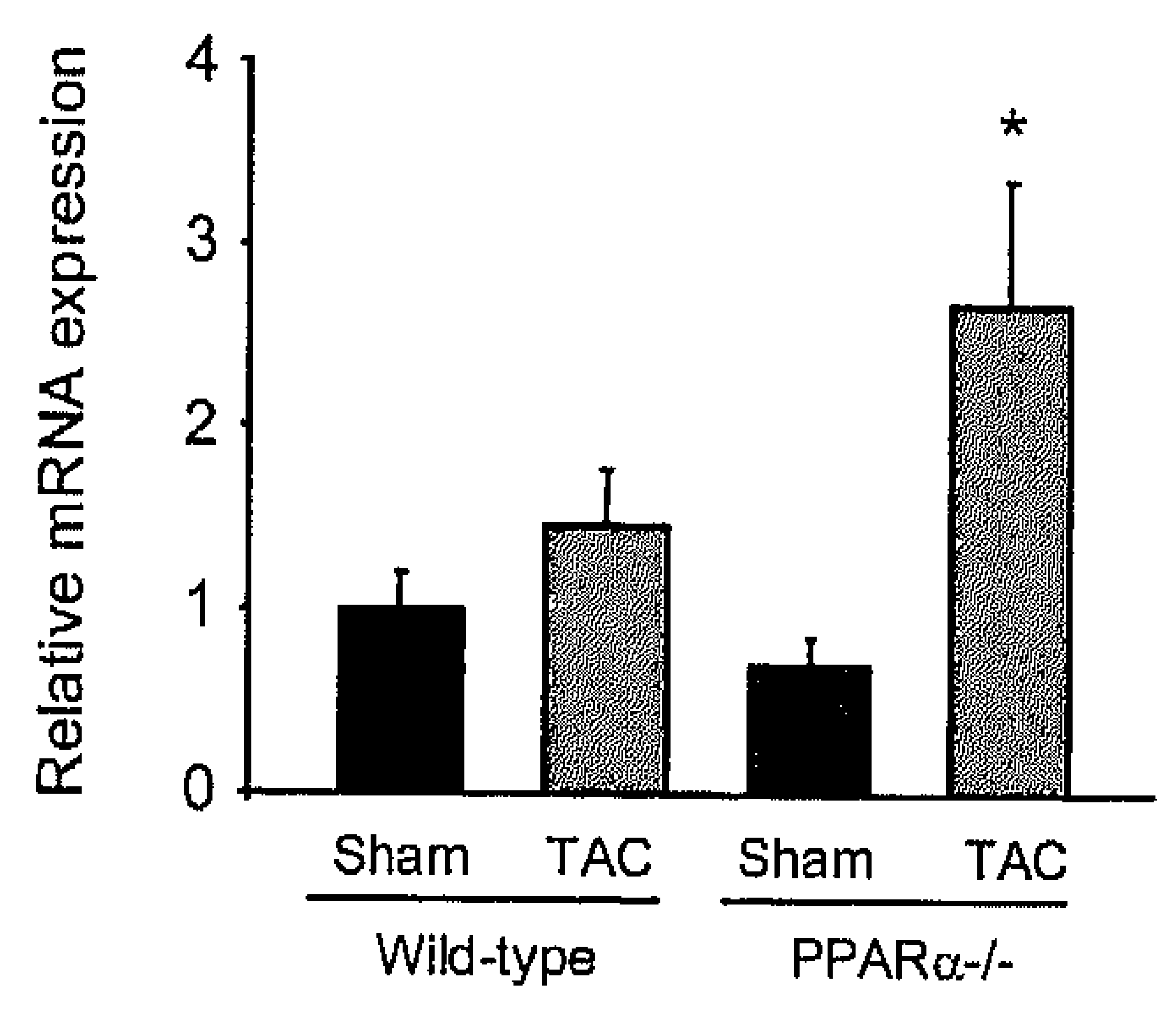

E. COX-2

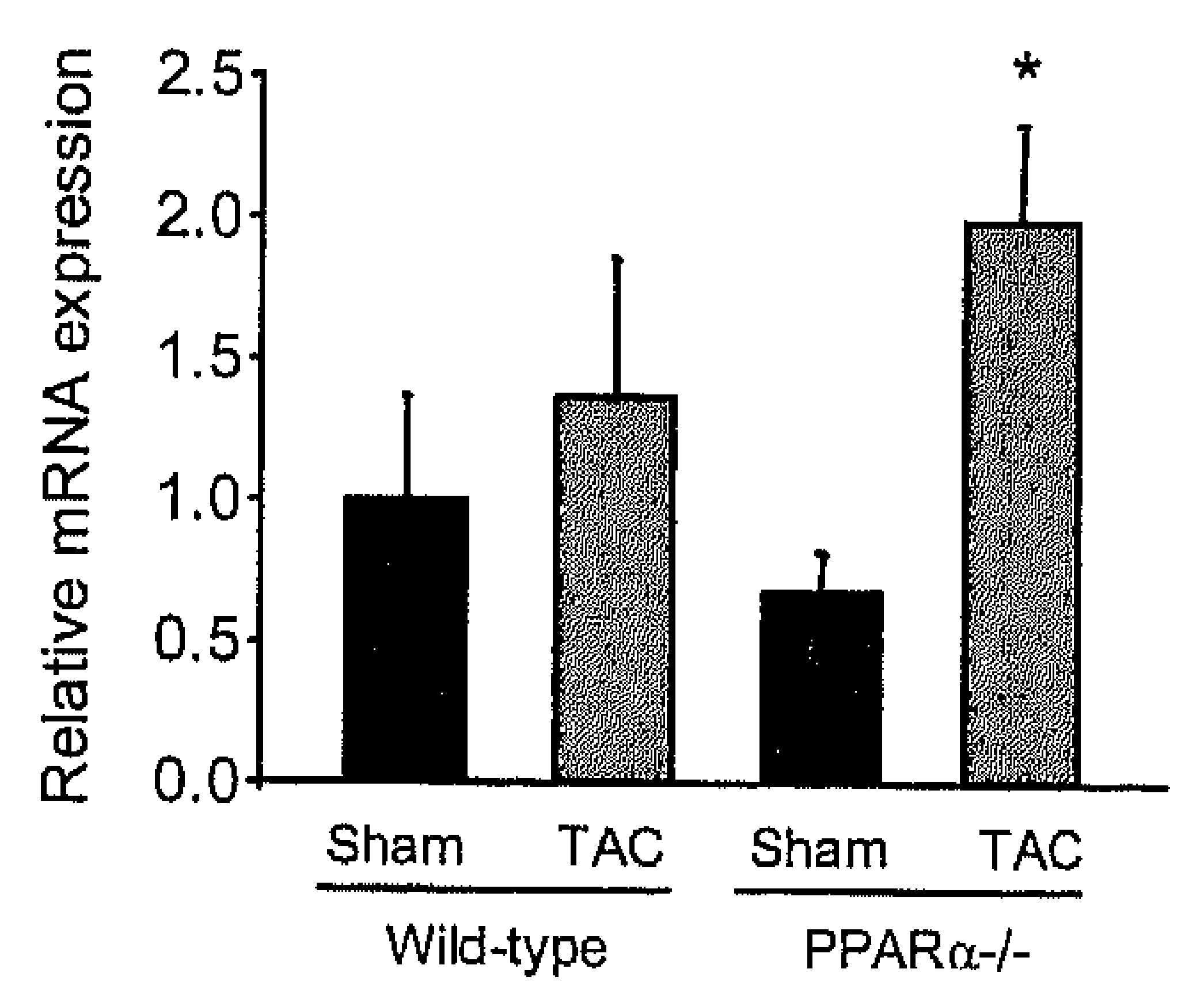

B. $\alpha-S K A$

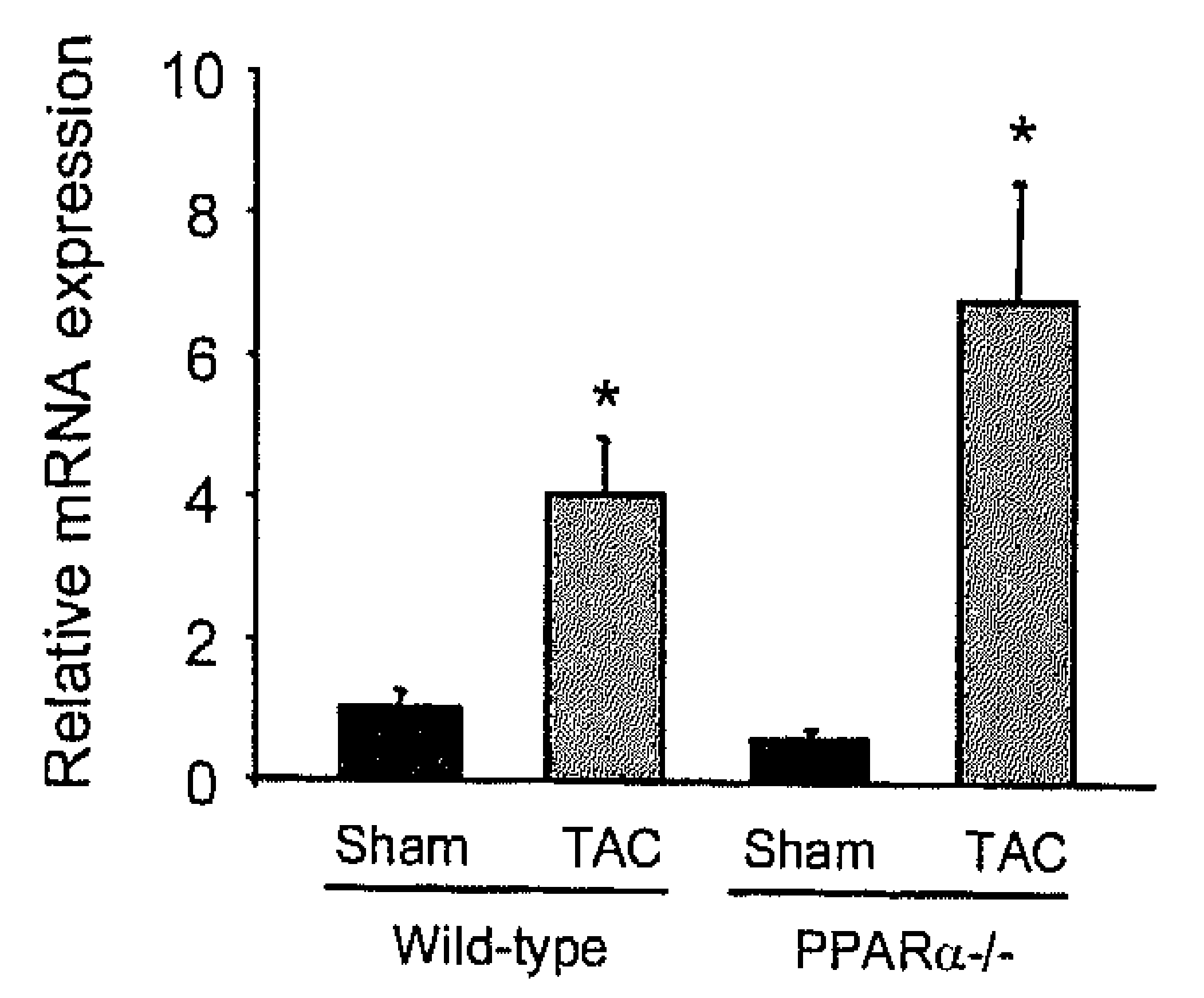

D. TNF $-\alpha$

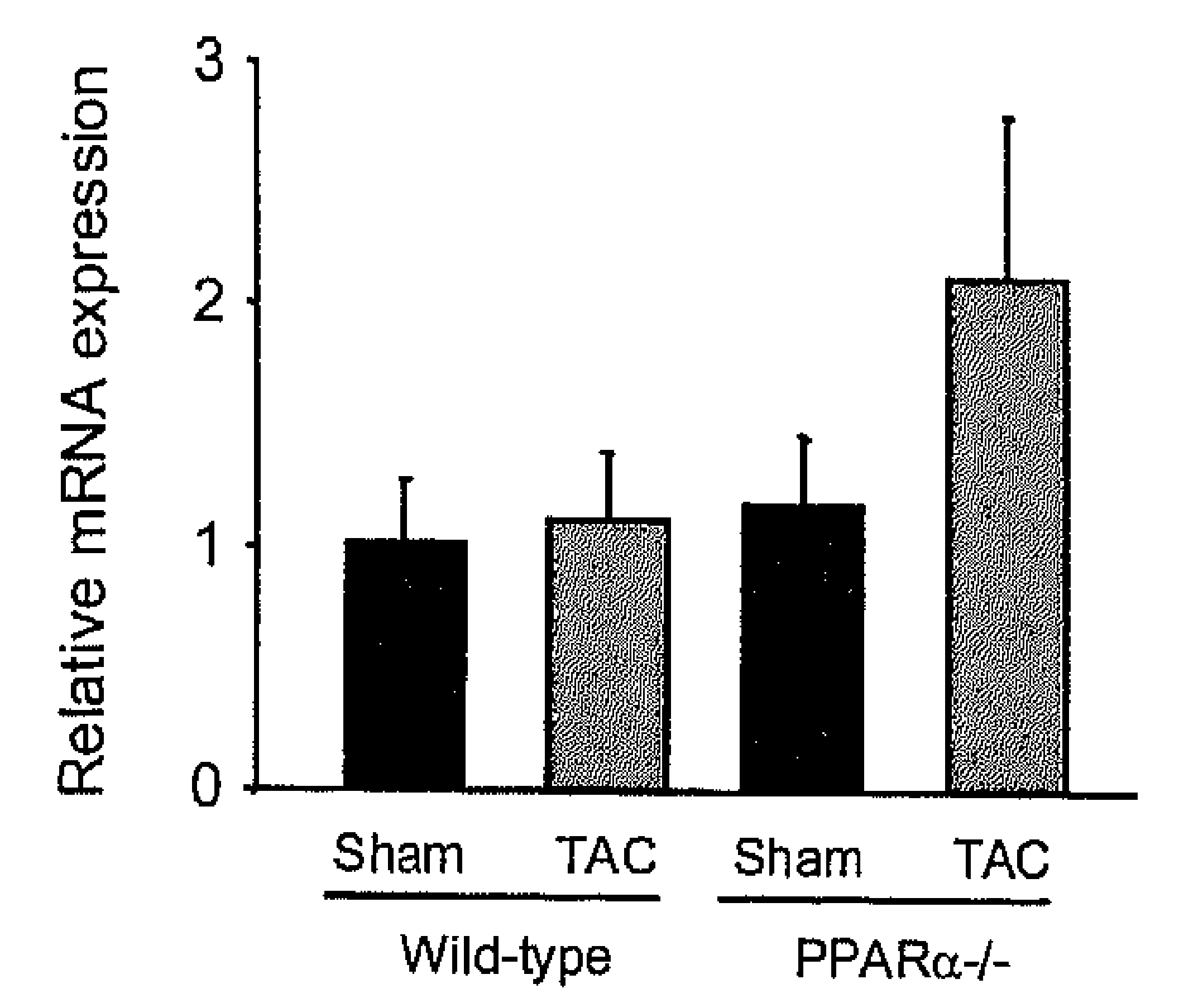

F. MCP-1

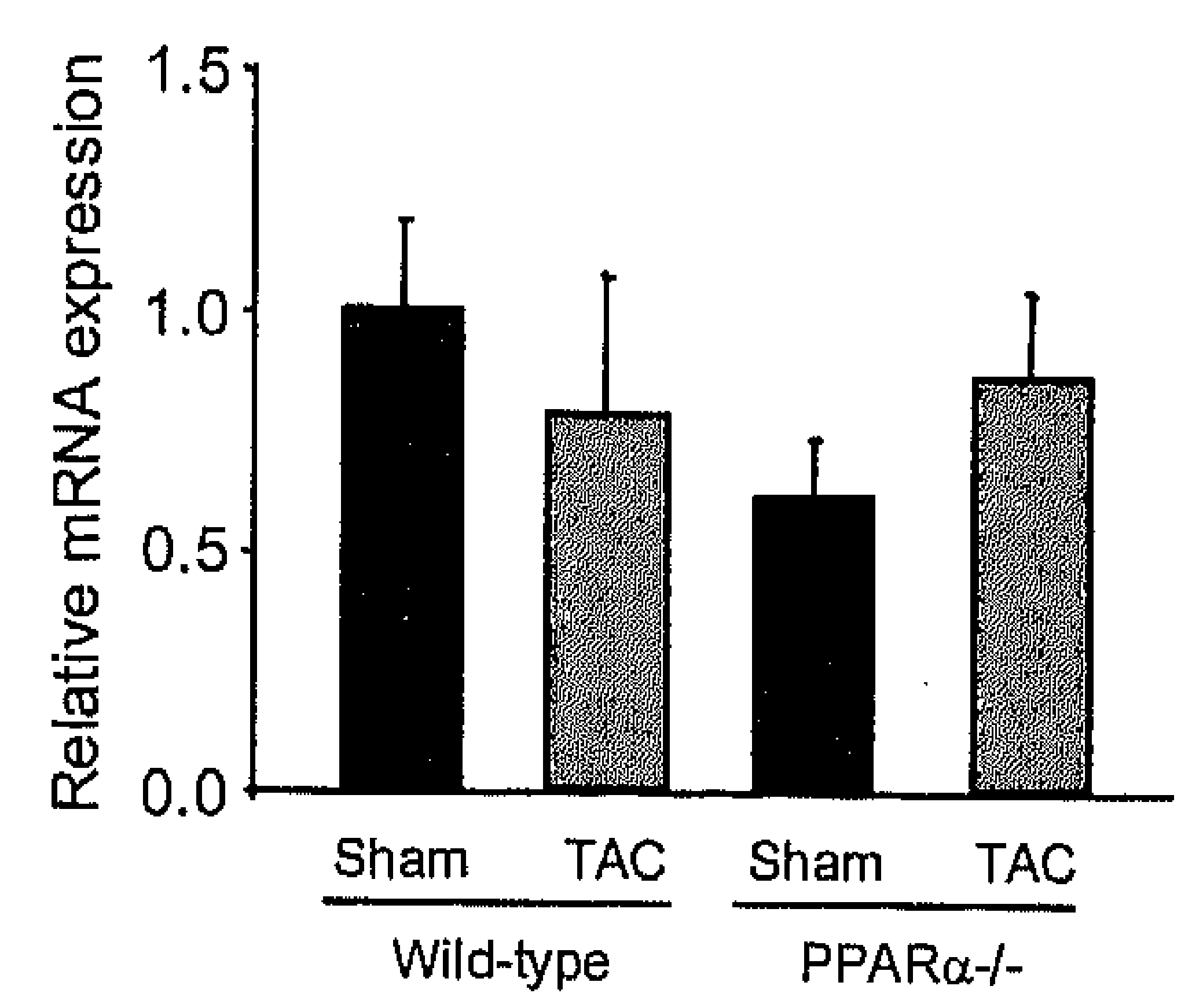


G. Col1

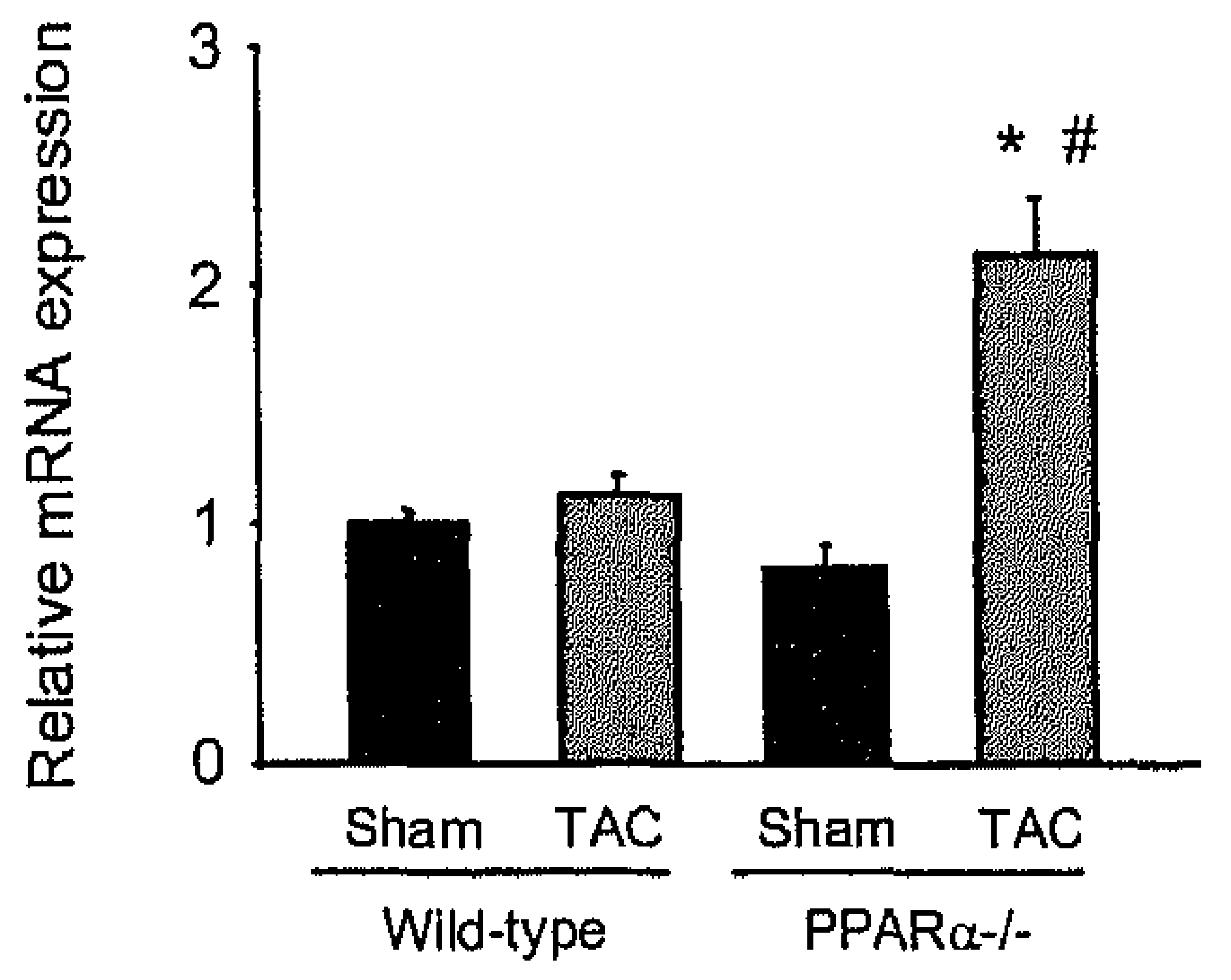

I. Acsl1

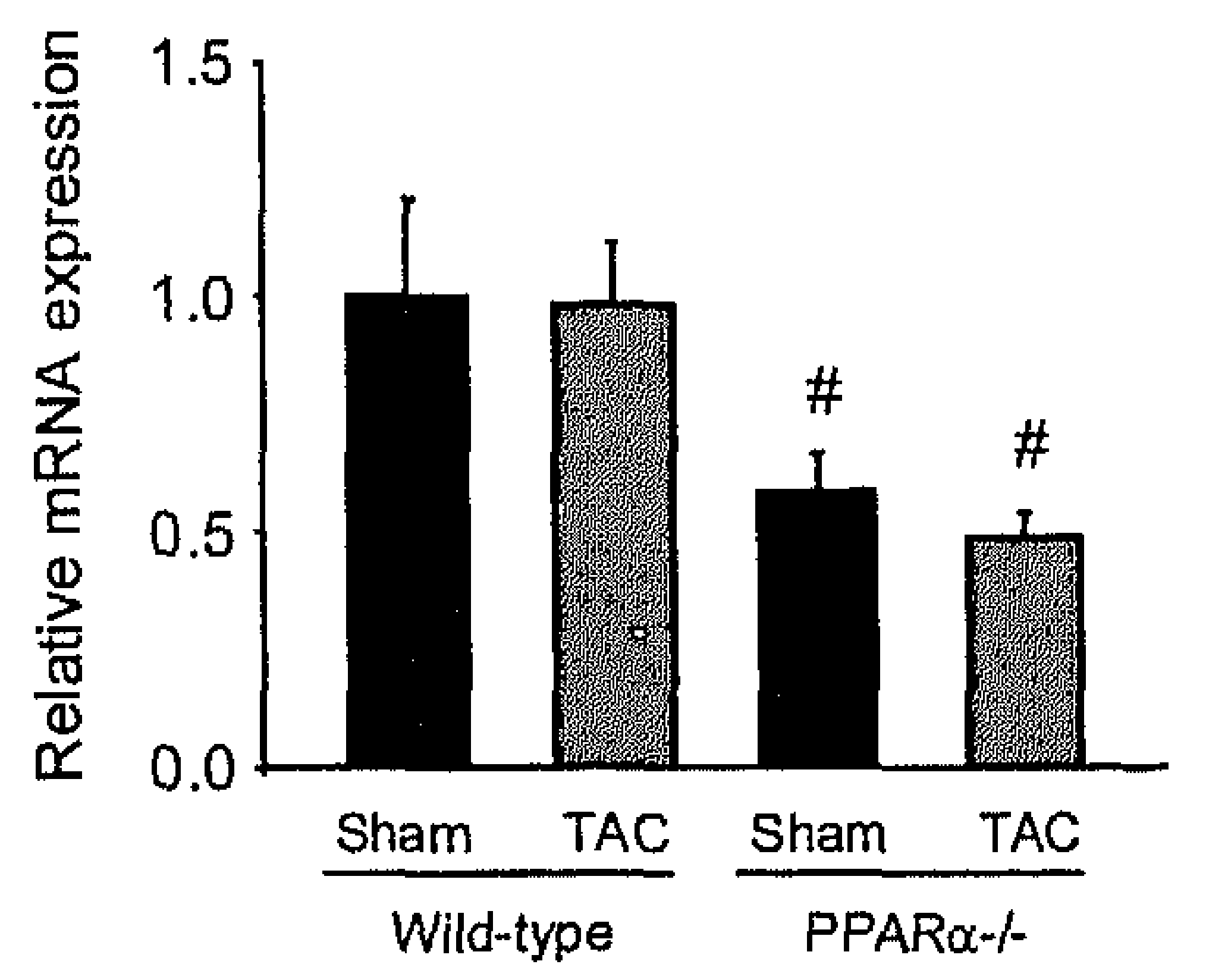

H. MMP-2

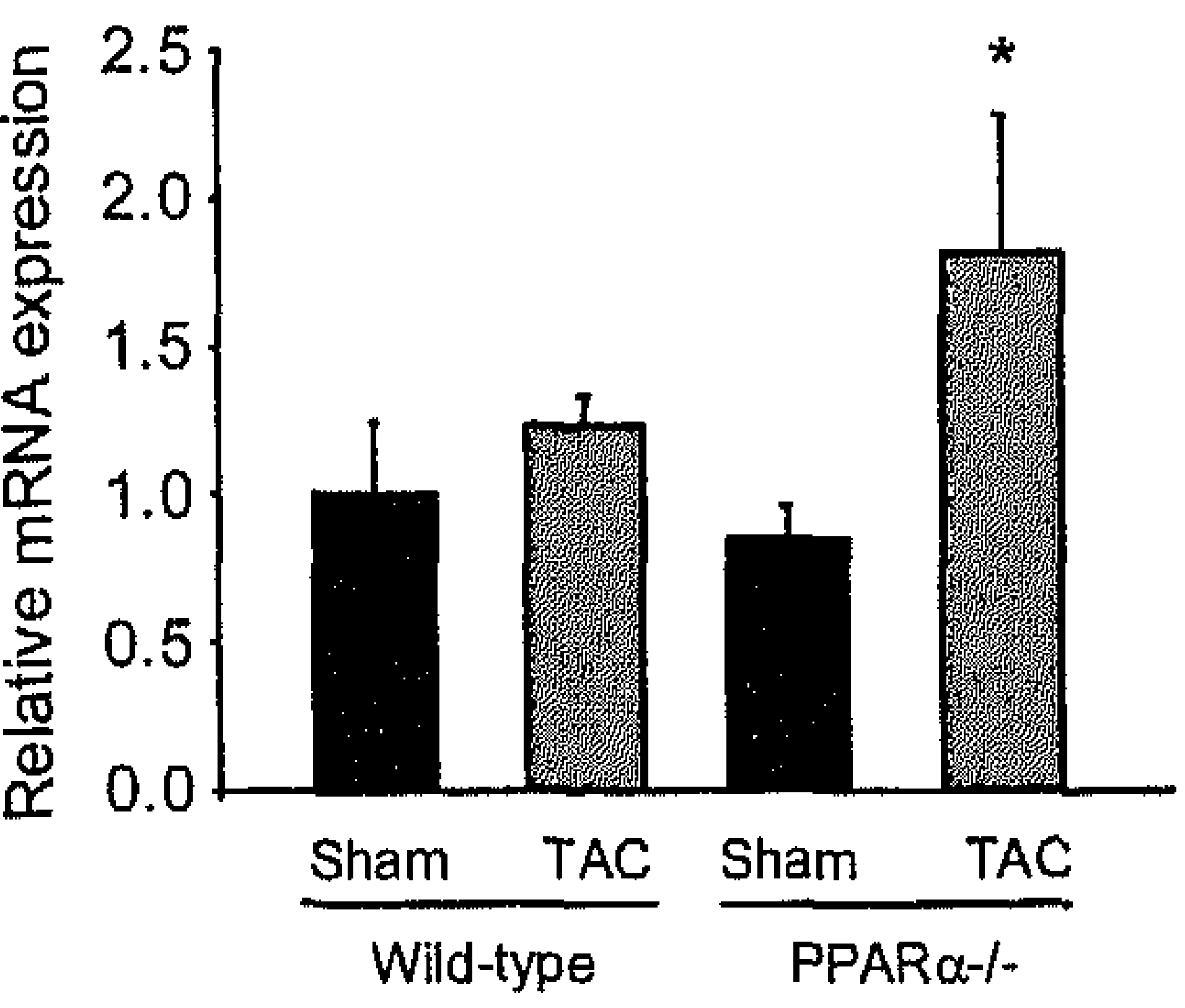

J. Hadha

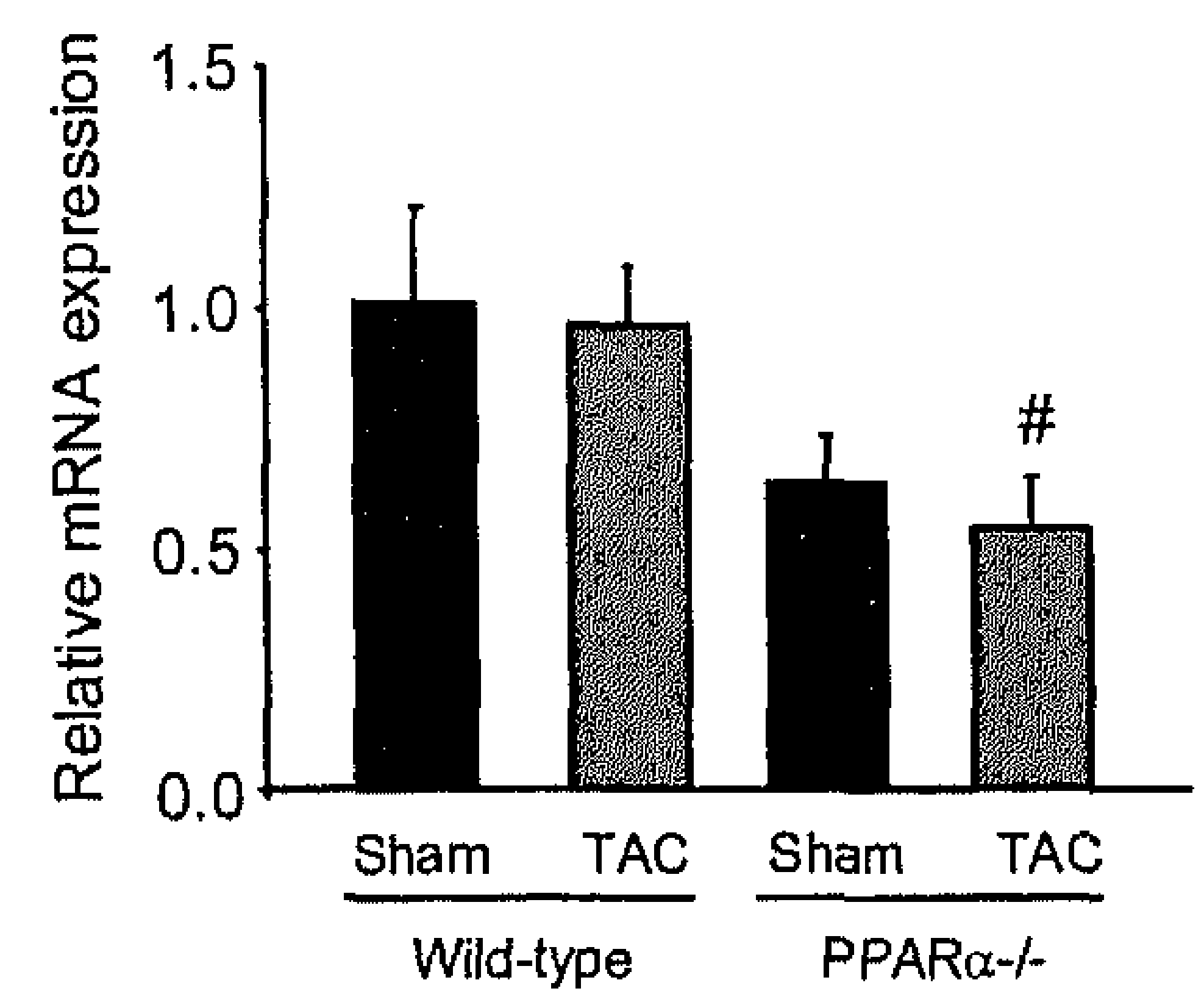

Figure 4. Distinct gene expression in hearts of sham-operated and TAC-subjected wild-type and PPAR $\alpha-/-$ mice. mRNA levels were assessed in left ventricular tissue 28 days after TAC or sham-operation. qPCR assays were performed to determine the expression level of hypertrophic (A: ANF, B: $\alpha-S K A$ ), inflammatory (C: IL-6, D: TNF- $\alpha$, E: COX-2, F: MCP-1), fibrotic (G: Coll and H: MMP-2) and metabolic (I: Acs1 1, J: Hadha) marker genes. Results are expressed as mean \pm SEM of $n=6$ per experimental group. * indicates statistically significant difference compared to corresponding sham operated animals $(\mathrm{p}<0.05)$. \# indicates statistically significant difference compared to corresponding wild-type animals $(\mathrm{p}<0.05)$.

already compromised under basal, unstressed conditions as reflected by a reduced fractional shortening ${ }^{185,186}$, or a decline in developed pressure of ex vivo perfused hearts. ${ }^{185}$ Other studies reported no change in baseline hemodynamic performance of ex vivo perfused PPAR $\alpha-/-$ hearts. $^{30,187}$ However, when the workload was increased acutely the myocardial ATP content dropped and cardiac function rapidly deteriorated. ${ }^{187}$ Consistent with this, we show that the imposition of an acute stress in situ via dobutamine infusion, unveils differences in cardiac function between sham-operated PPAR $\alpha-/$ - and wild-type mice.

The oxidation of fatty acids (FA) forms the principal source of ATP for the healthy, beating heart. ${ }^{52}$ Confirming the importance of PPAR $\alpha$ in the transcriptional control of cardiac FA 
oxidation capacity, the expression of rate determining enzymes involved in FA activation (Acs11) and mitochondrial $\beta$-oxidation (Hadha) is reduced in the hearts of sham-operated PPAR $\alpha-/$ mice (see figure 4). Accordingly, it is quite conceivable that loss of PPAR $\alpha$ compromises the energy generating capacity of the cardiac muscle and may explain some of the dobutamine stress-induced functional abnormalities observed in the sham-operated PPAR $\alpha-/$ - mice.

The compromised cardiac function in PPAR $\alpha-/$ - mice has not only been attributed to disturbances in energy production ${ }^{187}$, but also to diminished $\beta$-adrenergic responsiveness. ${ }^{185}$ The blunted dobutamine response as observed in the present study would fit with the latter notion. Finally, an increased vulnerability to oxidative stress has been invoked as a cause of functional abnormalities. ${ }^{186}$ It remains to be established, however, to what extent each of these mechanisms contributes to the impairment of cardiac function under basal condition or after imposition of an acute or chronic stress.

\section{CARDIAC HYPERTROPHY IN PPAR $\alpha-/-$ MICE}

In the present study young male PPAR $\alpha-/$ and wild-type mice were subjected to a relatively mild chronic increase in afterload as reflected by the modest pressure-gradient created by the TAC $(35-40 \mathrm{~mm} \mathrm{Hg})$. The chronic increase in workload led to a marked functional impairment of the heart in the PPAR $\alpha / /$ - mice as shown by the decline in ejection fraction and fractional shortening and the reduced LV systolic pressure and $+\mathrm{dP} / \mathrm{dt}_{\max }$. The differences in contractility became even more pronounced when the TAC mice were subjected to a dobutamine stress test.

Interestingly, in sham-operated PPAR $\alpha-/$ - mice CSA tended to be increased despite the fact that $L V$ wall thickness is unchanged. Very recently, Guellich and colleagues ${ }^{186}$ also reported that CSA was enhanced in 9 month old PPAR $\alpha-/$ - mice, whereas LV weight was not affected. They argued that this was due to loss of cardiomyocytes secondary to the increased oxidative stress to which the hearts of PPAR $\alpha-/$ - mice are exposed. Strikingly, it has also been reported that activation, instead of lack, of PPAR $\alpha$ is associated with cardiomyocyte necrosis, secondary to enhanced oxidative stress. ${ }^{188}$ In the current study, we measured the expression of the putative PPAR-responsive gene Heme Oxygenase- $1^{189}$, but found no effect of genotype or TAC on the cardiac mRNA level of this anti-oxidant enzyme (data not shown). An alternative explanation could be that the number of muscle cells is lower due to effect of PPAR $\alpha$ on the proliferation of cardiomyocytes during cardiac development and maturation. It is of note that the tendency to increased cardiomyocyte size is not associated with hallmarks of pathological cardiac hypertrophy, such the shift in Myosin Heavy Chain (MHC $\alpha \rightarrow M H C \beta)$ protein isoform ${ }^{186}$, or increased mRNA expression of ANF or $\alpha$-SKA (see figure 4).

The chronic imposition of pressure overload for 4 weeks led to a more pronounced cardiac hypertrophy in mice lacking PPAR $\alpha$, as shown by the substantial increased LV mass and the 
incraas: in LV wall thickness fehowardingraphy. After TAC. CSA also tended to be larger in PPAR(t-i- mice than in wild-type mice (p 0.081). It should he noted, however. that the

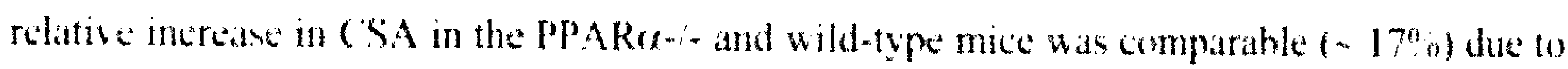
the late that. as discused carlier. (SA was somewhat higger in shammperated PPARerto mice compared to wild-type mice. Nonetheless. in line with the larger increase in cardiat mass after TAC, the rise in cardiac ANF and a-SK A expression was more promounced in the PPARa--/ mice, which also puints 10 an enhanced hypertrophic response in the PPARex-1mice. The more pronounced hypertrophic response cannot be explained by differences in

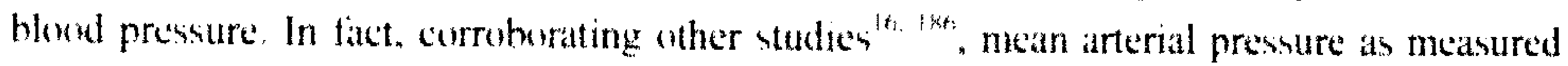

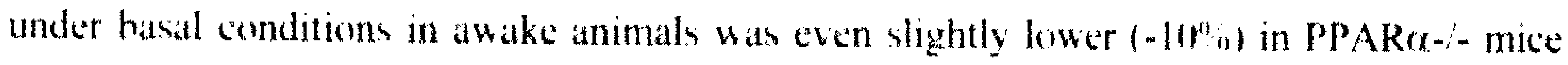
than in wild-type anmals data not shown. Collectively, these lindings indicate that the absence of PPARe enhances pathological bypertrophy of the heart after impesition of pressure overload.

This conclusion is supported by earlier studies showing that actration of PPARa via the administration of isoform specitic ligands blunts the hypertrophic response both of the heart in situ and in isolated cardiomyocytes. For example. fenofibrate was able to reduce endothelin-1 induced cardiomyocyte enlargement and protein synthesis." In the in vivo setting, treatment with fenotibrate normalised cardiac dimensions and fractional shortening in Dahl salt-sensitive rats and in mice subjected to TAC. ${ }^{134 .} 193$ Consistent with previous results in mildly hypertrophic hearts of rats subjected to abdominal aortic constriction ${ }^{(2)}$ the TAC. induced cardiac hypertrophy in wild-type mice was not associated with a diminished expression of $\mathrm{FA}$ handling genes. Likewise, in the myocardium of PPAR $\alpha-/$ - mice the already reduced expression of these genes did not diminish further after TAC. It cannot be excluded that the chronic increase in afterload may gradually exhaust the already compromised energygenerating capacity of the cardiac muscle cells of the PPAR $\alpha-$ - mice and, in this way, contribute to the observed cardiomyopathic changes.

The beneficial effect of PPAR $\alpha$ activation on $L V$ remodelling has also been attributed to the interference of PPAR $\alpha$ with pro-inflammatory pathways converging on activator protein-1 (AP-1) and nuclear factor- $\mathrm{kB}(\mathrm{NF}-\mathrm{kB})$, which are activated during hypertrophy. ${ }^{2}, 1$ th $\mathrm{PPAR} \alpha$ activation was indeed assceiated with a decrease in both AP-1 and NF-kB DNA-binding activity in FT-1 treated neonatal rat cardiomyocytes and angiotensin II (AngII) infused rats, respectively. 2\% " By inference, this would imply that in hearts devoid of PPARa inflammatory signalling pathways become more aetivated. Indeed, the current findings show that pro-inflammatory cytokines like $11 .-6$. INF- $\alpha$ and the inducible form of eyclo-oxygenase (C( $)$-2). the expression of which are under control of $\mathrm{NF}-\mathrm{kB}$, are more upregulated in the hearts of PPARo-/- mice subjected to TAC than in wild-type mice. It has previously been demonstrated that activation of $\mathrm{NF}-\mathrm{kl} 3$ is associated with an increased hypertrophic growth response. ${ }^{14} 19$ Moreover, targeted deletion or pharmacological inhibition of $\mathrm{NF}-\mathrm{kB}$, and hence 
the inflammatory response, attenuated cardiac hypertrophy in vivo. ${ }^{98,}{ }^{99}$ Furthermore, the expression of markers of extracellular matrix (ECM) remodelling, i.e., Col1 and MMP-2, was enhanced in PPAR $\alpha-/-$ mice. Sirius red staining, however, did not show changes in total collagen content in the affected hearts suggesting that, despite the enhanced ECM remodelling, collagen synthesis was still in balance with its degradation. The mRNA findings indicate that, in addition to interfering with the inflammatory pathway, PPAR $\alpha$ modulates ECM remodelling. This notion fits with the observation that the in vivo administration of synthetic PPAR $\alpha$ ligands to rats attenuates AngII induced cardiac fibrosis. ${ }^{106}$

\section{CONCLUSION}

The present findings show that the absence of PPAR $\alpha$ results in a more pronounced hypertrophic growth response and signs of functional deterioration, associated with an enhanced expression of markers of inflammation and extracellular matrix remodelling. By inference, this implies that in the normal heart PPAR $\alpha$ attenuates pathological cardiac remodelling and, hence, mitigates the functional decline following pressure overload of the affected myocardium.

\section{ACKNOWLEDGEMENTS}

Netherlands Organization for Scientific Research (912-04-017); EUGeneHeart (EU-FP6 grant LSHM-CT-2005-018833). 


\title{
5
}

\section{TRANSCRIPTOMIC ANALYSIS OF PPAR $\alpha$-DEPENDENT}

\section{ALTERATIONS DURING CARDIAC HYPERTROPHY}

\author{
Pascal J.H. Smeets, Heleen M. de Vogel-van den Bosch, Peter H. M. Willemsen, Fons
}

Stassen, Torik Ayoubi, Ger J. van der Vusse and Marc van Bilsen

Accepted for publication. Physiological Genomics 2008.

\footnotetext{
ABSTRACT $\mid$ Peroxisome proliferator-activated receptor $\alpha(P P A R \alpha)$ regulates lipid metabolism at the transcriptional level and modulates the expression of genes involved in inflammation, cell proliferation and differentiation. Although PPAR $\alpha$ has been shown to mitigate cardiac hypertrophy, knowledge about underlying mechanisms and nature of signalling pathways involved is fragmentary and incomplete. The aim of this study was to identify the processes and signalling pathways regulated by PPAR $\alpha$ in hearts challenged by a chronic pressure overload by means of whole genome transcriptomic analysis. Thereto, PPAR $\alpha-/$ - and wildtype mice were subjected to transverse aortic constriction (TAC) for 28 days and left ventricular gene expression profile was determined using Affymetrix GeneChip Mouse Genome 4302.0 arrays containing over 45,000 probe sets. In unchallenged hearts, the mere lack of PPAR $\alpha$ resulted in 821 differentially expressed genes, many of which were related to lipid metabolism and immune response. TAC resulted in a more pronounced cardiac hypertrophy and more extensive changes in gene expression (1910 and 312 differentially expressed genes, respectively) in PPAR $\alpha-/$ - mice than in wild-type mice. Many of the hypertrophy related genes were related to development, signal transduction, actin filament organization, and collagen synthesis. Compared to wild-type hypertrophied hearts, PPAR $\alpha-/-$ hypertrophied hearts revealed enrichment of gene clusters related to extracellular matrix remodelling, immune response, oxidative stress, and inflammatory signalling pathways. The present study demonstrates therefore that, in addition to lipid metabolism, PPAR $\alpha$ is an important modulator of the immune- and inflammatory response in the cardiac muscle.
} 


\section{INTRODUCTION}

Peroxisome proliferator-activated receptor $\alpha$ (PPAR $\alpha, N R 1 C 1)$ is a ligand-activated transcription factor belonging to the nuclear hormone receptor family. ${ }^{21}$ PPAR $\alpha$ is primarily known for its pivotal role in the transcriptional regulation of lipid metabolism. ${ }^{181}$ Together with its dimerization partner RXR, PPAR $\alpha$ binds to cis-regulatory elements, the so-called PPAR-response elements (PPREs), of many genes involved in lipid uptake and metabolism. Via this transactivation mechanism, PPAR $\alpha$. increases the expression of fatty acid (FA)handling genes in tissues with high oxidative capacity, including the cardiac muscle. ${ }^{20}$

In addition, PPAR $\alpha$ has been shown to modulate the expression of genes involved in nonmetabolic processes, such as inflammation ${ }^{42}$, cell proliferation and differentiation ${ }^{191}$, and the response to oxidative stress. ${ }^{189}$ PPAR $\alpha$ is thought to suppress inflammation through interference with components of pro-inflammatory pathways, like nuclear factor- $\mathrm{KB}(\mathrm{NF}-\mathrm{kB})$ and activator protein-1 (AP-1), a process referred to as transrepression. ${ }^{173}$ Currently, it is less clear whether the modulation of cell proliferation involves transactivation or transrepression primarily. In some cases, PPAR $\alpha$-mediated transactivation of cell cycle inhibitors has been demonstrated. ${ }^{192,193}$

Inflammatory processes are likely to play a prominent role in the challenged heart, for instance during cardiac hypertrophy, as supported by the observations that activation of NF$\mathrm{KB}$ is intricately linked to cardiomyocyte hypertrophy ${ }^{15}$ and that mice overexpressing TNF- $\alpha$ develop hypertrophic cardiomyopathy. ${ }^{98}$ Furthermore, fibroblast proliferation, extracellular matrix (ECM) remodelling, and oxidative stress all contribute to the deterioration of cardiac function. ${ }^{194}$ Therefore, in view of the pleiotropic effects of PPAR $\alpha$, it is conceivable that PPAR $\alpha$ modulates tissue remodelling during cardiac hypertrophy. Indeed, treatment of aortabanded rats with the PPAR $\alpha$ ligand fenofibrate has been reported to attenuate cardiac hypertrophy. ${ }^{27}$ Deletion of PPAR $\alpha$ in mice resulted in a normal cardiac function at a young age, but the hearts showed an increased vulnerability under conditions of stress, like $\beta$ adrenergic stimulation, ${ }^{185}$ ischemia-reperfusion ${ }^{65}$ or transverse aortic constriction (TAC). ${ }^{18}$ However, the outcome of studies examining the role of PPAR $\alpha$ during cardiac hypertrophy is not entirely clear as cardiac-specific overexpression of PPAR $\alpha$ resulted in impaired function of the murine heart. ${ }^{29}$

The collective findings suggest that PPAR $\alpha$ plays a decisive role in the development of hypertrophy, affecting the functional outcome of the heart. Unfortunately, information on the nature of PPAR $\alpha$-dependent processes in cardiac hypertrophy is fragmentary and incomplete. Therefore, the primary aim of this study was to identify the processes and signalling pathways regulated by PPAR $\alpha$ in hearts challenged by a chronic pressure overload by means of whole genome transcriptomic analysis. Second, we wanted to gain insight how PPAR $\alpha$ modulates the identified processes, e.g. by transactivation or by transrepression. Thereto, wild-type and 
PPAR $\alpha-/$ - mice were sham-operated or subjected to TAC for 28 days. Left ventricular gene expression profile was determined using Affymetrix GeneChip Mouse Genome 4302.0 arrays containing over 45,000 probe sets (covering over 34,000 mouse genes) to detect PPAR $\alpha$ related differences in cardiac gene expression under basal conditions and after imposition of a sustained hemodynamic stress.

\section{METHODS}

\section{EXPERIMENTAL ANIMALS}

Three-month-old male PPAR $\alpha-/-$ mice $^{174}$ and age-matched wild-type C57B16/J mice (Charles River) were used in this study. The PPAR $\alpha-/$ - mice were back-crossed for more than 10 generations into a pure C57Bl6/J background. Mice were kept on a $12 \mathrm{~h} / 12 \mathrm{~h} \mathrm{light/dark}$ cycle in temperature-controlled rooms and had ad libitum access to water and standard lab-chow (Ssniff R/M-H, Ssniff, Soest, Germany). Animal experiments were approved by the Institutional Animal Care and User Committee of the Maastricht University and compliant with the guidelines of the Guide for the Care and Use of Laboratory Animals (NIH Publication No. 85-23, revised 1996).

\section{PRESSURE OVERLOAD INDUCED HYPERTROPHY}

The surgical procedure of TAC has been previously described. ${ }^{175}$ Briefly, mice were anesthetized with xylazine ( $5 \mathrm{mg} / \mathrm{kg}$ s.c.) and ketamine (100 mg/ $\mathrm{kg}$ i.m.). Anaesthesia was maintained by isoflurane inhalation $(1.5 \%-2.5 \%)$. After opening the chest, the transverse aorta of PPAR $\alpha-1-(n=4)$ and wild-type $(n=4)$ mice was ligated between the truncus brachiocephalicus and the left common carotid artery by tying a 6-0 silk suture against a 25 gauge needle. Sham-operated PPAR $\alpha-/-(n=4)$ and wild-type $(n=4)$ mice underwent the same procedure without ligation of the aorta. Animals recovered at $30^{\circ} \mathrm{C}$ for $24 \mathrm{~h}$ and were injected with the analgesic buprenorphine (Temgesic; $0.1 \mathrm{mg} / \mathrm{kg}$ s.c.). Mice were sacrificed 28 days after TAC or sham operation. The heart was excised, rinsed and atria were removed. Hypertrophy was assessed by determining total ventricular weight, which was normalized to body weight or tibia length. Subsequently, the LV was separated from the right ventricle and snap-frozen for RNA analysis.

\section{RNA EXTRACTION, LABELLING AND HYBRIDIZATION}

LV tissue was homogenised using an UltraTurrax (Janke \& Kunkel, Staufen, Germany) and total RNA was isolated with TRI reagent (Sigma) according to manufacturer's instructions and complemented with an additional wash step of $70 \%$ ethanol to increase the purity of the RNA. For all RNA samples quantity and purity were determined using the Nanodrop ND1000 spectrophotometer (Nanodrop Technologies, Wilmington, USA) and RNA integrity was 
determined using the Bioanalyzer 2100 (Agilent Technologies, Palo Alto, USA). Five $\mu \mathrm{g}$ of total RNA was amplified using the One-Cycle cDNA synthesis and target labelling kit according to manufacturer's instructions (Affymetrix, Santa Clara, USA). Biotin labelled target complementary RNA (cRNA) was fractionated and hybridized to Affymetrix GeneChip Mouse Genome 4302.0 according to manufacturer's instructions. On this chip, 45,101 probe sets analyse the expression of over 39,000 transcripts representing over 34,000 known genes.

\section{MICROARRAY ANALYSIS}

Affymetrix GeneChip Operating Software (GCOS, version 1.4) was used to analyze image data. For each transcript represented on the array by a probe set, the expression algorithm computed the detection call (present, absent, or marginal), the detection p-value, and the signal which is an average intensity value for each probe set. This resulted in a table with 45,101 probe sets. For each probe set the detection calls of the 16 arrays were used to determine whether the probe set was reliably detected and selected for further analysis. ${ }^{195}$ To this end, for every 2 groups of 4 arrays that were compared, the probe had to be present in at least 3 samples of one of these two groups. In addition, only probe sets with average signal intensity higher than 100 in one of the two groups compared was selected for further analysis. Finally, the over- or underexpression of the remaining probe sets in one of the two groups was analyzed using the class comparison method in BRB ArrayTools software package applying a univariate test with random variance model. BRB ArrayTools is developed by the Biometric Research Branch of the US National Cancer Institute (http://linus.nci.nih.gov/BRBArrayTools.html). The data set was submitted to the NCBI Gene Expression Omnibus (GEO; http://www.ncbi.nih.gov/projects/geo) with the accession number GSE12337.

To search for enrichment of specific biological processes the genes showing significant differential expression between the two groups $(p<0.0125)$ were classified into functional groups using DAVID [Database for Annotation, Visualization and Integrated Discovery] according to Gene Ontology (Biological Process). ${ }^{196}$ As input, the differentially regulated probe sets (up- as well as downregulated; upregulated only; downregulated only) from each comparison were used and analysed to all probe sets selected on call and signal intensity of the appropriate comparison. As output, enriched processes (GOTERM) with $p<0.05$ were generated and the differentially expressed probe sets for each process were listed. In addition, related biological processes were clustered using the functional annotation clustering algorithms of DAVID. For each clustered process this results in an Enrichment Score, being the - $\log$ value of the geometric mean of the member's p-values.

Additionally, biological interaction network maps for each comparison were generated through the use of Ingenuity Pathways Analysis (IPA, Ingenuity ${ }^{\circledR}$ Systems, www.ingenuity.com). This bioinformatics tool is based on the Ingenuity Pathways Knowledge Base. This large database of biological networks has been created from relationships between proteins, genes, complexes, cells, tissues, drugs, and diseases, obtained 
from over 200,000 peer reviewed scientific publications. All differentially regulated probe sets with their corresponding fold change for each comparison were used as input in IPA.

\section{QPCR ANALYSIS}

To assess the degree of hypertrophy and to verify the microarray data, qPCR was performed on markers of hypertrophy, inflammation, and metabolism. $500 \mathrm{ng}$ total RNA was used for DNaseI treatment (Sigma) and subsequent cDNA synthesis (Iscript cDNA synthesis kit, Biorad Inc., Hercules, CA, USA). qPCR assays were performed as previously described. ${ }^{23}$ Primers used for analysis are given in Supplementary Table I. Results were normalised to the geometric mean of three reference genes, i.e., cyclophilin A (CycloA), acidic ribosomal phosphoprotein P0 (ARBP), and hypoxanthine guanine phosphoribosyl transferase (HPRT) according to Vandesompele et al. ${ }^{179}$ using qBase software ${ }^{180}$ as described before. ${ }^{18}$ The expression of these reference genes was not affected by genotype and intervention.

\section{STATISTICS}

Results from ventricular weight measurements and $\mathrm{qPCR}$ analysis are presented as mean \pm SEM. Data were analysed by one-way ANOVA and contrast analysis for multiple comparisons using SPSS 12 software (SPSS Inc.). A p-value of less than 0.05 was considered to be statistically significant.

\section{RESULTS AND DISCUSSION}

\section{CARDIAC HYPERTROPHIC RESPONSE OF PPAR $\alpha-/$ - AND WILD-TYPE MICE TO TAC}

In unstressed, sham-operated PPAR $\alpha-/$ - and wild-type mice no differences in ventricular weight (VW) were apparent (Table 1). After 28 days of TAC, VW was substantially increased in both PPAR $\alpha-/-$ and wild-type mice. The relative increase in $V W$ in response to

Table 1. Degree of hypertrophy in wild-type and PPAR $\alpha-/-$ mice 28 days after TAC or sham-operation.

\begin{tabular}{lcccc}
\hline & \multicolumn{2}{c}{ Wild-type } & \multicolumn{2}{c}{ PPAR $\alpha /-$} \\
\cline { 2 - 5 } & Sham & TAC & Sham & TAC \\
Ventricular weight (VW), mg & $114 \pm 5$ & $132 \pm 2^{*}$ & $126 \pm 6$ & $176 \pm 15^{*} \#$ \\
VW/BW, mg/g & $4.2 \pm 0.1$ & $5.0 \pm 0.2^{*}$ & $4.3 \pm 0.2$ & $6.2 \pm 0.3^{*} \#$ \\
VW/TL, mg/mm & $6.6 \pm 0.3$ & $7.5 \pm 0.2^{*}$ & $7.2 \pm 0.4$ & $10.4 \pm 0.8^{*} \#$ \\
ANF mRNA expression, FC & $1.0 \pm 0.0$ & $2.1 \pm 0.3^{*}$ & $1.2 \pm 0.2$ & $10.6 \pm 2.2^{*} \#$ \\
$\alpha-S K A$ mRNA expression, FC & $1.0 \pm 0.3$ & $2.4 \pm 0.8$ & $0.5 \pm 0.1$ & $6.7 \pm 1.4^{*} \#$ \\
\hline * indicates statistically significant difference compared to corresponding sham-operated animals $(\mathrm{p}<0.05$ ). \\
\# indicates statistically significant difference compared to corresponding wild-type animals (p<0.05) \\
n=4 animals per group; FC=fold change
\end{tabular}


TAC was more pronounced in PPAR $\alpha-/-$ mice $(+40 \%)$ than in wild-type mice $(+16 \%)$. The difference persisted when VW was normalised to body weight or to tibia length. Consistent with this, qPCR analysis showed that the expression of the hypertrophic marker genes ANF and $\alpha$-skeletal actin ( $\alpha$-SKA) increased after TAC in wild-type and PPAR $\alpha-/$ - mice, and that the increase was significantly higher in PPAR $\alpha-/-$ mice. These collective data point to a more pronounced hypertrophic response in the PPAR $\alpha-/$ - mice compared to wild-type, suggesting that the absence of PPAR $\alpha$ is unfavourable for the pressure overloaded heart.

\section{TRANSCRIPTOMIC ANALYSIS}

\section{QPCR VALIDATION OF MICRO-ARRAY ANALYSIS}

Gene expression profiling was performed on left ventricular tissue samples of 4 mice per experimental group using Affymetrix GeneChip Mouse Genome 4302.0 arrays. In each experimental group, approximately 17,000 filtered probe sets were selected on detection call and signal intensity (Fig. 1A). To validate the micro-array data, eight genes that were either up- or downregulated in the micro-array analysis as a function of genotype or TAC, were also determined by $\mathrm{qPCR}$. The selected genes were related to metabolism (pyruvate dehydrogenase kinase-4, PDK4; $\beta$-oxidation enzyme hydroxyacyl-coenzyme A dehydrogenase, Hadha; acyl coenzyme A (CoA) oxidase, AOX; acylcoA synthetase, Acsl1), ECM remodelling (matrix-metalloproteinase-2, MMP-2, collagenase-3, Col3), and inflammation (cyclo-oxygenase-2, COX-2 and interleukin-6, IL6). Scatter plot analysis of the relative changes in expression as determined by $\mathrm{qPCR}$ and micro-analysis, respectively, revealed a good correlation between the micro-array and $\mathrm{QPCR}$ data, thereby confirming the validity of the micro-array data-set (Fig. 2).

\section{BASAL DIFFERENCES BETWEEN PPAR K-/ AND WILD-TYPE MICE (COMPARISON 1)}

In the left ventricular tissue of sham-operated, un-stressed mice already 821 probe sets were found to be differentially regulated between PPAR $\alpha-/$ - and wild-type animals (Fig. 1A). Of these 821 probe sets, 458 were upregulated and 363 downregulated (Fig. 1B). To assess the function of the differentially regulated probe sets, overrepresented Gene Ontology (GO) classes were determined using DAVID. Using this unbiased approach biological processes affected by PPAR $\alpha$ were identified (Supplementary Table II). In table 2 these processes are summarized along with the other three comparisons. The annotated clusters in this table are listed alphabetically. For the purpose of comparison, the enrichment scores in Table 2 are ranked with 1 being the highest enrichment score. The individual genes belonging to the clustered process are provided in Supplementary Table III. When comparing sham-operated PPAR $\alpha-/$ - mice and wild-type mice by far the most prominently enriched biological processes in the heart were lipid metabolism and defence mechanisms with enrichment scores of 7.63 and 6.38, respectively (Supplementary Tables II and III). 
A.

\begin{tabular}{|c|c|c|}
\hline $\begin{array}{l}\text { Comparison 1: } \\
\text { PPAR } \alpha-/- \text { sham vs. } \\
\text { wild-type sham }\end{array}$ & $\begin{array}{l}\text { Filtered probesets } \\
\qquad 17086\end{array}$ & $\begin{array}{c}\text { Differentially regulated } \\
\text { probesets } \\
821\end{array}$ \\
\hline $\begin{array}{l}\text { Comparison 2: } \\
\text { wild-type TAC vs. } \\
\text { wild-type sham }\end{array}$ & $\begin{array}{l}\text { Filtered probesets } \\
\qquad 16664\end{array}$ & $\begin{array}{l}\text { Differentially regulated } \\
\text { probesets } \\
312\end{array}$ \\
\hline $\begin{array}{l}\text { Comparison 3: } \\
\text { PPAR } \alpha /- \text { TAC vs. } \\
\text { PPAR } \alpha-/ \text { sham }\end{array}$ & $\begin{array}{l}\text { Filtered probesets } \\
\qquad 17550\end{array}$ & $\begin{array}{c}\text { Differentially regulated } \\
\text { probesets } \\
1910\end{array}$ \\
\hline $\begin{array}{c}\text { Comparison 4: } \\
\text { PPAR } \alpha-/- \text { TAC vs. } \\
\text { wild-type TAC }\end{array}$ & $\begin{array}{l}\text { Filtered probesets } \\
\qquad 17259\end{array}$ & $\begin{array}{c}\text { Differentially regulated } \\
\text { probesets } \\
1831\end{array}$ \\
\hline
\end{tabular}

B.

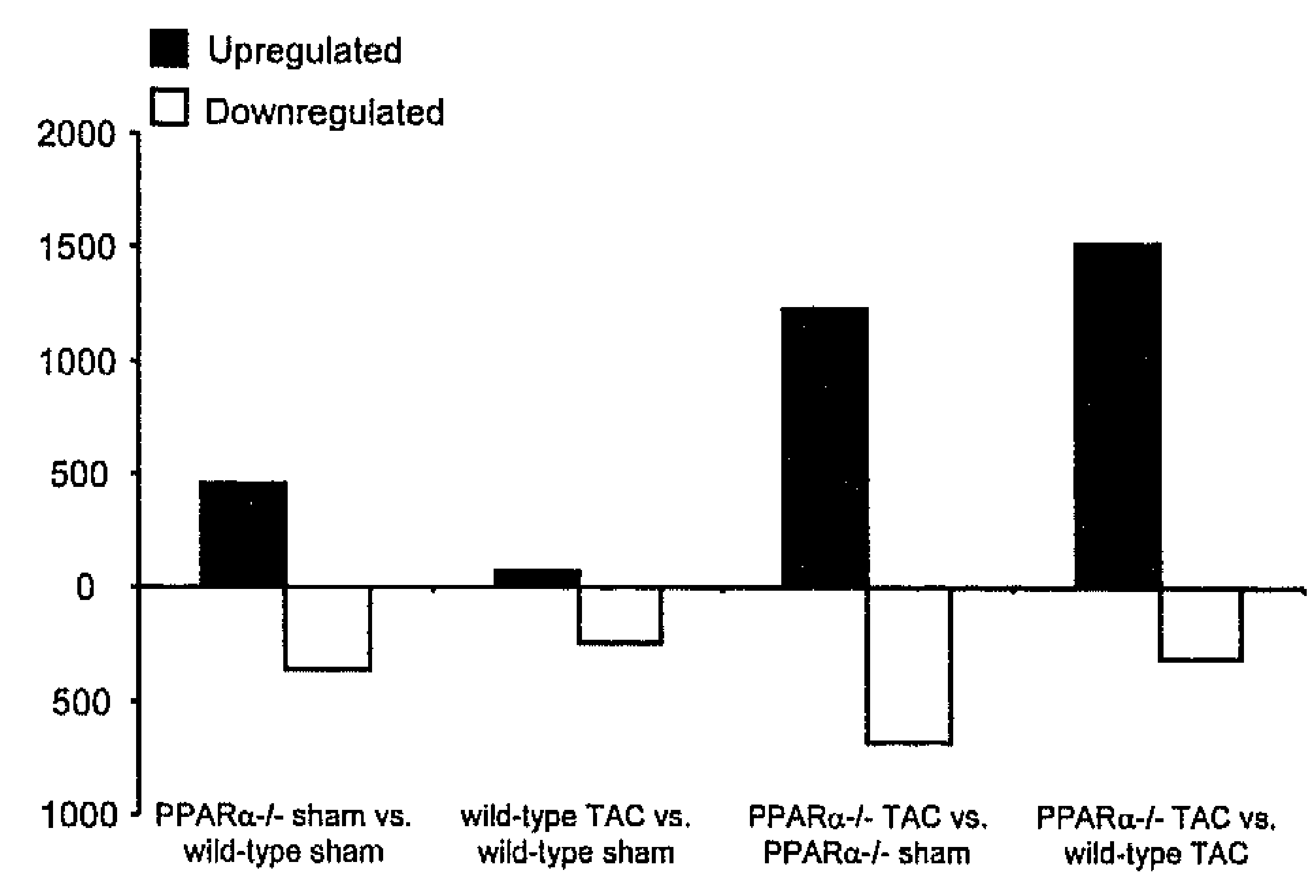

Figure 1. Number of differentially regulated probe sets for the four distinct comparisons after each step of the selection procedure (Panel A) and the number of probe sets up- or downregulated in each comparison (Panel B).

The overrepresentation of genes involved in lipid metabolism is in line with the notion that $\operatorname{PPAR} \alpha$ is a major regulator of genes involved in cardiac lipid metabolism and that PPAR $\alpha-/-$ mice show an impaired fatty acid catabolism. ${ }^{16,20,181}$ Indeed, this cluster consisted primarily of downregulated genes, that are involved in intracellular fatty acid transport (e.g. cytoplasmic fatty acid-binding protein, FABP) and metabolism (e.g Acsll; mitochondrial carnitine palmitoyl transferase I, mCPT-I, ) and confirms that PPAR $\alpha$ plays an important role in the transactivation of these genes in the cardiac muscle.

The annotation cluster "defence mechanisms" mainly comprises genes related to antigen presentation and processing (histocompatibility-related) and the immune response (complement system, interferons, chemokines). The fact that these genes are upregulated in the hearts of PPAR $\alpha-/-$ mice is indicative of the transrepression activity of PPAR $\alpha$ in these processes. In this respect it is worthy to note that previous investigations revealed a functional 
relationship between PPAR $\alpha$ and immune response. ${ }^{197,}{ }^{198}$ PPAR $\alpha$ was found to repress the host defence in the small intestine. ${ }^{198}$ The latter finding correlates well with the present GOanalysis indicating that in the cardiac context lack of PPAR $\alpha$ leads to enhanced expression of genes involved in cardiac immune response.

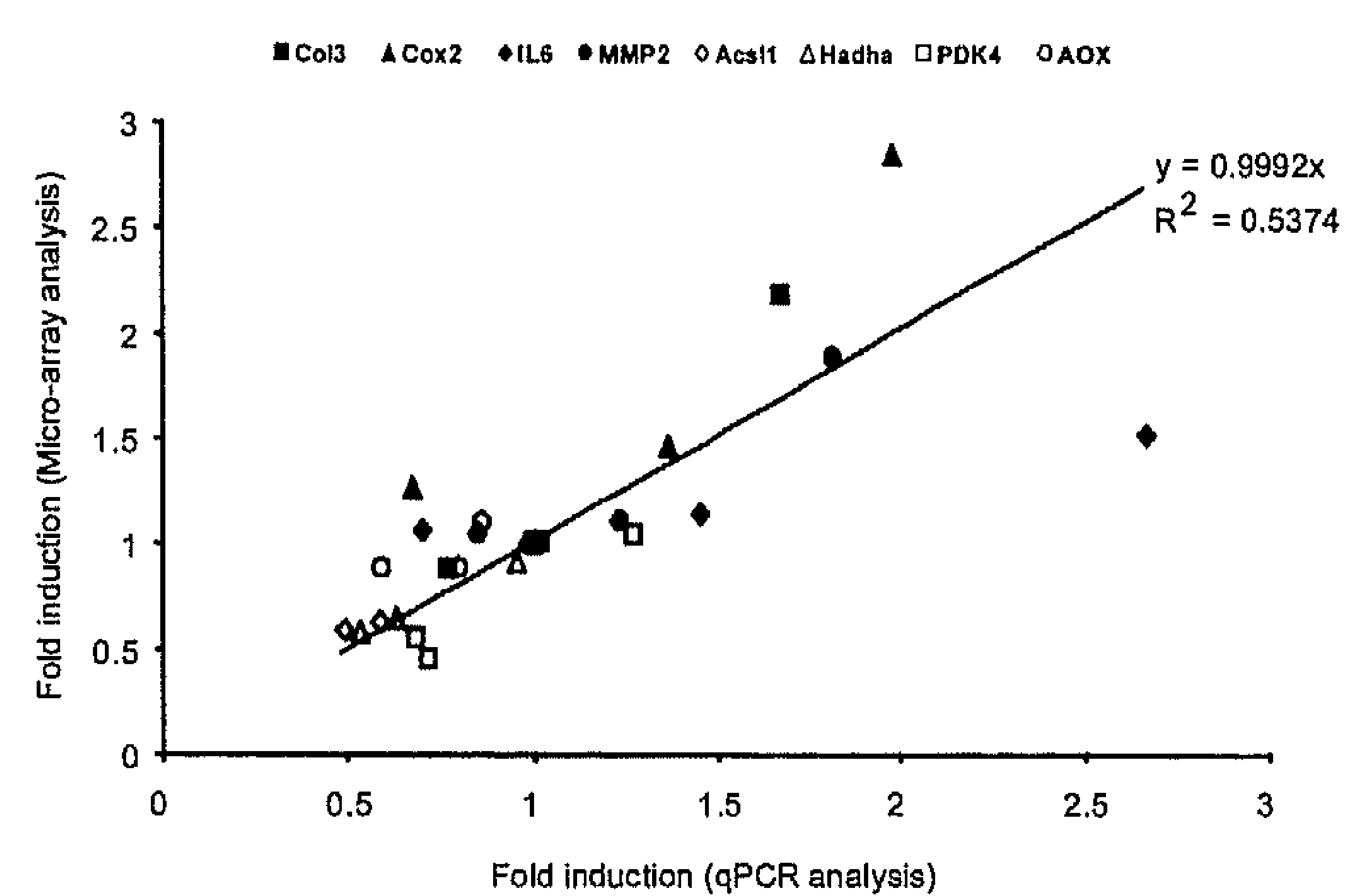

Figure 2. Scatter plot of relative changes in gene expression as determined by microarray analysis and by $q P C R$. Eight genes were analysed: the metabolic marker genes pyruvate dehydrogenase kinase-4 (PDK4), hydroxy-acyl CoA dehydrogenase (Hadha), acyl COA oxidase (AOX) and acyl CoA. synthetase (Acsll) and the extracellular matrix (ECM) and inflammatory marker genes cyclooxygenase-2 (COX-2), matrix metalloproteinase-2 (MMP-2), Interleukin-6 (IL6) and Collagen-3 (Col3), Each symbol represents the fold change of the respective gene for one of the four comparisons investigated.

To explore in more detail the role of PPAR $\alpha$ in the murine heart, biological interaction networks of each comparison were constructed using Ingenuity Pathways Analysis (IPA). In Supplementary Figure 1A the merged biological networks in sham-operated PPAR $\alpha-/$ - mice compared to wild-type animals are shown. In line with the notion that PPAR $\alpha$ regulates cardiac lipid homeostasis, many downregulated genes involved in lipid metabolism are directly linked to PPAR $\alpha$. It is of interest to note that many differentially regulated genes connections are linked to NF-kB indicating that many of the effects identified in unstressed hearts of PPAR $\alpha$ deficient mice are mediated via the PPAR $\alpha-N F-\kappa B$ axis. At least three other genes, positioned at important nodes in the composite network, i.e., p38MAPK, TGF $\beta$ and CDKN1A, are apparently indirectly linked to PPAR $\alpha$. The indirect relation between PPAR $\alpha$ and cycle-dependent kinases (CDK) is of great interest, as it points towards a role of this PPAR isoform in cell proliferation and growth. Collectively, the present findings support the notion that PPAR $\alpha$ is an important regulator of cardiac fatty acid metabolism and modulator of the immune-inflammatory response in the myocardium of PPAR $\alpha-/-$ mice. 
Table 2. Overrepresented annotations clusters in all comparisons

\begin{tabular}{|c|c|c|c|c|}
\hline Annotation cluster & Comp. 1 & Comp. 2 & Comp. 3 & Comp. 4 \\
\hline Actin filament organization & & & $\overline{3}$ & 5 \\
\hline Anion transport & & & 4 & 1 \\
\hline Apoptosis and cell death & & & 17 & 9 \\
\hline Cell development and migration & & & 13 & \\
\hline Cell growth & 6 & & 6 & 8 \\
\hline Cell (trans-)location & 8 & & & \\
\hline Chromatine processes & 11 & & & \\
\hline Coagulation & & & 12 & \\
\hline Carbohydrate metabolism & 10 & 3 & & \\
\hline Defence mechanisms & 2 & & 9 & 3 \\
\hline Development & & 1 & 1 & 11 \\
\hline Embryonic morphogenesis & & 2 & & \\
\hline Exocytosis & & & & 7 \\
\hline Glycerol metabolism & 4 & & & \\
\hline Hemopoiesis & & & 10 & \\
\hline Immune response & 9 & & & 2 \\
\hline Ion transport & & & 15 & \\
\hline Lipid metabolism & 1 & & & \\
\hline Localization & & & & 6 \\
\hline Muscle development & & & & 10 \\
\hline Organic acid synthesis & 7 & & & \\
\hline Organic acid metabolism & & & 14 & \\
\hline Organic acid transport & & & 16 & \\
\hline Perception and response & & & & 12 \\
\hline Protein (de)polymerization & & & 7 & \\
\hline Response to stress & 5 & 4 & 5 & 4 \\
\hline Rhythmic processes & 3 & & & \\
\hline Signal transduction & & & 2 & 14 \\
\hline Ossification & & & 18 & \\
\hline Vasculature development & & & 8 & \\
\hline Wound healing & & & & 13 \\
\hline \multicolumn{5}{|c|}{ 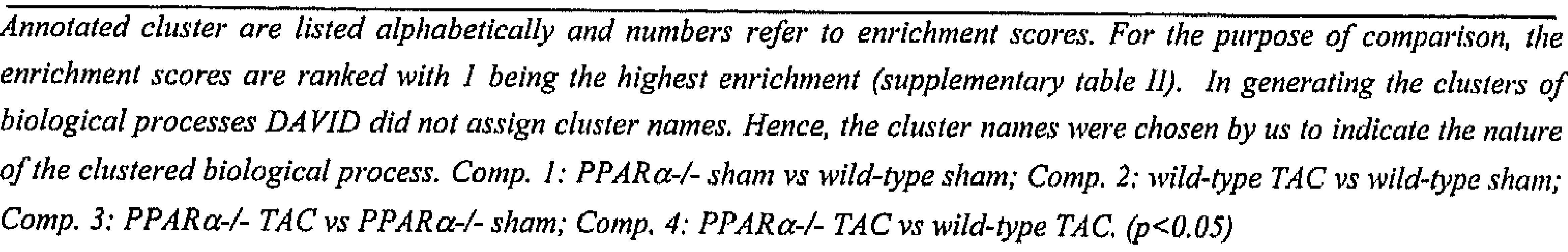 } \\
\hline
\end{tabular}

\section{CARDIAC HYPERTROPHY IN WILD-TYPE MICE (COMPARISON 2)}

In wild-type mice, the TAC-induced hypertrophy resulted in 312 (72 up; 240 down) differentially regulated probe sets (Fig. 1). Overrepresented GO processes in wild-type mice in response to TAC (comparison 2), as identified with DAVID analysis, were related to development and morphogenesis with enrichment scores of 2.17 and 1.48, respectively (Table 2). The enrichment of these processes is indicative of the re-activation of the foetal gene 
programme, which is a hallmark of cardiac hypertrophy ${ }^{11,94,199}$, as exemplified by the upregulation of ANF and $\alpha$-SKA (Table 1).

Genome-wide changes in gene expression in wild-type mice after TAC have been extensively studied before. ${ }^{200-202}$ Most genes described in these studies are related to reactivation of foetal gene expression, in line with the present observations. Although genes involved in ECM organization and remodelling are also frequently found in hypertrophic hearts ${ }^{201}$, our study did not reveal significant changes in clusters, representing these processes (Table 2 and Supplementary table II). This might be due to the fact that the hypertrophic response in the wild-type mice is relatively mild $(+16 \%$, Table 1$)$ and that fibrosis is considered a feature of more advanced stages of cardiac hypertrophy. It is of note that from IPA analysis pivotal components of signalling pathways (e.g. p38MAPK, TGF, PI3K, Akt and AP-1), that traditionally are considered to play an important role in the activation of cardiomyocyte hypertrophy ${ }^{203-205}$, emerged as nodes in the composite network (Supplementary Figure 1B).

\section{CARDIAC HYPERTROPHY IN PPAR $\alpha-/-M I C E$ (COMPARISON 3)}

The TAC-induced hypertrophy in PPAR $\alpha-/-$ mice gave rise to 1910 differentially regulated probe sets, 1230 of which were upregulated and 680 were downregulated (Fig. 1). This large number of probe sets (as compared with comparison 2) is in line with the observation that the PPAR $\alpha-/-$ mice are more sensitive to chronic hemodynamic stress than wild-type mice. ${ }^{18,} 153$, ${ }^{187}$ Moreover, the mere fact, that the degree of hypertrophy is more pronounced in this group $(+40 \%$, Table 1$)$, likely results in a larger number of genes for which the change in expression reaches the level of statistical significance. Accordingly, substantially more GO processes were overrepresented in this comparison relative to wild-type mice subjected to TAC (Table 2 and Supplementary Table II). The most enriched processes are development, signal transduction, actin filament organization, and anion transport. The first 3 processes again reflect elements of the hypertrophic response. It is of note that a closer inspection of the contents of the fourth cluster (anion transport) reveals that virtually all of the differentially expressed genes in this functional group actually are procollagens (Supplementary Table III). This finding is consistent with the up-regulation of profibrotic growth factors, like connective tissue growth factor (CTGF) and TGF $\beta$ that is seen in this comparison. Hence, the enrichment of this cluster is indicative of ECM remodelling in the hypertrophied myocardium. Previous studies mainly reported a role of PPAR $\gamma$ in suppressing TGF $\beta$-mediated processes in various cell types. ${ }^{206,207}$ The present findings suggest that PPAR $\alpha$ has similar effects, at least in the cardiac context. Interestingly, in a recent study ${ }^{208}$ it was shown that PPAR $\delta$ may have opposite effects, as it was able to directly enhance transcription of TGF $\beta 1$ in vascular smooth muscle cells. 
IPA analysis (Supplementary Figure I C) indicated that in the PPAR $\alpha-/$ - hypertrophied heart p38MAPK, TP53, NFKB and Akt1 are important nodes in linking up- and downregulated genes.

The Venn diagram of Figure 3A shows the overlap in probe sets between the two genotypes after TAC. Approximately $28 \%$ ( 86 out of 312 ) of the probe sets in wild-type mice after TAC are also regulated in PPAR $\alpha-/$ mice after TAC. As expected, the overlapping probe sets primarily belonged to functional groups that are important in hypertrophy (muscle development, actin filament organization) and included, among others, typical hypertrophic marker genes like ANF, $\alpha$-SKA and $\beta-\mathrm{MHC}$, and are indicative of processes not dependent on the absence or presence of PPAR $\alpha$ (see Supplementary Table IV for detailed information).

A.

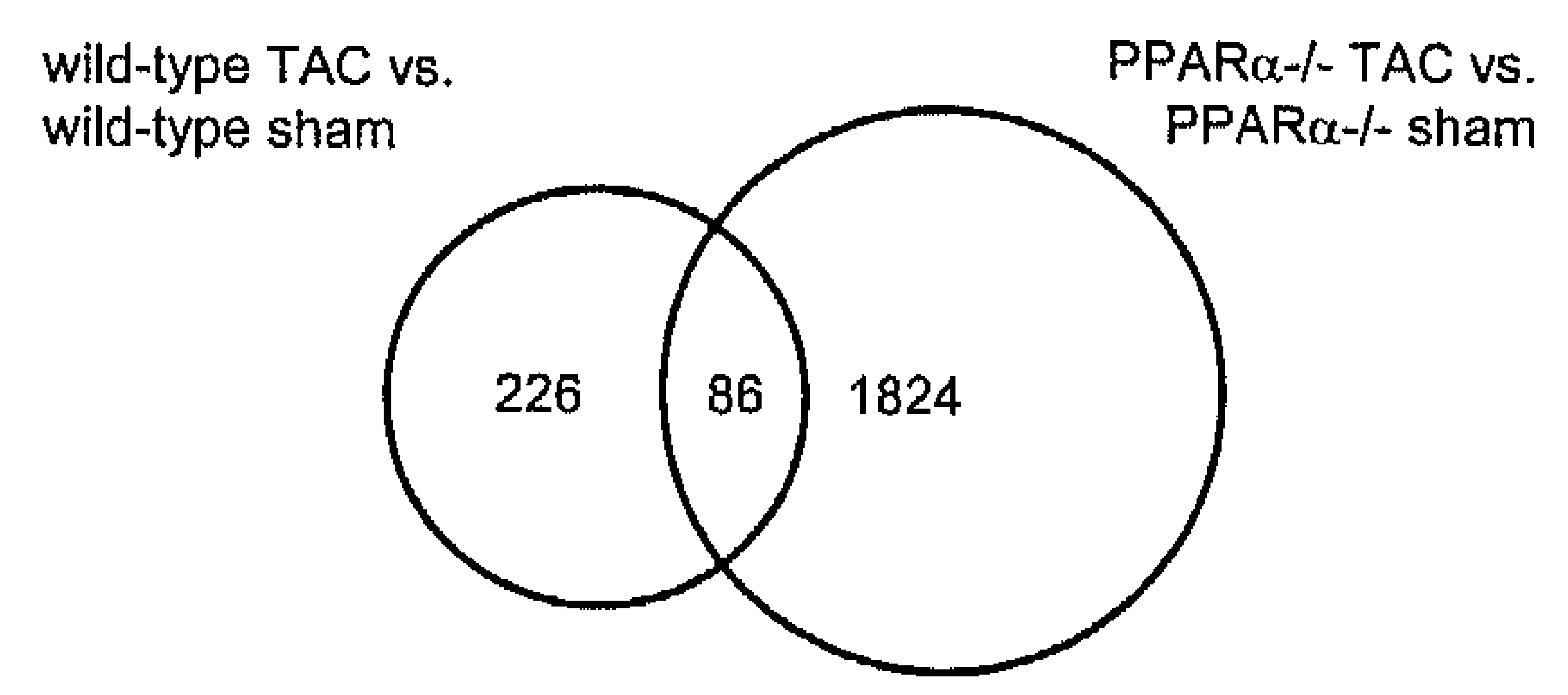

B.

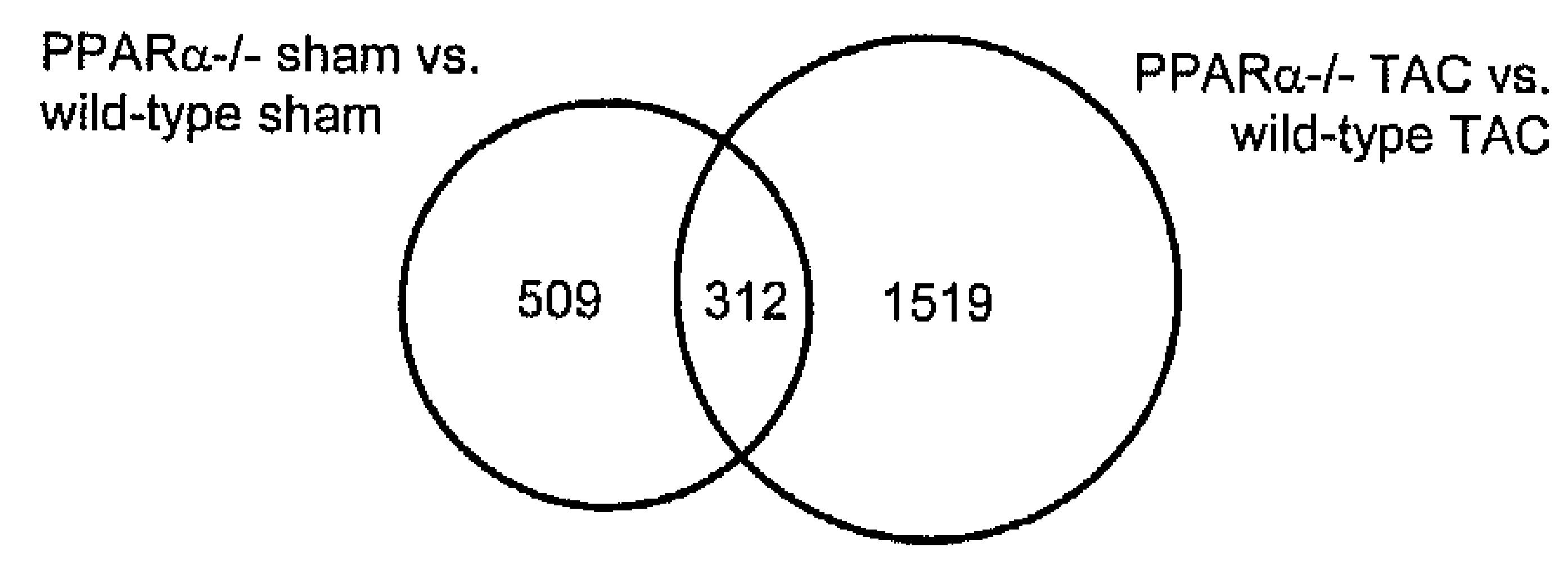

Figure 3. Venn diagrams with numbers of overlapping and non-overlapping probe sets. The overlap encompasses genes that are primarily regulated by genotype (PPAR $\alpha-$ Panel A) or by intervention (TAC-panel B).

\section{GENOTYPE-RELATED DIFFERENCES IN PRESSURE OVERLOADED HEARTS (COMPARISON 4)}

After imposition of a chronic pressure overload 1831 differentially regulated probe sets were identified when comparing the hypertrophied hearts of PPARQ $-\%$ and wild-type mice (comparison 4) (Fig. 1A). The vast majority (83\%) of these differentially expressed probe sets was upregulated, probably pointing to a diminished transrepression activity in the PPAR $\alpha-/$ mouse heart (Fig. 1B). DAVID analysis revealed that processes related to immune response, defense mechanisms, response to stress, anion transport (a category mainly including genes involved in collagen synthesis), and actin filament organization were enriched (enrichment scores: 3-2) among the differentially regulated probe sets (Table 2 and Supplementary Table II). More detailed analysis of Supplementary table III indicates that in the enriched biological 
processes, e.g. GO-term cell adhesion, genes involved in organization of the ECM, like tissue inhibitor of metalloproteinase-2 (TIMP-2), matrix gla-protein (MGP) and CTGF, were overrepresented in PPAR $\alpha-/$ - mice after TAC as compared to hypertrophied wild-type hearts. $\operatorname{PPAR} \alpha$ has been reported previously to beneficially affect ECM remodelling in the hypertrophied heart. ${ }^{106}$ Moreover, it has been demonstrated that the PPAR $\alpha$ agonist fenofibrate decreased fibrosis in mice with aldosterone-induced hypertension. ${ }^{209}$ The present findings might indicate that PPAR $\alpha$ modulates cardiac ECM at the gene expression level via transrepression, although other, most likely indirect mechanisms can not be excluded. In this respect, the more pronounced hypertrophic response in PPAR $\alpha$ deficient mice could also have influenced the expression of ECM related genes. Further experimentation is required to deeply investigate this issue.

Again, the immune-related processes were highly enriched in this comparison. Examples of genes belonging to this group are e.g. histocompatibility 2, fc receptor, components of the complement system, and interferon regulatory factors. Earlier studies indicated that the immune response is affected in cardiac hypertrophy and failure. Enhanced immune activation, closely related to the inflammatory response, appeared to be a major contributor to the development of chronic heart failure, enhancing disease progression and increasing mortality. ${ }^{210}$ The association of $\operatorname{PPAR} \alpha$ with the cardiac immune response represents a new mechanism as to how PPAR $\alpha$ may modulate cardiac disease. Activation of PPAR $\alpha$ is anticipated to suppress the exaggerated immune reaction during LV hypertrophy and heart failure. ${ }^{211}$ Given the recent interest in the relation between immuno-modulation, inflammation and cardiac disease $\mathrm{e}^{210}$, the regulatory role of PPAR $\alpha$ in this process warrants further investigation.

The combined biological interaction network (IPA analysis; Figure 4) clearly reveals four nodes that were central in connecting many of the genes differentially expressed in the hypertrophic heart of PPAR $\alpha$ deficient mouse compared to wild-type. These nodes relate to two transcription factors, i.e., the inflammatory transcription factor NF-kB and tumour suppressor p53 (TP53), and protein kinases, i.e., MAPK including p38MAPK, enzymes playing important roles in signalling pathways leading to cardiac hypertrophy. ${ }^{205}$ The central position of NF- $\kappa B$ in the composite network is in line with earlier studies revealing the pivotal role of NF-KB in cardiac hypertrophic growth ${ }^{14,15}$ and showing that activation of PPAR $\alpha$ inhibits NF- $\mathrm{BB}$-dependent signalling via transrepression. ${ }^{18,104}$ At present, the functional impact of mitogen-activated protein kinases and related genes in the hypertrophied heart of PPAR $\alpha-/$ - mice is incompletely understood, as recent studies have revealed complex roles for individual MAPK pathways in both cardiac protection and cardiac pathologies. ${ }^{212}$

When looking at genotype-related genomic effects, only 312 of the differentially expressed probe sets in unstressed hearts (sham PPAR $\alpha$-/- versus sham wild-type) also emerge when comparing the two TAC groups (PPAR $\alpha-/-$ TAC versus wild-type TAC) (Venn diagram, Fig. 
3B; Supplementary Table IV). The overlapping probe sets often belonged to functional groups related to lipid metabolism and immune response. A large fraction of the 1519 nonoverlapping probe sets in TAC mice are related to hypertrophy and ECM remodelling. It is of note that the functional clusters related to "response to stress" were also strongly represented in this group. A role of PPAR $\alpha$ in response to stress has already been observed by Ichihara and co-workers ${ }^{104}$, demonstrating that activation of PPAR $\alpha$ repressed redox-regulated transcription factors, among which NF-kB. Our microarray analysis also showed that lack of

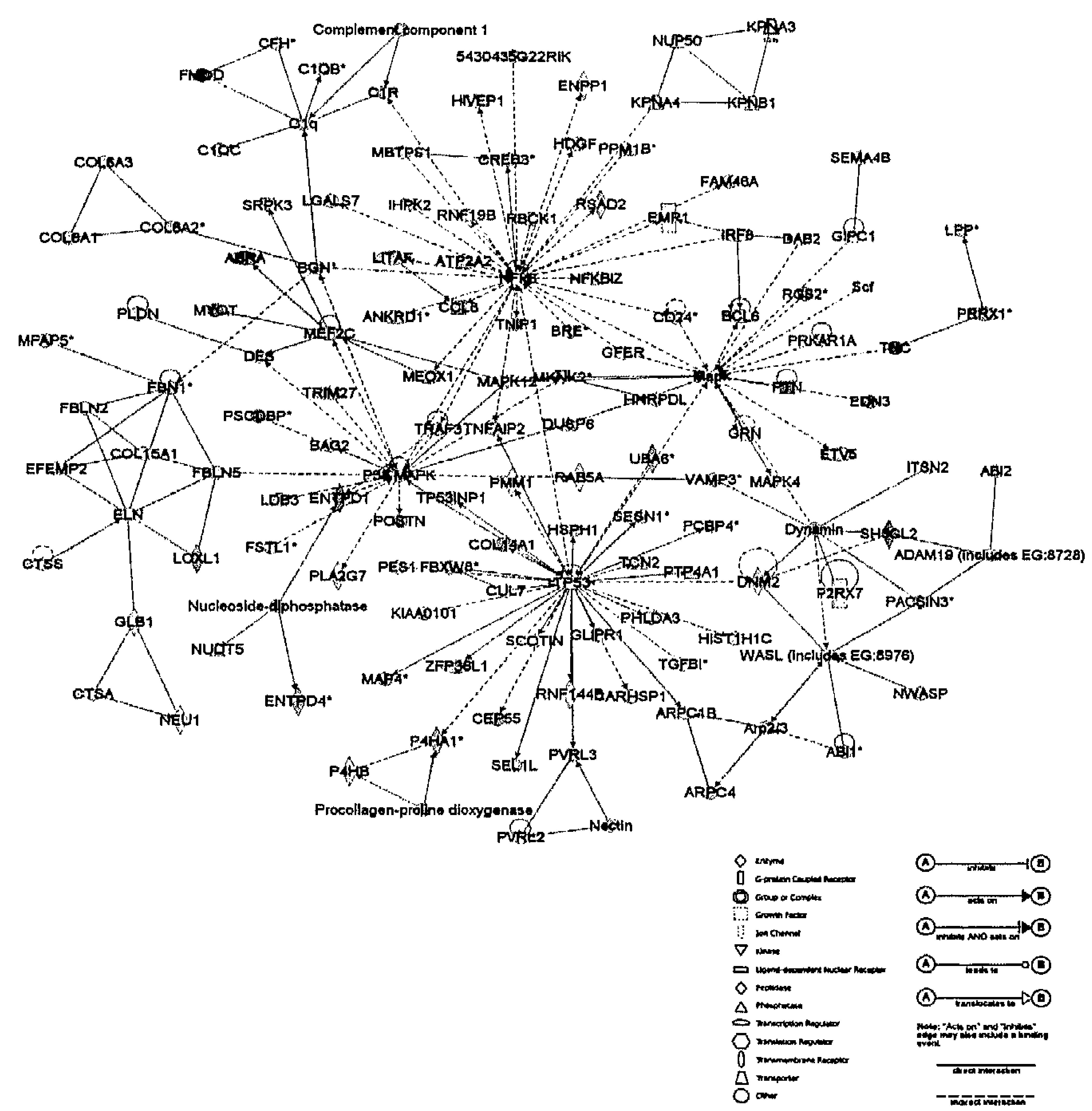

Figure 4. Biological interaction networks with central genes. Ingenuity Pathway Analysis (IPA) was used to search for biological networks in Comparison 4 (PPAR $\alpha-/-$ TAC vs. wild-type TAC). In short, all differentially regulated probe sets, including fold changes per comparison were entered into IPA. Individual genes are linked in biological networks. In these networks, differentially regulated genes are distinguished by the use of color coding (red: upregulated, green: downregulated in the PPAR $\alpha-/$ - TAC group compared to corresponding wildtype group; a greater intensity represents a higher degree of regulation). The biological networks obtained were merged in larger biological networks, indicating the mutual relationship between networks. As a cut-off value, networks with a significance score of $>35\left(p<10^{35}\right)$ were chosen to be merged. IPA analysis of comparisons 1 , 2 and 3 are shown in Supplementary Figure 1. 
$\operatorname{PPAR} \alpha$ resulted in the down-regulation of antioxidant genes e.g. super oxide dismutase-2 (SOD2), catalase and glutathione transferase. This finding is consistent with the observation that several of these genes are directly activated by PPARs ${ }^{213}$ and that the hearts of PPAR $\alpha-/-$ mice are more susceptible to oxidative stress. ${ }^{186}$

In summary, the present transcriptomic analysis demonstrates that in the normal heart, in addition to regulating lipid metabolism, PPAR $\alpha$ is an important factor in cardiac immune response. After 28 days of increased hemodynamic load, lack of PPAR $\alpha$ was associated with a more pronounced hypertrophy phenotype, accompanied by extensive changes in gene expression. NF-kB- and tumour suppressor p53-regulated genes were upregulated in hypertrophied hearts of PPAR $\alpha-/-$ mice, indicating that PPAR $\alpha$, next to its well established role in cardiac lipid metabolism, modulates immune-inflammatory signalling pathways, and the expression of extracellular matrix genes in cardiac muscle. The association between PPAR $\alpha$ and the immune-inflammatory axis, and genes involved in cardiac fibrosis might direct further studies to the transactivation and transrepression properties of PPAR $\alpha$ and to explore new opportunities for pharmacological interventions in cardiac disease.

\section{GRANTS}

This work was supported by the Netherlands Organization for Scientific Research NWO (912-04-017) and the EU-FP6 grant LSHM-CT-2005-018833, EUGeneHeart.

\section{Note}

All supplementary figures and colour figure 4 can be found on physiolgenomics.physiology.org. 


\title{
6
}

\section{Loss of PPAR $\alpha$ reduces infarct size and promotes hypertrophy of the surviving murine myocardium}

\author{
Pascal J.H. Smeets*, Birgit E.J. Teunissen*, Peter H.M. Willemsen, Chantal C.J. Munts, \\ Ben J.A. Janssen, Jack P.M. Cleutjens, Ger J. van der Vusse and Marc van Bilsen
}

Submitted for publication. *Both authors contributed equally.

\footnotetext{
ABSTRACT $\mid$ The nuclear hormone receptor peroxisome proliferator-activated receptor- $\alpha$ (PPAR $\alpha$ ) is believed to protect the heart by attenuating inflammation and fibrosis. To test this notion we examined how PPAR $\alpha$ deletion modulates infarct healing and hypertrophic remodelling of the viable myocardium after regional myocardial infarction (MI). Thereto, PPAR $\alpha-/$ - and wild-type mice were subjected to occlusion of the left anterior descending coronary artery for 5 or 28 days. Histological and echocardiographic analysis showed that MI in PPAR $\alpha-/$ - mice was associated with improved survival, lower incidence of cardiac rupture, smaller infarct size, less cardiac dilatation and better preservation of ejection fraction and fractional shortening. In the infarct region apoptosis, inflammatory cell infiltration and expression of inflammatory markers increased 5 days post-MI, but did not differ between the two genotypes. Differences in extracellular matrix gene expression in the infarct region were neither observed. In the surviving myocardium of wild-type mice endogenous PPAR $\alpha$ mRNA was substantially downregulated 5 days after MI, while PPAR $\delta$ mRNA was increased. Cardiomyocyte cross-sectional area was larger and capillary density was preserved in viable myocardium of PPAR $\alpha-\%$ mice compared to wild-type mice. The present findings show that PPAR $\alpha$ deficiency limits cardiac rupture rates after MI and reduces infarct size, and simultaneously promotes cardiomyocyte hypertrophy and maintains the degree of capillarization in the remote myocardium, accompanied by improved hemodynamical outcome. This study questions the potentially beneficial application of PPAR $\alpha$ ligands in coronary heart disease.
} 


\section{INTRODUCTION}

Permanent coronary artery occlusion leads to irreversible loss of cardiac myocytes followed by a reparative wound healing process. The infarct healing process is characterized by an intense acute and chronic inflammatory reaction that includes the induction of proinflammatory cytokines, infiltration and proliferation of inflammatory cells and (myo)fibroblasts and subsequent deposition of fibrotic scar tissue. ${ }^{214-216}$ Concomitantly, regional myocardial infarction (MI) initiates remodelling of the non-infarcted, viable myocardium leading to regional hypertrophy in an attempt to compensate for the loss of viable tissue. ${ }^{8.214}$

The nuclear hormone receptor peroxisome proliferator-activated receptor- $\alpha$ (PPAR $\alpha$ ) has been reported to inhibit both inflammation and cell proliferation. ${ }^{169,193,217}$ These properties of PPAR $\alpha$, and its abundant expression in cardiac tissue ${ }^{22,}{ }^{23}$, make it a potential therapeutic target for interfering with cardiac remodelling subsequent to regional MI.

Interestingly, the outcome of studies examining the role of PPAR $\alpha$ in the diseased heart is not unequivocal. On the one hand, treatment with PPAR $\alpha$ ligands has been shown to attenuate the development of myocardial fibrosis and hypertrophy in several hypertensive rat models. ${ }^{155,218,}$ ${ }^{219}$ Consistent with this, we recently showed that deletion of the PPAR $\alpha$ gene was associated with pronounced hypertrophy and cardiac dysfunction in mice subjected to pressure overload. ${ }^{18}$ On the other hand, activation of PPAR $\alpha$ with its ligand Wy-14,643 depressed cardiac performance of pressure overloaded hypertrophic rat hearts. ${ }^{103}$ Moreover, the role of PPAR $\alpha$ in cardiac ischemia-reperfusion (I/R) is unclear. Ex vivo perfused hearts of PPAR $\alpha-/-$ mice demonstrated improved cardiac recovery after $I / R$, which most likely was related to improved metabolic efficiency. ${ }^{30}$ Short-term in vivo studies on pre-treatment with PPAR $\alpha$ agonists demonstrated limitation of infarct size following transient coronary artery occlusion in rats. ${ }^{24,67}$ The role of PPAR $\alpha$ following permanent coronary artery occlusion has not been investigated so far. In view of the pivotal role of inflammation in the infarct healing process and the reported anti-inflammatory effects of PPAR $\alpha$, we hypothesized that PPAR $\alpha$ deficiency leads to a more pronounced inflammatory response both in the flow-deprived and surviving myocardium and, hence, deterioration of hemodynamic function subsequent to regional MI.

In this study we aimed to delineate the biological significance of PPAR $\alpha$ in myocardial infarct healing and accompanying hypertrophic remodelling of the surviving myocardium. Thereto, PPAR $\alpha-/-$ and wild-type mice were subjected to permanent occlusion of the left coronary artery descending (LAD) for either 5 or 28 days and infarct size and cardiac function were analysed. Markers of cardiac hypertrophy, inflammation, apoptosis, extracellular matrix remodelling, metabolism, and angiogenesis were measured to determine to what extent these processes were affected by the lack of PPAR $\alpha$. 
Contrary to our expectations, we found that PPAR $\alpha-/$ - mice have smaller infarcts and were less prone to cardiac rupture. Lack of PPAR $\alpha$ did not affect inflammation and fibrosis in the infarct and surviving myocardium. However, PPAR $\alpha-/$ mice showed both higher hypertrophic response and better preserved capillary density in the surviving myocardium, relative to wild-type hearts. Concurrently, overall cardiac hemodynamic function was less depressed in PPAR $\alpha-/$ - hearts after regional myocardial infarction.

\section{METHODS}

\section{ANIMALS}

Experiments were performed with male PPAR $\alpha-/$ mice backcrossed on a pure C57B16/J background for $>10$ generations and wild-type C57B16/J mice. ${ }^{18}$ Mice were age-matched $(\sim 15$ weeks) and weighed $\sim 28 \mathrm{~g}$ at the time of surgery. Animals had ad libitum access to water and standard lab-food pellets (Ssniff R/M-H, Sniff, Soest, Germany). Experiments were approved by the institutional animal ethics committee and performed according to Guide for the Care and Use of Laboratory Animals (NIH Publication No. 85-23, revised 1996).

\section{REGIONAL MYOCARDIAL INFARCTION}

Mice were pre-treated $(30 \mathrm{~min})$ with buprenorphine $(0.1 \mathrm{mg} / \mathrm{kg}$ s.c.). After induction of anesthesia with isoflurane (4\%) mice were intubated with a stainless-steel tube and connected to a respirator (respiratory volume $250 \mu 1$, rate $250 \mathrm{~min}^{-1}$ ). Anesthesia was maintained by isoflurane inhalation (1.5-2.5\%). Body temperature was monitored with a rectal probe and maintained at $37^{\circ} \mathrm{C}$. After opening of the left thorax and intra-costal exposure of the heart, the LAD was ligated just proximal to its main branching point with a 6-0 polypropylene suture (Surgipro, Chicago, IL, USA). Sham procedures were identical with exception of actual tying of the suture. Thorax and skin were closed with 5-0 silk sutures. Animals were allowed to recover for 24 hours at $30^{\circ} \mathrm{C}$ and the analgesic buprenorphine (Temgesic; $0.1 \mathrm{mg} / \mathrm{kg} \mathrm{s.c.}$.) was re-administered $18-24 \mathrm{~h}$ after surgery. Peri-operative mortality was low (12-15\%) and did not differ between genotypes. In total, 35 wild-type (14 sham, $21 \mathrm{MI}$ ) and 43 PPAR $\alpha-/-$ mice (12 sham, $31 \mathrm{MI}$ ) were included. Mice were sacrificed 5 or 28 days after MI or sham surgery.

\section{ECHOCARDIOGRAPHY}

Immediately before and 28 days after coronary ligation or sham operation, mice were anesthetized with isoflurane and placed on a heating pad $\left(37^{\circ} \mathrm{C}\right)$. Trans-thoracic echocardiography was performed using a Hewlett-Packard $15 \mathrm{MHz}$ linear array transducer interfaced with a Sonos 5500 ultrasound machine (Philips, Eindhoven, the Netherlands). ${ }^{176}$

After the hemodynamic measurements the heart was excised, atria were removed and ventricles weighed and then dissected longitudinally through the infarct center. Half of the 
heart was fixed for $24 \mathrm{~h}$ in $4 \%$ paraformaldehyde and embedded in paraffin for histological analysis. The other half was separated in left ventricle (LV), septum and infarct zone and snap-frozen for RNA analysis.

\section{HISTOCHEMISTRY AND IMMUNOSTAINING}

For histology, tissues sections were deparaffinized and stained with AZAN, hematoxylineosin (H\&E), or Sirius red. ${ }^{178}$ Infarct size was measured using a computerized morphometry software (Owin version 3.2.1, Leica, the Netherlands) on AZAN-stained sections. The percentage of infarcted tissue was calculated as ratio of AZAN-stained tissue area over total left ventricular tissue area. Myocyte short-axis cross-sectional area was determined on H\&Estained sections using the morphometry system described above. Collagen was visualized with Picro-Sirius red staining.

To determine capillary density deparaffinized tissue sections were incubated with GSI-Biotin (GSI-B1105, Vector Laboratories, Burlingame, CA, USA). Staining was visualized using an Alkaline Phosphatase Vector ${ }^{\circledR}$ Red substrate kit (Vector Laboratories). Number of capillaries per tissue area was assessed with morphometry software.

To assess macrophage infiltration tissue sections were incubated with Mac-3 (CD107b) antibody (BD Biosciences, Franklin Lakes, NJ, USA). Next, sections were incubated with secondary biotinylated anti-rat IgG (DAKO, Glostrup, Denmark). Staining was visualized using the Alkaline phosphatase substrate kit and analyzed with morphometry software.

Apoptotic cells were detected by the TUNEL assay using the In Situ Detection Kit, Fluorescein (Roche Applied Science, Basel, Switzerland) according to the manufacturer's instructions. Sections were first incubated with Proteinase $\mathrm{K}(20 \mu \mathrm{g} / \mathrm{ml}$ in PBS, $15 \mathrm{~min}, \mathrm{RT})$ and subsequently blocked with $3 \%$ bovine serum albumin and $20 \%$ fetal bovine serum in PBS (30 min, RT). Then, the sections were incubated with the TUNEL reaction mixture ( $60 \mathrm{~min}$, $37^{\circ} \mathrm{C}$ ). After washing ( $3 \mathrm{x}$ PBS) sections were mounted in Vectashield mounting medium with DAPI (Vector laboratories, Burlingame, U.S.). Sections were analyzed by fluorescent microscopy (Leica DM5000B; Leica Microsystems, Wetzlar, Germany) and the Leica Qwin software program. Apoptosis in both infarcted tissue and surviving myocardium (septum) was quantified and expressed as number of TUNEL-positive cells per $\mathrm{mm}^{2}$.

\section{QUANTITATIVE PCR}

Tissue from LV, septum and the infarct zone was homogenized using an UltraTurrax (Janke\&Kunkel, Staufen, Germany) and total RNA was extracted using TriReagent (Sigma, St. Louis, MO, USA). RNA concentration was determined at OD260/280 nm measurements. cDNA synthesis and quantitative PCR (qPCR) was performed as described previously. ${ }^{23}$ Primers used for analysis are given in table 1. Results were normalized to the geometric mean of three reference genes, e.g. Cyclophilin A (CycloA), Acidic Ribosomal Phosphoprotein P0 
(ARBP) and Hypoxanthine Guanine Phosphoribosyl Transferase (HPRT). ${ }^{179}$ Relative changes in expression levels were calculated using GeneX (Biorad) and qBase analyzer. ${ }^{180}$

Table 1. Oligo's used for qPCR

\begin{tabular}{lll}
\hline Gene & Forward & Reverse \\
\hline Cyclo A & CAAATGCTGGACCAAACACAA & TTCACCTTCCCAAAGACCACAT \\
ARBP & GGACCCGAGAAGACCTCCTT & GCACATCACTCAGAATTTCAATGG \\
HPRT & CCTAAGATGAGCGCAAGTTGAA & CCACAGGACTAGAACACCTGCTAA \\
PPAR $\alpha$ & AGAAGTTGCAGGAGGGGATT & TTGAAGGAGCTTTGGGAAGA \\
PPAR $\delta$ & CCGGGAAGAGGAGAAAGAG & GAGGAAGGGGAGGAATTCTG \\
PPAR $\gamma$ & AGGCCGAGAAGGAGAAGCTGTTG & TGGCCACCTCTTTGCTCTGCTC \\
ANF & ATTGACAGGATTGGAGCCCAGAGT & TGACACACCACAAGGGCTTAGGAT \\
$\alpha-S K A$ & TGAGACCACCTACAACAGCA & CCAGAGCTGTGATCTCCTTC \\
Serca2 & ATGGAGAACGCTCACACAAAG & ACTGCTCAATCACAAGTTCCAG \\
Hadha & GGTGTCCCTGAAGTGTTGCT & TCTGTCTGCACGAATGTTCC \\
PDK4 & GCATTTCTACTCGGATGCTCATG & CCAATGTGGCTTGGGTTTCC \\
Acs11 & GAGGGTGAGGTGTGTGTGAA & CAGCTGTTCTTGCTGGGTCT \\
Col1 & CGAAGGCAACAGTCGCTTCA & GGTCTTGGTGGTTTTGTATTCGAT \\
MMP2 & TTTGCTCGGGCCTTAAAAGTAT & CCATCAAACGGGTATCCATCTC \\
$\alpha-S M A$ & GTCCCAGACATCAGGGAGTAA & TCGGATACTTCAGCGTCAGGA \\
TNF- $\alpha$ & CATCTTCTCAAAATTCGAGTGACAA & TGGGAGTAGACAAGGTACAACCC \\
MCP-1 & TTAAAAACCTGGATCGGAACCAA & GCATTAGCTTCAGATTTACGGGT \\
CD68 & TGACCTGCTCTCTCTAAGGCTACA & TCACGGTTGCAAGAGAAACATG \\
VEGF & CTTGTTCAGAGCGGAGAAAGC & ACATCTGCAAGTACGTTCGTT \\
VEGFR2 & GCCCTGCTGTGGTCTCACTAC & CAAAGCATTGCCCATTCGAT \\
VEGFR1 & TGGACCCAGATGAAGTTCCC & GCGATTTGCCTAGTTTCAGTCT \\
\hline & &
\end{tabular}

STATISTICS

Data are expressed as mean \pm SEM. Data were analyzed by one-way ANOVA and polynominal contrast analysis for multiple comparisons using SPSS software. The dosedependent curves for dobutamine were compared using two-way ANOVA and a post-hoc Bonferonni test. To determine survival after MI Kaplan-Meier analysis was performed. Pvalues $<0.05$ were considered statistically significant.

\section{Results}

\section{SURVIVAL}

Kaplan-Meier analysis revealed that after MI the cumulative survival rate of PPAR $\alpha-/-$ mice was significantly higher (17/23) than that of wild-type mice (12/21) (Figure 1). Of the mice that did not survive the 28 day period, the majority died 4 to 10 days after coronary artery occlusion. Autopsy demonstrated that infarct rupture was the cause of death in both genotypes in virtually all cases. 


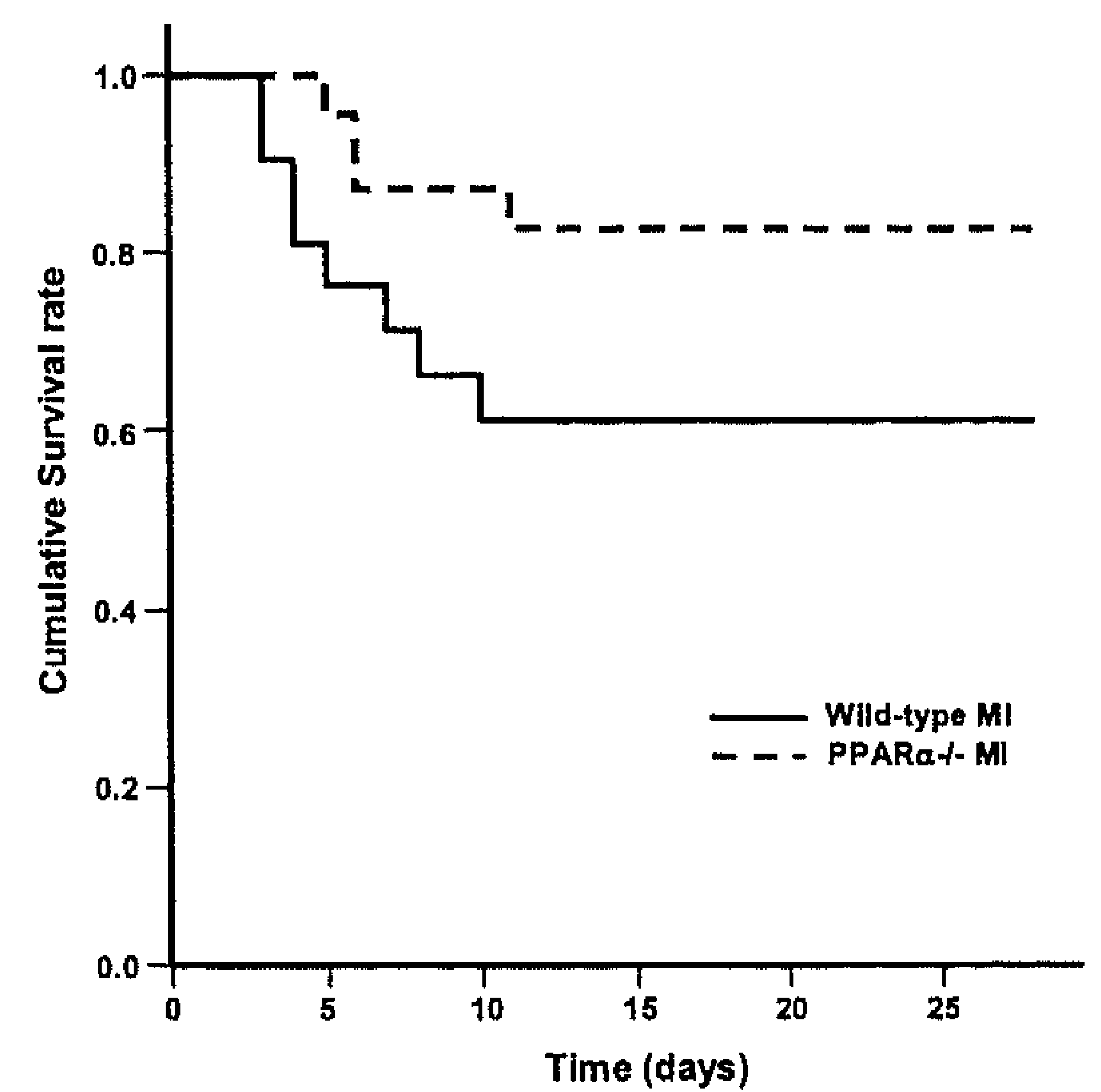

Figure 1. Kaplan-Meier analysis was performed to compare survival of PPAR $\alpha-/$ - and wild-type mice after regional myocardial infarction. PPAR $\alpha-/$ - mice showed better survival after MI than wild-type mice. Obduction showed that cardiac rupture caused all deaths

\section{VENTRICULAR WEIGHT, CARDIAC DIMENSIONS AND FUNCTION}

Both in wild-type and PPAR $\alpha-/-$ mice, MI was associated with a marked increase in total ventricular weight, also when normalized to body weight or tibia length (table 2). The increase in ventricular weight was comparable between wild-type and PPAR $\alpha-/-$ mice. Lung weight was slightly but non-significantly increased after MI in both genotypes.

Table 2. Characteristics of wild-type and PPAR $\alpha-/$ mice 28 days after MI or sham operation

\begin{tabular}{lcccc}
\hline & \multicolumn{2}{c}{ Wild-type } & \multicolumn{2}{c}{ PPAR $\alpha-/ \sim$} \\
\cline { 2 - 5 } $\mathrm{n}$ & sham & MI & sham & MI \\
Body Weight (BW), g & 13 & 12 & 12 & 17 \\
Ventricular Weight (VW), mg & $122.2 \pm 3.7$ & $172.4 \pm 6.2^{*}$ & $125.3 \pm 3.6$ & $159.1 \pm 6.4^{*}$ \\
Tibia Length (TL), mm & $17.6 \pm 0.1$ & $17.8 \pm 0.2$ & $17.4 \pm 0.1$ & $17.4 \pm 0.1$ \\
VW/BW, mg/g & $4.4 \pm 0.1$ & $5.8 \pm 0.3^{*}$ & $4.5 \pm 0.1$ & $5.6 \pm 0.2^{*}$ \\
VW/TL, mg/mm & $6.9 \pm 0.2$ & $9.7 \pm 0.3^{*}$ & $7.2 \pm 0.2$ & $9.1 \pm 0.4^{*}$ \\
Lung Weight, mg & $134.1 \pm 5.2$ & $149.0 \pm 3.2$ & $133.1 \pm 4.4$ & $150.8 \pm 6.5$ \\
\hline
\end{tabular}

* $\mathrm{p}<0.05$ vs corresponding sham animals. Note: no statistical differences between PPAR $\alpha-/-$ and corresponding wild-type animals.

Echocardiography revealed that in sham-operated wild-type and PPAR $\alpha-/-$ mice cardiac dimensions did not change during the course of the study (from day 0 to 28 ; data not shown) and were not different between genotypes (table 3). MI led to a marked dilatation of the LV in wild-type mice as demonstrated by the 3 -fold increase in end-diastolic volume. LV dilatation after MI was less pronounced in PPAR $\alpha$-/ - mice as end-diastolic and end-systolic LV internal diameters and volumes were significantly smaller. 
In the infarcted region the LV anterior wall displayed marked thinning (AWT; Table 3). Wall thinning was less prominent in PPAR $\alpha-/$ - mice than in wild-type mice $(-31 \%$ versus $-71 \%)$. The thickness of the septum in diastole (PWTdia) did not decline in wild-type mice and even tended to increase in PPAR $\alpha-/$ - mice, indicating compensatory hypertrophic remodelling of the viable myocardium.

Table 3. Left ventricular dimensions of wild-type and PPAR $\alpha-/$ - mice 28 days after MI or sham-operation

\begin{tabular}{|c|c|c|c|c|}
\hline & \multicolumn{2}{|c|}{ Wild-type } & \multicolumn{2}{|c|}{ PPAR $\alpha-1-$} \\
\hline & sham & MI & sham & MI \\
\hline $\mathrm{n}$ & 13 & 11 & 9 & 16 \\
\hline LVIDdia, mm & $3.97 \pm 0.06$ & $6.38 \pm 0.29^{*}$ & $4.24 \pm 0.10$ & $5.26 \pm 0.20+*$ \\
\hline LVIDsys, mm & $2.97 \pm 0.07$ & $6.07 \pm 0.32^{*}$ & $3.14 \pm 0.07$ & $4.75 \pm 0.26 \dagger^{*}$ \\
\hline $\mathrm{EDV}, \mathrm{mm}^{3}$ & $59 \pm 2$ & $174 \pm 2^{*}$ & $67 \pm 4$ & $117 \pm 1 \dagger$ \\
\hline $\mathrm{ESV}, \mathrm{mm}^{3}$ & $25 \pm 1$ & $153 \pm 2 *$ & $26 \pm 2$ & $90 \pm 1 \dagger$ \\
\hline AWTdia, mm & $1.12 \pm 0.05$ & $0.36 \pm 0.10^{*}$ & $1.10 \pm 0.03$ & $0.81 \pm 0.12 \dagger$ \\
\hline AWTsys, mm & $1.43 \pm 0.04$ & $0.39 \pm 0.11^{*}$ & $1.41 \pm 0.05$ & $0.92 \pm 0.14 \dagger^{*}$ \\
\hline PWTdia, mm & $1.12 \pm 0.04$ & $1.11 \pm 0.09$ & $1.09 \pm 0.05$ & $1.24 \pm 0.05$ \\
\hline PWTsys, mm & $1.34 \pm 0.06$ & $1.20 \pm 0.07$ & $1.37 \pm 0.08$ & $1.31 \pm 0.05$ \\
\hline
\end{tabular}

A.

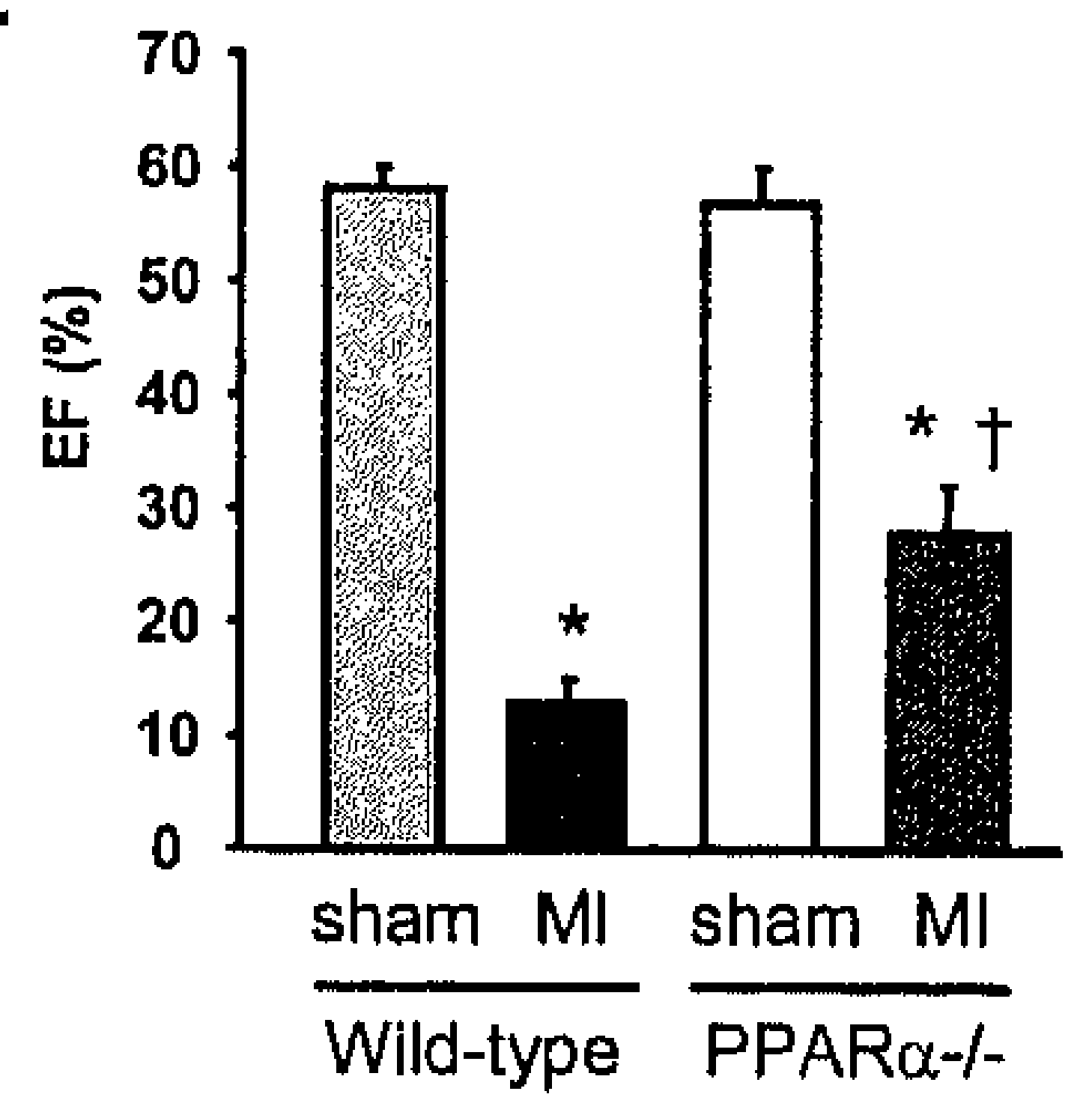

B.

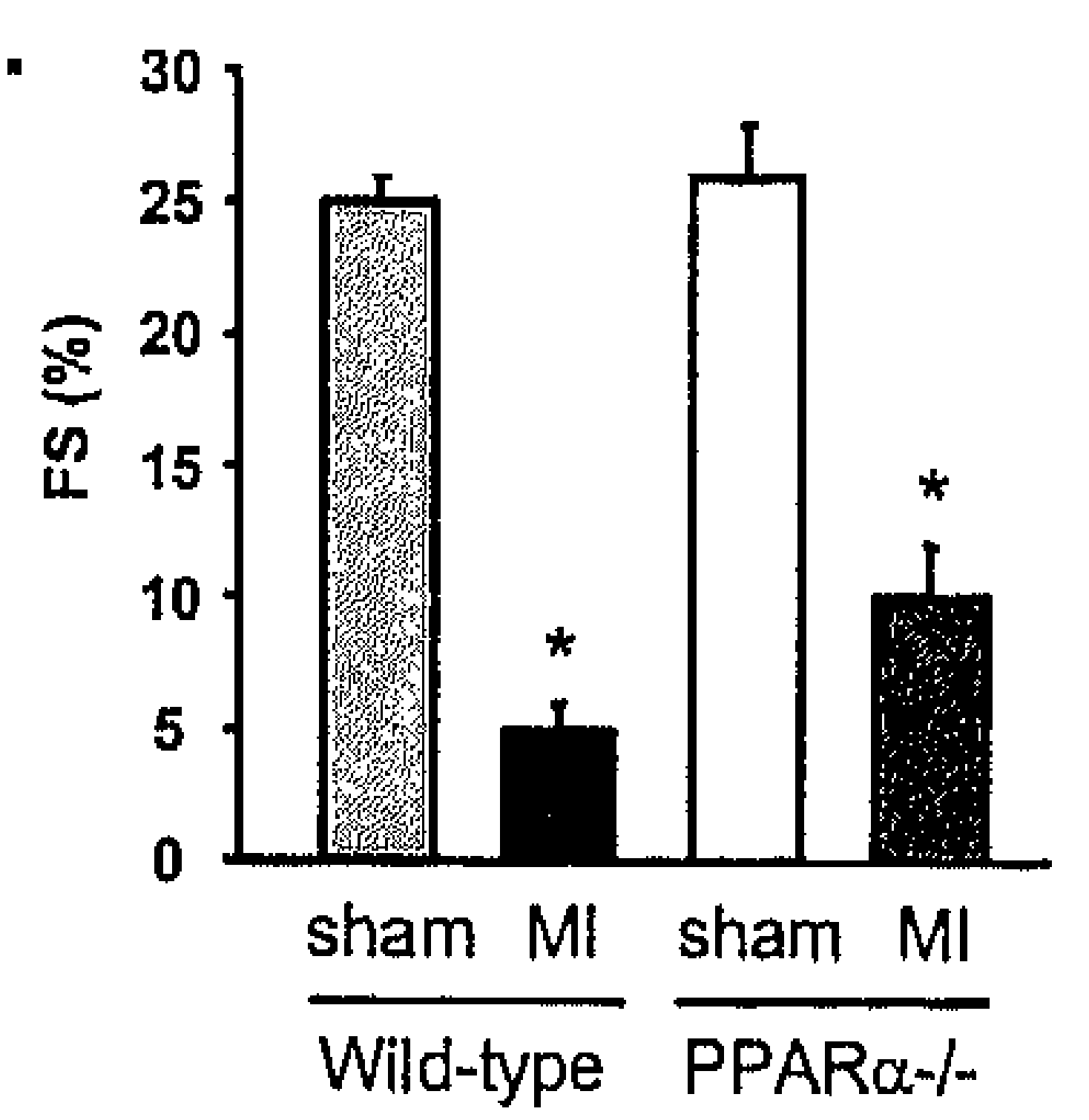

Figure 2. Cardiac function of PPAR $\alpha \%$ and wild-type mice 28 days after MI or sham surgery. Ejection fraction (EF, panel A) and fractional shortening (FS, panel B) were determined echocardio-graphically. *Significantly different from corresponding (PPAR $\alpha-/-$ or wild-type) sham mice. $\uparrow$ Significantly different from corresponding (MI or sham operated) wild-type mice.

In wild-type mice MI was associated with a substantial decline in ejection fraction (EF) and fractional shortening (FS). The decline in EF and FS was less pronounced in PPAR $\alpha-/$ - than in wild-type mice (Figure 2A and 2B). 


\section{HISTOLOGY OF INFARCT ZONE}

AZAN staining demonstrated that the infarct areas of wild-type mice were all transmural and very thin 28 days after LAD occlusion. In contrast, 4 out of 9 PPAR $\alpha-/$ - mice demonstrated pathchy non-transmural infarcts (Figure $3 \mathrm{~A}$ shows typical example). Sirius red-staining showed that in transmural infarcts of both PPAR $\alpha-/$ - and wild-type mice almost the entire infarct area consisted of collagen bundles, while in non-transmural infarcts of PPAR $\alpha-/-$ mice bundles of collagen were interspersed with stretches of surviving cardiomyocytes (Figure 3B). Moreover, total infarct size was significantly smaller in PPAR $\alpha \%$ than in wild-type mice ( $23 \%$ vs. $33 \%$ of total ventricular cross-sectional area, Figure $3 \mathrm{C}$ ).

\section{EARLY CHANGES IN THE INFARCT ZONE (5 DAYS AFTER MI)}

As the incidence of cardiac rupture was markedly different between wild-lype and PPAR $\alpha-/-$ mice, a subgroup of mice was sacrificed 5 days after MI, i.e., at a time when rupture events were about to start (Figure 1) and reparative processes are fully active. ${ }^{220}$ Indeed, H\&E staining and Mac-3 staining of the 5 days-old infarct zone revealed massive infiltration of inflammatory cells both in wild-type and PPAR $\alpha-/-$ mice. Mac-3-immunopositive macrophages were clearly present in the early infarct zone of wild-type and PPAR $\alpha-/-$ mice (Figure 4A). It is of note, however, that Mac-3 positive cell infiltration did not differ between genotypes and that 28 days after MI their number was almost back to baseline (Fig. 4B). Likewise, 5 days post MI the number of apoptotic cells was very low in the remote viable myocardium and dramatically increased in the infarct area, without differences in genotypes $\left(229 \pm 24\right.$ and $222 \pm 33$ TUNEL-positive cells $/ \mathrm{mm}^{2}$ in wild-type and PPAR $\alpha-/-$ mice, respectively).

\section{STRUCTURAL REMODELLING OF THE REMOTE, VIABLE MYOCARDIUM.}

To determine whether regional MI led to tissue remodelling of the non-ischemic region cardiomyocyte short-axis cross-sectional area in the remote, viable myocardium was measured (Figure 5A). Cardiomyocyte area was significantly larger in sham-operated PPAR $\alpha$-/- than in wild-type mice. Relative to the corresponding sham groups, MI resulted in a statistically significant further increase in cardiomyocyte area in PPAR $\alpha-/-$, but not in wildtype mice.

Capillary density, based on GSI-Lectin staining, was similar in sham-operated wild-type and PPAR $\alpha-/-$ mice (Figure 5B). In wild-type mice capillary density in the remote, viable myocardium was significantly decreased $(-25 \%) 28$ days after MI. In contrast, in PPAR $\alpha-/-$ MI mice capillary density in the remote regions was completely preserved. Sirius red-staining showed mainly perivascular and little interstitial collagen in the remote viable myocardium. Wild-type and PPAR $\alpha-/$ - mice did not differ (data not shown). 
A.

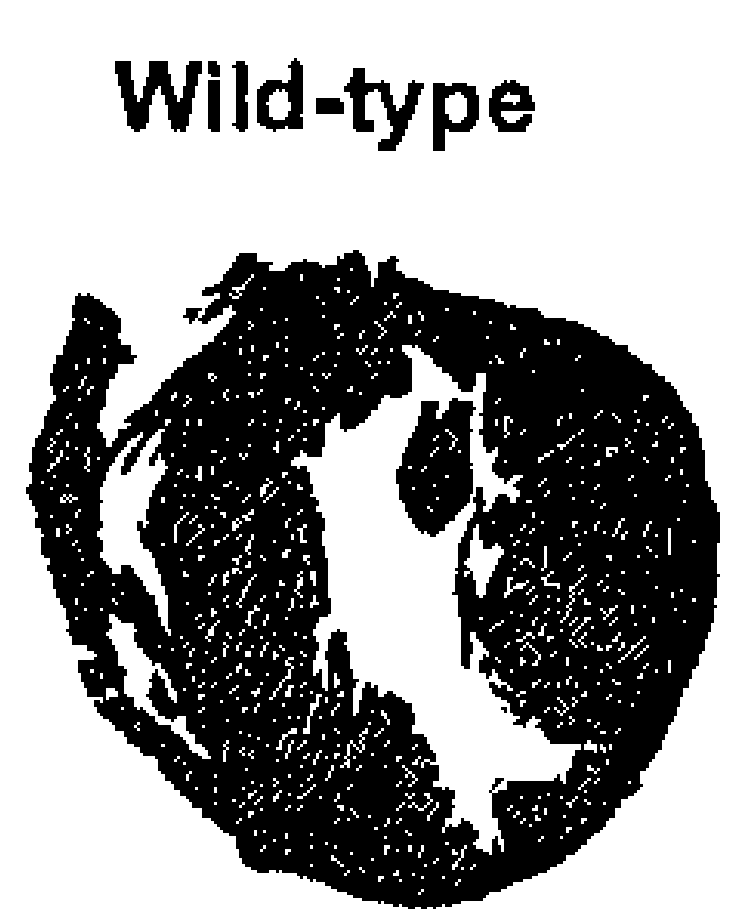

MI

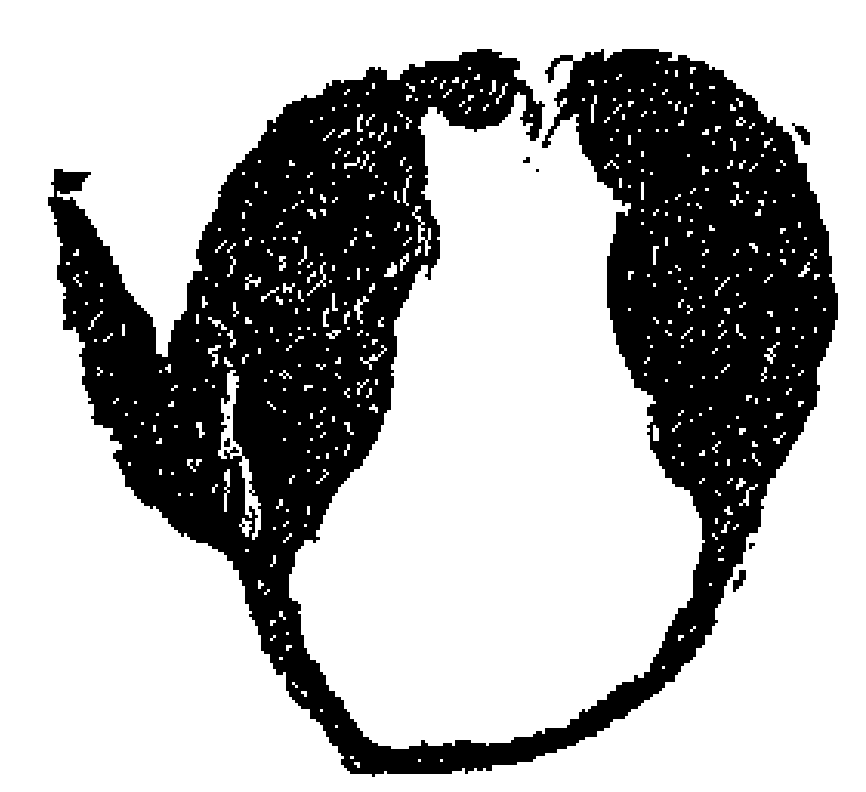

B.

Wild-type $M$

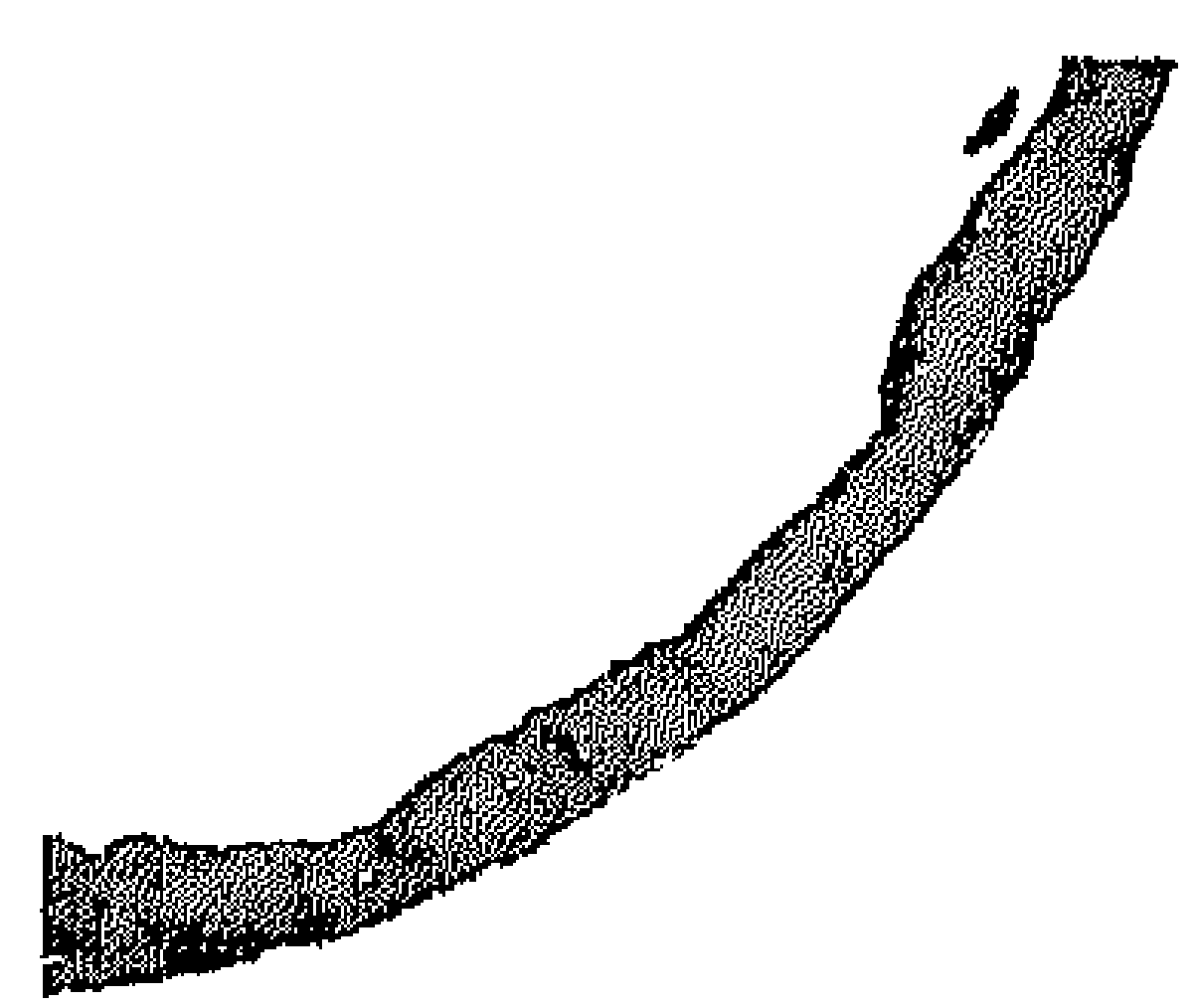

PPAR $\alpha-1-$
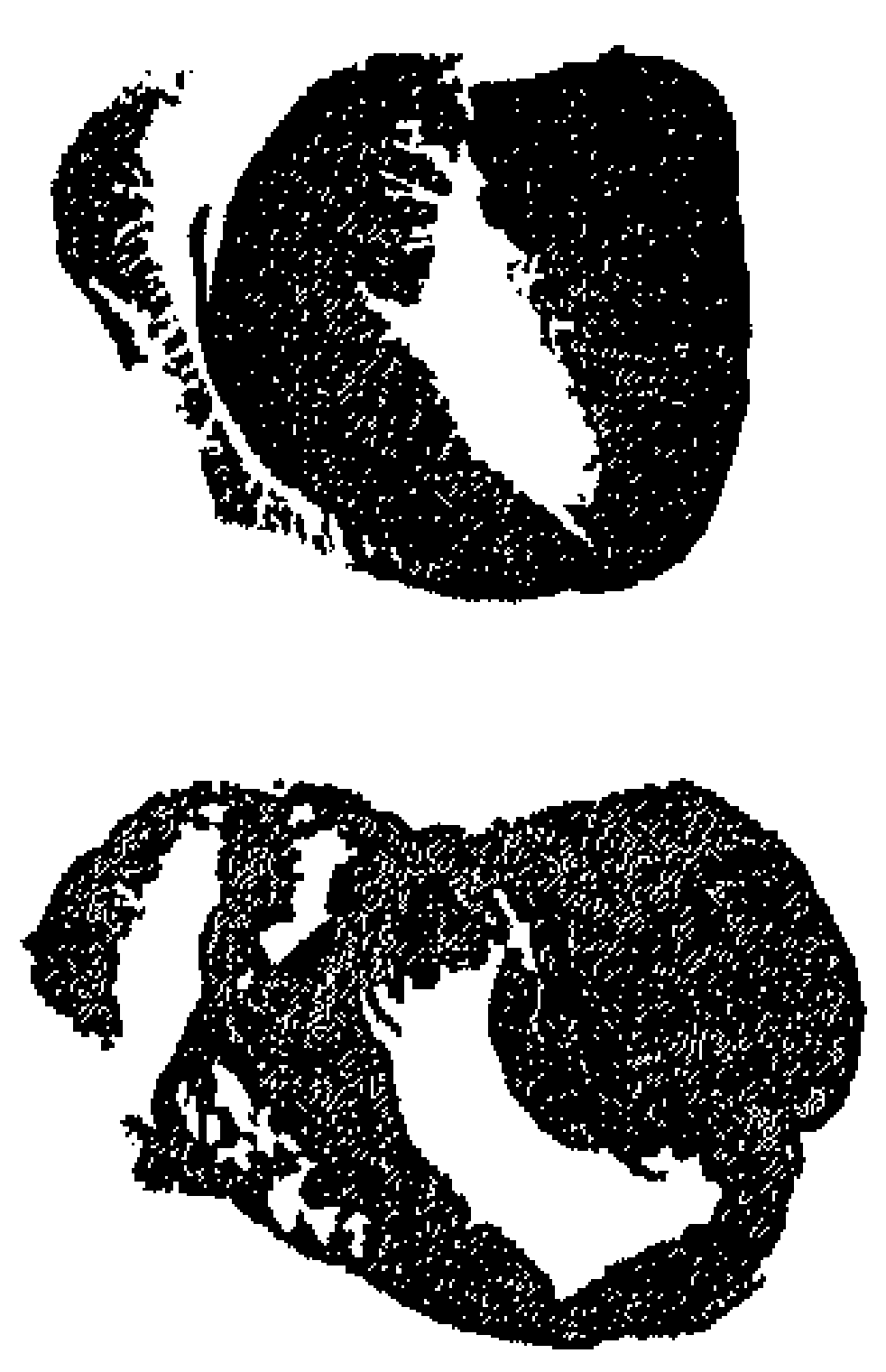

PPAR $\alpha-/-$ MI

C.

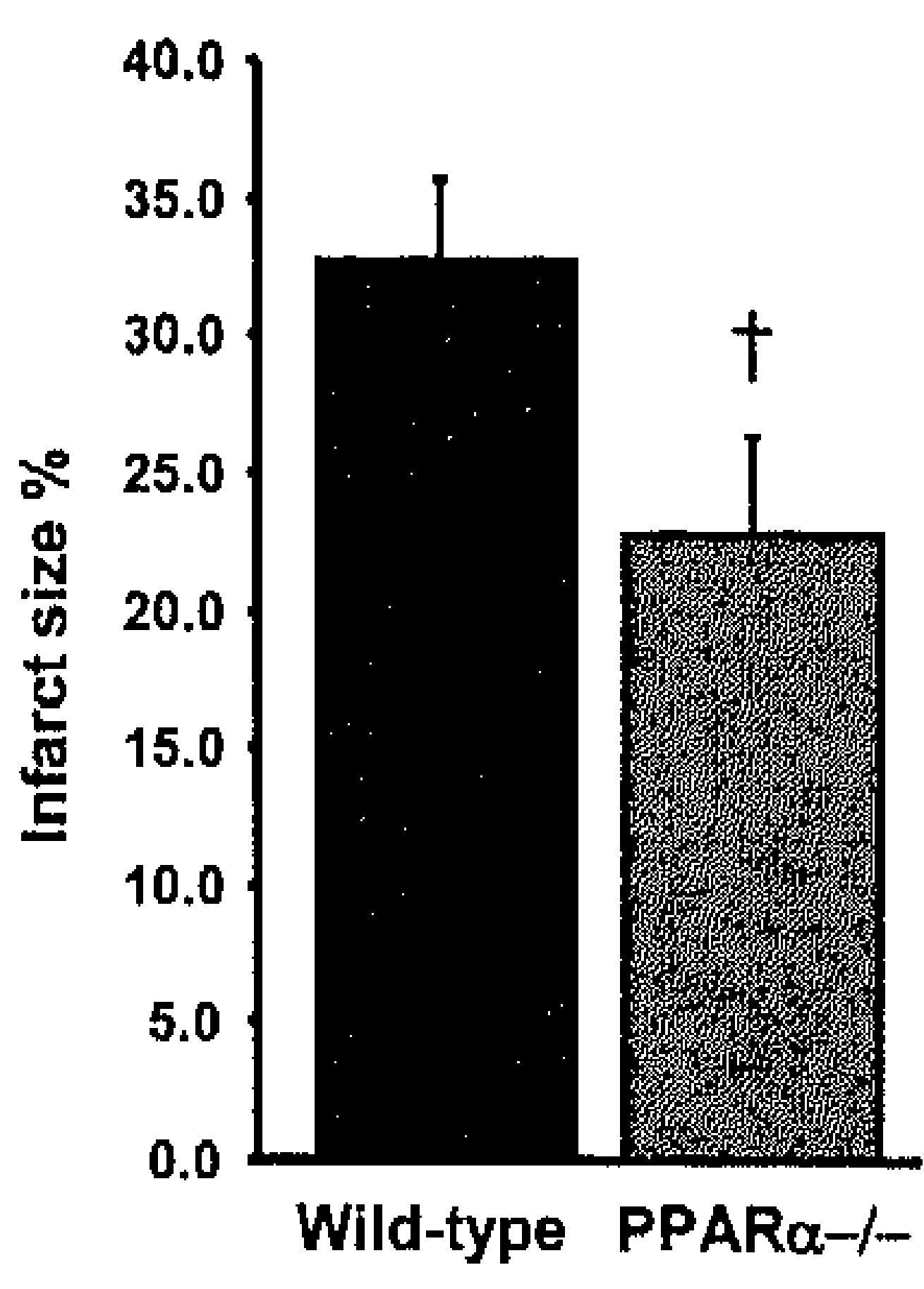

Figure 3. Representative AZAN-stained sections of hearts from MI and sham-operated PPAR $\alpha$ - and wild-type mice (28 days after operation) showing (non-)transmurality of infarcts (panel A). Representative samples of Sirius Red staining of the infarct zone of PPAR $\alpha-/$ and wild-type mice 28 days after MI (panel B). Bar indicates $100 \mu \mathrm{m}$. Collagen (scar tissue) is stained red. Arrow indicates bundles of surviving cardiomyocytes within the infarct zone (C) Infarct size was measured on AZAN-stained sections and expressed as percentage infarcted area of total left ventricular area. $\dagger$ Significantly different from wild-type mice.

\section{MOLECULAR REMODELLING OF THE REMOTE, VIABLE MYOCARDIUM}

mRNA expression of the PPAR isoforms and markers for metabolism, hypertrophy, inflammation, extracellular matrix (ECM), and angiogenesis was analyzed to characterize remodelling of viable myocardium (Table 4).

PPAR ISOFORMS: In the septum of wild-type mice expression levels of PPAR $\alpha$ dropped dramatically after 5 days and partly recovered after 28 days of MI. Deletion of PPAR $\alpha$ was not associated with compensatory upregulation of PPAR $\delta$ and PPAR $\gamma$ in sham-operated hearts of PPAR $\alpha-/$ mice. However, 5 days post-MI PPAR $\delta$ expression was transiently increased both in wild-type and PPAR $\alpha-1$ - mice. PPAR $\gamma$ mRNA levels were not affected by regional MI. 
A.

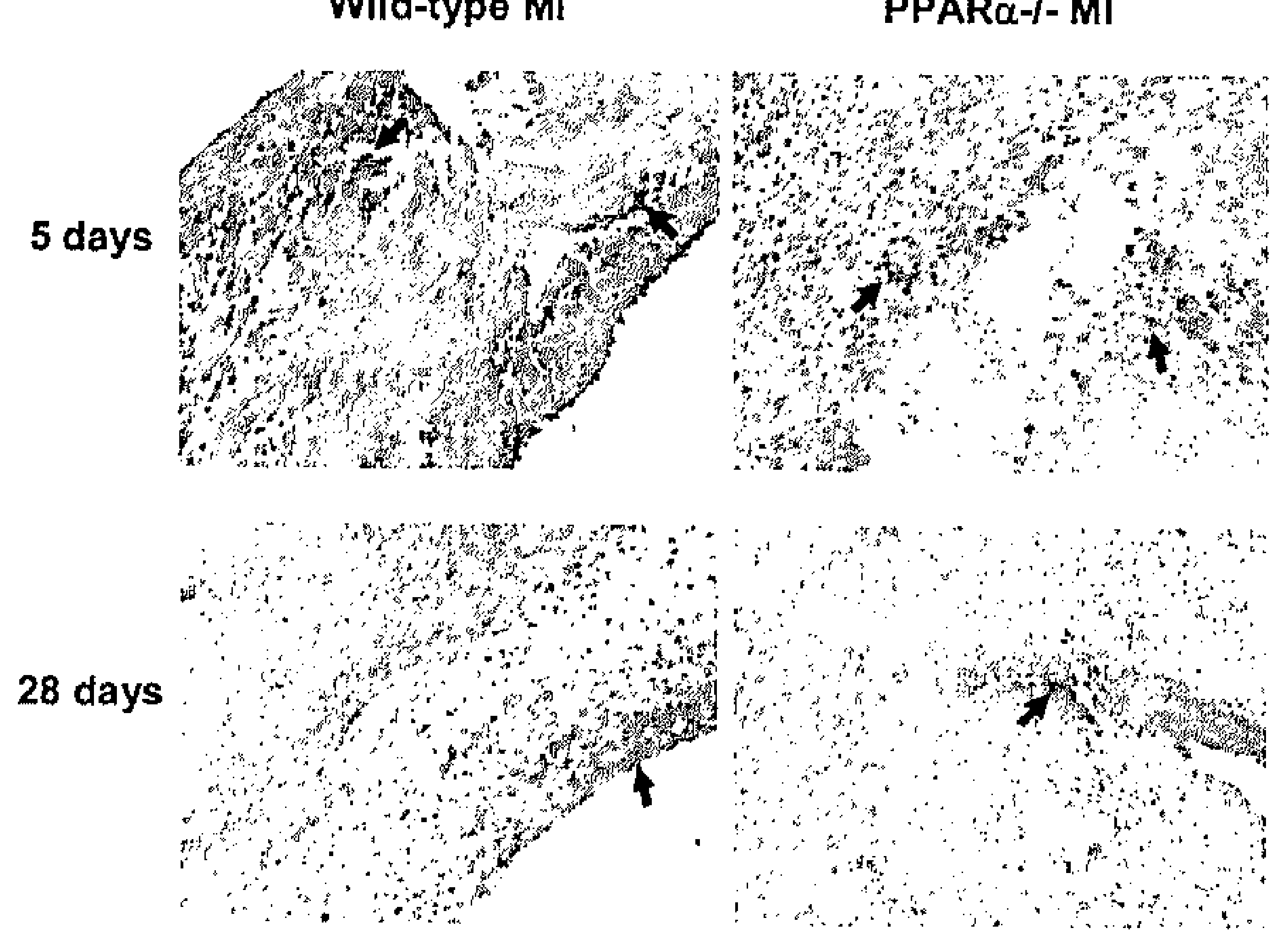

B.

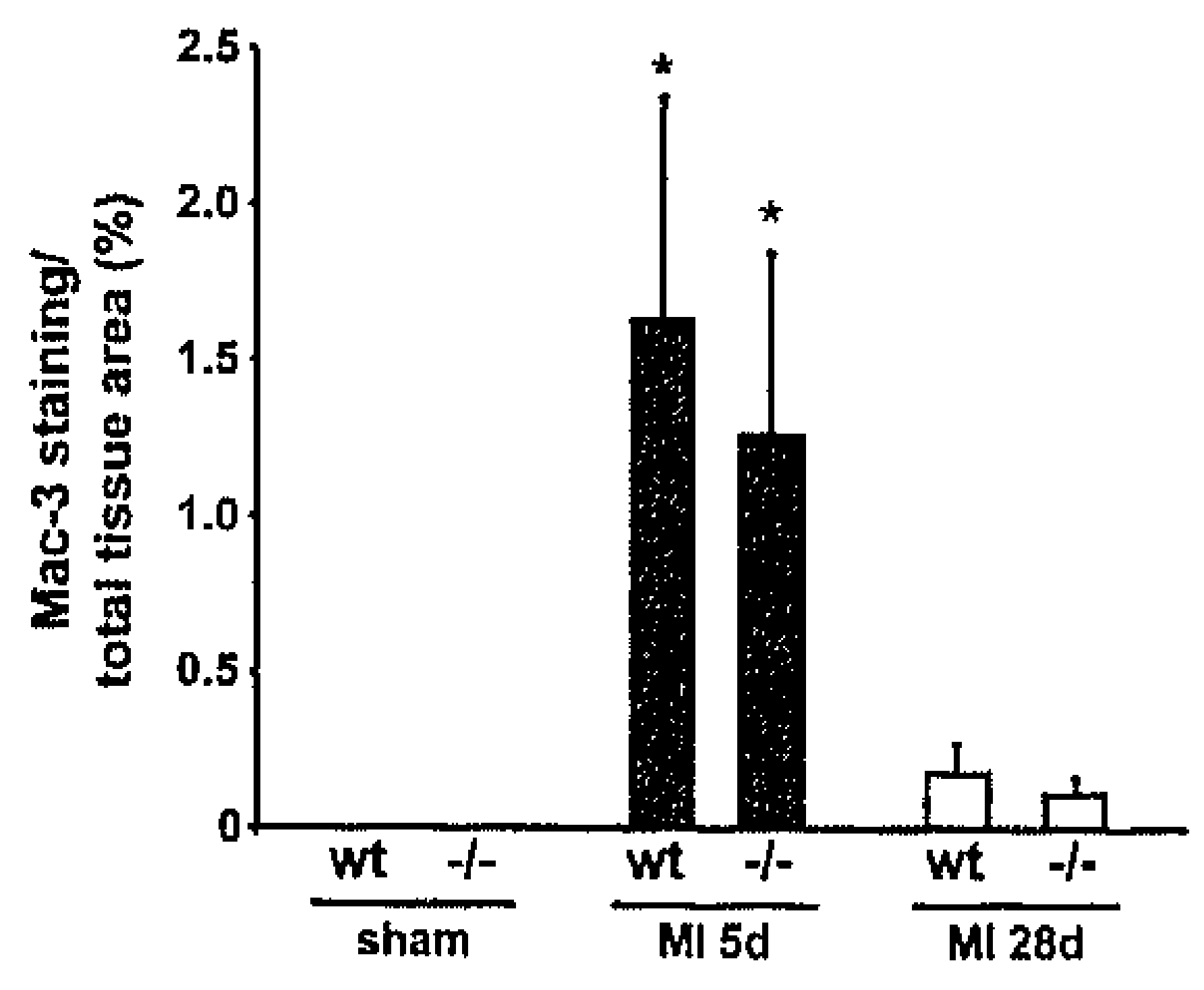

Figure 4. (A) Representative samples of Mac-3 stained sections of the infarct area from PPAR $\alpha /$ - and wildtype mice 5 and 28 days post-MI. Infiltrating macrophages in are indicated by arrows. (B) Relative surface area of Mac-3 positive macrophages in infarct area 5 and 28 days post MI. In sham-operated mice the $\%$ Mac-3 positive surface of the LV free wall was close to zero. * Significantly different from corresponding (PPAR $\alpha-/-$ or wild-type) sham mice.

METABOLISM: As expected, the expression of PPAR-regulated genes involved in mitochondrial fatty acid and glucose metabolism, e.g. hydroxyacyl-coenzyme A dehydrogenase (Hadha), acyl-coA synthetase long-chain family member 1 (Acsl1), and pyruvate dehydrogenase kinase 4 (PDK4), respectively, was already about 50\% lower in sham PPAR $-/$ - than in sham wildtype mice. Expression of Hadha was significantly reduced in the septum of wild-type mice after 5 and 28 days of MI. Similarly, Ascl1 mRNA levels were diminished by about $40 \%$ in wild-type mice both 5 and 28 days after MI. However, this reduction did not reach the level of statistical significance. In contrast, expression of PDK4 was not affected by MI in

A.

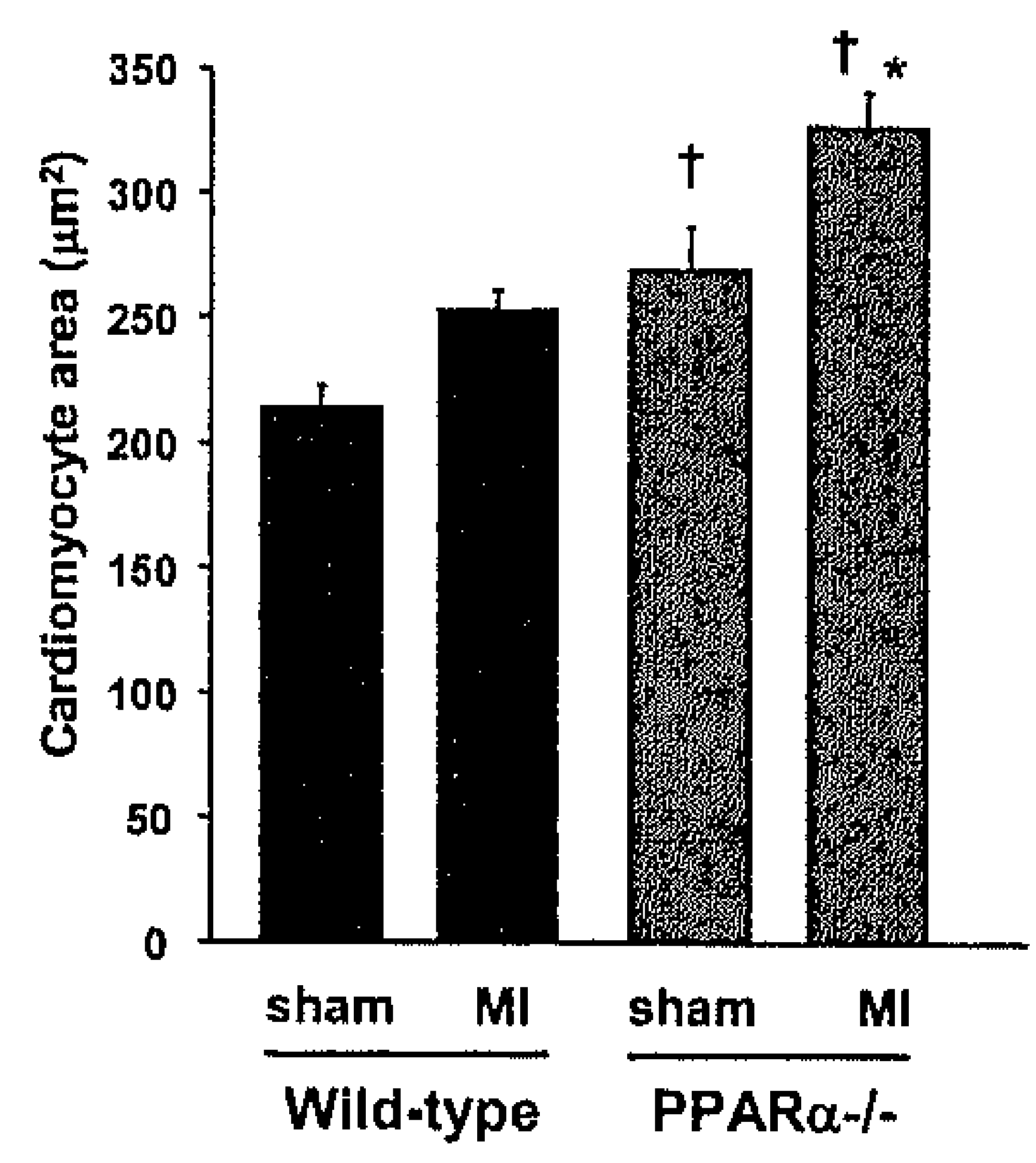

B.

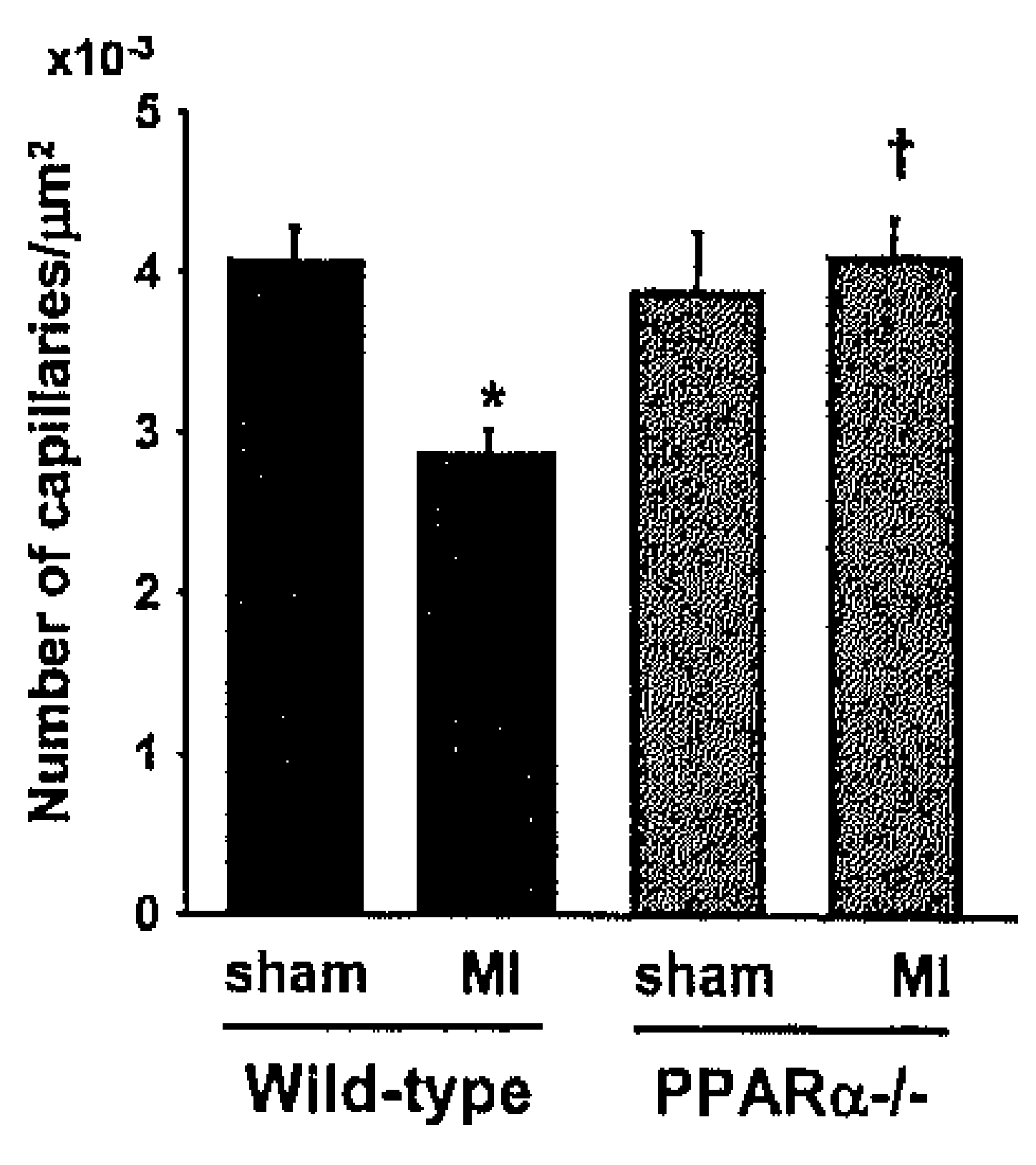

Figure 5. (A) Cardiomyocyte cross-sectional area $\left(\mu \mathrm{m}^{2}\right)$ in remote, viable myocardium of sham and MI operated PPAR $\alpha-/-$ and wild-type mice. (B) Number of capillaries per tissue area $\left(\mu \mathrm{m}^{2}\right)$ was assessed with GSILectin staining. * Significantly different from corresponding (PPAR $\alpha-/$ or wild-type) sham mice. $†$ Significantly different from corresponding (MI or shamoperated) wild-type mice. 
wild-type mice. In PPAR $\alpha-/-$ mice MI did not further reduce expression of Hadha, Acsll or PDK4.

HYPERTROPHY: Expression of the hypertrophic marker genes ANF and $\alpha$-skeletal-actin ( $\alpha$ SKA) in the non-ischemic septum was increased after both 5 and 28 days of regional MI in both genotypes. Expression of SERCA2 was significantly decreased by $\sim 50 \%$ after 5 , but not after 28 days of MI both in wild-type and PPAR $\alpha-/-$ mice. The changes in expression of ANF, $\alpha$-SKA and SERCA2 after MI did not significantly differ between genotypes.

INFLAMMATION: After MI expression of tumour necrosis factor $\alpha$ (TNF $\alpha$ ) in surviving tissue was not significantly affected in both genotypes. In contrast, mRNA levels of the chemotactic factor MCP1 and monocyte/macrophage marker CD68 were significantly upregulated 5 days post-MI. At 28 days, both inflammatory markers had returned to baseline. Genotype-related differences in the response of inflammatory markers were absent.

EXTRACELLULAR MATRIX: In sham-operated mice no genotype-related differences in expression of genes involved in extracellular matrix (ECM) remodelling, e.g. collagen I (Col1), matrix metalloproteinase 2 (MMP2), and the myofibroblast marker $\alpha$-smooth muscle actin ( $\alpha$-SMA), were detected. Following 5 days MI, expression of these matrix modulating genes tended to increase in the remote myocardium. However, due to large inter-individual differences, only the increase in MMP2 in wild-type mice and $\alpha$-SMA both in wild-type and PPAR $\alpha-/-$ mice reached the level of significance. After 28 days MI expression of the ECM markers returned to baseline values, suggesting that ECM remodelling was completed.

ANGIOGENESIS: The preservation of capillary density in the surviving myocardium of PPAR $\alpha$ /- MI mice prompted us to investigate whether differences in expression of pro-angiogenic factors could explain this observation. However, significant changes in the expression of VEGF and its receptors (VEGFR1 and VEGFR2) as a function of genotype or intervention were not detected (Table 4).

\section{MOLECULAR REMODELLING IN THE INFARCT ZONE}

Since infarct healing is characterized by an inflammatory process followed by scar formation, we analyzed mRNA expression of several inflammatory and ECM markers within the infarct zone (Figure 6).

INFLAMMATION: Both in wild-type and PPAR $\alpha$-/- mice mRNA levels of the pro-inflammatory genes TNF $\alpha$, MCP1 and CD68 were substantially elevated 5 days after MI (Figure 6A-C). When infarct healing progressed expression of these genes markedly declined, reaching values comparable to that of sham-operated mice after 28 days of MI. With respect to all genes investigated, differences between wild-type and PPAR $\alpha-/-$ mice were not observed, the only exception being CD68 (Figure 6C), the expression of which was slightly, but significantly higher $(+35 \%)$ in PPAR $\alpha-/$ - than in wild-type mice 5 days after MI. 
EXTRACELLULAR MATRLX: Similar to the inflammatory markers, expression of ECM markers Col1, MMP2, and $\alpha$-SMA was significantly increased after 5 days MI in both genotypes. Expression of Coll and MMP2 was still markedly elevated 28 days post-MI, whereas $\alpha-\mathrm{SMA}$ had returned to baseline (Figure 6D-E). Again no genotype-related differences were observed.

Table 4. mRNA levels in the viable myocardium of PPAR $\alpha-/$ - and wild-type mice 5 or 28 days after regional myocardial infarction (MI).

\begin{tabular}{|c|c|c|c|c|c|c|}
\hline & \multicolumn{2}{|c|}{ Sham } & \multicolumn{2}{|c|}{ MI 5d } & \multicolumn{2}{|c|}{ MI 28d } \\
\hline & Wild-type & PPAR $\alpha-/-$ & Wild-type & PPAR $\alpha-/-$ & Wild-type & PPAR $\alpha-/-$ \\
\hline \multicolumn{7}{|l|}{ PPARs } \\
\hline PPAR $\alpha$ & $1.00 \pm 0.07$ & $0.01 \pm 0.00 \dagger$ & $0.13 \pm 0.02 *$ & $0.00 \pm 0.00$ & $0.75 \pm 0.09^{*}+$ & $0.01 \pm 0.00 \dagger$ \\
\hline PPARS & $1.00 \pm 0.07$ & $0.93 \pm 0.11$ & $2.31 \pm 0.25^{*}$ & $2.55 \pm 0.21^{*}$ & $0.88 \pm 0.01 \ddagger$ & $0.78 \pm 0.06 \ddagger$ \\
\hline PPAR & $1.00 \pm 0.22$ & $0.83 \pm 0.14$ & $0.83 \pm 0.14$ & $0.65 \pm 0.09$ & $0.94 \pm 0.13$ & $0.92 \pm 0.10$ \\
\hline \multicolumn{7}{|l|}{ Metabolism } \\
\hline Acsll & $1.00 \pm 0.32$ & $0.44 \pm 0.09$ & $0.60 \pm 0.10$ & $0.39 \pm 0.04$ & $0.62 \pm 0.12$ & $0.40 \pm 0.06$ \\
\hline Hadha & $1.00 \pm 0.11$ & $0.51 \pm 0.06 \uparrow$ & $0.57 \pm 0.08 *$ & $0.36 \pm 0.06$ & $0.64 \pm 0.05^{*}$ & $0.38 \pm 0.03 \dagger$ \\
\hline PDK4 & $1.00 \pm 0.18$ & $0.56 \pm 0.09$ & $1.33 \pm 0.55$ & $0.45 \pm 0.03$ & $1.34 \pm 0.24$ & $0.60 \pm 0.11 \dagger$ \\
\hline \multicolumn{7}{|c|}{ Hypertrophy } \\
\hline ANF & $1.00 \pm 0.12$ & $1.36 \pm 0.17$ & $5.75 \pm 0.78^{*}$ & $9.90 \pm 2.14^{*}$ & $4.23 \pm 0.95$ & $6.19 \pm 1.52^{*}$ \\
\hline$\alpha-S K A$ & $1.00 \pm 0.16$ & $0.58 \pm 0.07$ & $1.56 \pm 0.16$ & $2.04 \pm 0.42^{*}$ & $2.80 \pm 0.32 *$ & $2.13 \pm 0.44^{*}$ \\
\hline Serca2 & $1.00 \pm 0.07$ & $0.89 \pm 0.07$ & $0.40 \pm 0.12 *$ & $0.47 \pm 0.08^{*}$ & $0.74 \pm 0.07$ & $0.73 \pm 0.07$ \\
\hline \multicolumn{7}{|c|}{ Inflammation } \\
\hline CD68 & $1.00 \pm 0.07$ & $1.25 \pm 0.16$ & $2.81 \pm 0.62^{*}$ & $3.75 \pm 0.87^{*}$ & $1.08 \pm 0.15+$ & $1.13 \pm 0.10 \neq$ \\
\hline MCP 1 & $1.00 \pm 0.18$ & $1.54 \pm 0.25$ & $6.66 \pm 2.13^{*}$ & $7.62 \pm 1.69 *$ & $0.81 \pm 0.19+$ & $1.05 \pm 0.22 \ddagger$ \\
\hline TNF $\alpha$ & $1.00 \pm 0.27$ & $1.17 \pm 0.33$ & $1.33 \pm 0.28$ & $1.68 \pm 0.38$ & $0.43 \pm 0.09$ & $0.88 \pm 0.22$ \\
\hline \multicolumn{7}{|l|}{ Fibrosis } \\
\hline$\alpha-S M A$ & $1.00 \pm 0.13$ & $0.67 \pm 0.10$ & $2.10 \pm 0.58 *$ & $1.77 \pm 0.51^{*}$ & $0.98 \pm 0.07$ & $0.68 \pm 0.08$ \\
\hline Collagen 1 & $1.00 \pm 0.08$ & $0.72 \pm 0.06$ & $6.44 \pm 3.24^{*}$ & $6.07 \pm 3.31$ & $1.42 \pm 0.10$ & $1.46 \pm 0.24$ \\
\hline MMP2 & $1.00 \pm 0.09$ & $0.82 \pm 0.05$ & $2.36 \pm 0.29 *$ & $1.32 \pm 0.40$ & $0.96 \pm 0.08$ & $1.11 \pm 0.17$ \\
\hline \multicolumn{7}{|c|}{ Angiogenesis } \\
\hline VEGF & $1.00 \pm 0.22$ & $0.75 \pm 0.06$ & $0.52 \pm 0.14$ & $0.70 \pm 0.12$ & $0.78 \pm 0.08$ & $0.81 \pm 0.07$ \\
\hline VEGFR1 & $1.00 \pm 0.16$ & $0.83 \pm 0.04$ & $0.64 \pm 0.07$ & $0.67 \pm 0.08$ & $0.86 \pm 0.05$ & $0.73 \pm 0.05$ \\
\hline VEGFR2 & $1.00 \pm 0.16$ & $0.90 \pm 0.15$ & $0.81 \pm 0.16$ & $1.09 \pm 0.24$ & $0.76 \pm 0.10$ & $0.62 \pm 0.07$ \\
\hline
\end{tabular}

For each gene the mRNA level of sham-operated wild-type mice was set to 1.0; other mRNA levels were expressed relative to this value. RNA was extracted from non-ischemic basal part of the septum. * Significantly different from corresponding sham-operated mice. $\uparrow$ Significantly different from corresponding wild-type mice. $\ddagger$ Significantly different between 28 days and corresponding 5 days MI group.

\section{DISCUSSION}

In the present study, we show that deletion of the PPAR $\alpha$ gene is associated with smaller infarct size and decline in the incidence of cardiac rupture. Concurrently, in the remote, viable myocardium of PPAR $\alpha$-l- mice cardiomyocyte cross-sectional area is increased and capillary density is higher, relative to wild-type mice subjected to regional MI. The combined effects 
on the infarcted and surviving myocardium most likely account for the observed better preservation of cardiac hemodynamic function in the PPAR $\alpha-/$ - mice. The marked differences

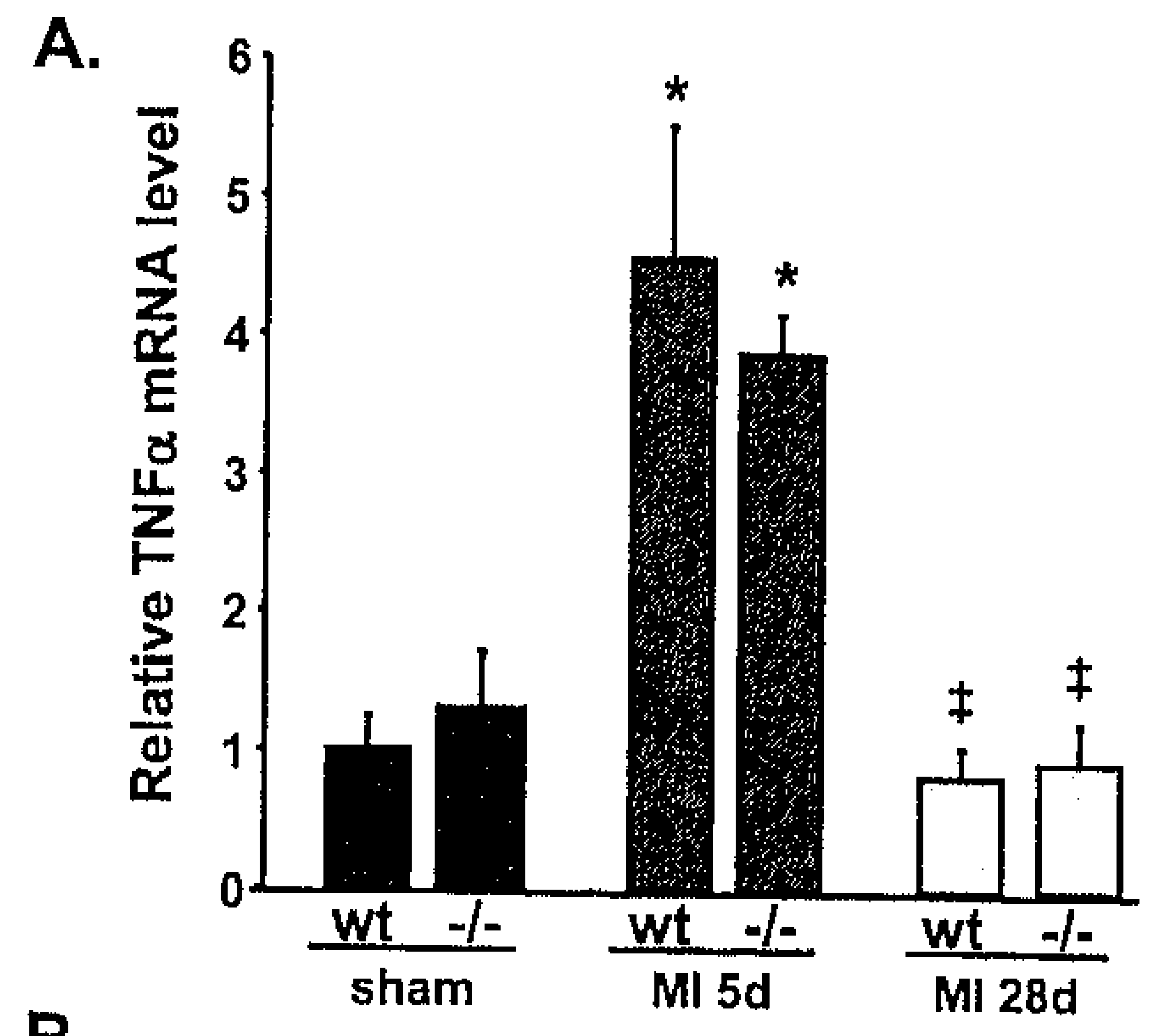

B.
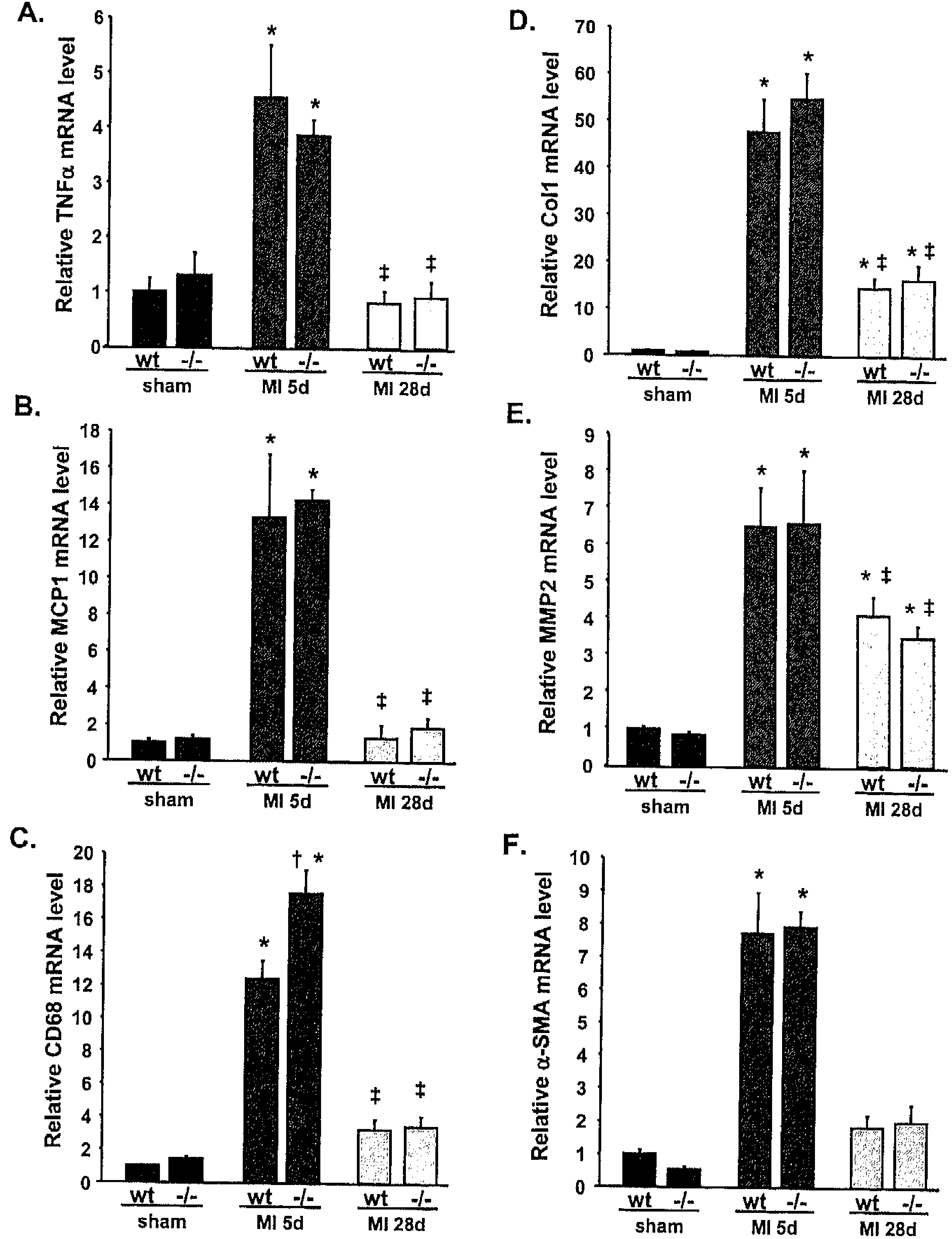

Figure 6. mRNA expression in the central infarct zone of PPAR $\alpha-/-$ and wild-type (WT) mice. Inflammation markers TNF- $\alpha$, MCP1 (B), and CD68 (C), and fibrotic marker genes C011 (D), MMP2 (E), and $\alpha$-SMA (F) are shown. For each gene the mRNA level in the left ventricular free wall of sham-operated wild-type mice was set to 1.0 ; other mRNA levels were expressed relative to this value. * Significantly different from corresponding sham mice. $\dagger$ Significantly different from corresponding wild-type mice. $\ddagger$ Significantly different between 28 day and corresponding 5 day MI groups. 
in outcome between wild-type and PPAR $\alpha$-/- mice cannot be attributed to PPAR-related effects on inflammatory, apoptotic or fibrotic processes. The preservation of capillary density PPAR $\alpha-/$ - after MI might point to a beneficial pro-angiogenic effect in these hearts.

\section{INFARCT REMODELLING IN PPAR $\alpha-/$ MICE}

After coronary occlusion and the consequent loss of contractile myocardium by apoptosis and/or necrosis, a healing process is quickly initiated characterized by inflammatory cell infiltration and extracellular matrix deposition to rebuild the infarcted myocardium and to maintain structural integrity of the ventricle. ${ }^{7,215}$

In the present study we observed that, rather than the anticipated detrimental outcome in the mice lacking PPAR $\alpha$, the incidence of cardiac rupture was lower and that the final infarct size was significantly smaller. Rupture is believed to be caused by overstretching of the structurally weakened myocardium, and its incidence is related to infarct size and transmurality. ${ }^{216}$ Accordingly, the lower incidence of rupture in PPAR $\alpha-/$ - mice is likely to be caused by the smaller infarct size in combination with the non-transmurality of the infarct in about half of the animals.

Although PPAR $\alpha$ has been implicated in attenuating inflammation and fibrosis ${ }^{221,222}$, in this study no clear evidence for an exaggerated inflammatory or fibrotic response in PPAR $\alpha-/-$ mice was found. Although the expression of inflammatory and fibrotic markers substantially increased in the early infarcts, the level of induction was comparable between genotypes at 5 days post-MI. The only difference we observed was that mRNA expression of the monocyte/macrophage marker CD68 was modestly higher ( $+35 \%)$ in the infarct zone of PPAR $\alpha-/$ - mice. Likewise, 28 days post-MI mRNA levels were reduced to the same extent in both genotypes. Furthermore, immuno-histochemistry revealed that 5 days post-MI the number of infiltrating (MAC-3 positive) macrophages and number of TUNEL positive apoptotic cells were comparable between PPAR $\alpha-/$ - and wild-type mice. Accordingly, the collective observations suggest that modulation of the inflammatory, apoptotic or fibrotic processes is not the principal mechanism by which PPAR $\alpha$ affects, directly or indirectly, the reparative process in the infarcted tissue.

\section{REMODELLING OF THE VIABLE MYOCARDIUM OF PPAR $\alpha-/$ - MICE}

Loss of viable myocardium upon MI leads to LV dilatation and increased loading of the remaining viable tissue, resulting in compensatory hypertrophy. ${ }^{178}$ However, the level of hypertrophy of the viable myocardium following $\mathrm{MI}$ is difficult to deduce from changes in ventricular weight or wall thickness, as it is the outcome of loss of cardiac muscle tissue, wall thinning and increased LV volume due to dilatation per se, and hypertrophy of surviving cardiomyocytes. Changes in cardiomyocyte cross-sectional area and expression of hypertrophic markers are probably more decisive. In this sense the larger cardiomyocyte size 
and higher ANF mRNA level in the non-ischemic septum of PPAR $\alpha-/$ - mice post-MI point to more pronounced hypertrophic response of the surviving cardiomyocytes despite a smaller infarct size of the flow-deprived area. This observation corroborates earlier studies in which we showed that cardiac hypertrophy is enhanced in PPAR $\alpha-/$ - mice after imposition of an increased afterload via transverse aortic constriction. ${ }^{18}$

Notably, in the viable myocardium of wild-type mice MI was associated with marked transient changes in the expression of PPAR $\alpha$ and PPAR $\delta$. but not PPAR $\gamma$. Five days post-MI PPAR $\alpha$ mRNA levels had dropped to less than $20 \%$ to that of hearts of sham-operated mice. This coincided with a rise in PPARס mRNA. The significance of this isoform switch remains to be determined. As shown here and before ${ }^{223}$ the absence of PPAR $\alpha$ was associated with a reduced expression of genes involved in cardiac fatty acid metabolism, thereby limiting the aerobic capacity of the cardiac muscle. ${ }^{224}$ On the other hand, the hearts of PPAR $\alpha-/-$ mice are more adapted to using glucose as energy source. This may be advantageous under certain disease conditions, especially conditions involving oxygen shortage. Indeed, chronically increased glucose utilization secondary to forced GLUT1 overexpression was found to protect the murine heart against $\mathrm{I} / \mathrm{R}$ damage. ${ }^{225}$ It is conceivable that the better hemodynamic outcome of PPAR $\alpha-/$ - mice after regional MI is also related to such a metabolic effect.

An alternative explanation for better preserved cardiac function may be based on the putative effects of PPAR $\alpha$ on angiogenesis as, unlike wild-type mice, capillary density in the viable myocardium was maintained in PPAR $\alpha-/-$ mice 28 days post-MI. Indeed, there is close relationship between capillary density in the viable hypertrophic myocardium and preservation of cardiac function after MI. ${ }^{226}$ PPAR $\alpha$ agonists have been shown to attenuate capillary network formation by targeting VEGFR2 expression. ${ }^{227}$ Therefore, we hypothesized that expression of pro-angiogenic genes would be increased in PPAR $\alpha-/$ - hearts. However, mRNA levels of the canonical mediators VEGF and its receptors VEGFR1 and VEGFR2, were comparable in both genotypes. Further studies are necessary to elucidate mechanisms responsible for the maintenance of capillary density in PPAR $\alpha-/$ - mice after MI.

\section{PERSPECTIVES}

Lack of PPAR $\alpha-/$ - resulted in smaller infarcts, less rupture, and better overall cardiac function after MI. Despite the profound activation of inflammatory processes in the infarcted myocardium and the reported anti-inflammatory effects of $\operatorname{PPAR} \alpha$, we found no evidence whatsoever of an enhanced inflammatory response in the infarct zone in the PPAR $\alpha-/$ - mice. Concurrently, in the surviving myocardium of PPAR $\alpha-/-$ mice cardiomyocyte cross-sectional area was bigger than in wild-type mice and capillary density was preserved. Collectively these findings indicate that PPAR $\alpha$ has multiple effects on hearts suffering from regional MI by acting on both the infarcted and surviving tissue. Further studies are required to delineate the exact molecular mechanism(s) underlying the beneficial effect of PPAR $\alpha$ deletion on infarct 
size and cardiac function. Consistent with previous reports on unexpected effects of PPAR $\alpha$ ligands on blood pressure and atherosclerosis ${ }^{228}$, the present findings point to a beneficial effect of the absence of PPAR $\alpha$ on the regionally infarcted myocardium. This observation warrants a critical reevaluation of the supposedly therapeutic effects of PPAR $\alpha$ activation by administration of synthetic ligands on the diseased heart.

\section{ACKNOWLEDGEMENTS}

Investigations were supported by Netherlands Organization of Scientific Research NWO (912-04-017) and EU-FP6 grant LSHM-CT-2005-018833, EUGeneHeart. 


$$
\mid
$$




\section{INTRODUCTION}

In this thesis the role of PPARs, especially PPAR $\alpha$ and PPAR $\delta$, in cardiac disease were studied. Using PPAR $\alpha /$ - mice, pressure overload-induced hypertrophy and myocardial infarction were investigated in vivo. Challenged neonatal cardiomyocytes served as a model for in vitro pressure overload-induced hypertrophy. The studies described in this thesis contribute to the understanding of PPARs as modulators in cardiac disease and provide new scientific challenges. First, we will discuss the role of PPARs during normal physiological functioning, followed by its role in left ventricular hypertrophy (LVH) and myocardial infarction (MI). Next, the clinical significance of the findings described in this thesis and new valuable, future studies are discussed in this chapter.

\section{PPARS IN NORMAL CARDIAC PHYSIOLOGY}

Of the three PPAR isoforms, i.e., PPAR $\alpha$ (NR1C1), PPAR $(\mathrm{NR} 1 \mathrm{C} 2)$ and PPAR $\gamma$ (NR1C3), PPAR $\alpha$ is primarily expressed in tissues with a high level of fatty acid metabolism, while the PPAR $\delta$ isoform is ubiquitously expressed. ${ }^{21}$ From the two PPAR $\gamma$ splice variants, PPAR $\gamma 1$ is expressed in various cell types, like macrophages, while PPAR $\gamma 2$ is exclusively expressed in adipocytes. ${ }^{47}$ Two of the three PPAR isoforms, PPAR $\alpha$ and PPAR $\delta$, are abundantly expressed in cardiac muscle cells and fibroblasts and therefore extensively studied in this thesis. ${ }^{22,23}$ Long-chain fatty acids (FA) are natural ligands of PPARs. The majority of genes regulated by PPAR via transactivation are involved in lipid metabolism, so FA can regulate their own metabolism via PPAR activation. It is important to note that approximately $65 \%$ of the energy conversion, needed to sustain the mechanical activity of the heart, is derived from fatty acid oxidation (FAO), indicating the crucial role of PPARs in cardiac physiology. ${ }^{52}$

Furthermore, PPARs are able to inhibit gene expression via transrepression. It is of interest to note that most of the genes of which the gene expression is inhibited by PPARs are involved in inflammatory signalling, defence mechanisms and the cell cycle (chapter 5). The inflammatory response is in this thesis primarily defined as the level of activity of the nuclear receptor nuclear factor- $\mathrm{KB}(\mathrm{NF}-\mathrm{kB})$. NF- $\mathrm{kB}$ is considered to be one of the major regulators of inflammatory signalling but also has a central role in immune response. ${ }^{125,229}$ As discussed in chapter five, PPAR $\alpha$ has a prominent role in the modulation of the immune-inflammatory axis. Next to this, cell proliferation and growth are modulated by the transrepression property of PPAR $\alpha$, namely by inhibiting genes belonging to the cell cycle.

\section{EFFECT OF PPAR $\alpha$ DURING MYOCARDIAL INFARCTION AND CARDIAC HYPERTROPHY}

To study the role of PPAR $\alpha$ during myocardial infarction and cardiac hypertrophy, the deletion of the gene encoding PPAR $\alpha$ in mice yields valuable information. An important 
parameter to determine the effect of ligation of the left anterior descending coronary artery (LAD) or induction of transverse aortic constriction (TAC) in PPAR $\alpha-/$ - mice is survival. After 28 days of TAC survival was rather poor in the PPAR $\alpha-/$ - mice but survival rate was significantly better in PPAR $\alpha-/$ - mice after MI. Thus, in terms of survival, PPAR $\alpha-/$ - mice can cope relatively well with an episode of MI but cannot manage a sustained increase in pressure. We will discuss metabolic and inflammatory processes and the functional parameter hypertrophy in PPAR $\alpha-/$ - mice with respect to the difference in outcome.

\section{METABOLISM IN STRESSED PPAR $\alpha-/$ - MICE}

To date, FA metabolism is one of the best studied processes which is regulated by PPAR $\alpha^{20 \text {, }}$

${ }^{22}$ It is anticipated that cardiac FA metabolism negatively influences the heart under conditions of ischemia. ${ }^{69,71}$ Since PPAR $\alpha-/-$ mice have a decreased expression of FA-metabolizing enzymes, PPAR $\alpha-/$ - mice are more adapted to the use of glucose as an energy source and this favours the heart in periods of ischemia. ${ }^{230}$ This is supported by studies in which glucose metabolism was enhanced in PPAR $\alpha-/-$ mice resulting in better cardiac performance of PPAR $\alpha-/$ mice compared to wild-type mice. ${ }^{72}$ However, in the long-term the already compromised energy-generating capacity of the cardiac muscle cells may be insufficient to cope with the increased demand of the surviving myocardium after MI or in the LV after chronic pressure overload (as shown in chapter 4). In line with our observations in PPAR $\alpha-/-$ mice subjected to MI, isolated hearts of PPAR $\alpha-/-$ mice have been reported to perform better during ischemia-reperfusion compared to wild-type. ${ }^{30}$ Thus, regulation of metabolic processes by PPAR $\alpha$ has important consequences in different cardiac disorders because changes in glucose or FA metabolism affect the functional outcome.

\section{INFLAMMATION IN STRESSED PPAR $\alpha-/-$ MICE}

The in vitro data in chapter three indicate that activation of PPAR $\alpha$ and PPAR $\delta$ has beneficial effects on cardiomyocyte hypertrophy by inhibiting the inflammatory response. The findings in chapter three are corroborated by the studies in PPAR $\alpha-/-$ mice showing that targets of NF$\kappa \mathrm{B}$ are significantly upregulated during pressure overload-induced hypertrophy. Although inflammatory processes are an integral part of the $\mathrm{MI}$ episode, no anti-inflammatory effect of PPAR $\alpha$ was observed in the infarcted area or in the surviving myocardium. It is noteworthy to mention that differences in inflammation are probably better to distinguish in a pressure overload model then after MI. Possibly, the effects of PPAR $\alpha$ on inflammatory signalling are not prominent enough to be detected in the MI model where massive inflammation and ECM remodelling takes place. ${ }^{6}$ Moreover, PPAR effects could be seen later in time after the initial massive inflammatory reaction and when ECM remodelling is complete. So, long-term observations of PPAR $\alpha-/$ - mice subjected to MI can provide more in-depth information. An 
alternative explanation of the findings is that inhibition of inflammation by PPARs is not the principal mechanism by which PPARs alleviate cardiac disorders.

Recently, PPAR signalling has been associated with the differentiation of M1 and M2 macrophages. ${ }^{231}$ The difference lies in the fact that a distinction is made between "good" and "bad" macrophages, affecting the direction of the inflammatory response. Different cytokines will differentiate monocytes into proatherogenic M1 macrophages or in anti-inflammatory M2 macrophages. In this respect, PPAR $\gamma$ has been reported to turn monocytes towards the M2 phenotype. $^{231}$ The effect of PPAR $\alpha$ on M1 and M2 macrophages and whether this plays a significant role during $\mathrm{MI}$ is still not delineated and warrants further research. It cannot be excluded that the type of macrophages is altered in PPAR $\alpha-/$ - mice compared to wild-type after MI.

Whatever the underlying reason may be, the findings in chapter six trigger to re-evaluate the use of PPAR ligands as anti-inflammatory therapy to alleviate coronary artery disease.

\section{HYPERTROPHY}

Interestingly, the hypertrophic response was more pronounced in hearts from PPAR $\alpha-/-$ mice following the induction of TAC or MI. After a sustained pressure overload ventricular weight was more pronounced in PPAR $\alpha-/$ mice while after MT there was an increase in cardiomyocyte cross-sectional area in the surviving myocardium of PPAR $\alpha-/$-mice compared to wild-type. Although this adaptive growth will first improve cardiac performance, a sustained increase in pressure affects cardiac function and will eventually turn the heart to $\mathrm{HF} .^{93}$ Indeed, mice subjected to TAC have deteriorated cardiac function and develop towards heart failure after four weeks. Studies designed to investigate the long-term effects of cardiac remodelling after $\mathrm{MI}$ in PPAR $\alpha-/$ mice could be helpful in understanding the functional effects of the increase in hypertrophic growth. Despite the fact that no differences were observed in the degree of inflammation between PPAR $\alpha-/$ - and wild-type mice in the MI model, it is still conceivable that the response of signalling pathways in individual cardiomyocytes or fibroblasts to the circulating inflammatory mediators in PPAR $\alpha-/-$ mice is altered and could enhance the hypertrophic growth of the surviving muscle cells. Although inflammatory processes don't exhibit increased activity, PPAR $\alpha-/$ mice may be more susceptible to pro-inflammatory mediators.

Finally, some general remarks can be made to discuss the observed differences in inflammation between the $\mathrm{MI}$ and pressure overload model. It should be emphasized that the mouse model studied here has a systemic deletion of PPAR $\alpha$ since embryonic development. ${ }^{174}$ It is possible that changes in anatomy or physiology compared to normal mice have affected the obtained findings. Alternatively, compensatory upregulation of PPAR $\delta$ could also be an underlying mechanism for the preservation of cardiac function in PPAR $\alpha-/$ mice. However, mRNA analysis revealed that PPAR $\delta$ mRNA expression was not changed in 
sham-operated PPAR $\alpha$ null mice. It has been demonstrated previously that there is no compensatory upregulation of PPAR $\delta$ in PPAR $\alpha-/$ mice. ${ }^{232}$ However, PPAR $\delta$ mRNA expression was upregulated after MI in the remote, viable myocardium in both genotypes. This increase in PPAR gene expression coincided with a downregulation of PPAR $\alpha$ mRNA in wild-type mice. Apparently, this decreased expression of PPAR $\alpha$ mRNA, and its target genes, points to the adaptive mechanism to shift from FA metabolism to glucose metabolism during ischemia, an effect not occurring in the pressure overload model. The significance of the observed increase in PPAR $\delta$ mRNA expression still remains to be determined.

\section{NEW INSIGHTS IN THE MODULATION OF CARDIAC DISORDERS BY PPARS}

When evaluating all discussed effects of PPAR $\alpha$ on cardiac disorders, the question arises which pathways are affected by PPAR $\alpha$. This will help understanding the mechanism of modulation of cardiac disease by PPAR $\alpha$ and to create specific clinical treatments. In chapter 5 , an extensive microarray experiment was performed to help resolving these open gaps in the current knowledge of PPARs. Although the microarray experiments found some usual suspects (e.g. FA metabolism), some unexpected processes were unravelled. PPAR $\alpha$ was associated with the immune-inflammatory axis and this might direct further studies to explore new opportunities for pharmacological interventions in cardiac disease.

Currently, PPAR research focuses, next to the effects of PPAR $\alpha$ and PPAR $\gamma$, to the effects of PPARS on cardiac disease. Thanks to the development of better tools to study the effects of PPARס, e.g. PPAR $\delta$-specific ligands and PPAR $\delta$ conditional knock-out models, and to the awareness that its activity may have a broader impact (since this receptor is ubiquitously expressed) compared to PPAR $\alpha$. or $\operatorname{PPAR} \gamma$, the attention for this nuclear receptor is increasing. More and more studies are designed to delineate the effects of PPAR $\delta$ on left ventricular hypertrophy $(\mathrm{LVH}) .{ }^{172,232,}{ }^{233}$ In this respect, an interesting study is the one performed by Burkat and collegues. ${ }^{233}$ In this particular study, the effects of PPAR $\alpha$. and PPAR $\delta$ in mice with cardiac overexpression of PPAR $\alpha$ and PPAR $\delta$ were compared. Interestingly, in mice overexpressing PPAR $\delta$ myocardial glucose utilization was enhanced while in mice overexpressing PPAR $\alpha$ FA metabolism was activated. Differential transcriptional control mechanisms may account for the observed differences. During ischemia-reperfusion, myocardial injury was reduced in mice with a cardiac-specific overexpression of PPAR $\delta$. These findings support earlier considerations (section METABOLISM IN STRESSED PPAR $\alpha-/$ MICE) concerning the important role of metabolism in the protective effect of lack of PPAR $\alpha$ during MI.

Another member of the PPAR family, which hasn't been extensively discussed in this thesis, is PPAR $\gamma$. The PPAR $\gamma$-independent effects of their ligands, as discussed in chapter two, argue against use of PPAR $\gamma$ therapy in cardiac disease. Moreover, it has been reported that PPAR $\gamma$ 
activation does not modulate the expression of genes involved in cardiac lipid metabolism. ${ }^{22}$ However, evidence is present that beneficial effects occur during ischemia-reperfusion. Still, cardiac hypertrophy is likely not to be treated with PPAR $\gamma$ ligands despite the fact that PPAR $\gamma$ has been reported to reduce the hypertrophic phenotype in adult cardiac myocytes. ${ }^{234}$

\section{CLINICAL IMPLICATIONS OF THE PRESENT RESEARCH}

\section{RELEVANCE OF INFLAMMATION IN CARDIAC DISEASE}

Why is inflammation so important in cardiac disease? A nice example where inflammation and cardiac disease meet is the association between rheumatoid arthritis and cardiovascular death. It has been shown that patients with rheumatoid arthritis have an increased risk for cardiovascular death. ${ }^{235,}{ }^{236}$ Moreover, even systemic inflammatory mediators are independent predictors of cardiovascular events, especially in older persons. ${ }^{237}$ According to the Framingham study, elderly with elevated serum levels of C-reactive protein (CRP), interleukin-6 (IL-6) and production of TNF- $\alpha$ by peripheral blood mononuclear cell (PBMC TNF- $\alpha$ ) had over a fourfold increased risk of congestive HF. ${ }^{238}$ Next to originating from circulating macrophages, systemic cytokines or endotoxins affecting the cardiac inflammatory response can also be produced by the gut and the liver. ${ }^{239}$ Besides systemic inflammatory mediators, cardiac-specific production of cytokines contributes also to disease progression. ${ }^{31}$

\section{THERAPEUTIC USE OF PPAR LIGANDS}

Several important aspects to consider the use of PPAR ligands in the human situation are (1) the expression of PPARs in humans during cardiac disease, (2) existing polymorphisms in humans and (3) evidence obtained from clinical trials using PPAR ligands. The first topic is still a highly controversial one. Several studies have pointed to a decrease of cardiac PPAR $\alpha$ . expression in the failing heart. ${ }^{240,241}$ However, others found an increase in protein expression of PPAR $\alpha$ in heart failure patients. ${ }^{242,243}$ Whether PPAR expression increases or decreases during HF is still inconclusive. Further research is warranted, especially since knowledge about PPAR expression during cardiac disease can be an important determinant for treatment with PPAR ligands. The experimental evidence described in this thesis support that treatment of the diseased heart with PPAR $\alpha$ or PPAR $\delta$ ligands would be of clinical value to improve cardiac disorders. Interestingly, in a recent published study in vitro cardiac hypertrophy resulted in decreased mRNA expression but in unaltered protein levels of all three PPAR isoforms in adult rat myocytes. ${ }^{234}$ The inactivation of PPARs could be reversed by treating adult rat myocytes with their respective PPAR ligands. The fact that the decreased DNAbinding activity of PPAR during hypertrophy, as observed in this study, can be reversed is in favour of using PPAR ligands in heart disease. Secondly, evidence from polymorphisms in the genes encoding PPARs in the human population associated with cardiac disorders 
identifies populations at risk. PPAR polymorphisms leading to loss- or gain-of-function have been studied in relation to distinct cardiac disorders. In addition to the findings discussed by Flavell et al. ${ }^{244}$ in chapter two, it is worth mentioning that PPARA gene variation is also associated with physical performance. ${ }^{245}$ The GG genotype was more prevalent among endurance athletes. These data support the hypothesis that activation of PPAR $\alpha$ is beneficial to the human heart, thus in favour of PPAR $\alpha$ treatment during LVH. The third consideration for use of PPAR ligands in humans to combat cardiac disease is the clinical evidence obtained from randomized prospective trials. Two major controlled randomised trials have been published, namely the PROactive (PROspective pioglitAzone Clinical Trial in macroVascular Events) and the FIELD (Fenofibrate Intervention and Event Lowering in Diabetes) study., 10 The first trial investigated whether the PPAR $\gamma$ ligand pioglitazone reduces morbidity and mortality in type 2 diabetes. Using a study population of 5238 patients, a beneficial effect on all-cause mortality and non-fatal myocardial infarction was reported. ${ }^{9}$ The FIELD study included 9795 type 2 diabetes patients and investigated the effects of fenofibrate (PPAR $\alpha$ ligand) on coronary events. They reported a reduction in total cardiovascular events but were probably confounded by the effect of the use of statins, which prevented a larger treatment benefit. Thus, these outcomes support that application of PPAR ligands has beneficial effects in cardiovascular disease.

Clinical trials studying the effects of fenofibrate on inflammation are scarce. Thus far, only short-term treatment of fenofibrate on circulating markers of inflammation and haemostasis in patients with impaired glucose tolerance was studied ${ }^{246}$ In this study, fenofibrate normalised the increase in monocyte release of TNF- $\alpha$, IL-1 $\beta$, IL- 6 , and monocyte chemoattractant protein-1 (MCP-1). The authors suggested that these effects were related to the improvement on insulin sensitivity by fenofibrate. Intriguingly, no clinical studies to assess the inflammatory state in cardiovascular disease using PPAR ligands have been performed. However, a study designed to assess inflammatory markers in relation to cardiovascular disease in patients receiving PPAR therapy could have important consequences.

As already pointed out in a previous section of this chapter, to know when to use PPAR ligands is important regarding to the different outcomes of PPAR activation in cardiac disorders. In this respect, the development of selective PPAR modulators (SPPARM) is in line with this statement. SPPARMs are PPAR-specific ligands but are chemically altered to specifically modulate gene expression and avoiding adverse effects. ${ }^{247}$ This could open some new perspectives with respect to PPAR $\gamma$. Oedema is namely an important side-effect of PPAR $\gamma$ agonists and therefore limits its use in cardiac disease. By this means, new clinical use could be foreseen for PPAR ligands. ${ }^{248,} 249$ 


\section{Clinical RAMIFICATIONS}

Should PPAR $\alpha$ ligands be used in patients with high risk of MI? Seen the failure of antiinflammatory therapies thus $\mathrm{far}^{36-39}$, more research is warranted to the behaviour of PPAR $\alpha$ in MI. New studies should be designed to treat mice subjected to MI with PPAR ligands in the short- and long-term. Moreover, clinical studies aimed at delineating the anti-inflammatory properties of PPAR ligands in the diseased heart can answer important questions regarding the clinical efficacy of PPAR ligands. The fact that processes such as extracellular matrix remodelling, immune response, oxidative stress, and inflammatory signalling pathways are enriched in the studies we performed in pressure overload induced LVH offers some promising possibilities for further research and therapy.

\section{CONCLUSION AND FUTURE PERSPECTIVES}

Much progress is made in PPAR research to identify the role of all PPAR isoforms and their respective ligands in cardiovascular disease and to explore the use of PPAR activators in the clinical setting. The mechanism by which PPARs act are a complex interplay between its transactivation (e.g. metabolism) and transrepression (e.g inflammation) properties and requires fine-tuning of current therapies. Finally, the development of SPPARMs or related drugs to put PPARs in the transactivation or transrepression mode can bring PPAR therapy to the next level, e.g. wide-spread use in cardiac disorders. 


\section{REFERENCES}

1. Koek, H.L., Engelfriet-Rijk, C.J.M., Bots, M.L., Hart-en vaatziekten in Nederland, in Hart-en vaatziekten in Nederland 2006, cijfers over ziekte en sterfte, M.H. Jager-Geurts, et al., Editors. 2006, Nederlandse Hartstichting: Den Haag.

2. Slobbe L.C.J., Kommer G.J., Smit J.M., Groen J., Meerding W.J., J.J., P., Costs of illness in the Netherlands 2003. 2006 RIVM.

3. Guyton, A.C.Hall, J.E., Textbook of medical physiology. 1996: W.B. Saunders company.

4. Towbin, J.A.Bowles, N.E. The failing heart. Nature. 6868: 227-233, 2002.

5. Eefting, F., Rensing, B., Wigman, J., Pannekoek, W.J., Liu, W.M., Cramer, M.J., Lips, D.J., Doevendans, P.A. Role of apoptosis in reperfusion injury. Cardiovasc Res. 3: 414-426, 2004.

6. Frangogiannis, N.G., Smith, C.W., Entman, M.L. The inflammatory response in myocardial infarction. Cardiovasc Res. 1: 31-47, 2002.

7. Anversa, P., Cheng, W., Liu, Y., Leri, A., Redaelli, G., Kajstura, J. Apoptosis and myocardial infarction. Basic Res Cardiol, 8-12, 1998.

8. Braunwald, E.Pfeffer, M.A. Ventricular enlargement and remodelling following acute myocardial infarction: mechanisms and management. Am J Cardiol. 14: 1D-6D, 1991.

9. Opie, L.H., Commerford, P.J., Gersh, B.J., Pfeffer, M.A. Controversies in ventricular remodelling. Lancet. 9507: 356-367, 2006.

10. van Bilsen, M., Smeets, P.J., Gilde, A.J., van der Vusse, G.J. Metabolic remodelling of the failing heart: the cardiac burn-out syndrome? Cardiovasc Res. 2: 218-226, 2004.

11. Swynghedauw, B. Molecular mechanisms of myocardial remodelling. Physiol Rev. 1: 215-262, 1999.

12. Thaik, C.M., Calderone, A., Takahashi, N., Colucci, W.S. Interleukin-1 beta modulates the growth and phenotype of neonatal rat cardiac myocytes. J Clin Invest. 2: 1093-1099, 1995.

13. Palmer, J.N., Hartogensis, W.E., Patten, M., Fortuin, F.D., Long, C.S. Interleukin-I beta induces cardiac myocyte growth but inhibits cardiac fibroblast proliferation in culture. J Clin Invest. 6:25552564, 1995.

14. Purcell, N.H., Tang, G., Yu, C., Mercurio, F., DiDonato, J.A., Lin, A. Activation of NF-kappa B is required for hypertrophic growth of primary rat neonatal ventricular cardiomyocytes. Proc Natl Acad Sci U S A. 12: 6668-6673, 2001.

15. Li, Y., Ha, T., Gao, X., Kelley, J., Williams, D.L., Browder, I.W., Kao, R.L., Li, C. NF-kappaB activation is required for the development of cardiac hypertrophy in vivo. Am J Physiol Heart Circ Physiol. 4: H1712-1720, 2004.

16. Watanabe, K., Fujii, H., Takahashi, T., Kodama, M., Aizawa, Y., Ohta, Y., Ono, T., Hasegawa, G., Naito, M., Nakajima, T., Kamijo, Y., Gonzalez, F.J., Aoyama, T. Constitutive regulation of cardiac fatty acid metabolism through peroxisome proliferator-activated receptor alpha associated with agedependent cardiac toxicity. J Biol Chem. 29: 22293-22299, 2000.

17. Devchand, P.R., Keller, H., Peters, J.M., Vazquez, M., Gonzalez, F.J., Wahli, W. The PPARalphaleukotriene B4 pathway to inflammation control. Nature. 6604: 39-43, 1996.

18. Smeets, P.J., Teunissen, B.E., Willemsen, P.H., van Nieuwenhoven, F.A., Brouns, A.E., Janssen, B.J., Cleutjens, J.P., Staels, B., van der Vusse, G.J., van Bilsen, M. Cardiac hypertrophy is enhanced in PPAR \{alpha\}-1-mice in response to chronic pressure overload. Cardiovasc Res. 78: 79-89, 2008.

19. Issemann, I.Green, S. Activation of a member of the steroid hormone receptor superfamily by peroxisome proliferators. Nature. 6294: 645-650, 1990.

20. van Bilsen, M., van der Vusse, G.J., Gilde, A.J., Lindhout, M., van der Lee, K.A. Peroxisome proliferator-activated receptors: lipid binding proteins controling gene expression. Mol Cell Biochem. 1-2: 131-138, 2002. 
21. Nuclear Receptors Nomenclature Committee. A unified nomenclature system for the nuclear receptor superfamily. Cell. 2: 161-163, 1999.

22. Gilde, A.J., van der Lee, K.A., Willemsen, P.H., Chinetti, G., van der Leij, F.R., van der Vusse, G.J., Staels, B., van Bilsen, M. Peroxisome proliferator-activated receptor (PPAR) alpha and PPARbetaldelta, but not PPARgamma, modulate the expression of genes involved in cardiac lipid metabolism. Circ Res. 5: 518-524, 2003.

23. Teunissen, B.E., Smeets, P.J., Willemsen, P.H., De Windt, L.J., Van der Vusse, G.J., Van Bilsen, M. Activation of PPARdelta inhibits cardiac fibroblast proliferation and the transdifferentiation into myofibroblasts. Cardiovasc Res. 3: 519-529, 2007.

24. Wayman, N.S., Hattori, Y., McDonald, M.C., Mota-Filipe, H., Cuzzocrea, S., Pisano, B., Chatterjee, P.K., Thiemermann, C. Ligands of the peroxisome proliferator-activated receptors (PPAR-gantma and PPAR-alpha) reduce myocardial infarct size. Faseb J. 9: 1027-1040, 2002.

25. Barger, P.M., Brandt, J.M., Leone, T.C., Weinheimer, C.J., Kelly, D.P. Deactivation of peroxisome proliferator-activated receptor-alpha during cardiac hypertrophic growth. J Clin Invest. 12: 17231730., 2000.

26. Liang, F., Wang, F., Zhang, S., Gardner, D.G. Peroxisome proliferator activated receptor (PPAR)alpha agonists inhibit hypertrophy of neonatal rat cardiac myocytes. Endocrinology . 9: 4187-4194, 2003.

27. Irukayama-Tomobe, Y., Miyauchi, T., Sakai, S., Kasuya, Y., Ogata, T., Takanashi, M., Iemitsu, M., Sudo, T., Goto, K., Yamaguchi, I. Endothelin-I-induced cardiac hypertrophy is inhibited by activation of peroxisome proliferator-activated receptor-alpha partly via blockade of c-Jun NH2-terminal kinase pathway. Circulation. 7: 904-910, 2004.

28. Rose, M., Balakumar, P., Singh, M. Ameliorative Effect of Combination of Fenofibrate and Rosiglitazone in Pressure Overload-Induced Cardiac Hypertrophy in Rats. Pharmacology. 2-3: $177-$ 184, 2007.

29. Finck, B.N., Lehman, J.J., Leone, T.C., Welch, M.J., Bennett, M.J., Kovacs, A., Han, X., Gross, R.W., Kozak, R., Lopaschuk, G.D., Kelly, D.P. The cardiac phenotype induced by PPARalpha overexpression mimics that caused by diabetes mellitus. J Clin Invest. 1: 121-130, 2002.

30. Panagia, M., Gibbons, G.F., Radda, G.K., Clarke, K. PPAR-alpha activation required for decreased glucose uptake and increased susceptibility to injury during ischemia. Am J Physiol Heart Circ Physiol. 6: H2677-2683, 2005.

31. Yndestad, A., Damas, J.K., Oie, E., Ueland, T., Gullestad, L., Aukrust, P. Systemic inflammation in heart failure- the whys and wherefores. Heart Fail Rev. 1: 83-92, 2006.

32. Levine, B., Kalman, J., Mayer, L., Fillit, H.M., Packer, M. Elevated circulating levels of tumor necrosis factor in severe chronic heart failure. $\mathrm{N}$ Engl J Med. 4: 236-241, 1990.

33. Seta, Y., Shan, K., Bozkurt, B., Oral, H., Mann, D.L. Basic mechanisms in heart failure: the cytokine hypothesis. J Card Fail. 3: 243-249, 1996.

34. Hall, G., Hasday, J.D., Rogers, T.B. Regulating the regulator: NF-kappaB signalling in heart. J Mol Cell Cardiol. 4: 580-591, 2006.

35. Krack, A., Sharma, R., Figulla, H.R., Anker, S.D. The importance of the gastrointestinal system in the pathogenesis of heart failure. Eur Heart J. 22: 2368-2374, 2005.

36. Chung, E.S., Packer, M., Lo, K.H., Fasanmade, A.A., Willerson, J.T. Randomized, double-blind, placebo-controlled, pilot trial of infliximab, a chimeric monoclonal antibody to tumor necrosis factor. alpha, in patients with moderate-to-severe heart failure: results of the anti-TNF Therapy Against Congestive Heart Failure (ATTACH) trial. Circulation. 25: 3133-3140, 2003.

37. Mann, D.L., McMurray, J.J., Packer, M., Swedberg, K., Borer, J.S., Colucci, W.S., Djian, J., Drexler, H., Feldman, A., Kober, L., Krum, H., Liu, P., Nieminen, M., Tavazzi, L., van Veldhuisen, D.J., Waldenstrom, A., Warren, M., Westheim, A., Zannad, F., Fleming, T. Targeted anticytokine therapy in 
patients with chronic heart failure: results of the Randomized Etanercept Worldwide Evaluation (RENEWAL). Circulation. 13: 1594-1602, 2004.

38. Mamdani, M., Juurlink, D.N., Lee, D.S., Rochon, P.A., Kopp, A., Naglie, G., Austin, P.C., Laupacis, A., Stukel, T.A. Cyclo-oxygenase-2 inhibitors versus non-selective non-steroidal anti-inflammatory drugs and congestive heart failure outcomes in elderly patients: a population-based cohort study. Lancet. 9423: 1751-1756, 2004.

39. Solomon, S.D., Pfeffer, M.A., McMurray, J.J., Fowler, R., Finn, P., Levin, B., Eagle, C., Hawk, E., Lechuga, M., Zauber, A.G., Bertagnolli, M.M., Arber, N., Wittes, J. Effect of celecoxib on cardiovascular events and blood pressure in two trials for the prevention of colorectal adenomas. Circulation. 10: 1028-1035, 2006.

40. Lahera, V., Goicoechea, M., de Vinuesa, S.G., Miana, M., de Las Heras, N., Cachofeiro, V., Luno, J, Endothelial dysfunction, oxidative stress and inflammation in atherosclerosis: beneficial effects of statins. Curr Med Chem. 2: 243-248, 2007.

41. Chinetti, G., Fruchart, J.C., Staels, B. Peroxisome proliferator-activated receptors (PPARs): nuclear receptors at the crossroads between lipid metabolism and inflammation. Inflamm Res. 10: 497-505, 2000.

42. Delerive, P., De Bosscher, K., Besnard, S., Vanden Berghe, W., Peters, J.M., Gonzalez, F.J., Fruchart, J.C., Tedgui, A., Haegeman, G., Staels, B. Peroxisome proliferator-activated receptor alpha negatively regulates the vascular inflammatory gene response by negative cross-lalk with transcription factors NF-kappaB and AP-1. J Biol Chem. 45: 32048-32054, 1999.

43. Dormandy, J.A., Charbonnel, B., Eckland, D.J., Erdmann, E., Massi-Benedetti, M., Moules, I.K., Skene, A.M., Tan, M.H., Lefebvre, P.J., Murray, G.D., Standl, E., Wilcox, R.G., Wilhelmsen, L., Betteridge, J., Birkeland, K., Golay, A., Heine, R.J., Koranyi, L., Laakso, M., Mokan, M., Norkus, A., Pirags, V., Podar, T., Scheen, A., Scherbaum, W., Schernthaner, G., Schmitz, O., Skrha, J., Smith, U., Taton, J. Secondary prevention of macrovascular events in patients with type 2 diabetes in the PROactive Study (PROspective pioglitAzone Clinical Trial In macroVascular Events): a randomised controlled trial. Lancet. 9493: 1279-1289, 2005.

44. Keech, A., Simes, R.J., Barter, P., Best, J., Scott, R., Taskinen, M.R., Forder, P., Pillai, A., Davis, T., Glasziou, P., Drury, P., Kesaniemi, Y.A., Sullivan, D., Hunt, D., Colman, P., d'Emden, M., Whiting, M., Ehnholm, C., Laakso, M. Effects of long-term fenofibrate therapy on cardiovascular events in 9795 people with type 2 diabetes mellitus (the FIELD study): randomised controlled trial. Lancet. 9500: 1849-1861, 2005.

45. Nissen, S.E., Wolski, K., Topol, E.J. Effect of muraglitazar on death and major adverse cardiovascular events in patients with type 2 diabetes mellitus. Jama. 20: 2581-2586, 2005.

46. Nissen, S.E.Wolski, K. Effect of rosiglitazone on the risk of myocardial infarction and death from cardiovascular causes. N Engl J Med. 24: 2457-2471, 2007.

47. Braissant, O., Foufelle, F., Scotto, C., Dauca, M., Wahli, W. Differential expression of peroxisome proliferator-activated receptors (PPARs): tissue distribution of PPAR-alpha, -beta, and-gamma in the adult rat. Endocrinology. 1: 354-366, 1996.

48. Puigserver, P.Spiegelman, B.M. Peroxisome proliferator-activated receptor-gamma coactivator 1 alpha (PGC-1 alpha); transcriptional coactivator and metabolic regulator. Endocr Rev, 1: 78-90, 2003.

49. Stanley, T.B., Leesnitzer, L.M., Montana, V.G., Galardi, C.M., Lambert, M.H., Holt, J.A., Xu, H.E., Moore, L.B., Blanchard, S.G., Stimmel, J.B. Subtype Specific Effects of Peroxisome ProliferatorActivated Receptor Ligands on Corepressor Affinity. Biochemistry. 31: 9278-9287., 2003.

50. Desvergne, B.Wahli, W. Peroxisome proliferator-activated receptors: nuclear control of metabolism. Endocr Rev. 5: 649-688,, 1999. 
51. Feige, J.N., Gelman, L., Michalik, L., Desvergne, B., Wahli, W. From molecular action to physiological outputs: peroxisome proliferator-activated receptors are nuclear receptors at the crossroads of key cellular functions. Prog Lipid Res. 2: 120-159, 2006.

52. van der Vusse, G.J., Glatz, J.F., Stam, H.C., Reneman, R.S. Fatty acid homeostasis in the normoxic and ischemic heart. Physiol Rev. 4: 881-940, 1992.

53. Lee, C.H., Chawla, A., Urbiztondo, N., Liao, D., Boisvert, W.A., Evans, R.M. Transcriptional repression of atherogenic inflammation: modulation by PPARdelta. Science. 5644: 453-457, 2003.

54. Planavila, A., Rodriguez-Calvo, R., Jove, M., Michalik, L., Wahli, W., Laguna, J.C., Vazquez-Carrera, M. Peroxisome proliferator-activated receptor beta/delta activation inhibits hypertrophy in neonatal rat cardiomyocytes. Cardiovasc Res. 4: 832-841, 2005.

55. Huss, J.M.Kelly, D.P. Nuclear receptor signalling and cardiac energetics. Circ Res. 6: 568-578, 2004

56. Finck, B.N. The PPAR regulatory system in cardiac physiology and disease. Cardiovasc Res. 2: 269$277,2007$.

57. Stanley, W.C., Recchia, F.A., Lopaschuk, G.D. Myocardial substrate metabolism in the normal and failing heart. Physiol Rev. 3: 1093-1129, 2005.

58. Hearse, D.J. Ischemia, reperfusion, and the determinants of tissue injury. Cardiovasc Drugs Ther. 767$776,1990$.

59. Li, C., Browder, W., Kao, R.L. Early activation of transcription factor NF-kappaB during ischemia in perfused rat heart. Am J Physiol. 2 Pt 2: H543-552, 1999.

60. Onai, Y., Suzuki, J., Kakuta, T., Maejima, Y., Haraguchi, G., Fukasawa, H., Muto, S., Itai, A., Isobe, M. Inhibition of IkappaB phosphorylation in cardiomyocytes attentuates myocardial ischemia/reperfusion injury. Cardiovasc Res. 1: 51-59, 2004.

61. Razeghi, P., Young, M.E., Abbasi, S., Taegtmeyer, H. Hypoxia in vivo decreases peroxisome proliferator-activated receptor alpharregulated gene expression in rat heart. Biochem Biophys Res Commun. 1: 5-10, 2001.

62. Dewald, O., Sharma, S., Adrogue, J., Salazar, R., Duerr, G.D., Crapo, J.D., Entman, M.L., Taegtmeyer, $\mathrm{H}$. Downregulation of peroxisome proliferator-activated receptor-alpha gene expression in a mouse model of ischemic cardiomyopathy is dependent on reactive oxygen species and prevents lipotoxicity. Circulation. 3: 407-415, 2005.

63. Wayman, N.S., Ellis, B.L., Thiemermann, C. Ligands of the peroxisome proliferator-activated receptorPPAR-a reduce myocardial infarct size. Med Sci Monit. 7: BR243-247, 2002.

64. Yue, T.L., Bao, W., Jucker, B.M., Gu, J.L., Romanic, A.M., Brown, P.J., Cui, J., Thudium, D.T., Boyce, R., Burns-Kurtis, C.L., Mirabile, R.C., Aravindhan, K., Ohlstein, E.H. Activation of peroxisome proliferator-activated receptor-alpha protects the heart from ischemia/reperfusion injury. Circulation. 19: 2393-2399, 2003.

65. Tabernero, A., Schoonjans, K., Jesel, L., Carpusca, I., Auwerx, J., Andriantsitohaina, R. Activation of the peroxisome proliferator-activated receptor alpha protects against myocardial ischaemic injury and improves endothelial vasodilatation. BMC Pharmacol. 10, 2002.

66. Tian, Q., Grzemski, F.A., Panagiotopoulos, S., Ahokas, J.T. Peroxisome proliferator-activated receptor alpha agonist, clofibrate, has profound influence on myocardial fatty acid composition. Chem Biol Interact. 3: 241-251, 2006.

67. Bulhak, A.A., Sjoquist, P.O., Xu, C.B., Edvinsson, L., Pernow, J. Protection against myocardial ischaemia/reperfusion injury by PPAR-alpha activation is related to production of nitric oxide and endothelin-1. Basic Res Cardiol. 3: 244-252, 2006.

68. Xu, Y., Lu, L., Greyson, C., Rizeq, M., Nunley, K., Wyatt, B., Bristow, M.R., Long, C.S., Schwartz, G.G. The PPAR-alpha activator fenofibrate fails to provide myocardial protection in ischemia and reperfusion in pigs. Am J Physiol Heart Circ Physiol. 5: H1798-1807, 2006. 
69. Sambandam, N., Morabito, D., Wagg, C., Finck, B.N., Kelly, D.P., Lopaschuk, G.D. Chronic activation of PPARalpha is detrimental to cardiac recovery after ischemia. Am J Physiol Heart Circ Physiol. 1: H87-95, 2006.

70. Yeh, C.H., Chen, T.P., Lee, C.H., Wu, Y.C., Lin, Y.M., Lin, P.J. Cardiomyocytic apoptosis following global cardiac ischemia and reperfusion can be attenuated by peroxisome proliferator-activated receptor alpha but not gamma activators. Shock. 3: 262-270, 2006.

71. Kantor, P.F., Dyck, J.R., Lopaschuk, G.D. Fatty acid oxidation in the reperfused ischemic heart. Am J Med Sci. 1: 3-14, 1999.

72. Lam, A.Lopaschuk, G.D. Anti-anginal effects of partial fatty acid oxidation inhibitors. Curr Opin Pharmacol. 2: 179-185, 2007.

73. Xu, Y., Gen, M., Lu, L., Fox, J., Weiss, S.O., Brown, R.D., Perlov, D., Ahmad, H., Zhu, P., Greyson, C., Long, C.S., Schwartz, G.G. PPAR-gamma activation fails to provide myocardial protection in ischemia and reperfusion in pigs. Am J Physiol Heart Circ Physiol. 3: H1314-1323, 2005.

74. Yue, T.L., Chen, J., Bao, W., Narayanan, P.K., Bril, A., Jiang, W., Lysko, P.G., Gu, J.L., Boyce, R., Zimmerman, D.M., Hart, T.K., Buckingham, R.E., OhIstein, E.H. In vivo myocardial protection from ischemia/reperfusion injury by the peroxisome proliferator-activated receptor-gamma agonist rosiglitazone. Circulation. 21: 2588-2594, 2001.

75. Gonon, A.T., Bulhak, A., Labruto, F., Sjoquist, P.O., Pernow, J. Cardioprotection mediated by rosiglitazone, a peroxisome proliferatoractivated receptor gamma ligand, in relation to nitric oxide. Basic Res Cardiol. 1: 80-89, 2007.

76. Ito, H., Nakano, A., Kinoshita, M., Matsumori, A. Pioglitazone, a peroxisome proliferator-activated receptor-gamma agonist, attenuates myocardial ischemia/reperfusion injury in a rat model. Lab Invest. 12: 1715-1721, 2003.

77. Sivarajah, A., McDonald, M.C., Thiemermann, C. The cardioprotective effects of preconditioning with endotoxin, but not ischemia, are abolished by a peroxisome proliferator-activated receptor-gamma antagonist. J Pharmacol Exp Ther. 2: 896-901, 2005.

78. Molavi, B., Chen, J., Mehta, J.L. Cardioprotective effects of rosiglitazone are associated with selective overexpression of type 2 angiotensin receptors and inhibition of p42/44 MAPK. Am J Physiol Heart Circ Physiol. 2: H687-693, 2006.

79. Sidell, R.J., Cole, M.A., Draper, N.J., Desrois, M., Buckingham, R.E., Clarke, K. Thiazolidinedione treatment normalizes insulin resistance and ischemic injury in the zucker Fatty rat heart. Diabetes. 4 : $1110-1117,2002$.

80. Zhu, P., Lu, L., Xu, Y., Schwartz, G.G. Troglitazone improves recovery of left ventricular function after regional ischemia in pigs. Circulation. 10: 1165-1171, 2000.

81. Liu, H.R., Tao, L., Gao, E., Lopez, B.L., Christopher, T.A., Willette, R.N., Ohlstein, E.H., Yue, T.L., $\mathrm{Ma}, \mathrm{X}$.L. Anti-apoptotic effects of rosiglitazone in hypercholesterolemic rabbits subjected to myocardial ischemia and reperfusion. Cardiovasc Res. 1: 135-144, 2004.

82. Lee, T.M.Chou, T.F. Troglitazone administration limits infarct size by reduced phosphorylation of canine myocardial connexin43 proteins. Am J Physiol Heart Circ Physiol. 4: H1650-1659, 2003.

83. Wynne, A.M., Mocanu, M.M., Yellon, D.M. Pioglitazone mimics preconditioning in the isolated perfused rat heart: a role for the prosurvival kinases PI3K and P42/44MAPK. J Cardiovasc Pharmacol. 6: 817-822, 2005.

84. Shimabukuro, M., Higa, S., Shinzato, T., Nagamine, F., Komiya, I., Takasu, N. Cardioprotective effects of troglitazone in streptozotocin-induced diabetic rats. Metabolism. 9: 1168-1173, 1996.

85. Khandoudi, N., Delerive, P., Berrebi-Bertrand, I., Buckingham, R.E., Staels, B., Bril, A. Rosiglitazone, a peroxisome proliferator-activated receptor-gamma, inhibits the Jun NH(2)-terminal kinase/activating 
protein 1 pathway and protects the heart from ischemia/reperfusion injury. Diabetes. 5: 1507-1514, 2002.

86. Aasum, E., Hafstad, A.D., Severson, D.L., Larsen, T.S. Age-dependent changes in metabolism, contractile function, and ischemic sensitivity in hearts from db/db mice. Diabetes. 2: 434-441, 2003.

87. Cheng, L., Ding, G., Qin, Q., Huang, Y., Lewis, W., He, N., Evans, R.M., Schneider, M.D., Brako, F.A., Xiao, Y., Chen, Y.E., Yang, Q. Cardiomyocyte-restricted peroxisome proliferator-activated receptor-delta deletion perturbs myocardial fatty acid oxidation and leads to cardiomyopathy. Nat Med. 11: 1245-1250, 2004.

88. Morgan, E.E., Rennison, J.H., Young, M.E., McElfresh, T.A., Kung, T.A., Tserng, K.Y., Hoit, B.D., Stanley, W.C., Chandler, M.P. Effects of chronic activation of peroxisome proliferator-activated receptor-alpha or high-fat feeding in a rat infarct model of heart failure. Am J Physiol Heart Circ Physiol. 5: H1899-1904, 2006.

89. Frantz, S., Hu, K., Widder, J., Bayer, B., Witzel, C.C., Schmidt, I., Galuppo, P., Strotmann, J., Ertl, G., Bauersachs, J. Peroxisome proliferator activated-receptor agonism and left ventricular remodelling in mice with chronic myocardial infarction. Br J Pharmacol. 1: 9-14, 2004.

90. Geng, D.F., Wu, W., Jin, D.M., Wang, J.F., Wu, Y.M. Effect of peroxisome proliferator-activated receptor gamma ligand. Rosiglitazone on left ventricular remodelling in rats with myocardial infarction. Int J Cardiol. 1: 86-91, 2006.

91. Shiomi, T., Tsutsui, H., Hayashidani, S., Suematsu, N., Ikeuchi, M., Wen, J., Ishibashi, M., Kubota, T., Egashira, K., Takeshita, A. Pioglitazone, a peroxisome proliferator-activated receptor-gamma agonist, attenuates left ventricular remodelling and failure after experimental myocardial infarction. Circulation. 24: 3126-3132, 2002.

92. Lygate, C.A., Hulbert, K., Monfared, M., Cole, M.A., Clarke, K., Neubauer, S. The PPARgammaactivator rosiglitazone does not alter remodelling but increases mortality in rats post-myocardial infarction. Cardiovasc Res. 3: 632-637, 2003.

93. Frey, N.Olson, E.N. Cardiac hypertrophy: the good, the bad, and the ugly. Annu Rev Physiol. 45-79., 2003.

94. Hunter, J.J.Chien, K.R. Signalling pathways for cardiac hypertrophy and failure. N Engl J Med. 17: 1276-1283, 1999.

95. Porter, K.E., Turner, N.A., O'Regan, D.J., Ball, S.G. Tumor necrosis factor alpha induces human atrial myofibroblast proliferation, invasion and MMP-9 secretion: inhibition by simvastatin. Cardiovasc Res. 3: 507-515, 2004.

96. Gurantz, D., Cowling, R.T., Varki, N., Frikovsky, E., Moore, C.D., Greenberg, B.H. IL-Ibeta and TNF alpha upregulate angiotensin II type 1 (ATI) receptors on cardiac fibroblasts and are associated with increased ATl density in the post-MI heart. J Mol Cell Cardiol. 3: 505 -515, 2005.

97. Yokoyama, T., Nakano, M., Bednarczyk, J.L., McIntyre, B.W., Entman, M., Mann, D.L. Tumor necrosis factor-alpha provokes a hypertrophic growth response in adult cardiac myocytes. Circulation. 5: 1247-1252, 1997.

98. Higuchi, Y., Chan, T.O., Brown, M.A., Zhang, J., DeGeorge, B.R., Jr., Funakoshi, H., Gibson, G., McTiernan, C.F., Kubota, T., Jones, W.K., Feldman, A.M. Cardioprotection afforded by NF-kappaB ablation is associated with activation of Akt in mice overexpressing TNF-alpha. Am J Physiol Heart Circ Physiol. 2: H590-598, 2006.

99. Gupta, S., Young, D., Sen, S. Inhibition of NF-kappaB induces regression of cardiac hypertrophy, independent of blood pressure control, in spontaneously hypertensive rats. Am J Physiol Heart Circ Physiol. 1: H20-29, 2005.

100. Sack, M.N., Rader, T.A., Park, S., Bastin, J., McCune, S.A., Kelly, D.P. Fatty acid oxidation enzyme gene expression is downregulated in the failing heart. Circulation. 11:2837-2842, 1996. 
101. Kanda, H., Nohara, R., Hasegawa, K., Kishimoto, C., Sasayama, S. A nuclear complex containing PPARalpha/RXRalpha is markedly downregulated in the hypertrophied rat left ventricular myocardium with normal systolic function. Heart Vessels. 4: 191-196, 2000.

102. Osorio, J.C., Stanley, W.C., Linke, A., Castellari, M., Diep, Q.N., Panchal, A.R., Hintze, T.H., Lopaschuk, G.D., Recchia, F.A. Impaired myocardial fatty acid oxidation and reduced protein expression of retinoid X receptor-alpha in pacing-induced heart failure. Circulation. 5: 606-612, 2002.

103. Young, M.E., Laws, F.A., Goodwin, G.W., Taegtmeyer, H. Reactivation of peroxisome proliferatoractivated receptor alpha is associated with contractile dysfunction in hypertrophied rat heart. J Biol Chem. 48: 44390-44395, 2001.

104. Ichihara, S., Obata, K., Yamada, Y., Nagata, K., Noda, A., Ichihara, G., Yamada, A., Kato, T., Izawa, H., Murohara, T., Yokota, M. Attenuation of cardiac dysfunction by a PPAR-alpha agonist is associated with down-regulation of redox-regulated transcription factors. J Mol Cell Cardiol. 2; 318-329, 2006.

105. Ogata, T., Miyauchi, T., Sakai, S., Irukayama-Tomobe, Y., Goto, K., Yamaguchi, I. Stimulation of peroxisome-proliferator-activated receptor alpha (PPAR alpha) attenuates cardiac fibrosis and endothelin-I production in pressure-overloaded rat hearts. Clin Sci (Lond). 284S-288S, 2002.

106. Diep, Q.N., Benkirane, K., Amiri, F., Cohn, J.S., Endemann, D., Schiffrin, E.L. PPARalpha activator fenofibrate inhibits myocardial inflammation and fibrosis in angiotensin II-infused rats. J Mol Cell Cardiol. 2: 295-304, 2004.

107. Yamamoto, K., Ohki, R., Lee, R.T., Ikeda, U., Shimada, K. Peroxisome proliferator-activated receptor gamma activators inhibit cardiac hypertrophy in cardiac myocytes. Circulation. 14: 1670-1675, 2001.

108. Asakawa, M., Takano, H., Nagai, T., Uozumi, H., Hasegawa, H., Kubota, N., Saito, T., Masuda, Y., Kadowaki, T., Komuro, I. Peroxisome proliferator-activated receptor gamma plays a critical role in inhibition of cardiac hypertrophy in vitro and in vivo. Circulation. 10: 1240-1246., 2002.

109. Duan, S.Z., Ivashchenko, C.Y., Russell, M.W., Milstone, D.S., Mortensen, R.M. Cardiomyocytespecific knockout and agonist of peroxisome proliferator-activated receptor-gamma both induce cardiac hypertrophy in mice. Circ Res. 4: 372-379, 2005.

110. Bell, D.McDermott, B.J. Effects of rosiglitazone and interactions with growth-regulating factors in ventricular cell hypertrophy. Eur J Pharmacol. 1-3: 69-76, 2005.

111. Edgley, A.J., Thalen, P.G., Dahllof, B., Lanne, B., Ljung, B., Oakes, N.D. PPARgamma agonist induced cardiac enlargement is associated with reduced fatty acid and increased glucose utilization in myocardium of Wistar rats. Eur J Pharmacol. 1-3: 195-206, 2006.

112. Wu, L., Wang, R., De Champlain, J., Wilson, T.W. Beneficial and deleterious effects of rosiglitazone on hypertension development in spontaneously hypertensive rats. Am J Hypertens. 9: 749-756, 2004.

113. Arakawa, K., Ishihara, T., Aoto, M., Inamasu, M., Kitamura, K., Saito, A. An antidiabetic thiazolidinedione induces eccentric cardiac hypertrophy by cardiac volume overload in rats. Clin Exp Pharmacol Physiol. 1-2: 8-13, 2004.

114. Zhang, H., Zhang, A., Kohan, D.E., Nelson, R.D., Gonzalez, F.J., Yang, T. Collecting duct-specific deletion of peroxisome proliferator-activated receptor gamma blocks thiazolidinedione-induced fluid retention. Proc Natl Acad Sci U S A. 26: 9406-9411, 2005.

115. Doney, A.S., Fischer, B., Lee, S.P., Morris, A.D., Leese, G., Palmer, C.N. Association of common variation in the PPARA gene with incident myocardial infarction in individuals with type 2 diabetes: $A$ Go-DARTS study. Nucl Recept. 4, 2005.

116. Doney, A.S., Fischer, B., Leese, G., Morris, A.D., Palmer, C.N. Cardiovascular risk in type 2 diabetes is associated with variation at the PPARG locus: a Go-DARTS study. Arterioscler Thromb Vasc Biol. 12: 2403-2407, 2004. 
117. Li, L., Cheng, L.X., Nsenga, R., He, M.A., Wu, T.C. Association between Pr012Ala polymorphism of peroxisome proliferator-activated receptor-gamma 2 and myocardial infarction in the Chinese Han population. Clin Cardiol. 7: 300-304, 2006.

118. Pischon, T., Pai, J.K., Manson, J.E., Hu, F.B., Rexrode, K.M., Hunter, D., Rimm, E.B. Peroxisome proliferator-activated receptor-gamma2 PI2A polymorphism and risk of coronary heart disease in US men and women. Arterioscler Thromb Vasc Biol. 8: 1654-1658, 2005.

119. Aberle, J., Hopfer, I., Beil, F.U., Seedorf, U. Association of the T+294C polymorphism in PPAR delta with low HDL cholesterol and coronary heart disease risk in women. Int J Med Sci. 3: 108-11 1, 2006.

120. Skogsberg, J., McMahon, A.D., Karpe, F., Hamsten, A., Packard, C.J., Ehrenborg, E. Peroxisome proliferator activated receptor delta genotype in relation to cardiovascular risk factors and risk of coronary heart disease in hypercholesterolaemic men. J Intern Med. 6: 597-604, 2003.

121. Jamshidi, Y., Montgomery, H.E., Hense, H.W., Myerson, S.G., Torra, I.P., Staels, B., World, M.J., Doering, A., Erdmann, J., Hengstenberg, C., Humphries, S.E., Schunkert, H., Flavell, D.M. Peroxisome proliferator-activated receptor alpha gene regulates left ventricular growth in response to exercise and hypertension. Circulation. 8: 950-955, 2002.

122. Morishima, A., Ohkubo, N., Maeda, N., Miki, T., Mitsuda, N. NFkappaB regulates plasma apolipoprotein A-I and high density lipoprotein cholesterol through inhibition of peroxisome proliferator-activated receptor alpha. J Biol Chem. 40: 38188-38193, 2003.

123. Planavila, A., Laguna, J.C., Vazquez-Carrera, M. Nuclear factor-kappaB activation leads to downregulation of fatty acid oxidation during cardiac hypertrophy. J Biol Chem. 17: 17464-17471, 2005.

124. Razeghi, P., Wang, M.E., Youker, K.A., Golfman, L., Stepkowski, S., Taegtmeyer, H. Lack of NFkappaBI (p105/p50) attenuates unloading-induced downregulation of PPARalpha and PPARalpharegulated gene expression in rodent heart. Cardiovasc Res. 1: 133-139, 2007.

125. Baldwin, A.S., Jr. The NF-kappa B and I kappa B proteins: new discoveries and insights. Annu Rev Immunol. 649-683, 1996.

126. Terrell, A.M., Crisostomo, P.R., Wairiuko, G.M., Wang, M., Morrell, E.D., Meldrum, D.R. Jak/STAT/SOCS signalling circuits and associated cytokine-mediated inflammation and hypertrophy in the heart. Shock. 3: 226-234, 2006.

127. Massague, J. How cells read TGF-beta signals. Nat Rev Mol Cell Biol. 3: 169-178, 2000.

128. Ghosh, A.K., Bhattacharyya, S., Lakos, G., Chen, S.J., Mori, Y., Varga, J. Disruption of transforming growth factor beta signalling and profibrotic responses in normal skin fibroblasts by peroxisome proliferator-activated receptor gamma. Arthritis Rheum. 4: 1305-1318, 2004.

129. Gao, D.F., Niu, X.L., Hao, G.H., Peng, N., Wei, J., Ning, N., Wang, N.P. Rosiglitazone inhibits angiotensin II-induced CTGF expression in vascular smooth muscle cells-role of PPAR-gamma in vascular fibrosis. Biochem Pharmacol. 2: 185-197, 2007.

130. Han, C., Demetris, A.J., Liu, Y., Shelhamer, J.H., Wu, T. Transforming growth factor-beta (TGF-beta) activates cytosolic phospholipase A2alpha (cPLA2alpha)-mediated prostaglandin E2 (PGE)2/EP1 and peroxisome proliferator-activated receptor-gamma (PPAR-gamma)/Smad signalling pathways in human liver cancer cells. A novel mechanism for subversion of TGF-beta-induced mitoinhibition. J Biol Chem. 43: 44344-44354, 2004.

131. Fu, M., Zhang, J., Zhu, X., Myles, D.E., Willson, T.M., Liu, X., Chen, Y.E. Peroxisome proliferatoractivated receptor gamma inhibits transforming growth factor beta-induced connective tissue growth factor expression in human aortic smooth muscle cells by interfering with Smad3. J Biol Chem. 49: 45888-45894, 2001.

132. Kintscher, U., Lyon, C., Wakino, S., Bruemmer, D., Feng, X., Goetze, S., Graf, K., Moustakas, A., Staels, B., Fleck, E., Hsueh, W.A., Law, R.E. PPARalpha inhibits TGF-beta-induced beta5 integrin transcription in vascular smooth muscle cells by interacting with Smad4. Circ Res. 11: e35-44, 2002. 
133. Kim, H.J., Rho, Y.H., Choi, S.J., Lee, Y.H., Cheon, H., Um, J.W., Sohn, J., Song, G.G., Ji, J.D. I5Deoxy-deltaI2, 14-PGJ2 inhibits IL-6-induced Stat 3 phosphorylation in lymphocytes. Exp Mol Med. 3: 179-185, 2005.

134. Ji, J.D., Kim, H.J., Rho, Y.H., Choi, S.J., Lee, Y.H., Cheon, H.J., Sohn, J., Song, G.G. Inhibition of IL10-induced STAT3 activation by 15-deoxy-Delta12,14-prostaglandin J2. Rheumatology (Oxford). 8: 983-988, 2005.

135. Shipley, J.M.Waxman, D.J. Down-regulation of STAT5b transcriptional activity by ligand-activated peroxisome proliferator-activated receptor (PPAR) alpha and PPARgamma. Mol Pharmacol. 2: 355364,2003

136. Tan, N.S., Michalik, L., Di-Poi, N., Ng, C.Y., Mermod, N., Roberts, A.B., Desvergne, B., Wahli, W. Essential role of Smad 3 in the inhibition of inflammation-induced PPARbeta/delta expression. Embo J. 21: 4211-4221, 2004.

137. Zhou, Y.C.Waxman, D.J. STATSb down-regulates peroxisome proliferator-activated receptor alpha transcription by inhibition of ligand-independent activation function region-1 trans-activation domain J Biol Chem. 42: 29874-29882, 1999.

138. Park, E.J., Park, S.Y., Joe, E.H., Jou, I. 15d-PGJ2 and rosiglitazone suppress Janus kinase-STAT inflammatory signalling through induction of suppressor of cytokine signalling I (SOCSI) and SOCS3 in glia. J Biol Chem. 17: 14747-14752, 2003.

139. Kelly, D., Campbell, J.I., King, T.P., Grant, G., Jansson, E.A., Coutts, A.G., Pettersson, S., Conway, S. Commensal anaerobic gut bacteria attenuate inflammation by regulating nuclear-cytoplasmic shuttling of PPAR-gamma and RelA. Nat Immunol. 1: 104-112, 2004.

140. Delerive, P., De Bosscher, K., Vanden Berghe, W., Fruchart, J.C., Haegeman, G., Staels, B. DNA binding-independent induction of IkappaBalpha gene transcription by PPARalpha. Mol Endocrinol. 5: 1029-1039, 2002.

141. Delerive, P., Martin-Nizard, F., Chinetti, G., Trottein, F., Fruchart, J.C., Najib, J., Duriez, P., Staels, B. Peroxisome proliferator-activated receptor activators inhibit thrombin-induced endothelin-1 production in human vascular endothelial cells by inhibiting the activator protein-1 signalling pathway. Circ Res. 5: 394-402, 1999.

142. Subbaramaiah, K., Lin, D.T., Hart, J.C., Dannenberg, A.J. Peroxisome proliferator-activated receptor gamma ligands suppress the transcriptional activation of cyclooxygenase-2. Evidence for involvement of activator protein-1 and CREB-binding protein/p300. J Biol Chem. 15: 12440-12448, 2001.

143. Guo, B., Koya, D., Isono, M., Sugimoto, T., Kashiwagi, A., Haneda, M. Peroxisome proliferatoractivated receptor-gamma ligands inhibit TGF-beta l-induced fibronectin expression in glomerular mesangial cells. Diabetes. 1: 200-208, 2004.

144. Pascual, G., Fong, A.L., Ogawa, S., Gamliel, A., Li, A.C., Perissi, V., Rose, D.W., Willson, T.M., Rosenfeld, M.G., Glass, C.K. A SUMOylation-dependent pathway mediates transrepression of inflammatory response genes by PPAR-gamma. Nature. 7059: 759-763, 2005.

145. Blanquart, C., Mansouri, R., Paumelle, R., Fruchart, J.C., Staels, B., Glineur, C. The protein kinase C signalling pathway regulates a molecular switch between transactivation and transrepression activity of the peroxisome proliferator-activated receptor alpha. Mol Endocrinol. 8: 1906-1918, 2004.

146. Ding, G., Cheng, L., Qin, Q., Frontin, S., Yang, Q. PPARdelta modulates lipopolysaccharide-induced TNFalpha inflammation signalling in cultured cardiomyocytes. J Mol Cell Cardiol. 6: 821-828, 2006.

147. Kharroubi, I., Lee, C.H., Hekerman, P., Darville, M.I., Evans, R.M., Eizirik, D.L., Cnop, M. BCL-6: $a$ possible missing link for anti-inflammatory PPAR-delta signalling in pancreatic beta cells. Diabetologia. 10: 2350-2358, 2006. 
148. Morimura, K., Cheung, C., Ward, J.M., Reddy, J.K., Gonzalez, F.J. Differential susceptibility of mice humanized for peroxisome proliferator-activated receptor alpha to Wy-14,643-induced liver tumorigenesis. Carcinogenesis. 5: 1074-1080, 2006.

149. Cook, W.S., Yeldandi, A.V., Rao, M.S., Hashimoto, T., Reddy, J.K. Less extrahepatic induction of fatty acid beta-oxidation enzymes by PPAR alpha. Biochem Biophys Res Commun. 1: 250-257, 2000.

150. Trifilieff, A., Bench, A., Hanley, M., Bayley, D., Campbell, E., Whittaker, P. PPAR-alpha and -gamma but not -delta agonists inhibit airway inflammation in a murine model of asthma: in vitro evidence for an NF-kappaB-independent effect. Br J Pharmacol. 1: 163-171, 2003.

151. Clark, R.B. The role of PPARs in inflammation and immunity. J Leukoc Biol, 3: 388-400, 2002.

152. Chawla, A., Barak, Y., Nagy, L., Liao, D., Tontonoz, P., Evans, R.M. PPAR-gamma dependent and independent effects on macrophage-gene expression in lipid metabolism and inflammation. Nat Med. 1 : 48-52, 2001.

153. Duhaney, T.A., Cui, L., Rude, M.K., Lebrasseur, N.K., Ngoy, S., De Silva, D.S., Siwik, D.A., Liao, R., Sam, F. Peroxisome proliferator-activated receptor alpha-independent actions of fenofibrate exacerbates left ventricular dilation and fibrosis in chronic pressure overload. Hypertension. 5: 1084 1094, 2007.

154. Burkart, E.M., Courtois, M., Sambandam, N., Kelly, D.P. The nuclear receptor PPARbeta mediates novel effects on myocardial glucose metabolism (abstract). Circulation. 17: U88, 2005.

155. Ogata, T., Miyauchi, T., Sakai, S., Takanashi, M., Irukayama-Tomobe, Y., Yamaguchi, I. Myocardial fibrosis and diastolic dysfinction in deoxycorticosterone acetate-salt hypertensive rats is ameliorated by the peroxisome proliferator-activated receptor-alpha activator fenofibrate, partly by suppressing inflammatory responses associated with the nuclear factor-kappa-B pathway. J Am Coll Cardiol. 8: 1481-1488, 2004.

156. Kawano, S., Kubota, T., Monden, Y., Kawamura, N., Tsutsui, H., Takeshita, A., Sunagawa, K. Blockade of NF-kappaB ameliorates myocardial hypertrophy in response to chronic infusion of angiotensin II. Cardiovasc Res. 4: 689-698, 2005.

157. Delerive, P., Gervois, P., Fruchart, J.C., Staels, B. Induction of IkappaBalpha expression as a mechanism contributing to the anti-inflammatory activities of peroxisome proliferator-activated receptor-alpha activators. J Biol Chem. 47: 36703-36707, 2000.

158. Cuzzocrea, S., Pisano, B., Dugo, L., Ianaro, A., Maffia, P., Patel, N.S., Di Paola, R., Ialenti, A., Genovese, T., Chatterjee, P.K., Di Rosa, M., Caputi, A.P., Thiemermann, C. Rosiglitazone, a ligand of the peroxisome proliferator-activated receptor-gamma, reduces acute inflammation. Eur $\mathrm{J}$ Pharmacol. 1: 79-93, 2004.

159. Lee, K.S., Park, S.J., Hwang, P.H., Yi, H.K., Song, C.H., Chai, O.H., Kim, J.S., Lee, M.K., Lee, Y.C. PPAR-gamma modulates allergic inflammation through up-regulation of PTEN. Faseb J. 8: 1033-1035, 2005.

160. de Vries, J.E., Vork, M.M., Roemen, T.H., de Jong, Y.F., Cleutjens, J.P., van der Vusse, G.J., van Bilsen, M. Saturated but not mono-unsaturated fatty acids induce apoptotic cell death in neonatal rat ventricular myocytes. J Lipid Res. 7: 1384-1394, 1997.

161. Shubeita, H.E., Martinson, E.A., Van Bilsen, M., Chien, K.R., Brown, J.H. Transcriptional activation of the cardiac myosin light chain 2 and atrial natriuretic factor genes by protein kinase $C$ in neonatal rat ventricular myocytes. Proc Natl Acad Sci U S A. 4: 1305-1309, 1992.

162. Bradford, M.M. A rapid and sensitive method for the quantitation of microgram quantities of protein utilizing the principle of protein-dye binding. Anal Biochem. 248-254, 1976.

163. Takano, H., Nagai, T., Asakawa, M., Toyozaki, T., Oka, T., Komuro, I., Saito, T., Masuda, Y. Peroxisome proliferator-activated receptor activators inhibit lipopolysaccharide-induced tumor necrosis factor-alpha expression in neonatal rat cardiac myocytes. Circ Res. 7: 596-602, 2000. 
164. Peng, T., Lu, X., Feng, Q. NADH oxidase signalling induces cyclooxygenase-2 expression during lipopolysaccharide stimulation in cardiomyocytes. Faseb J. 2: 293-295, 2005.

165. Clerk, A., Harrison, J.G., Long, C.S., Sugden, P.H. Pro-inflammatory cytokines stimulate mitogenactivated protein kinase subfamilies, increase phosphorylation of $c-J u n$ and ATF2 and upregulate $c-J u n$ protein in neonatal rat ventricular myocytes. J Mol Cell Cardiol. 12: 2087-2099, 1999.

166. Nishikawa, K., Yoshida, M., Kusuhara, M., Ishigami, N., Isoda, K., Miyazaki, K., Ohsuzu, F. Left ventricular hypertrophy in mice with a cardiac-specific overexpression of interleukin-1. Am J Physiol Heart Circ Physiol. 1: H176-183, 2006.

167. Kubota, T., McTiernan, C.F., Frye, C.S., Slawson, S.E., Lemster, B.H., Koretsky, A.P., Demetris, A.J., Feldman, A.M. Dilated cardiomyopathy in transgenic mice with cardiac-specific overexpression of tumor necrosis factor-alpha. Circ Res. 4: 627-635, 1997.

168. Ha, T., Li, Y., Gao, X., McMullen, J.R., Shioi, T., Izumo, S., Kelley, J.L., Zhao, A., Haddad, G.E., Williams, D.L., Browder, I.W., Kao, R.L., Li, C. Attenuation of cardiac hypertrophy by inhibiting both mTOR and NFkappaB activation in vivo. Free Radic Biol Med. 12: 1570-1580, 2005.

169. Blanquart, C., Barbier, O., Fruchart, J.C., Staels, B., Glineur, C. Peroxisome proliferator-activated receptors: regulation of transcriptional activities and roles in inflammation. I Steroid Biochem $\mathrm{Mol}$ Biol. 2-5: 267-273, 2003.

170. Smeets, P.J., Planavila, A., Van der Vusse, G.J., Van Bilsen, M. Peroxisome proliferator-activated receptors and inflammation: take it to heart. Acta Physiol. 3: 171-188, 2007.

171. Smeets, P.J., Teunissen, B.E., Willemsen, P.H., van Nieuwenhoven, F.A., Brouns, A.E., Janssen, B.J., Cleutjens, J.P., Staels, B., van der Vusse, G.J., van Bilsen, M. Cardiac hypertrophy is enhanced in PPAR \{alpha\}-1- mice in response to chronic pressure overload. Cardiovasc Res. 78: 79-89, 2008.

172. Jucker, B.M., Doe, C.P., Schnackenberg, C.G., Olzinski, A.R., Maniscalco, K., Williams, C., Hu, T.C., Lenhard, S.C., Costell, M., Bernard, R., Sarov-Blat, L., Steplewski, K., Willette, R.N. PPARdelta activation normalizes cardiac substrate metabolism and reduces right ventricular hypertrophy in congestive heart failure. J Cardiovasc Pharmacol. 1:25-34, 2007.

173. Pascual, G.Glass, C.K. Nuclear receptors versus inflammation: mechanisms of transrepression. Trends Endocrinol Metab. 8: 321-327, 2006.

174. Lee, S.S., Pineau, T., Drago, J., Lee, E.J., Owens, J.W., Kroetz, D.L., Fernandez-Salguero, P.M., Westphal, H., Gonzalez, F.J. Targeted disruption of the alpha isoform of the peroxisome proliferatoractivated receptor gene in mice results in abolishment of the pleiotropic effects of peroxisome proliferators. Mol Cell Biol. 6: 3012-3022, 1995.

175. Rockman, H.A., Ross, R.S., Harris, A.N., Knowlton, K.U., Steinhelper, M.E., Field, L.J., Ross, J., Jr., Chien, K.R. Segregation of atrial-specific and inducible expression of an atrial natriuretic factor transgene in an in vivo murine model of cardiac hypertrophy. Proc Natl Acad Sci U S A. 18: 8277$8281,1991$.

176. De Celle, T., Cleutjens, J.P., Blankesteijn, W.M., Debets, J.J., Smits, J.F., Janssen, B.J. Long-term structural and functional consequences of cardiac ischaemia-reperfusion injury in vivo in mice. Exp Physiol. 5: 605-615, 2004.

177. Creemers, E.E., Davis, J.N., Parkhurst, A.M., Leenders, P., Dowdy, K.B., Hapke, E., Hauet, A.M., Escobar, P.G., Cleutjens, J.P., Smits, J.F., Daemen, M.J., Zile, M.R., Spinale, F.G. Deficiency of TIMP1 exacerbates $L V$ remodelling after myocardial infarction in mice. Am J Physiol Heart Circ Physiol. 1: H364-371, 2003.

178. Lutgens, E., Daemen, M.J., de Muinck, E.D., Debets, J., Leenders, P., Smits, J.F. Chronic myocardial infarction in the mouse: cardiac structural and functional changes. Cardiovasc Res. 3: 586-593, 1999. 
179. Vandesompele, J., De Preter, K., Pattyn, F., Poppe, B., Van Roy, N., De Paepe, A., Speleman, F. Accurate normalization of real-time quantitative RT-PCR data by geometric averaging of multiple internal control genes. Genome Biol. 7: RESEARCH0034, 2002.

180. Hellemans, J., Mortier, G., De Paepe, A., Speleman, F., Vandesompele, J. qBase relative quantification framework and software for management and automated analysis of real-time quantitative PCR data. Genome Biol. 2: R19, 2007.

181. Aoyama, T., Peters, J.M., Iritani, N., Nakajima, T., Furihata, K., Hashimoto, T., Gonzalez, F.J. Altered constitutive expression of fatty acid-metabolizing enzymes in mice lacking the peroxisome proliferatoractivated receptor alpha (PPARalpha). J Biol Chem. 10: 5678-5684, 1998.

182. Leone, T.C., Weinheimer, C.J., Kelly, D.P. A critical role for the peroxisome proliferator-activated receptor alpha (PPARalpha) in the cellular fasting response: the PPARalpha-null mouse as a model of fatty acid oxidation disorders. Proc Natl Acad Sci U S A. 13: 7473-7478, 1999.

183. Guerre-Millo, M., Rouault, C., Poulain, P., Andre, J., Poitout, V., Peters, J.M., Gonzalez, F.J., Fruchart, J.C., Reach, G., Staels, B. PPAR-alpha-null mice are protected from high-fat diet-induced insulin resistance. Diabetes. 12: 2809-2814, 2001.

184. Muoio, D.M., MacLean, P.S., Lang, D.B., Li, S., Houmard, J.A., Way, J.M., Winegar, D.A., Corton, J.C., Dohm, G.L., Kraus, W.E. Fatty acid homeostasis and induction of lipid regulatory genes in skeletal muscles of peroxisome proliferator-activated receptor (PPAR) alpha knock-out mice. Evidence for compensatory regulation by PPAR delta. J Biol Chem. 29: 26089-26097, 2002.

185. Loichot, C., Jesel, L., Tesse, A., Tabernero, A., Schoonjans, K., Roul, G., Carpusca, I., Auwerx, J., Andriantsitohaina, R. Deletion of peroxisome proliferator-activated receptor-alpha induces an alteration of cardiac functions. Am J Physiol Heart Circ Physiol. 1: H161-166, 2006.

186. Guellich, A., Damy, T., Lecarpentier, Y., Conti, M., Claes, V., Samuel, J.L., Quillard, J., Hebert, J.L., Pineau, T., Coirault, C. Role of oxidative stress in cardiac dysfunction of PPAR\{alpha\}-/- mice. Am J Physiol Heart Circ Physiol. 1: H93-H102, 2007.

187. Luptak, I., Balschi, J.A., Xing, Y., Leone, T.C., Kelly, D.P., Tian, R. Decreased contractile and metabolic reserve in peroxisome proliferator-activated receptor-alpha-null hearts can be rescued by increasing glucose transport and utilization. Circulation. 15: 2339-2346, 2005.

188. Pruimboom-Brees, I., Haghpassand, M., Royer, L., Brees, D., Aldinger, C., Reagan, W., Singh, J., Kerlin, R., Kane, C., Bagley, S., Hayward, C., Loy, J., O'Brien, P., Francone, O.L. A critical role for peroxisomal proliferator-activated receptor-alpha nuclear receptors in the development of cardiomyocyte degeneration and necrosis. Am J Pathol. 3: 750-760, 2006.

189. Kronke, G., Kadl, A., Ikonomu, E., Bluml, S., Furnkranz, A., Sarembock, I.J., Bochkov, V.N., Exner, M., Binder, B.R., Leitinger, N. Expression of heme oxygenase-1 in human vascular cells is regulated by peroxisome proliferator-activated receptors. Arterioscler Thromb Vasc Biol. 6: 1276-1282, 2007.

190. Degens, H., de Brouwer, K.F., Gilde, A.J., Lindhout, M., Willemsen, P.H., Janssen, B.J., van der Vusse, G.J., van Bilsen, M. Cardiac fatty acid metabolism is preserved in the compensated hypertrophic rat heart. Basic Res Cardiol. 1: 17-26, 2006.

191. Pozzi, A., Ibanez, M.R., Gatica, A.E., Yang, S., Wei, S., Mei, S., Falck, J.R., Capdevila, J.H. Peroxisomal proliferator-activated receptor-alpha-dependent inhibition of endothelial cell proliferation and tumorigenesis. J Biol Chem. 24: 17685-17695, 2007.

192. Zandbergen, F., Mandard, S., Escher, P., Tan, N.S., Patsouris, D., Jatkoe, T., Rojas-Caro, S., Madore, S., Wahli, W., Tafuri, S., Muller, M., Kersten, S. The G0/G1 switch gene 2 is a novel PPAR target gene. Biochem J. Pt 2: 313-324, 2005.

193. Gizard, F., Amant, C., Barbier, O., Bellosta, S., Robillard, R., Percevault, F., Sevestre, H., Krimpenfort, P., Corsini, A., Rochette, J., Glineur, C., Fruchart, J.C., Torpier, G., Staels, B. PPAR alpha inhibits 
vascular smooth muscle cell proliferation underlying intimal hyperplasia by inducing the tumor suppressor pl6INK4a. J Clin Invest. I1: 3228-3238, 2005.

194. Hein, S., Arnon, E., Kostin, S., Schonburg, M., Elsasser, A., Polyakova, V., Bauer, E.P., Klovekorn, W.P., Schaper, J. Progression from compensated hypertrophy to failure in the pressure-overloaded human heart: structural deterioration and compensatory mechanisms. Circulation. 7: 984-991, 2003.

195. McClintick, J.N.Edenberg, H.J. Effects of filtering by Present call on analysis of microarray experiments. BMC Bioinformatics. 49, 2006.

196. Dennis, G., Jr., Sherman, B.T., Hosack, D.A., Yang, J., Gao, W., Lane, H.C., Lempicki, R.A. DAVID; Database for Annotation, Visualization, and Integrated Discovery. Genome Biol. 5: P3, 2003.

197. Cunard, R., DiCampli, D., Archer, D.C., Stevenson, J.L., Ricote, M., Glass, C.K., Kelly, C.J. WY14,643, a PPAR alpha ligand, has profound effects on immune responses in vivo. J Immunol. 12: 6806-6812., 2002.

198. Bunger, M., van den Bosch, H.M., van der Meijde, J., Kersten, S., Hooiveld, G.J., Muller, M. Genomewide analysis of PPARalpha activation in murine small intestine. Physiol Genomics. 2: 192-204, 2007.

199. Chien, K.R., Zhu, H., Knowlton, K.U., Miller-Hance, W., van-Bilsen, M., O’Brien, T.X., Evans, S.M. Transcriptional regulation during cardiac growth and development. Annu Rev Physiol. 77-95, 1993.

200. van den Bosch, B.J., Lindsey, P.J., van den Burg, C.M., van der Vlies, S.A., Lips, D.J., van der Vusse, G.J., Ayoubi, T.A., Doevendans, P.A., Smeets, H.J. Early and transient gene expression changes in pressure overload-induced cardiac hypertrophy in mice. Genomics. 4: 480-488, 2006.

201. Mirotsou, M., Dzau, V.J., Pratt, R.E., Weinberg, E.O. Physiological genomics of cardiac disease: quantitative relationships between gene expression and left ventricular hypertrophy. Physiol Genomics. 1: 86-94, 2006.

202. Rajan, S., Williams, S.S., Jagatheesan, G., Ahmed, R.P., Fuller-Bicer, G., Schwartz, A., Aronow, B.J., Wieczorek, D.F. Microarray analysis of gene expression during early stages of mild and severe cardiac hypertrophy. Physiol Genomics. 3: 309-317, 2006.

203. Rosenkranz, S. TGF-betal and angiotensin networking in cardiac remodelling. Cardiovasc Res. 3: 423-432, 2004.

204. Lammerding, J., Kamm, R.D., Lee, R.T. Mechanotransduction in cardiac myocytes. Ann N Y Acad Sci. 53-70, 2004.

205. Clerk, A., Cullingford, T.E., Fuller, S.J., Giraldo, A., Markou, T., Pikkarainen, S., Sugden, P.H. Signalling pathways mediating cardiac myocyte gene expression in physiological and stress responses. J Cell Physiol. 2: 311-322, 2007.

206. Zhao, C., Chen, W., Yang, L., Chen, L., Stimpson, S.A., Diehl, A.M. PPARgamma agonists prevent TGFbetal/Smad3-signalling in human hepatic stellate cells. Biochem Biophys Res Commun. 2:385391, 2006.

207. Maeda, A., Horikoshi, S., Gohda, T., Tsuge, T., Maeda, K., Tomino, Y. Pioglitazone attenuates TGFbeta(1)-induction of fibronectin synthesis and its splicing variant in human mesangial cells via activation of peroxisome proliferator-activated receptor (PPAR)gamma. Cell Biol Int. 6: 422-428,
2005.

208. Kim, H.J., Ham, S.A., Kim, S.U., Hwang, J.Y., Kim, J.H., Chang, K.C., Yabe-Nishimura, C., Seo, H.G. Transforming growth factor-betal is a molecular target for the peroxisome proliferator-activated receptor delta. Circ Res. 2: 193-200, 2008.

209. Lebrasseur, N.K., Duhaney, T.A., De Silva, D.S., Cui, L., Ip, P.C., Joseph, L., Sam, F. Effects of fenofibrate on cardiac remodelling in aldosterone-induced hypertension. Hypertension. 3: 489-496, 2007. 
210. Jankowska, E.A., Ponikowski, P., Piepoli, M.F., Banasiak, W., Anker, S.D., Poole-Wilson, P.A. Autonomic imbalance and immune activation in chronic heart failure-pathophysiological links. Cardiovasc Res. 3: 434-445, 2006.

211. Woerly, G., Honda, K., Loyens, M., Papin, J.P., Auwerx, J., Staels, B., Capron, M., Dombrowicz, D. Peroxisome proliferator-activated receptors alpha and gamma down-regulate allergic inflammation and eosinophil activation. J Exp Med. 3: 411-421, 2003.

212. Wang, Y. Mitogen-activated protein kinases in heart development and diseases. Circulation. 12: 14131423, 2007.

213. Girnun, G.D., Domann, F.E., Moore, S.A., Robbins, M.E. Identification of a functional peroxisome proliferator-activated receptor response element in the rat catalase promoter. Mol Endocrinol. 12: 2793-2801, 2002.

214. Anversa, P., Zhang, X., Li, P., Olivetti, G., Cheng, W., Reiss, K., Sonnenblick, E.H., Kajstura, J. Ventricular remodelling in global ischemia. Cardioscience. 2: 89-100, 1995.

215. Ertl, G.Frantz, S. Healing after myocardial infarction. Cardiovasc Res. 1: 22-32, 2005.

216. Gao, X.M., Xu, Q., Kiriazis, H., Dart, A.M., Du, X.J. Mouse model of post-infarct ventricular rupture: time course, strain-and gender-dependency, tensile strength, and histopathology. Cardiovasc Res. 2: 469-477, 2005.

217. Zandbergen, F., Mandard, S., Escher, P., Tan, N.S., Patsouris, D., Jatkoe, T., Rojas-Caro, S., Madore, S., Wahli, W., Tafuri, S., Muller, M., Kersten, S. The G0/G1 switch gene 2 is a novel PPAR target gene. Biochem J. 2005.

218. Diep, Q.N., Benkirane, K., Amiri, F., Cohn, J.S., Endemann, D., Schiffrin, E.L. PPAR alpha activator fenofibrate inhibits myocardial inflammation and fibrosis in angiotensin II-infused rats. J Mol Cell Cardiol. 2: 295-304, 2004.

219. Iglarz, M., Touyz, R.M., Viel, E.C., Paradis, P., Amiri, F., Diep, Q.N., Schiffrin, E.L. Peroxisome proliferator-activated receptor-alpha and receptor-gamma activators prevent cardiac fibrosis in mineralocorticoid-dependent hypertension. Hypertension. 4: 737-743, 2003.

220. Blankesteijn, W.M., Creemers, E., Lutgens, E., Cleutjens, J.P., Daemen, M.J., Smits, J.F. Dynamics of cardiac wound healing following myocardial infarction: observations in genetically altered mice. Acta Physiol Scand. 1: 75-82, 2001.

221. Lakatos, H.F., Thatcher, T.H., Kottmann, R.M., Garcia, T.M., Phipps, R.P., Sime, P.J. The Role of PPARs in Lung Fibrosis. PPAR Res. 71323, 2007.

222. Smeets, P.J., Planavila, A., van der Vusse, G.J., van Bilsen, M. Peroxisome proliferator-activated receptors and inflammation: take it to heart. Acta Physiol (Oxf). 3: 171-188, 2007.

223. Smeets, P.J.H., Teunissen, B.E.J., Willemsen, P.H.M., van Nieuwenhoven, F.A., Brouns, A.E., Janssen, B.J.A., Cleutjens, J.P.M., Staels, B., van der Vusse, G.J., van Bilsen, M. Cardiac hypertrophy is enhanced in PPAR \{alpha\}-/- mice in response to chronic pressure overload. Cardiovasc Res. cvn001, 2008.

224. Luptak, I., Balschi, J.A., Xing, Y., Leone, T.C., Kelly, D.P., Tian, R. Decreased Contractile and Metabolic Reserve in Peroxisome Proliferator-Activated Receptor-\{alpha\}-Null Hearts Can Be Rescued by Increasing Glucose Transport and Utilization. Circulation. 15: 2339-2346, 2005.

225. Luptak, I., Yan, J., Cui, L., Jain, M., Liao, R., Tian, R. Long-Term Effects of Increased Glucose Entry on Mouse Hearts During Normal Aging and Ischemic Stress. Circulation. 8: 901-909, 2007.

226. van der Meer, P., Lipsic, E., Henning, R.H., Boddeus, K., van der Velden, J., Voors, A.A., van Veldhuisen, D.J., van Gilst, W.H., Schoemaker, R.G. Erythropoietin Induces Neovascularization and Improves Cardiac Function in Rats With Heart Failure After Myocardial Infarction. Journal of the American College of Cardiology. 1: 125-133, 2005. 
227. Meissner, M., Stein, M., Urbich, C., Reisinger, K., Suske, G., Staels, B., Kaufmann, R., Gille, J. PPARalpha activators inhibit vascular endothelial growth factor receptor-2 expression by repressing SpI-dependent DNA binding and transactivation. Circ Res. 3: 324-332, 2004.

228. Yagil, C.Yagil, Y. Peroxisome Proliferator-Activated Receptor \{alpha\}: Friend or Foe? Hypertension. 5: 847-850, 2007.

229. Valen, G., Yan, Z.Q., Hansson, G.K. Nuclear factor kappa-B and the heart. J Am Coll Cardiol. 2: 307$314,2001$.

230. Campbell, F.M., Kozak, R., Wagner, A., Altarejos, J.Y., Dyck, J.R., Belke, D.D., Severson, D.L., Kelly, D.P., Lopaschuk, G.D. A role for peroxisome proliferator-activated receptor alpha (PPARalpha) in the control of cardiac malonyl-CoA levels: reduced fatty acid oxidation rates and increased glucose oxidation rates in the hearts of mice lacking PPARalpha are associated with higher concentrations of malonyl-CoA and reduced expression of malonyl-CoA decarboxylase. J Biol Chem. 6: 4098-4103., 2002.

231. Bouhlel, M.A., Derudas, B., Rigamonti, E., Dievart, R., Brozek, J., Haulon, S., Zawadzki, C., Jude, B., Torpier, G., Marx, N., Staels, B., Chinetti-Gbaguidi, G. PPARgamma activation primes human monocytes into alternative M2 macrophages with anti-inflammatory properties. Cell Metab. 2: 137143, 2007.

232. Bedu, E., Desplanches, D., Pequignot, J., Bordier, B., Desvergne, B. Double gene deletion reveals the lack of cooperation between PPARalpha and PPARbeta in skeletal muscle. Biochem Biophys Res Commun. 4: 877-881, 2007.

233. Burkart, E.M., Sambandam, N., Han, X., Gross, R.W., Courtois, M., Gierasch, C.M., Shoghi, K., Welch, M.J., Kelly, D.P. Nuclear receptors PPARbeta/delta and PPARalpha direct distinct metabolic regulatory programs in the mouse heart. J Clin Invest. 12: 3930-3939, 2007.

234. Pellieux, C., Montessuit, C., Papageorgiou, I., Lerch, R. Inactivation of peroxisome proliferatoractivated receptor isoforms alpha, betaldelta, and gamma mediate distinct facets of hypertrophic transformation of adult cardiac myocytes. Pflugers Arch. 3: 443-454, 2007.

235. Maradit-Kremers, H., Nicola, P.J., Crowson, C.S., Ballman, K.V., Gabriel, S.E. Cardiovascular death in rheumatoid arthritis: a population-based study. Arthritis Rheum. 3: 722-732, 2005.

236. Wolfe, F.Michaud, K. Heart failure in rheumatoid arthritis: rates, predictors, and the effect of antitumour necrosis therapy. Am J Med. 305-311, 2004.

237. Cesari, M., Penninx, B.W., Newman, A.B., Kritchevsky, S.B., Nicklas, B.J., Sutton-Tyrrell, K., Rubin, S.M., Ding, J., Simonsick, E.M., Harris, T.B., Pahor, M. Inflammatory markers and onset of cardiovascular events: results from the Health ABC study. Circulation. 19: 2317-2322, 2003.

238. Vasan, R.S., Sullivan, L.M., Roubenoff, R., Dinarello, C.A., Harris, T., Benjamin, E.J., Sawyer, D.B., Levy, D., Wilson, P.W., D'Agostino, R.B. Inflammatory markers and risk of heart failure in elderly subjects without prior myocardial infarction: the Framingham Heart Study. Circulation. 11: 14861491, 2003.

239. Anker, S.D., Egerer, K.R., Volk, H.D., Kox, W.J., Poole-Wilson, P.A., Coats, A.J. Elevated soluble CD14 receptors and altered cytokines in chronic heart failure. Am J Cardiol. 10; 1426-1430, 1997.

240. Karbowska, J., Kochan, Z., Smolenski, R.T. Peroxisome proliferator-activated receptor alpha is downregulated in the failing human heart. Cell Mol Biol Lett. 1: 49-53, 2003.

241. Goikoetxea, M.J., Beaumont, J., Gonzalez, A., Lopez, B., Querejeta, R., Larman, M., Diez, J. Altered cardiac expression of peroxisome proliferator-activated receptor-isoforms in patients with hypertensive heart disease. Cardiovasc Res. 4: 899-907, 2006.

242. Schupp, M., Kintscher, U., Fielitz, J., Thomas, J., Pregla, R., Hetzer, R., Unger, T., Regitz-Zagrosek, V. Cardiac PPARalpha expression in patients with dilated cardiomyopathy. Eur J Heart Fail. 3: 290-294, 2006. 
243. Gomez-Garre, D., Herraiz, M., Gonzalez-Rubio, M.L., Bernal, R., Aragoncillo, P., Carbonell, A., Rufilanchas, J.J., Fernandez-Cruz, A. Activation of peroxisome proliferator-activated receptor-alpha and-gamma in auricular tissue from heart failure patients. Eur J Heart Fail. 2: 154-161, 2006.

244. Flavell, D.M., Jamshidi, Y., Hawe, E., Pineda Torra, I., Taskinen, M.R., Frick, M.H., Nieminen, M.S., Kesaniemi, Y.A., Pasternack, A., Staels, B., Miller, G., Humphries, S.E., Talmud, P.J., Syvanne, M. Peroxisome proliferator-activated receptor alpha gene variants influence progression of coronary atherosclerosis and risk of coronary artery disease. Circulation. 12: 1440-1445, 2002.

245. Ahmetov, II, Mozhayskaya, I.A., Flavell, D.M., Astratenkova, I.V., Komkova, A.I., Lyubaeva, E.V., Tarakin, P.P., Shenkman, B.S., Vdovina, A.B., Netreba, A.I., Popov, D.V., Vinogradova, O.L., Montgomery, H.E., Rogozkin, V.A. PPARalpha gene variation and physical performance in Russian athletes. Eur J Appl Physiol. I: 103-108, 2006.

246. Okopien, B., Krysiak, R., Herman, Z.S. Effects of short-term fenofibrate treatment on circulating markers of inflammation and hemostasis in patients with impaired glucose tolerance. $\mathrm{J}$ Clin Endocrinol Metab. 5: 1770-1778, 2006.

247. Berger, J.P., Akiyama, T.E., Meinke, P.T. PPARs: therapeutic targets for metabolic disease. Trends Pharmacol Sci. 5: 244-251, 2005.

248. Schupp, M., Clemenz, M., Gineste, R., Witt, H., Janke, J., Helleboid, S., Hennuyer, N., Ruiz, P., Unger, T., Staels, B., Kintscher, U. Molecular characterization of new selective peroxisome proliferatoractivated receptor gamma modulators with angiotensin receptor blocking activity. Diabetes. 12:3442$3452,2005$.

249. Bruemmer, D., Berger, J.P., Liu, J., Kintscher, U., Wakino, S., Fleck, E., Moller, D.E., Law, R.E. A non-thiazolidinedione partial peroxisome proliferator-activated receptor gamma ligand inhibits vascular smooth muscle cell growth. Eur J Pharmacol. 3: 225-234, 2003. 


\section{SUMMARY}

In the Netherlands, cardiovascular disease is the primary cause of death. It is expected that the prevalence of heart failure will increase due to aging and increased survival after myocardial infarction. Therefore, heart failure represents a serious socio-economic burden requiring further research for new therapies.

This thesis starts with a brief conceptual description of myocardial remodelling and heart failure (Chapter 1). The possible association of ligand-activated transcription factors called peroxisome proliferator-activated receptors (PPARs) and cardiac disease is being discussed. Given their role in the control of myocardial fatty acid metabolism as well as inflammation, the main aim of this thesis is to study the role of PPARs in cardiac remodelling during the development of hypertrophy and after regional myocardial infarction.

The different cardiac disorders described in the review paper (Chapter 2), i.e., ischemiareperfusion, myocardial infarction (MI) and cardiac hypertrophy, are all accompanied by activation of pro-inflammatory processes. Attenuation of the inflammatory response might therefore exert significant salutary effects on the cardiac muscle. Each of the three PPAR isoforms $(-\alpha,-\delta$ and $-\gamma)$ is endowed with the dual capacity to modulate both metabolism and inflammation. In this way these nuclear receptors are likely to interfere with cardiac remodelling, ultimately affecting cardiac energy homeostasis, apoptosis, fibrosis, and possibly angiogenesis. However, detailed molecular understanding about the regulation of the transactivating and transrepressing properties of the PPAR isoforms is required. Such knowledge will allow optimal use of the therapeutic potential of PPARs in the diseased heart. One of the research questions formulated in chapter 1 aimed at investigating whether PPAR $\alpha$ and PPAR $\delta$ interfere with inflammatory signalling, more specifically nuclear factor- $\mathrm{kB}$ (NF$\kappa B)$, and whether this interference modulates the hypertrophic response. This study is described in chapter 3 dealing with the relationship between PPAR and NF-kB. Activation of $\mathrm{NF}-\mathrm{\kappa B}$ is considered as an essential step in the development of cardiac hypertrophy. The findings in chapter 3 demonstrate that in the cardiac muscle cell inflammatory and hypertrophic stimuli converge on NF- $\mathrm{kB}$. In addition, the transcription factors PPAR and NF$\mathrm{KB}$ are functionally intertwined in their ability to regulate hypertrophic and inflammatory processes in the cardiac muscle cell. The close relationship between hypertrophy and inflammation is also of great importance from a clinical point of view since chronic low-grade inflammation is thought to play a significant role in cardiac hypertrophy and failure. PPARs are able to inhibit myocardial inflammation and hypertrophy via inhibition of NF-kB.

Chapter 4 deals with the question whether the lack of PPAR $\alpha$ resulted in altered cardiac responses after chronic pressure overload. PPAR $\alpha$-/- and wild-type mice were subjected to transverse aortic constriction (TAC) for 28 days. The absence of PPAR $\alpha$ resulted in a more pronounced hypertrophic response and cardiac dysfunction, associated with an enhanced expression of markers of inflammation and extracellular matrix remodelling. These findings 
indicated that PPAR $\alpha$ exerts salutary effects during pressure overload-induced cardiac hypertrophy. Additionally, in chapter 5 it was investigated which genes are affected by PPAR $\alpha$ during chronic pressure overload. The left ventricular gene expression profile was determined using a microarray set-up. TAC resulted in more extensive changes in gene expression in PPAR $\alpha-/$ - mice than in wild-type mice. Many of the hypertrophy related genes were related to development, signal transduction, actin filament organization, and collagen synthesis. Compared to wild-type, PPAR $\alpha$-deficient hypertrophied hearts revealed enrichment of gene clusters related to immune response, extracellular matrix remodelling, inflammatory signalling pathways and oxidative stress. These findings therefore demonstrated that, in addition to lipid metabolism, PPAR $\alpha$ is an important modulator of the immune- and inflammatory response in the cardiac muscle.

Chapter 6 described the effects of MI in wild-type and PPAR $\alpha-/$ - mice, resulting in improved survival, lower incidence of cardiac rupture, smaller infarct size, less cardiac dilatation and better preservation of ejection fraction and fractional shortening in mice lacking PPAR $\alpha$. Furthermore, PPARa deficiency simultaneously promotes cardiomyocyte hypertrophy and maintains the degree of capillarization in the non-ischemic remote myocardium, accompanied by improved hemodynamical outcome after MI. In this study the pro and cons of treatment with PPAR $\alpha$ ligands in coronary heart disease are being questioned.

Finally, a general discussion is presented in chapter 7 concerning the main findings, their clinical implications, and future lines of research. In general, it is tempting to speculate that PPARs serve as therapeutic targets to inhibit inflammatory signalling and, consequently, prevent hypertrophic growth of the heart. However, delineation of the exact role of PPARs, especially PPAR $\alpha$, during MI appears to be complicated, as in addition to its metabolic and anti-inflammatory effects, it may differentially influence the infarct healing process and the remodelling of the remote, viable myocardium. Future studies are warranted to delineate the role and mode of action of each PPAR isoform in cardiac disease. 


\section{SAMENVATTING}

In Nederland vormen cardiovasculaire aandoeningen de belangijkste doodsoorzaak. Men verwacht dat de prevalentie van hartfalen wegens het verouderen van de bevolking en de verhoogde overleving na een hartinfarct zal toenemen. Daarom heeft hartfalen een grote sociaal-economische impact en is verder onderzoek voor nieuwe therapieën vereist.

Dit proefschrift begint met een korte conceptuele beschrijving van cardiale remodelering en hartfalen (Hoofdstuk 1). De mogelijke rol van ligand-geactiveerde transcriptiefactoren, peroxisome proliferator-activated receptors (PPARs), in diverse hartaandoeningen wordt besproken. Gezien hun controlerende rol in vetzuurmetabolisme en ontstekingsprocessen in het hart, is het belangrijkste doel van dit proefschrift de effecten van PPARs te bestuderen tijdens de ontwikkeling van hypertrofie en na een hartinfarct.

De verschillende hartaandoeningen die in het tweede hoofdstuk worden beschreven, namelijk ischemie-reperfusie, hartinfarct en hypertrofie gaan allen gepaard met activatie van ontstekingsprocessen. De vermindering van de ontstekingsreactie kan daarom positieve effecten hebben voor de hartspier. Elk van de drie PPAR subtypes $(-\alpha,-\delta$ en- $\gamma)$ heeft de eigenschap om zowel metabolisme als ontsteking te moduleren. Op deze wijze interfereren deze receptoren met cardiale remodelering en beïnvloeden zo energiehomeostase, apoptose, fibrose en mogelijk angiogenese in het hart. We missen echter nog een gedetailleerde kennis van de moleculaire eigenschappen, namelijk transactivatie en transrepressie, van de PPAR subtypes. Door dergelijke kennis kan het therapeutische potentieel van PPARs in het zieke hart optimaal benut worden.

Één van de onderzoekvragen uit hoofdstuk 1 was gericht op de rol van PPAR $\alpha$ en PPAR $\delta$ in ontstekingsprocessen: interfereren PPAR $\alpha$ en PPAR $\delta$ met één van de belangrijkste ontstekingseiwitten, nuclear factor- $\kappa B$ (N-FKB), en moduleert dit hypertrofie? Deze vraag werd in hoofdstuk 3 behandeld. Activering van NF-KB wordt beschouwd als een essentiële stap in de ontwikkeling van cardiale hypertrofie. De bevindingen in hoofdstuk 3 tonen aan dat in de hartspiercel NF- $\mathrm{KB}$ een gemeenschappelijke factor vormt in ontsteking en hypertrofie. PPAR en NF-KB zijn functioneel met elkaar geassocieerd om hypertrofie en ontsteking in de hartspiercel te reguleren. Het verband tussen hypertrofie en ontsteking is ook van groot belang vanuit een klinisch standpunt aangezien chronische ontstekingen een significante rol in hypertrofie en hartfalen spelen. PPARs kunnen dus zowel ontsteking als hypertrofie remmen via remming van $\mathrm{NF}-\mathrm{kB}$.

Hoofdstuk 4 behandelt de vraag of het gebrek aan PPAR $\alpha$ resulteert in een andere reactie van het hart na een chronische drukbelasting. Bij PPAR $\alpha-/$ - en wildtype muizen werd de aortaboog (transverse aortic constriction, TAC) vernauwd voor 28 dagen. De afwezigheid van PPAR $\alpha$ resulteert in meer uitgesproken hypertrofie, verminderde functie van het hart, en een verhoogde expressie van genen betrokken bij ontstekingsprocessen en de extracellulaire matrix. Deze bevindingen wijzen erop dat PPAR $\alpha$ positieve effecten heeft tijdens een 
verhoogde drukbelasting. In hoofdstuk 5 werd bestudeerd welke genen door PPAR $\alpha$ worden beïnvloed tijdens een chronische drukbelasting. De genexpressie van het linker ventrikel werd bepaald door middel van een microarray experiment. TAC resulteerde in beduidend meer veranderingen op genexpressie niveau in PPAR $\alpha-/$ - muizen ten opzichte van wildtype muizen. Veel van de aan hypertrofie verwante genen waren betrokken bij ontwikkeling, signaaltransductie, actine-filamenten organisatie, en collageen synthese. Vergeleken met wildtype muizen hebben PPAR $\alpha$-/- muizen met hypertrofe harten een verrijking van clusters met genen die betrekking hebben tot het immuunsysteem, extracellulaire matrix, ontstekingsprocessen en oxidatieve stress. Deze bevindingen tonen daarom aan dat, naast vetzuurmetabolisme, PPAR $\alpha$ een belangrijke modulator is van de immuun- en ontstekingsreacties in de hartspier.

Hoofdstuk 6 beschreef de gevolgen van een hartinfarct in wildtype en PPAR $\alpha / /$ muizen. PPAR $\alpha-/$ - muizen hadden een betere overleving, minder cardiale ruptuur, een minder groot infarct, minder hartdilatatie en een betere ejectiefractie. Voorts zorgt de deficiëntie van PPARa voor meer cardiale hypertrofie, behoud van capillairen in het niet ischemische myocard, en voor een betere hemodynamica. In deze studie worden de voor- en nadelen in de behandeling van een hartinfarct met PPAR liganden in vraag gesteld.

Tot slot volgt in hoofdstuk 7 een algemene bespreking betreffende de belangrijkste bevindingen, hun klinische implicaties, en toekomstige onderzoeksmogelijkheden. Het is verleidelijk om te stellen dat PPARs in therapieen gebruikt kunnen worden om ontstekingsprocessen te remmen en, bijgevolg, de hypertrofie van het hart te remmen. Naast de effecten op metabolisme en ontsteking, heeft PPAR $\alpha$ een verschillende invloed op het helingsproces na een hartinfarct en remodelering van het gezonde weefsel. Toekomstige studies zijn noodzakelijk om de rol en het mechanisme van elke PPAR subtype in het hart te bestuderen. 


\section{LIST OF PUBLICATIONS}

Smeets PJH*, Teunissen BEJ*, Willemsen PHM, Munts CCJ, Janssen BJA, Cleutjens JPM, van der Vusse GJ, van Bilsen M. Loss of PPARa reduces infarct size and promotes hypertrophy of the surviving murine myocardium. Submitted for publication. * Both authors contributed equally.

Smeets PJH, de Vogel-van den Bosch HM, Willemsen PHM, Stassen A, Ayoubi T, van der Vusse GJ, van Bilsen M. Transcriptomic analysis of PPAR $\alpha$-dependent alterations during cardiac hypertrophy. Accepted for publication: Physiological Genomics 2008.

Smeets PJH, Teunissen BEJ, Willemsen PHM, Planavila A, de Vogel-van den Bosch HM, van der Vusse GJ, van Bilsen M. Inflammatory pathways are activated during hypertrophy and attenuated by PPAR $\alpha$ and PPAR Journal of Biological Chemistry 2008;283:29109-29118.

Smeets PJH, Teunissen BEJ, Willemsen PHM, van Nieuwenhoven FA, Brouns AE, Janssen BJA, Cleutjens JPM, Staels B, van der Vusse GJ, van Bilsen M. Cardiac hypertrophy is enhanced in PPAR $\alpha-$ - mice in response to chronic pressure-overload. Cardiovascular Research. 2008;78:79-89.

Smeets PJH, Planavila A, van der Vusse GJ, van Bilsen M. Peroxisome proliferator-activated receptors and inflammation: take it to heart. Acta Physiologica 2007;191:171-188.

Teunissen BEJ, Smeets PJH, Willemsen PH, de Windt LJ, van der Vusse GJ, van Bilsen M. Activation of PPAR $\delta$ inhibits cardiac fibroblast proliferation and the transdifferentiation into myofibroblasts. Cardiovascular Research 2007;75:519-29.

van Bilsen M., Smeets PJH, Gilde AJ, van der Vusse GJ, Metabolic remodelling of the failing heart: the cardiac burn-out syndrome? Cardiovascular Research 2004;61:218-26.

\section{SELECTED ABSTRACTS}

Smeets PJH, Willemsen PH, Brouns AE, Janssen BJ, van der Vusse GJ, van Bilsen M. Deletion of PPAR $\alpha$ results in more pronounced cardiac hypertrophy in response to chronic pressure overload. Journal of Molecular and Cellular Cardiology 2007;42:S130.

Smeets PJH, Teunissen BEJ, Willemsen PH, van der Vusse GJ, van Bilsen M. Mutual interaction between hypertrophic and inflammatory pathways in cardiac myocytes. Journal of Molecular and Cellular Cardiology 2005;38:1068. 


\section{CURRICULUM VITAE}

The author of this thesis, Pascal Jozef Henri Smeets, was born August 5, 1979 in Genk, Belgium. In 1997 he completed secundary school (Latin-Sciences). Subsequently, he started to study Health Sciences at the University of Maastricht. During this study he completed two master programs (Molecular Biology and Epidemiology) and graduated in 2002. In 2003, he started his Ph.D. at the department of Physiology at Maastricht University. The main goal of his project was to study the role of PPARs during left ventricular hypertrophy. Since January 2008 he is working as a Clinical Research Specialist at Medtronic Bakken Research Center, Maastricht. 


\section{DANKWOORD}

Een proefschrift als dit is en blijft een teamprestatie. Vandaar dat mijn intentie om dit dankwoord beknopt te houden moeilijk zal worden. Niettemin een poging:

Prof. dr. Ger van der Vusse, promotor. Beste Ger, met je analytische blik en immer kritische houding heb je een ontzettend belangrijke bijdrage geleverd aan dit proefschrift. Bedankt voor al je input en al je wetenschappelijke kennis. Ook je kunde omtrent muziek en film mag niet onvermeld blijven. Bedankt!

Dr. Marc van Bilsen, copromotor. Beste Marc, ik heb nog nooit iemand ontmoet met zo'n onophoudelijke scherpte. Dat heeft dit proefschrift een flinke stap voorwaarts gebracht. Het was een hele eer om in je lab te kunnen werken en dit proefschrift af te leveren. Al fietsend zal ik je waarschijnlijk nooit tegenkomen maar misschien des te meer op de golfbaan!

Ik wil graag alle leden van de leescommissie, Prof. dr. H.A.J. Struijker-Boudier, Prof. dr. L.H.E.H. Snoeckx, Prof. dr. M.H. Hofker, Prof. dr. E.E. Blaak en Dr. L.J. de Windt bedanken voor het kritisch doorlezen en beoordelen van dit proefschrift.

Het team waarin ik al die jaren met veel plezier heb mogen werken, wil ik hier extra in de verf zetten. Peter, de drijvende kracht achter het MolFys lab. Witte jas aan en koffie leeg was de regel vooraleer het lab te betreden. We hebben samen mooie experimenten uitgevoerd maar ook veel gefilosofeerd en nog meer gelachen. Bedankt! Birgit, je hebt een behoorlijk aandeel gehad in sommige hoofdstukken en ik wens je veel succes in je verdere carrière (zowel werk als privé). Andries, ik heb jouw laatste maanden van dichtbij meegemaakt, jij de mijne: misschien kruisen onze paden elkaar nog eens. Erik, harde werker, echte Groninger: veel succes met het afronden van je proefschrift. Ik wil de overige leden van de club waarmee ik in het begin of op het einde heb samengewerkt zeker niet vergeten: Theo, Martijn, Heleen, Frans, Anneleen en Chantal. Bedankt voor alle hulp en gezelligheid. Rinske en Victor, ik hoop dat er voor jullie nog een mooie carrière voor de boeg ligt. Sander, Sunniva, Els, Sonia, Vivian, Jurgen, Sjak, Richard en alle medewerkers van Fysiologie voor de gezellige en leerzame tijd.

Een proefschrift is ook nooit het resultaat van één afdeling maar een samenwerking tussen vele afdelingen. Ik wil de mensen van Cardiologie bedanken voor hun wetenschappelijke hulp, technische kennis, zangtalenten en gezelligheid langs het MolFys lab. Mark (met zijn telkens weer bijzondere visie en onophoudelijk PSV enthousiasme), Rick, Rudy, Nard, Blanche, Geert en Joost. 
Ik wil Ben, Agnieszka, Jacques en Peter (Farmacologie) heel erg hartelijk bedanken voor het vele werk dat zij voor de dierstudies in dit proefschrift hebben gedaan.

Jack Cleutjens (Pathologie) en Torik Ayoubi (MolGen) mogen niet onvermeld blijven voor hun waardevolle input en hulp bij de immunologie en microarray experimenten.

Ik wens alle andere -vaak voormalige- AIO's heel veel succes in hun verdere loopbaan: Judith, Kristiaan, Wilco, Ronald (Atilla!), Ruben, Steven, Andrei en de biochemie-AIO's.

Ik wil ook de collega's van mijn nieuwe thuishaven niet onvermeld laten. Dames (en de weinige heren) van CRDM-CE: dat we nog vele jaren vruchtbaar mogen samenwerken. Enkele mensen in het bijzonder: Daphne, Mireille, Rinie, Natasja, Myriam en Marieke (bedankt om me te bedanken!). Der Kollege aus Deutschland: Rainer (Audi A6 Quattro!), Klaus, Bernd, Birgit und Patricia.

Maarten, kameraad, makker, vriend. We hebben samen al veel beleefd en gelachen. Hopelijk komt daar nooit een einde aan. Hubert, Sjo, Ronnie \& Malgosia, Berno \& Olga voor de gezelligheid, de vele pintjes en vriendschap.

Jo \& Philo: indrukwekkend hoe jullie mij hebben opgenomen in de familie. Dat we samen nog een mooie tijd mogen tegemoet gaan. Martijn \& Nancy, ondanks al onze waarschuwingen beginnen jullie er toch aan: op 4 september 2008 gaan jullie trouwen! Heel veel plezier en liefde in jullie verdere leven.

Pateke en Nonkel Kolonel, bedankt voor alle leuke weekends en jullie hartverwarmend onthaal, iedere keer weer. Hopelijk maken we in de toekomst eindelijk eens samen een motortrip!

Lieve ouders, Mama, Papa: jullie hebben de grootste basis aan dit proefschrift gelegd. Jullie hebben mij de kansen gegeven en me altijd gesteund. Het was niet altijd even makkelijk maar uiteindelijk komen we er samen iedere keer weer uit. De liefde en de waardering blijft.

Filip, onze wegen hebben elkaar gekruist, zich gescheiden, gekruist en nu dichter bij elkaar dan ooit ondanks de afstand. We hebben beiden een andere aanpak en jij hebt een eigenwijze werkwijze. Je hebt in elk geval de kunde om straks criminologie met een grote $C$ te schrijven. Ik wens je samen met Feyza een mooie toekomst toe! 
Er kan maar een iemand de beste, de mooiste en de slimste zijn. Gelukkig ben ik met haar getrouwd! Lieve Chantal, bedankt om me onvoorwaardelijk te steunen en om het bloed, zweet en tranen van dit proefschrift een stuk draaglijker te maken. Dat jij de cover siert van dit proefschrift maakt het voor mij alleen maar mooier. Samen gaan we vol vertrouwen de toekomst in! Ik omhels je met duizend armen!

Pascal

PS: Voor allen die ik vergeten ben in dit dankwoord: bedankt! 